\title{
Funktionsanalyse der Ankyrin-repeat Proteine AKR2A und AKR2B in Arabidopsis thaliana
}

\author{
Dissertation \\ zur Erlangung des Doktorgrades \\ der Mathematisch-Naturwissenschaftlichen Fakultäten \\ der Georg-August-Universität zu Göttingen
}

vorgelegt von

Caroline Sophia Carsjens, geb. Mayer

aus Essen

Göttingen 2010 
D7

Referent:

Prof. Dr. Wolfgang Dröge-Laser

Korreferent:

Prof. Dr. Christiane Gatz

Tag der mündlichen Prüfung:

28.04.2010 


\section{Inhaltsverzeichnis}

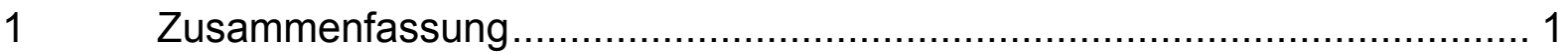

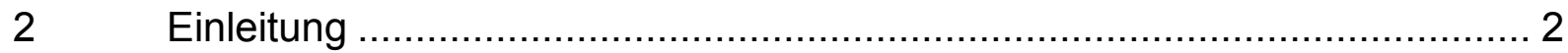

2.1 Der bZIP-Transkriptionsfaktor NtBZI-1 aus Tabak .................................. 2

2.2 Das Protein NtANK1 aus Tabak, ein Interaktionspartner von NtBZI-1 ......... 3

2.3 Die homologen Proteine zu NtBZI-1 aus Tabak sind die bZIPTranskriptionsfaktoren der Gruppe $C$ in Arabidopsis thaliana ....................... 6

2.4 Die Arabidopsis Proteine AKR2A und AKR2B sind homolog zu NtANK1 aus

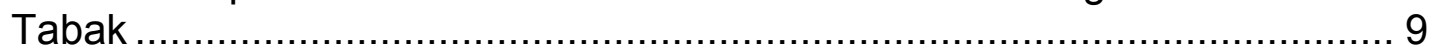

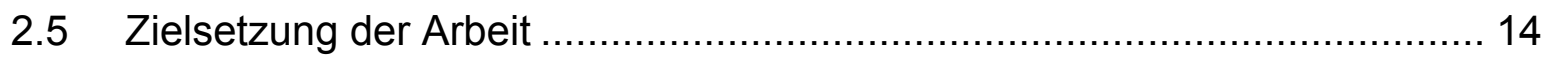

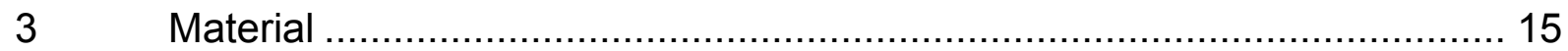

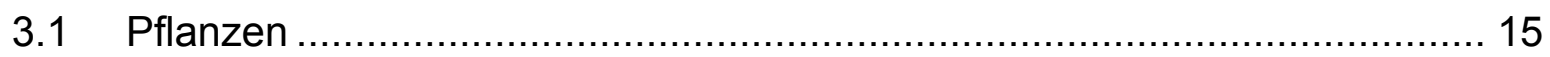

3.2 Hefestämme (Saccharomyces cerevisiae) ……................................... 15

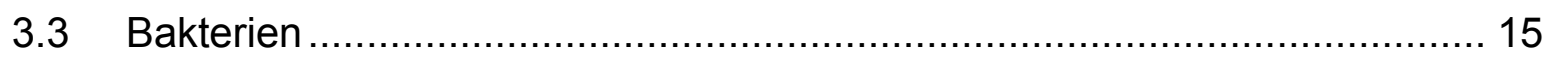

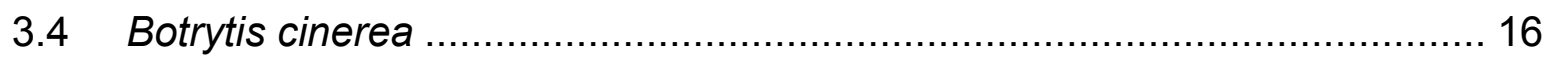

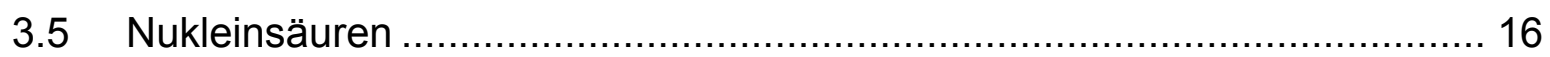

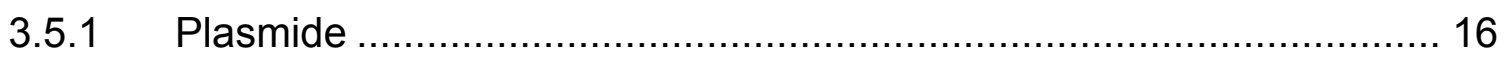

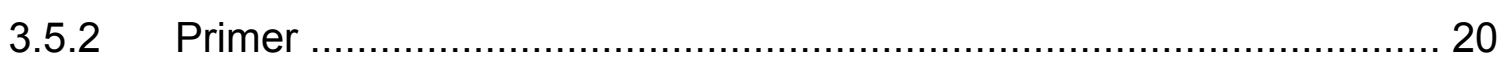

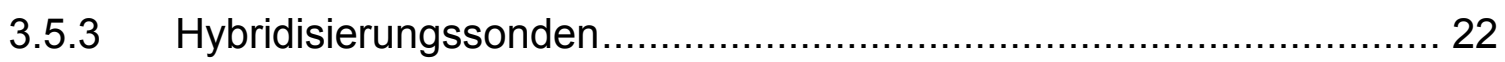

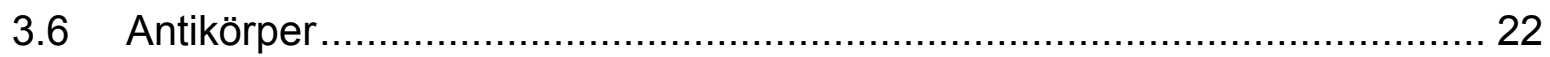

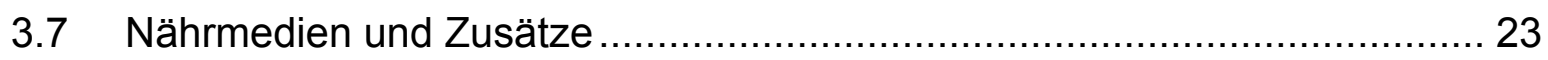

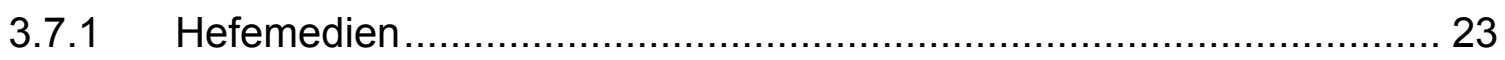

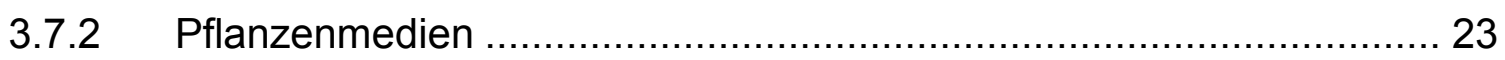

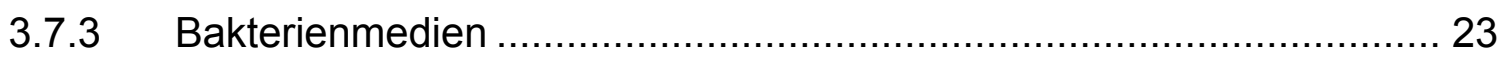

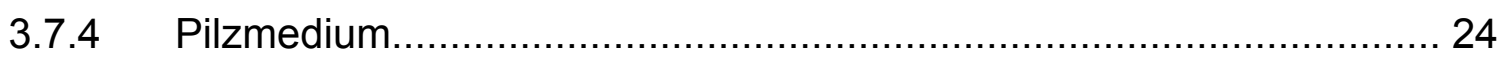

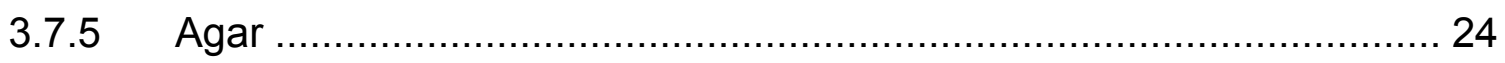

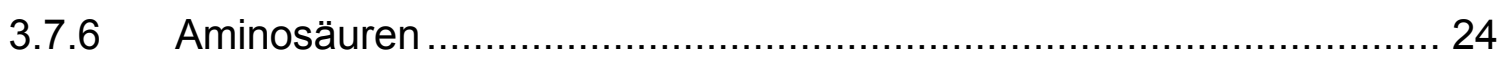

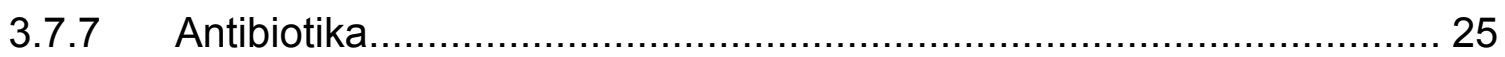

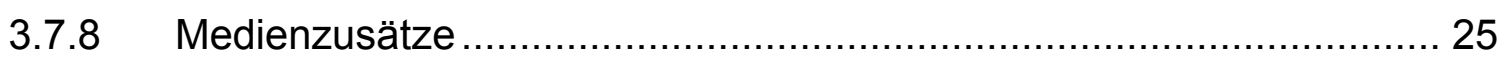

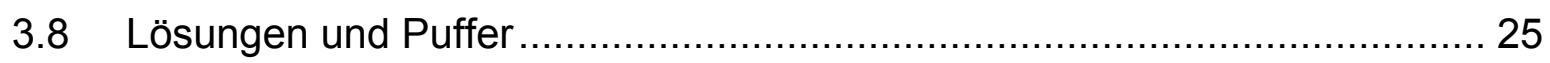

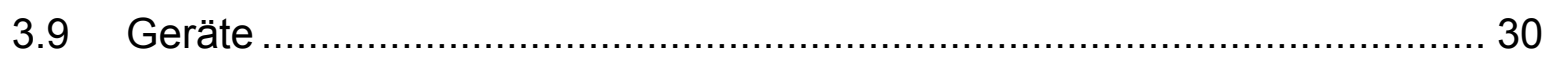

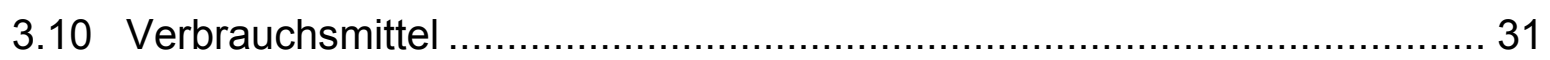

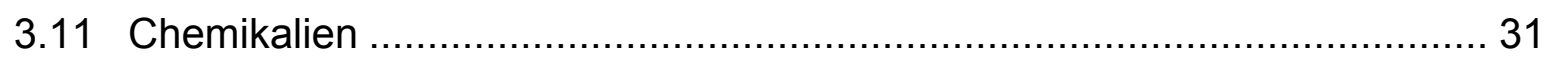




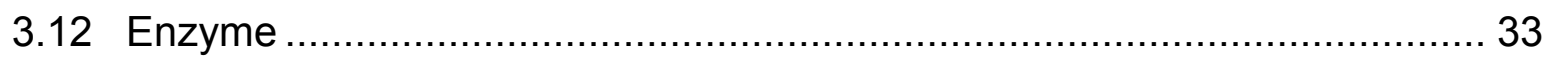

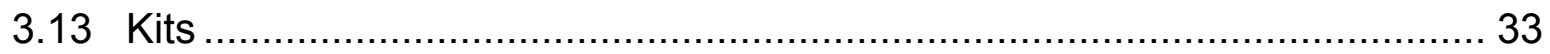

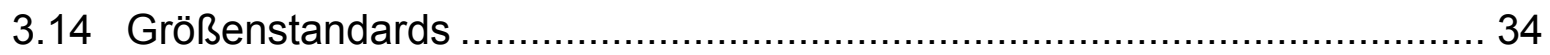

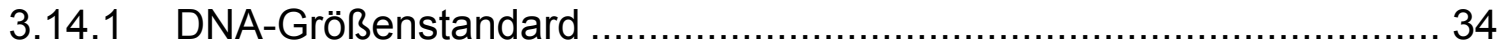

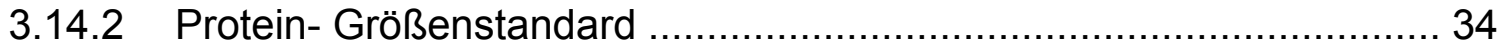

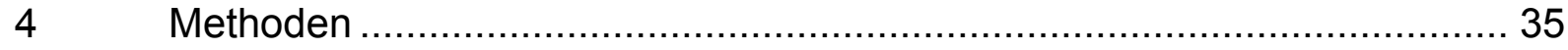

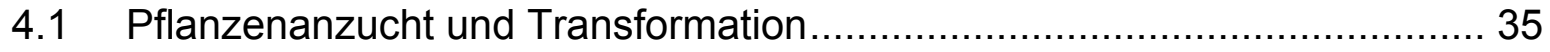

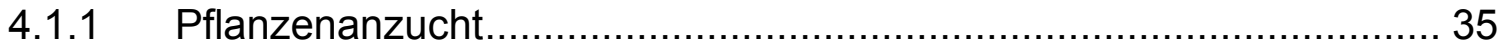

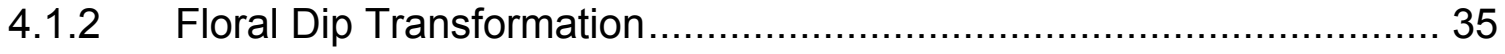

4.1.3 Selektion auf Basta ${ }^{\circledR}$-Resistenz................................................. 36

4.2 Anzucht und Lagerung von Bakterien und Hefen ..................................... 36

4.2.1 Anzucht von Escherichia coli..................................................... 36

4.2.2 Anzucht von Agrobacterium tumefaciens ......................................... 36

4.2.3 Anzucht von Pseudomonas syringae ............................................. 36

4.2.4 Anzucht von Saccharomyces cerevisiae .......................................... 36

4.2.5 Lagerung der Bakterien.............................................................. 36

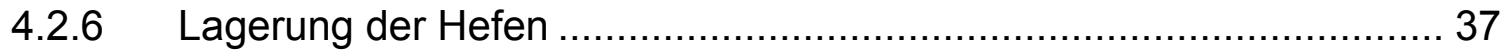

4.3 Methoden zur Präparation von Nukleinsäuren ........................................ 37

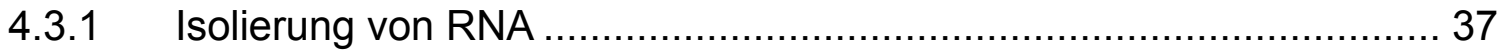

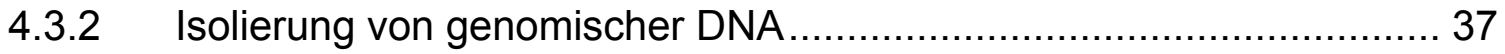

4.3.3 Isolierung von Plasmid-DNA aus E. coli ........................................ 38

4.3.4 Bestimmung der Nukleinsäurekonzentration .................................... 38

4.4 DNA-Amplifikation durch Polymerase-Kettenreaktion (PCR) …................ 38

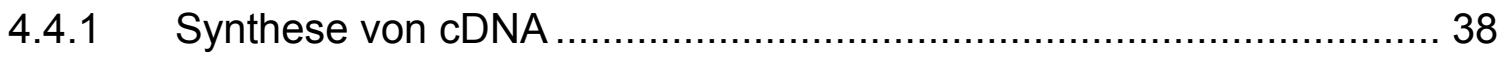

4.4.2 Ableitung von Oligonukleotid-Primern ………............................... 39

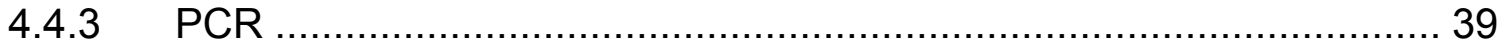

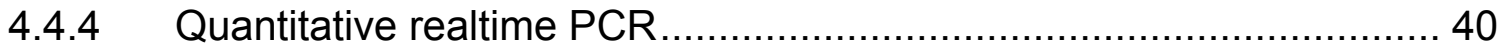

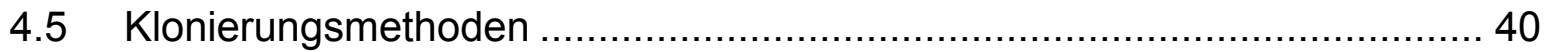

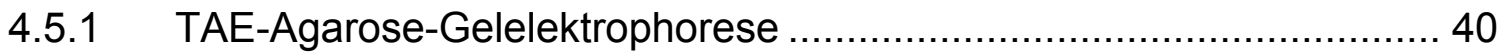

4.5.2 Isolierung von DNA-Fragmenten aus Agarosegelen ......................... 40

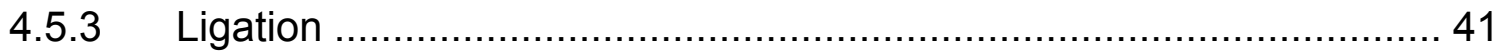

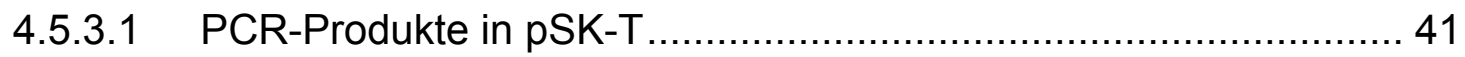

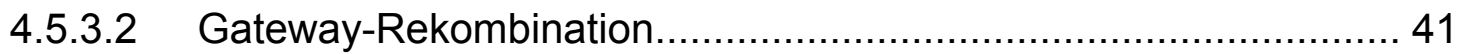

4.5.4 Transformation von E. coli.................................................. 43

4.5.4.1 Präparation kompetenter E. coli Zellen ...................................... 43 
4.5.4.2 Transformation kompetenter E. coli Zellen ................................ 43

4.5.5 Einfügen von Punktmutationen .................................................. 43

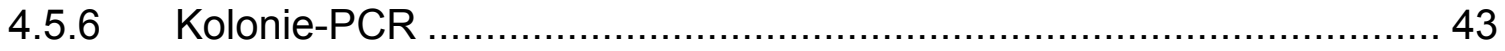

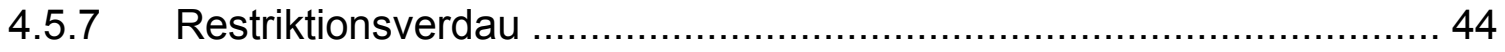

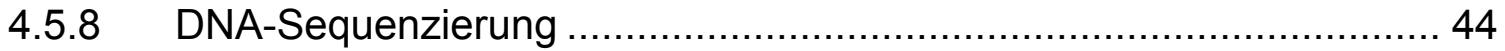

4.6 Transformation von Agrobakterien und Hefe .......................................... 45

4.6.1 Herstellung kompetenter Agrobakterien ........................................... 45

4.6.2 Transformation von Agrobacterium tumefaciens............................... 45

4.6.3 Herstellung kompetenter Hefezellen ........................................... 45

4.6.4 Transformation der kompetenten Hefezellen .................................. 45

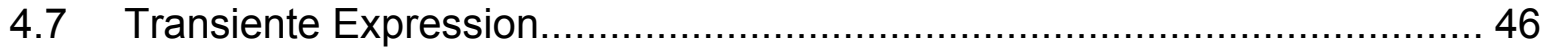

4.7.1 Transiente Expression in Arabidopsis Mesophyll-Protoplasten ........... 46

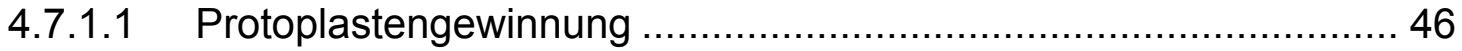

4.7.1.2 Protoplasten- PEG- Transformation...................................... 46

4.7.1.3 Messung der ß-Glucuronidase (GUS)-Aktivität........................... 46

4.7.1.4 Messung der Neuraminidase (NAN)-Aktivität ............................. 47

4.7.2 Transiente Expression in Nicotiana benthamiana .............................. 47

4.8 Detektion fluoreszenzmarkierter Proteine …....................................... 48

4.9 Infektion mit Pseudomonas syringae ............................................... 48

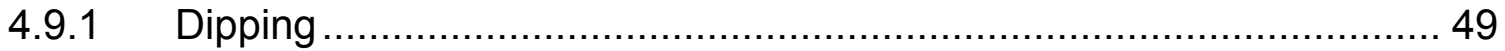

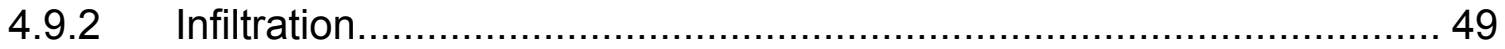

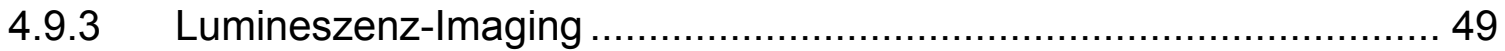

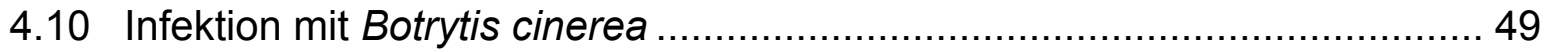

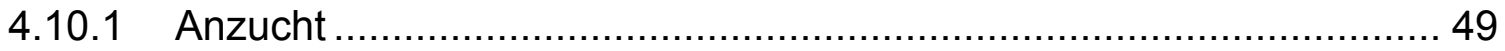

4.10.2 Sammeln der Sporen ......................................................... 50

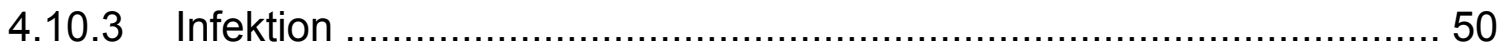

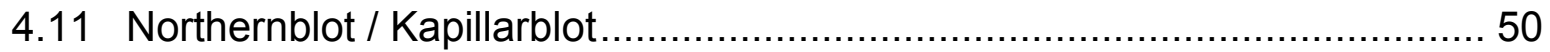

4.11.1 Denaturierende Agarosegelelektrophorese von RNA-Molekülen ........ 50

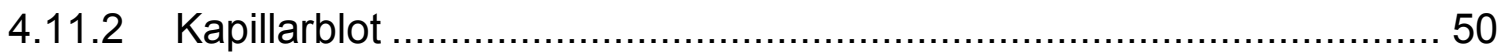

4.11.3 Herstellen einer radioaktiv markierten DNA-Sonde .......................... 51

4.11.4 Hybridisierung der Northern Blot Membran ..................................... 51

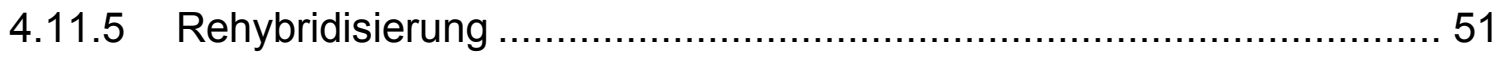

4.12 Transkriptomanalyse mit „ARIZONA whole genome arrays“ ..................... 52

4.12.1 Amplifikation der eingesetzten RNA ………................................. 52

4.12.2 Indirekte Markierung der aRNA ................................................... 52

4.12.3 Hybridisierung der „ARIZONA whole genome arrays“....................... 53 
4.13 Proteinbestimmung und Proteinfällung ........................................ 53

4.13.1 Proteinbestimmung nach Bradford ......................................... 53

4.13.2 Proteinfällung nach Wessel und Flügge ...................................... 54

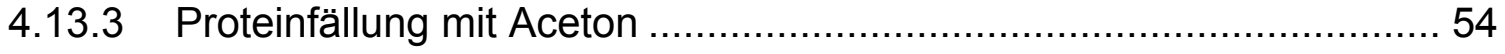

4.14 Western-Blot Analyse

4.14.1 Herstellung denaturierender Gesamtzellextrakte aus Pflanzen.......... 54

4.14.2 SDS-Polyacrylamidgelelektrophorese ........................................ 55

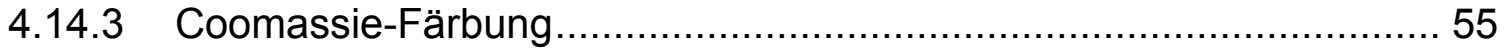

4.14.4 Proteintransfer auf PVDF-Membranen ........................................ 55

4.14.5 Immunodetektion mit dem ECL+ System .................................. 56

4.15 Einbettung von Proben für Elektronenmikroskopie ............................. 56

4.16 Bestimmung des Chlorophyllgehalts ............................................... 57

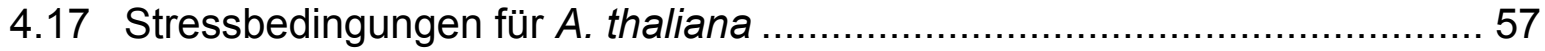

4.18 Analyse von T-DNA-Insertionsmutanten von $A$. thaliana ........................ 57

4.19 Verwendete Computerprogramme .................................................. 58

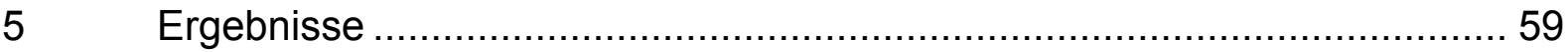

5.1 Eine Interaktion von AKR2A und AKR2B mit Gruppe C bZIP-

Transkriptionsfaktoren sollte überprüft werden 59

5.1.1 In zwei verschiedenen Two-Hybrid-Systemen wurde die Interaktion zwischen AKR2A/B und Gruppe C-bZIP-Faktoren getestet ............... 59

5.1.2 Test auf Interaktion mit „bimolecular fluorescence complementation“ (BiFC).

5.1.3 Die Zugabe von AKR2A oder AKR2B im Protoplasten-System steigert bZIP-Heterodimer-induzierte Reportergenaktivierung ......................6 64

5.2 Lokalisation von YFP-AKR2A/AKR2B .......................................... 65

5.2.1 AKR2A und AKR2B sind im Cytoplasma lokalisiert..........................65

5.2.2 Nach pharmakologischer Inhibierung des Kernexports sind AKR2A und

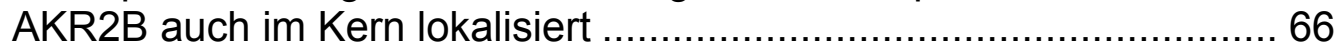

5.2.3 Mutation der putativen NES von AKR2A und AKR2B führt ebenfalls zur Kernlokalisation...................................................................... 68

5.3 Erzeugung von transgenen Pflanzen zur funktionalen Analyse von AKR2A

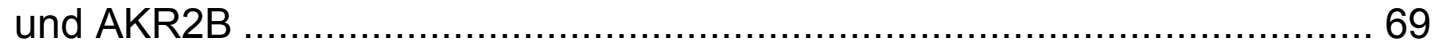

5.3.1 Erzeugung von Pro $_{355}: A K R 2 A$ und Pro $_{35 s}: A K R 2 B$ Pflanzen ................69 69

5.3.2 Identifizierung von $a k r 2 b$ Mutanten ....................................... 70

5.3.3 Erzeugung von AKR2-RNAi Pflanzen .................................... 72

5.3.4 AKR2-RNAi Pflanzen unterscheiden sich phänotypisch vom Wildtyp. 73

5.4 Funktionale Analyse der AKR2-RNAi und Pro ${ }_{355}$ :AKR2A Pflanzen und der $a k r 2 b$ Mutante 
5.4.1 Microarray zur Analyse der AKR2-RNAi und Pro ${ }_{355}$ :AKR2A Pflanzen 75

5.4.1.1 Ergebnisse der Transkriptomanalyse der AKR2-RNAi Pflanzen.... 75

5.4.1.2 AKR2-RNAi Pflanzen zeigen eine beeinträchtigte ChloroplastenBiogenese..

5.4.1.3 Ergebnisse der Transkriptomanalyse der Pro $355: A K R 2 A$ Pflanzen 81

5.4.2 AKR2-RNAi Pflanzen sind stressanfälliger als der Wildtyp 85

5.4.2.1 AKR2-RNAi Pflanzen sind anfälliger gegenüber oxidativem Stress als der Wildtyp

5.4.2.2 AKR2-RNAi Pflanzen sind suszeptibler gegenüber Pseudomonas syringae als der Wildtyp.

5.4.2.3 AKR2-RNAi Pflanzen sind anfälliger gegenüber einer Infektion mit Botrytis cinerea als der Wildtyp.

6 Diskussion

6.1 Interaktionen zwischen einem Ankyrin-repeat Protein und einem bZIP-

Transkriptionsfaktor unterscheiden sich in Tabak und Arabidopsis.

6.2 Mehrere zelluläre Lokalisationen von AKR2A und AKR2B (Cytoplasma, Kern und Chloroplastenmembran) deuten auf multiple Funktionen hin ....

6.3 Die Überexpression von AKR2A führt zu keiner deutlichen phänotypischen Veränderung

6.4 AKR2-RNAi Pflanzen zeigen reduziertes Wachstum und eine beeinträchtigte Chloroplasten-Biogenese

6.5 Die erhöhte Stressanfälligkeit der AKR2-RNAi Pflanzen könnte ein sekundärer Effekt sein 102

6.6 Modell der potentiellen Funktionen von AKR2A und AKR2B 103

$7 \quad$ Literatur. .105

8

Anhang

8.1 Daten

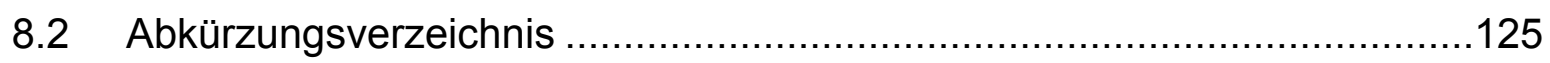

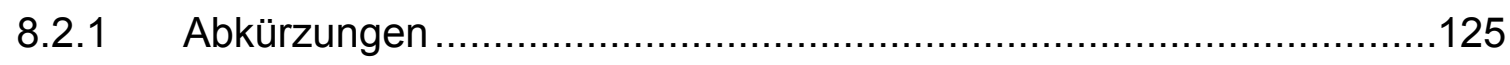

8.2.2 Einbuchstabenkürzel für Aminosäuren.....................................129

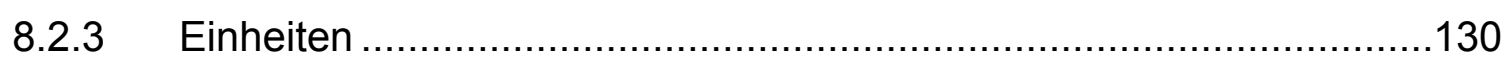

8.2.4 Vorsätze zur Bezeichnung von dezimalen Vielfachen und Teilen von Einheiten . 


\section{Zusammenfassung}

In Tabak interagieren das Ankyrin-repeat Protein NtANK1 und der basische Leucin Zipper (bZIP)-Transkriptionsfaktor NtBZI-1. Diese Proteine sind in Auxin-vermittelter Genaktivierung und in Pathogenabwehr involviert.

Ziel dieser Arbeit war es, die Funktion der homologen Ankyrin-repeat Proteine AKR2A und AKR2B aus Arabidopsis thaliana zu untersuchen. Dazu wurde die Interaktion zwischen AKR2A/B, und den homologen bZIP-Transkriptionsfaktoren der Gruppe C getestet. Mit verschiedenen Methoden, wie Hefe- und Protoplasten-twohybrid und BiFC („bimolecular fluorescence complementation“) konnte eine Interaktion der Arabidopsis Proteine nicht bestätigt werden. Lokalisationsstudien von YFP-AKR2A/B-Fusionsproteinen bestätigten, dass die Proteine im Cytoplasma lokalisiert sind. Sie besitzen eine funktionsfähige NES („nuclear export signal“) und akkumulieren nach Inhibierung des Kernexports im Kern. Eine Veröffentlichung beschreibt auch eine Lokalisation an der äußeren Chloroplastenmembran. Diese multiplen Lokalisationen (Cytoplasma, Chloroplastenmembran, Kern) deuten auf mehrere Funktionen von AKR2A und AKR2B hin.

Zur Funktionsaufklärung wurden AKR2-RNAi („RNA interference“) Pflanzen erzeugt, die sich phänotypisch vom Wildtyp unterscheiden: sie zeigen ein verringertes Wachstum und einen reduzierten Chlorophyllgehalt, abhängig von der Ausprägung des RNAi-Effektes. In elektronenmikroskopischen Untersuchungen ist zu erkennen, dass sich die Blattchloroplasten der AKR2-RNAi Pflanzen von denen des Wildtyps morphologisch unterscheiden und in ihrer Entwicklung beeinträchtigt sind.

Eine Transkriptomanalyse der AKR2-RNAi Pflanzen zeigte, dass Gene des Endomembransystems herunterreguliert sind und viele Stress-induzierte Gene hochreguliert sind. Deshalb wurden die Pflanzen verschiedenen Stressbedingungen unterzogen und übereinstimmend stellte sich heraus, dass sie anfälliger gegenüber oxidativem Stress, Infektion mit dem biotrophen Bakterium Pseudomonas syringae und Infektion mit dem nekrotrophen Pilz Botrytis cinerea waren. Diese erhöhte Anfälligkeit kann als sekundärer Effekt aufgrund der beeinträchtigten ChloroplastenBiogenese interpretiert werden, oder als spezifische Reaktion auf die reduzierte AKR2A/B-Proteinmenge.

Aufgrund dieser Daten werden multiple Funktionen für AKR2A und AKR2B diskutiert: Transport von Proteinen zu verschiedenen Endomembransystemen, eine Funktion im Signalaustausch zwischen Chloroplast und Kern, und eine Regulation der Transkriptionskontrolle im Kern. 


\section{Einleitung}

Zelluläre Funktionen sind fast immer das Ergebnis der Zusammenarbeit von mehreren Proteinen, die in Proteinkomplexen, Signalwegen oder Netzwerken interagieren (Bader et al., 2008). Die Proteine haben Interaktionsdomänen, die solche Protein-Protein Interaktionen vermitteln (Pawson und Nash, 2003). Eine typische Interaktionsdomäne ist die Ankyrin-repeat Domäne, die in Prokaryoten, Eukaryoten und einigen Viren vorkommt (Sedgwick und Smerdon, 1999). Ein Beispiel für ein Ankyrin-repeat Protein ist NtANK1 aus Tabak, das mit dem Transkriptionsfaktor NtBZI-1 aus Tabak interagiert (Kuhlmann et al., 2003; Böttner et al., 2009). Diese Protein-Protein Interaktion spielt eine Rolle in der Auxin-vermittelten Transkriptionskontrolle in Tabak (Böttner et al., 2009).

\subsection{Der bZIP-Transkriptionsfaktor NtBZI-1 aus Tabak}

Transkriptionsfaktoren regulieren den ersten Schritt der Genexpression. Sie haben eine DNA-Bindedomäne, die eine spezifische DNA-Sequenz im Promotor ihrer Zielgene erkennt, und können die Transkription dieser Zielgene aktivieren oder reprimieren (Mitsuda und Ohme-Takagi, 2009).

Transkriptionsfaktoren der basische Region/Leucin-Zipper- (bZIP) Familie besitzen eine basische Region, die an die DNA bindet und ein Leucin-Zipper Motiv, mit dem sie Dimere bilden (Jakoby et al., 2002; Abb. 1). Der Leucin-Zipper besteht aus Wiederholungen von Leucin, oder anderen hydrophoben Aminosäuren, im Abstand von 7 Aminosäuren ( $\mathrm{L}-\mathrm{X}_{6}-\mathrm{L}$,heptad repeat“). bZIP-Transkriptionsfaktoren kommen in allen bisher analysierten Eukaryonten vor (Jakoby et al., 2002).

In Tabak (Nicotiana tabacum) wurde der bZIP-Transkriptionsfaktor NtBZI-1 identifizert. Er bindet in vitro an G-Box und C-Box cis-Elemente, ist im Nukleus lokalisiert und seine N-terminale Region fungiert sowohl in Hefe als auch in Pflanzenzellen als Aktivierungsdomäne (Heinekamp et al., 2002). Außerdem wurden Interaktionspartner von NtBZI-1 durch „Yeast-two-hybrid“ (Y2H)-Experimente gefunden, nämlich die bZIP-Transkriptionsfaktoren NtBZI-2, NtBZI-3 und NtBZI-4 (Strathmann et al., 2001). Die Interaktion findet zwischen den Zipperdomänen statt, so dass sich ein Dimer bildet, das an die DNA binden kann (Abb. 1). Pflanzen, die eine dominant-negative Form von NtBZI-1 (NtBZI-1 $\Delta \mathrm{N})$ überexprimieren, haben 
verkürzte Internodien, mehr Seitentriebe und eine reduzierte Antwort auf Auxin. NtBZI-1 bindet in vivo und in vitro an den Promotor des Auxin-induzierten GH3Gens, und es wird NtBZI-1 eine Rolle bei der Regulation der Auxin-induzierten Transkription zugeordnet (Heinekamp et al., 2004). Eine Funktion bei der Pathogenabwehr wird für NtBZI-1 ebenfalls beschrieben, denn die NtBZI-1 Transkription wird bei der Antwort auf Pathogenbefall hochreguliert und NtBZI-1 $\Delta \mathrm{N}$ Pflanzen sind suszeptibler gegenüber Infektion mit dem Tabak-Mosaik-Virus (Kuhlmann et al., 2003).

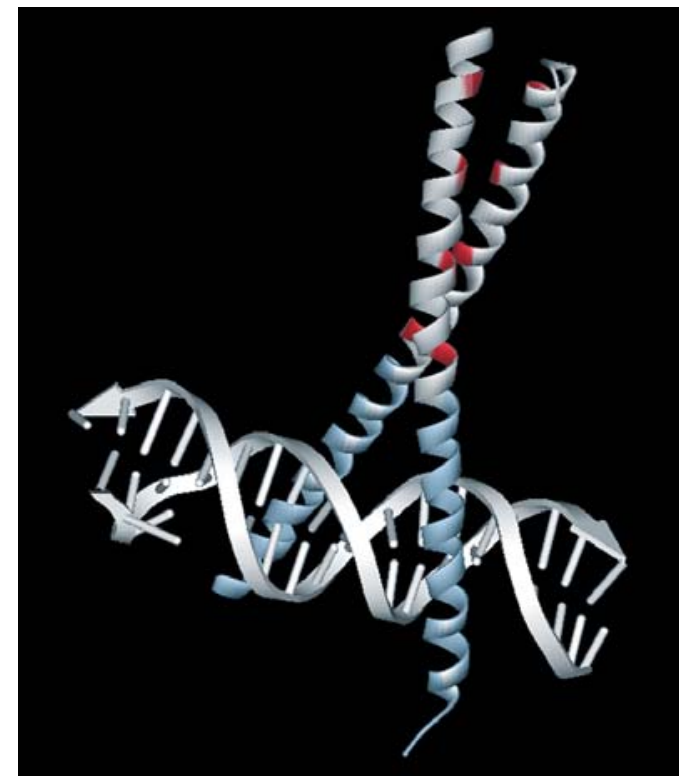

\begin{abstract}
Abbildung 1: Drei-dimensionale Struktur der GCN4bZIP-Domäne, als Dimer an die DNA gebunden (Jakoby et al., 2002). Die Zipper-Motive interagieren miteinander, die Leucine sind in rot eingezeichnet, in blau sind die basischen Regionen gekennzeichnet, die an die DNA binden.
\end{abstract}

\title{
2.2 Das Protein NtANK1 aus Tabak, ein Interaktionspartner von
} NtBZI-1

Das Ankyrin-repeat Protein NtANK1 wurde als Interaktionspartner von NtBZI-1 in einem Y2H-Experiment identifiziert (Kuhlmann et al., 2003, Böttner et al., 2009). Die Ankyrin-repeat Domäne ist eine typische Proteindomäne, die aus Wiederholungen (,repeats“) einer konservierten Sequenz von 33 Aminosäuren besteht, die $\alpha$-Helices und $\beta$-Faltblätter bilden (Abb. 2; Sedgwick und Smerdon, 1999). Es hat sich dabei gezeigt, dass nur ca. 11 Aminosäuren stark konserviert sein müssen, um die Tertiärstruktur zu formen (Mosavi et al., 2002). Ankyrin-repeats vermitteln Protein- 
Protein-Interaktionen; Proteine, in denen Ankyrin-repeats vorkommen, haben jedoch ganz unterschiedliche Aufgaben, z.B. im Zellzyklus, als mitochondriale Enzyme, oder bei der Signaltransduktion (Sedgwick und Smerdon, 1999; Bennett und Chen, 2001).
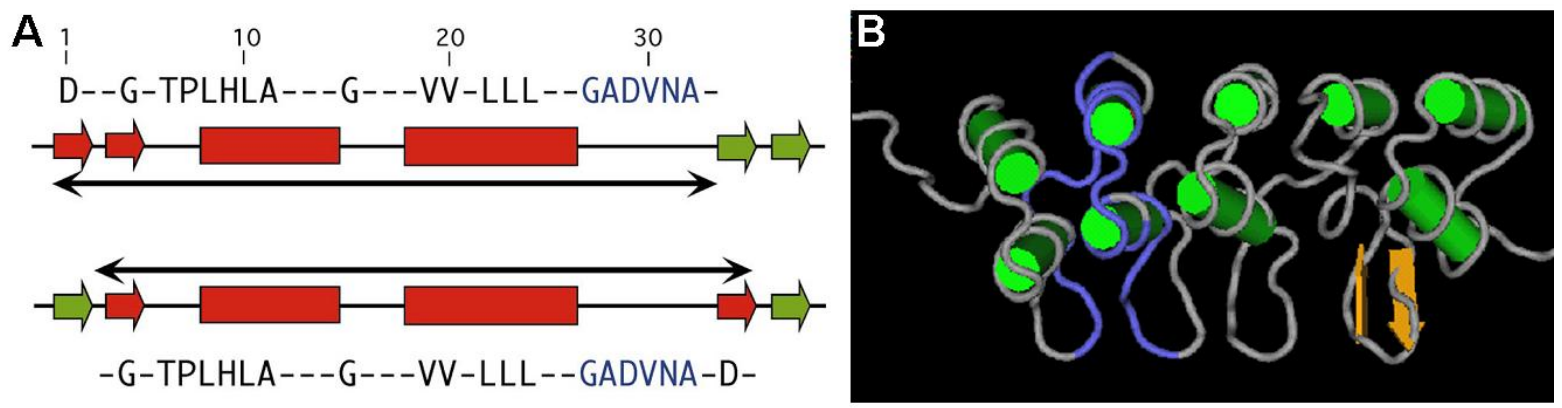

Abbildung 2: Aufbau und Struktur der Ankyrin-repeat Domäne A: Primärstruktur des Ankyrinrepeats, angegeben sind konservierte Aminosäuren, darunter in rot die entsprechende Sekundärstruktur: Pfeile für $\beta$-Faltblätter, Rechtecke für $\alpha$-Helices; der schwarze Pfeil gibt die Länge eines einzelnen Ankyrin-repeats an (Tertiärstruktur: $\beta_{2} \alpha_{2}$ ). Darunter ist eine alternative Definition der $\mathrm{N}$ - und C-terminalen Begrenzung eines Ankyrin-repeats angegeben: $\beta \alpha_{2} \beta$. B: Tertiärstruktur einer Ankyrin-repeat Domäne bestehend aus 4 Ankyrin-repeats mit $\alpha$-Helices in grün und $\beta$-Faltblättern als oranger Pfeil, ein einzelnes Ankyrin-repeat ist markiert in blau $\left(\beta \alpha_{2} \beta\right)$ (Sedgwick und Smerdon, 1999).

Das Ankyrin-repeat Protein NtANK1 aus Tabak hat 4 Ankyrin-repeats am C-Terminus (Abb. 2). Im Protoplast-two-hybrid (P2H) System konnte bestätigt werden, dass Mutationen in diesen Ankyrin-repeats die Interaktion mit NtBZI-1 zerstören (Böttner et al., 2009). N-terminal kommen in NtANK1 die Aminosäuren Prolin (P), Glutamat (E), Serin (S) und Threonin (T) gehäuft vor. Eine solche Peptidsequenz wird nach dem Ein-Buchstabencode dieser Aminosäuren als PEST-Domäne bezeichnet und es wird ihr eine Rolle im proteolytischen Abbau zugeordnet, die jedoch nicht weiter charakterisiert ist (Rechsteiner und Robers, 1996). Für NtANK1 konnte jedoch kein Abbau nachgewiesen werden, unter den getesteten Bedingungen waren blieb die NtANK1-Proteinmenge gleich (Böttner et al., 2009).

Proteine aus $N$. tabacum (TIP1-3, „TGB12K-interacting proteins“) und $N$. plumbaginifolia (GBP1+2, „Glucanohydrolase Binding Proteins“), die homolog zu NtANK1 sind, konnten als Interaktionspartner von $\beta$-Glucanasen identifiziert werden (Fridborg et al., 2003; Wirdnam et al., 2004). Für $\beta$-Glucanasen wird eine Funktion in der Pathogenabwehr beschrieben (Bucher et al., 2001).

NtANK1 aus Tabak bindet nicht an DNA und ist im Cytoplasma lokalisiert (Kuhlmann et al., 2003). Allerdings kann NtANK1 im Kern akkumulieren, wenn es als NLSFusionsprotein („nuclear localisation sequence“) exprimiert wird, wenn durch Zugabe von Leptomycin B (LMB; Haasen et al., 1999) der Kernexport inhibiert wird, bei 
Koexpression von NtBZI-1 oder bei Zugabe von Auxin (Böttner et al., 2009). Die Interaktion zwischen NtBZI-1 und NtANK1 konnte neben den Hefestudien auch indirekt in vitro und in planta nachgewiesen werden (mit „electrophoretic mobility shift assay“ (EMSA), P2H und "bimolecular fluorescence complementation“ (BiFC); Kuhlmann et al., 2003, Böttner et al., 2009). NtANK1 interagiert nur spezifisch mit NtBZI-1 und nicht mit NtBZI-2 oder anderen getesteten bZIP-Transkriptionsfaktoren. Im Protoplasten-System konnte gezeigt werden, dass NtANK1 in Anwesenheit von Auxin eine vom NtBZI-1/NtBZI-2-Heterodimer induzierte Genaktivierung erhöhen kann. Durch eine Kernlokalisation von NtANK1 als NLS-Fusionsprotein, wird die Genaktivierung nochmals verstärkt (Böttner et al., 2009). Außerdem führt eine Reduktion von funktionalem NtANK1-Protein in Pflanzen durch RNAi-Effekt zu einer reduzierten Auxin-Antwort. Dies gilt in vergleichbarer Weise auch für NtBZI-1-RNAi Pflanzen und NtBZI-2-RNAi Pflanzen, so dass für diese drei Proteine eine ähnliche Funktion postuliert wird. Ein Modell für das Zusammenspiel der drei Proteine wird in Böttner et al. (2009) beschrieben (Abb. 3). NtANK1 akkumuliert in Anwesenheit von Auxin im Kern, dabei könnte Auxin (a) den Kerntransport von NtANK1 oder (b) den Kerntransport des NtANK1/NtBZI-1-Heterodimers ermöglichen, oder (c) den Kernexport von NtANK1 inhibieren. Im Kern bilden sich NtANK1/NtBZI-1Heterodimere (d) und NtBZI-1/NtBZI-2-Heterodimere steigern Auxin-vermittelte Transkription, die durch NtANK1 als Interaktionspartner von NtBZI-1 noch verstärkt werden kann (e) (Abb. 3).

Die bisher bekannte Auxin-Antwort benötigt zwei Arten von Transkriptionsfaktoren: ARF-Transkriptionsfaktoren („auxin response factor“) binden an AuxREs („auxin response elements") in Promotoren von Auxin-responsiven Genen, und rekrutieren eine zweite Familie von Transkriptionsfaktoren, die Aux/IAA Repressoren, die nur in Anwesenheit von Auxin abgebaut werden, wodurch dann die Expression der Auxinresponsiven Gene stattfinden kann (Guilfoyle und Hagen, 2007). Es ist anzunehmen, dass der NtANK1/NtBZI-1/NtBZI-2 Komplex eine Feinregulierung dieser ARFvermittelten Transkription übernimmt. Daraus lässt sich folgern, dass NtANK1 eine regulatorische Komponente der Auxin-vermittelten Transkriptionskontrolle ist (Böttner et al., 2009). 


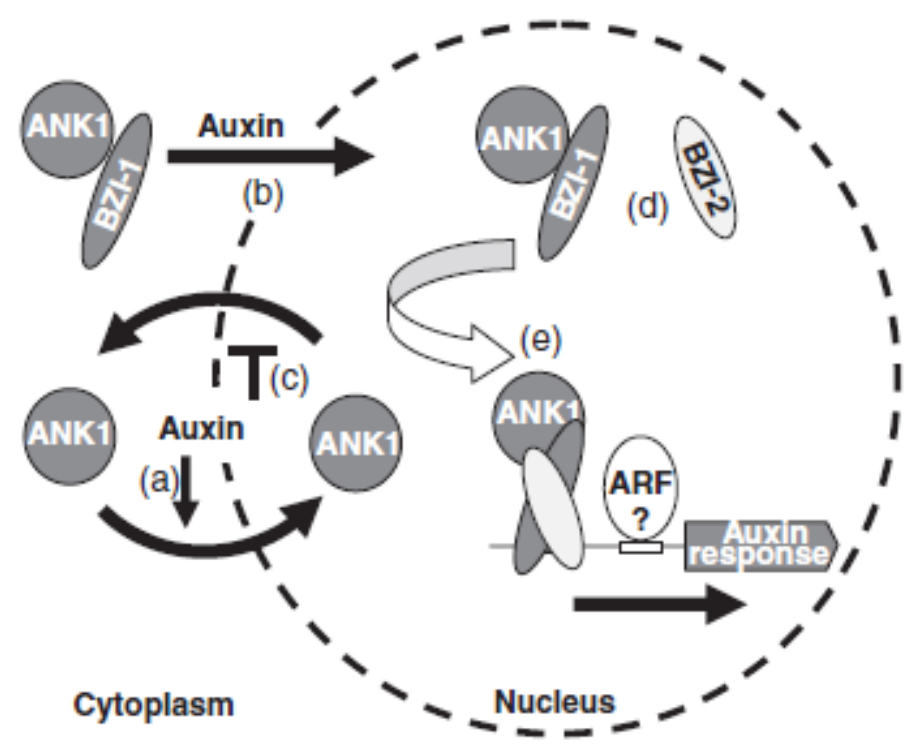

Abbildung 3: Modell für die Auswirkung von NtANK1 auf die Auxin-vermittelte Transkription. Nach Zugabe von Auxin wird NtANK1 in den Kern transportiert. Dafür kommen verschiedene Mechanismen infrage: Auxin kann z.B. den direkten Transport von NtANK1 in den Kern stimulieren (a), oder den indirekten Transport nach Interaktion mit NtBZI-1 (b). Auxin könnte auch den Kernexport reprimieren, ähnlich wie Leptomycin B (c). Im Kern interagiert NtANK1 mit NtBZI-1, jedoch nicht mit NtBZI-2 (d). NtBZI-1/NtBZI-2-Heterodimere stimulieren Auxin-vermittelte Transkription, die durch NtANK1 noch verstärkt werden kann, vermutlich durch Interaktion mit NtBZI-1 (e). Ob ein stabiler Proteinkomplex aus den drei Proteinen gebildet wird, oder ob es sich um eine transiente Proteininteraktion handelt, ist noch nicht klar. Da NtBZI-1/NtBZI-2-Heterodimere Auxin-vermittelte Transkription beeinflussen, sind sie wahrscheinlich abhängig von den „auxin response factors“ (ARFs) (Böttner et al., 2009).

\subsection{Die homologen Proteine zu NtBZI-1 aus Tabak sind die bZIP- Transkriptionsfaktoren der Gruppe $C$ in Arabidopsis thaliana}

Arabidopsis thaliana ist wie Tabak eine Modellpflanze, die bei der Arbeit im Labor einige Vorteile bietet. Sie ist einfach zu transformieren, und zwar indem die fast geöffneten Blüten in eine Suspension mit transformierten Agrobakterium tumefaciens getaucht werden (Clough und Bent, 1998). Durch die kurze Generationszeit von 6-8 Wochen können die homozygoten, transformierten Nachkommen bald verwendet werden. Da das gesamte Genom von A. thaliana im Jahre 2000 sequenziert wurde, stehen einige molekulare Werkzeuge zur Verfügung, wie z.B. einfache Amplifikation und Sequenzierung von Genen; T-DNA-Insertionsmutanten, die durch Transformation mit einem Derivat des zu untersuchenden Gens (z.B. die nichtinteragierende Version von NtANK1) komplementiert werden können, so dass das Fehlen einer bestimmten Eigenschaft (z.B. die fehlende Interaktion von NtANK1 und $\mathrm{NtBZI}-1$ ) in der Pflanze funktionell charakterisiert werden kann (Arabidopsis Genome Initiative, 2000). 
Mittlerweile sind 27.029 Gene, die für Proteine kodieren, vorhergesagt (Swarbreck et al., 2008). Davon werden 2.451 Gene als für Transkriptionsfaktoren kodierend postuliert (Pérez-Rodríguez et al., 2010). Sie werden aufgrund ihrer Struktur in verschiedene Familien eingeteilt.

In Arabidopsis sind 75 bZIP-Transkriptionsfaktoren bekannt, die in 10 Gruppen eingeteilt werden können (Jakoby et al., 2002). Die bZIP-Faktoren, die die höchste Homologie zu NtBZI-1 aus Tabak zeigen, gehören zur Gruppe C: bZIP9, bZIP10, bZIP25 und bZIP63 (Abb. 4). Die Proteine haben Homologie zu dem bZIPTranskriptionsfaktor OPAQUE2 (O2) aus Mais und sind dadurch charakterisiert, dass der Leucin-Zipper verlängert ist und bis zu neun Leucine ( $\left.L-X_{6}\right)$ enthält (Jakoby et al., 2002). O2 ist der erste beschriebene bZIP-Faktor in Pflanzen, dessen Expression nur im Endosperm zwischen Tag 10 und Tag 45 nach der Befruchtung stattfindet (Hartings et al., 1989). Das O2-Protein bindet als Homodimer an die DNA der Promotoren seiner Zielgene, um so deren Transkription zu aktivieren (Muth et al., 1996). Zu den Zielgenen gehört die Zein-Proteinfamilie, die im Mais-Endosperm die Haupt-Speicherproteine darstellen (Pirona et al., 2005; Locatelli et al., 2009).

Auch bZIP10 und bZIP25 aus Arabidopsis wurde eine Funktion in der Regulation der Samenspeicherproteine zugeordnet (Lara et al., 2003). In Ehlert et al. (2006) wurde gezeigt, dass bZIP-Faktoren der Gruppe C spezifisch mit bZIP-Faktoren der Gruppe S1 Heterodimere bilden („C/S1 Netzwerk“). Zur Gruppe S1 gehören bZIP1, bZIP2, bZIP11, bZIP44 und bZIP53 (Jakoby et al., 2002). Kürzlich konnte gezeigt werden, dass Heterodimere aus bZIP53 und bZIP10 oder bZIP53 und bZIP25 die Expression von Samenspeicherprotein-Genen verstärken (Alonso et al., 2009); und die ProlinDehydrogenase (ProDH) wurde als direktes Zielgen von bZIP53 identifiziert (Weltmeier et al., 2006).

Der Transkriptionsfaktor bZIP10 spielt eine Rolle bei der Antwort auf oxidativen Stress, insbesondere bei der Abwehr gegen das biotrophe Pathogen Hyaloperonospora parasitica (Kaminaka et al., 2006). Aus einer Verwandtschaftsanalyse der bZIP-Familie aus grünen Pflanzen ging hervor, dass sich die Gruppen C und $S$ in Arabidopsis aus einem gemeinsamen Vorfahren („Proto-C“) entwickelt haben, der in oxidativem Stress und Energiemetabolismus involviert war (Correa et al., 2008). Alle Mitglieder der Gruppen C und S1 werden in „sink“-Geweben exprimiert, wie z.B. junge Blätter, Antheren und Samen, was die Hypothese stützt, dass das C/S1 Netzwerk dabei mitwirkt, Nährstoffe und somit auch Energie zu den 
„sink“-Geweben zu verteilen (Rook et al., 1998a, 1998b). Die Translation der bZIPFaktoren der Gruppe S1 wird durch Zucker reprimiert, dafür ist ein konserviertes Peptid verantwortlich, das von einem uORF (,upstream open reading frame“) am 5'Ende der mRNA kodiert wird (Wiese et al., 2004). Für bZIP11 konnten zwei Enzyme aus dem Aminosäurestoffwechsel, Asparaginsynthetase1 (ASN1) und ProDH, als Zielgene identifiziert werden, so dass ein Modell vorgeschlagen wurde, indem Zucker durch bZIP11 den Aminosäurestoffwechsel regulieren (Hanson et al., 2008). Stress und Stoffwechselsignale verändern also die Expression von bZIP-Faktoren der Gruppe S1, jedoch nicht die der Gruppe C (Weltmeier et al., 2009).

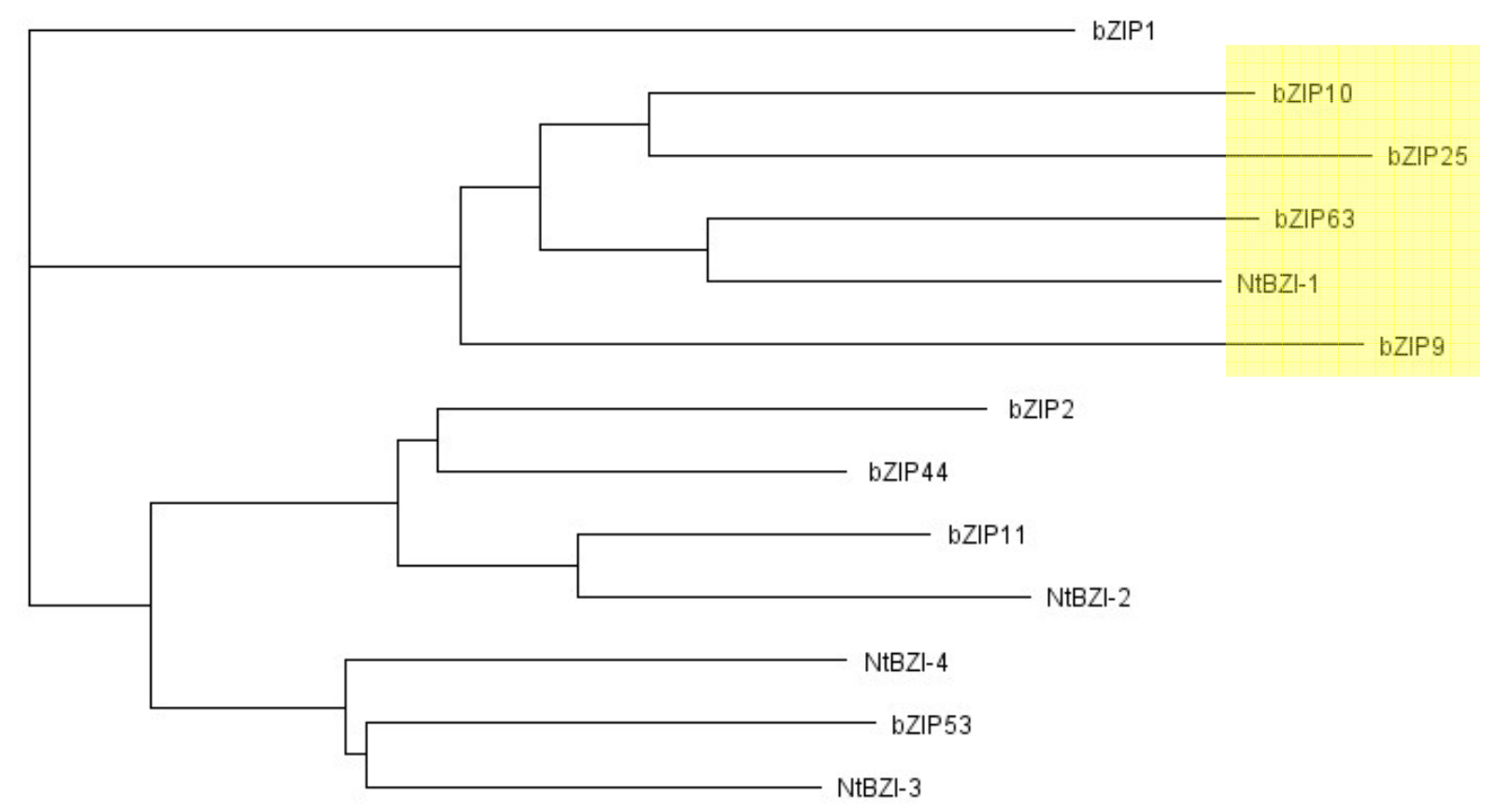

Abbildung 4: Verwandtschaft der Arabidopsis bZIP-Faktoren der Gruppen C und S1 mit NtBZI-1, -2, -3, -4 aus Tabak aufgetragen als phylogenetischer Baum, basierend auf der Gesamtsequenz der Proteine. NtBZI-1 zeigt die größte Homologie zu den Faktoren der Gruppe C aus Arabidopsis (gelb hinterlegt), während seine Interaktionspartner NtBZI-2, -3, -4 mehr Homologie zur Gruppe S1 aus Arabidopsis zeigen. 


\subsection{Die Arabidopsis Proteine AKR2A und AKR2B sind homolog zu} NtANK1 aus Tabak

In Arabidopsis gibt es 105 Ankyrin-repeat Proteine, die aufgrund von konservierten Domänen in verschiedene Cluster eingeteilt wurden (Becerra et al., 2004). Einige dieser Proteine sind schon charakterisiert worden, darunter sind NPR1 (At1g64280) als Regulator von Salizylsäure (SA)-abhängiger Pathogenabwehr (Mou et al., 2003; Dong, 2004) und Atapk1 (At2g43850) ist eine Kinase (Chinchilla et al., 2003). Im Cluster B sind die Ankyrin-repeat Proteine aus Arabidopsis zusammengefasst, in denen außer den Ankyrin-repeats keine weitere konservierte Domäne vorhanden ist (Becerra et al., 2004). Darunter befinden sich 4 bekannte Proteine: EMB506 (At5g40160) und AKRP (At5g66055) sind Chloroplastenproteine, die miteinander interagieren und essentiell für die Embryonalentwicklung und Plastidendifferenzierung sind (Zhang et al., 1992; Albert et al., 1999; Garcion et al., 2006). AKR2A (At4g35450, AKR2, Yan et al., 2002; Bae et al., 2008) und AKR2B (At2g17390, AtPhos43, Peck et al., 2001) sind Proteine mit 80\% Aminosäureidentität und es sind die beiden Proteine aus Arabidopsis, die die höchste Sequenzhomologie zu NtANK1 aus Tabak zeigen. Im phylogenetischen Baum mit Cluster B der Ankyrinrepeat Proteine (Becerra et al., 2004) und im „Alignment“ in Abb. 5 ist dies zu sehen. Bisher gibt es einige Hinweise auf die Funktion von AKR2A und AKR2B. AKR2A wurde zuerst isoliert aufgrund einer Interaktion mit einem 14-3-3-Protein (At5g10450, Yan et al., 2002). 14-3-3 Proteine spielen eine Rolle in der Regulation von verschiedenen zellulären Prozessen durch phosphorylierungsabhängige ProteinProtein-Interaktionen (Van Heusden, 2009; Oecking und Jaspert, 2009). Antisensepflanzen von AKR2A zeigen kleine nekrotische Flecken auf den Blättern und in diesen Blättern wurde ein erhöhter Gehalt an $\mathrm{H}_{2} \mathrm{O}_{2}$ nachgewiesen, wie es auch bei der HR („hypersensitive response“) nach Pathogeninfektion der Fall ist. Die Pflanzen zeigen eine erhöhte Resistenz gegen das Bakterium Pseudomonas syringae. Weil AKR2A außerdem mit der Ascorbat Peroxidase 3 (APX3), die $\mathrm{H}_{2} \mathrm{O}_{2}$ zersetzt, interagiert, wird eine Rolle im Antioxidationsmetabolismus vorgeschlagen, der sowohl bei Pathogenbefall als auch bei Stressantwort von Bedeutung ist (Yan et al., 2002). 


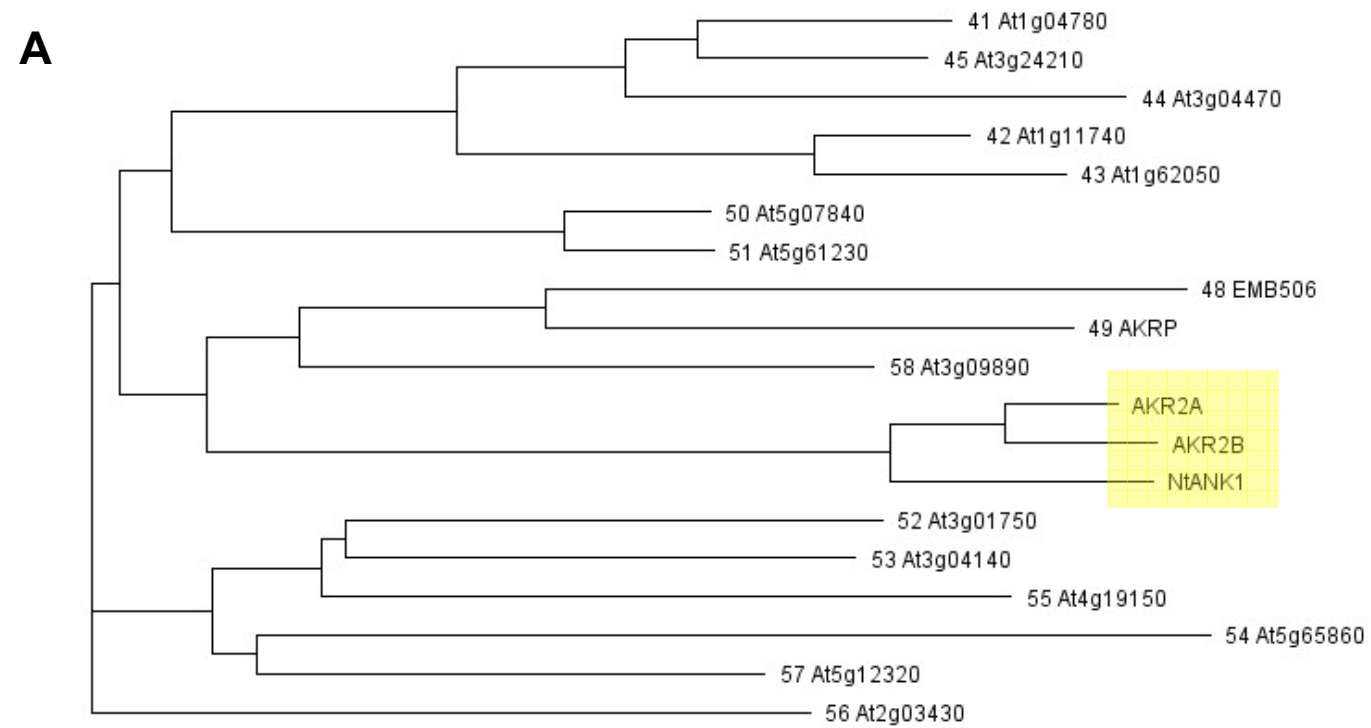

B Consensus
Identity

Consensus

Identity

1. AKR2A

2. AKR2B

4. ANK-repeat

Consensus

Identity

1. AKR2A

2. AKR2B

4. ANK-repeat

Consensus

Identity

1. AKR2A

2. AKR2B

4. ANK-repeat

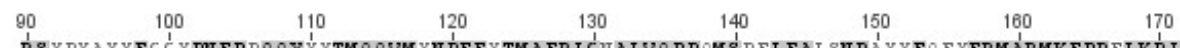

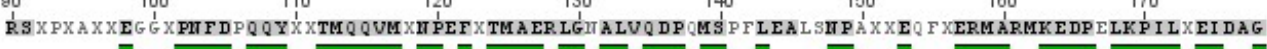

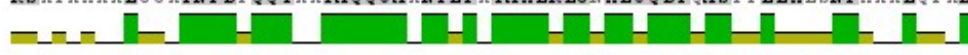

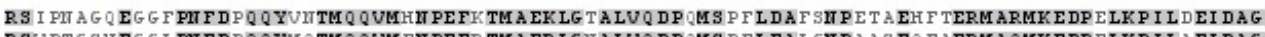

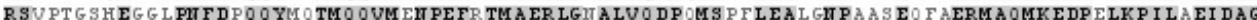

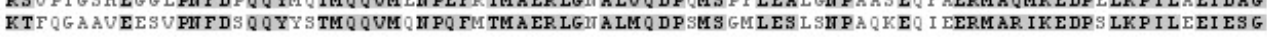
$\begin{array}{llllllll}180 & 190 & 200 & 210 & 220 & 230 & 240 & 250\end{array}$

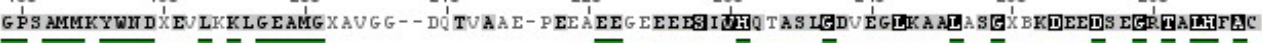
(2_-

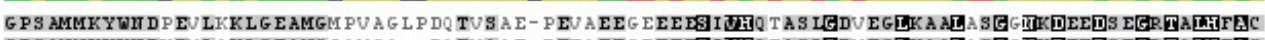

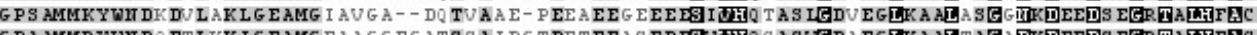

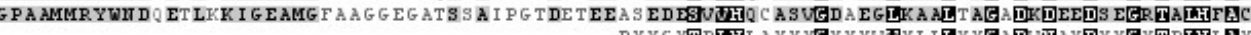

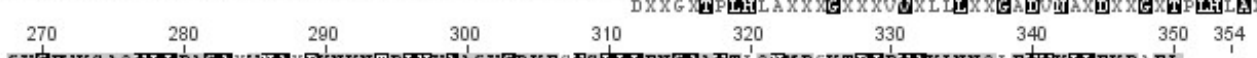

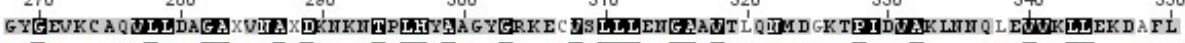
-

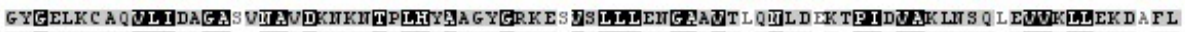

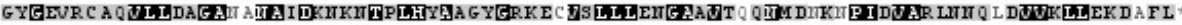

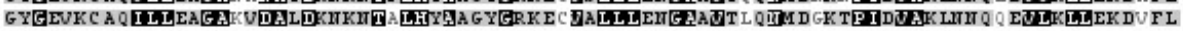

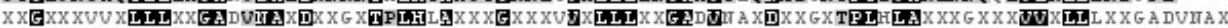

Abbildung 5: Homologievergleich von AKR2A, AKR2B und NtANK1. A: Phylogenetischer Baum mit Cluster B der Ankyrin-repeat Proteine aus Arabidopsis (Becerra et al., 2004) und NtANK1 aus Tabak, basierend auf der Gesamtsequenz der Proteine. Gelb hinterlegt sind die homologen Proteine AKR2A, AKR2B und NtANK1. B: Alignment von AKR2A und AKR2B aus Arabidopsis, NtANK1 aus Tabak und der konservierten Ankyrin-repeat Sequenz (ANK-repeat) nach Sedgwick und Smerdon (1999). Die drei Proteine haben $4 \mathrm{C}$-terminale Ankyrin-repeats, die jeweils 33 Aminosäuren umfassen (DXX...NAX), X steht für eine beliebige, nicht konservierte Aminosäure (s. auch Kuhlmann et al., 2003). Consensus: Konsensus-Sequenz, Identity: Die Höhe der Balken gibt den Grad der Aminosäuren-Identität an.

Mithilfe von Enzymen und nicht-enzymatischen Antioxidantien kann die Zelle reaktive Sauerstoffspezies (ROS) abbauen und sich gegen Schädigungen schützen. Superoxiddismutasen katalysieren die Reduktion von $\mathrm{O}_{2}^{-} \mathrm{zu} \mathrm{H}_{2} \mathrm{O}_{2}$ unter Bildung von $\mathrm{O}_{2}$ (Bowler et al., 1994). $\mathrm{H}_{2} \mathrm{O}_{2}$ wird von der Ascorbat Peroxidase eliminiert, wobei das Antioxidans Ascorbat oxidiert wird, welches durch die Oxidation von Glutathion wieder regeneriert werden kann (Grene, 2002; Heldt, 1999). ROS können bei oxidativem Stress in der Pflanze entstehen, der durch verschiedene abiotische 
Faktoren, wie Kälte und hohe Lichtintensitäten, ausgelöst wird (Mullineaux et al., 2000). Unter normalen Bedingungen, d.h. ohne Stress, sind Bildung und Beseitigung von Sauerstoff im Gleichgewicht, unter Stressbedingungen kann es vorkommen, dass die vermehrt gebildeten ROS nicht schnell genug abgebaut werden und die Zelle schädigen (Grene, 2002). Es können alle biologisch relevanten Makromoleküle geschädigt werden, insbesondere Nukleinsäuren (Hagar et al., 1996). Besonders anfällig für oxidativen Stress sind Chloroplasten und Peroxisomen, da in innen ROS gebildet werden.

AKR2B wurde in einem Proteomansatz identifiziert, weil es innerhalb weniger Minuten nach Zugabe von Flagellin oder Chitin (bakterieller bzw. pilzlicher Elicitor) zur Arabidopsis-Zellkultur phosphoryliert wird. Das Protein ist also Teil einer schnellen Antwort auf mikrobielle Pathogene, die allerdings noch nicht näher charakterisiert ist (Peck et al., 2001). Obwohl die funktionelle Bedeutung der Phosphorylierung von AKR2B noch nicht klar ist, implizieren diese Daten, dass sowohl AKR2A als auch AKR2B eine Rolle bei der Pathogenabwehr der Pflanze spielen.

Pathogene können eingeteilt werden in biotrophe, die sich von den Assimilaten einer lebenden Pflanzenzelle ernähren und auf das Überleben der Wirtspflanze angewiesen sind (z.B. das Bakterium Pseudomonas syringae) und nekrotrophe, die Pflanzenzellen töten, um sich in ihnen zu vermehren (z.B. dem Pilz Botrytis cinerea). $P$. syringae kann durch Wunden oder Stomata in die Blätter eintreten und vermehrt sich in suszeptiblen Pflanzen im Interzellularraum. Die infizierten Blätter zeigen nekrotische Läsionen und Chlorose (Katagiri et al., 2002). In resistenten Pflanzen löst P. syringae die HR (,hypersensitive response“) aus, bei der u.a. reaktive Sauerstoffspezies akkumulieren, und die dazu führt, dass im Zuge der pflanzlichen Abwehrreaktion ein lokaler Zelltod an der Infektionsstelle eintritt (Dangl et al., 1996; Lam et al., 2001).

Bei Kontakt mit einem Pathogen wird die pflanzliche Abwehrreaktion eingeschaltet, um das Wachstum des Mikroorganismus zu begrenzen. Biotrophe Pathogene führen zur Akkumulation des Phytohormons SA (Salizylsäure) und lösen so den SAabhängigen Signalweg aus (Katagiri et al., 2002).

Die Phytohormone JA (Jasmonsäure) und ET (Ethylen) werden bei Befall mit nekrotrophen Pathogenen benötigt. B. cinerea ist der Verursacher von Grauschimmel in vielen Pflanzenspezies. Nach dem Aufbrechen der Pflanzenzellen sterben diese 
durch pilzliche Toxine ab, so dass der Pilz sich ausbreiten kann (Govrin und Levine, 2000; van Kan, 2006). Das eigentliche "Ziel“ eines nekrotrophen Pathogens ist jedoch nicht der Tod der Wirtspflanze per se, sondern die Zersetzung von pflanzlichem Biomaterial und dessen Umwandlung in eigene Biomasse (van Kan, 2006). In Arabidopsis wird nach Befall mit B. cinerea u.a. das Defensin PDF1.2 exprimiert (Thomma et al., 2001). Defensine sind kleine Peptide, die direkte antimikrobielle Eigenschaften besitzen. Sie induzieren in Pilzzellen erhöhten $\mathrm{K}^{+}$Efflux, $\mathrm{Ca}^{2+}$-Aufnahme, Alkalinisierung des Mediums und Veränderungen im Membranpotential und verhindern so die weitere Ausbreitung in der Pflanze (Aerts et al., 2008). Unter anderem gehört auch die Akkumulation von Sekundärmetaboliten, wie das Phytoalexin Camalexin, zur pflanzlichen Abwehr gegen B. cinerea (Kliebenstein et al., 2005).

In einer Arbeit, die am Ende der experimentellen Phase dieser Arbeit veröffentlicht wurde, wird eine weitere Funktion für AKR2A und AKR2B beschrieben (Bae et al., 2008). Es wurde gezeigt, dass $A K R 2 A / B$ an chloroplastidäre Membranproteine (OEP7 und OEP64, „outer envelope protein“) binden und auch selbst an die äußere Chloroplastenmembran binden können. In Anwesenheit von AKR2A kann eine Aggregation der OEPs im Cytosol verhindert werden und sie binden stattdessen an die Chloroplasten. Dies konnte sowohl in GFP-Studien als auch biochemisch gezeigt werden. Aus diesen Ergebnissen wurde ein Modell entwickelt, in dem AKR2A das Transporterprotein ist, das an ein neu synthetisiertes OEP im Cytoplasma bindet und es zur äußeren Chloroplastenmembran transportiert (Abb. 6; Bae et al., 2008; Bedard und Jarvis, 2008). An der Membran bindet AKR2A an einen unbekannten Rezeptor, so dass das OEP in die Membran inseriert werden kann. Für diese Insertion wird das Kanalprotein Toc75 (,translocon of the outer chloroplast membrane") benötigt. Toc75 ist der Haupt-Membrankanal der äußeren Chloroplastenmembran, der in Assoziation mit Toc34 und Toc159 Stromaproteine ins Chloroplasteninnere transportiert. Dazu erkennt Toc159, an GTP gebunden, das Signalpeptid des Stromaproteins. GTP-Hydrolyse von Toc34 kann diese Signalerkennung und/oder den Transport von Signalpeptiden in Toc75 modulieren ( $\mathrm{Li}$ und Chiu, 2010). Es wurde gezeigt, dass einige Membranproteine auch ohne Toc34 und Toc159, nur durch Toc75 in die äußere Chloroplastenmembran inseriert werden können (Li und Chiu, 2010). So wird es für den AKR2A-vermittelten Import in Abb. 6 vorgeschlagen. 
Aus dem Modell geht hervor, dass AKR2A essentiell für eine intakte äußere Chloroplastenmembran ist. Diese These konnte durch Untersuchung von transgenen Pflanzen gestützt werden: Dexamethason induzierbare AKR2-RNAi Pflanzen im akr2b-Hintergrund zeigen bei Wachstum auf Dexamethason einen ausgeprägten Phänotyp: sie haben gelbe oder weiße Blätter und stark reduziertes Wachstum. Elektronenmikroskopische Bilder zeigen, dass die Chloroplasten-Biogenese stark beeinträchtigt ist: in den Chloroplasten befinden sich keine Thylakoidmembranen, stattdessen enthalten sie mehrere runde Vesikel-ähnliche Strukturen verschiedener Größe (Bae et al., 2008). Es wird nicht beschrieben, ob diese von einer Membran umgeben sind.

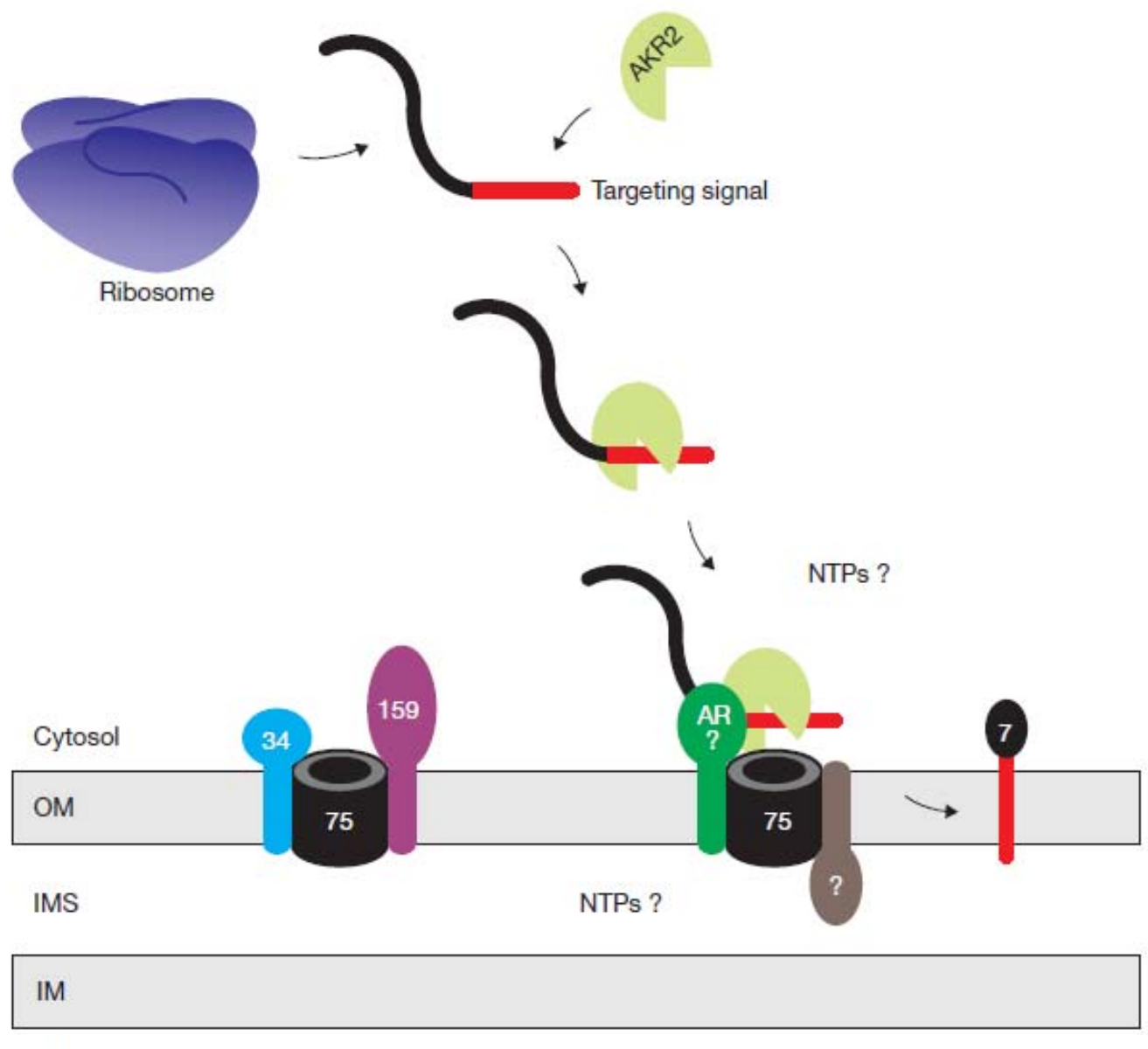

Stroma

Abbildung 6: Der Transport von AtOEP7 zur äußeren Chloroplastenmembran mithilfe von AKR2. AKR2 bindet an das Sortierungssignal (rot) eines neu translatierten AtOEP7-Proteins im Cytosol und transportiert es zur Oberfläche des Chloroplasten. An der äußeren Chloroplastenmembran bindet AKR2 an einen unbekannten AKR2-Rezeptor (AR?) oder direkt an Toc75 (schwarz) und erleichtert die Insertion von AtOEP7 in die Membran (Bae et al., 2008). Die Insertion von chloroplastidären Membranproteinen wird von dem Proteinimportkanal, Toc75, vermittelt, der in diesem Fall ohne die TOC-Rezeptoren Toc34 und Toc159 zu fungieren scheint (Tu et al., 2004; Hofmann et al., 2005). Energie in Form von Nukleotiden (NTPs) wird für eine effiziente Insertion benötigt, wann und wo sie umgesetzt wird, ist allerdings unklar (Hofmann et al., 2005). OM: äußere Chloroplastenmembran, IMS: Intermembranraum, IM: innere Chloroplastenmembran (Bedard und Jarvis, 2008). 


\subsection{Zielsetzung der Arbeit}

In dieser Arbeit sollen die Ankyrin-repeat Proteine AKR2A und AKR2B aus Arabidopsis funktionell charakterisiert werden. Vorarbeiten hierzu wurden an dem homologen Protein NtANK1 aus Tabak durchgeführt, weshalb zuerst eine Interaktion mit einem bZIP-Transkriptionsfaktor überprüft werden soll, wie sie in Tabak gefunden wurde. Dazu stehen zwei Two-Hybrid-Systeme zur Verfügung (Hefe und Protoplasten) und eine weitere in planta Methode soll etabliert werden (BiFC). Die zelluläre Lokalisation von AKR2A und AKR2B soll untersucht werden und ob sich diese, wie bei NtANK1 in Tabak, durch Verhinderung des Kernexports verändern lässt. Zur funktionellen Analyse sollen transgene Pflanzen hergestellt werden, sowohl mit einem erhöhten Gehalt an AKR2A und AKR2B, als auch mit reduziertem Gehalt der beiden Proteine. Dafür können T-DNA-Insertionsmutanten verwendet werden, und Pflanzen, die aufgrund von RNA-Interferenz (RNAi) einen reduzierten Proteingehalt haben. Neben der phänotypischen Analyse sollen die Pflanzen für ein Microarray-Experiment eingesetzt werden, bei dem das Transkriptom analysiert wird, was wiederum Hinweise auf eine Funktion von AKR2A und AKR2B geben kann. Da es in der Literatur Hinweise auf eine Rolle in der Pathogenabwehr gibt (Peck et al., 2001; Yan et al., 2002), sollen die transgenen Pflanzen verschiedenen Stressbedingungen unterzogen werden, um festzustellen, ob AKR2A und AKR2B eine Rolle bei der Reaktion auf diese Stressbedingungen spielen. 


\section{Material}

Für alle Untersuchungen wurden sterilisierte Pipettenspitzen und Reaktionsgefäße verwendet. Alle Lösungen wurden mit dd $\mathrm{H}_{2} \mathrm{O}$ angesetzt und, wenn nicht anders beschrieben, entweder autoklaviert oder sterilfiltriert.

\subsection{Pflanzen}

Es wurden Arabidopsis thaliana L. Pflanzen (Ackerschmalwand) vom Ökotyp Columbia-O verwendet, der Wildtyp und verschiedene transgene Linien:

Tabelle 1: A. thaliana transgene Pflanzen, die in dieser Arbeit analysiert wurden

\begin{tabular}{|c|c|c|}
\hline Transgene Pflanze & Eigenschaften & Referenz \\
\hline SALK_039330 & $a k r 2 b$ knock out & Alonso et al., 2003 \\
\hline AKR2-RNAi & AKR2A u. AKR2B runterreguliert & diese Arbeit \\
\hline Prom $_{35 s}: A K R 2 A$ & AKR2A Überexpression mit HA-tag & diese Arbeit \\
\hline Prom $_{35 s}: A K R 2 B$ & AKR2B Überexpression mit HA-tag & diese Arbeit \\
\hline Prom $_{35 s}:$ bZIP10 & bZIP10 Überexpression mit HA-tag & diese Arbeit \\
\hline
\end{tabular}

Für Agrobakterien-Infiltration wurden Nicotiana benthamiana L. Pflanzen verwendet.

\subsection{Hefestämme (Saccharomyces cerevisiae)}

Tabelle 2: Verwendeter Hefestamm

\begin{tabular}{|c|c|c|c|}
\hline Stamm & Genotyp & Referenz & Verwendung \\
\hline MaV203 & 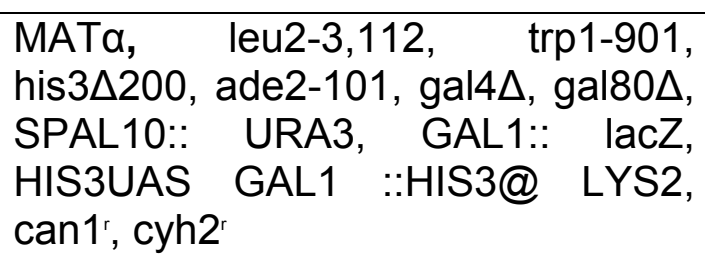 & Vidal, 1997 & $\begin{array}{l}\text { Yeast-two- } \\
\text { hybrid }\end{array}$ \\
\hline
\end{tabular}

\subsection{Bakterien}

Tabelle 3: Verwendete Bakterien-Stämme

\begin{tabular}{|c|c|c|c|}
\hline Stamm & Genotyp & Referenz & Verwendung \\
\hline $\begin{array}{l}\text { Escherichia } \\
\text { coli } \\
\text { DH5a }\end{array}$ & $\begin{array}{l}\mathrm{F}^{-}(\Phi 80 \mathrm{~d} / a c Z \Delta \mathrm{M} 15) \text { recA1 end } A 1 \\
\text { gyrA96 thi-1 hsdR17(}\left(\mathrm{r}_{\mathrm{k}}^{-} \mathrm{m}_{\mathrm{k}}{ }^{+}\right) \text {supE44 } \\
\text { rel } A 1 \text { deoR } \Delta(\text { lacZYA-argF } \mathrm{U} 169\end{array}$ & $\begin{array}{l}\text { Woodcock } \\
\text { et al., } 1989\end{array}$ & $\begin{array}{l}\text { Klonierung von } \\
\text { PCR-Produkten }\end{array}$ \\
\hline $\begin{array}{l}\text { Agrobacterium } \\
\text { tumefaciens } \\
\text { LBA } 4404\end{array}$ & $\mathrm{pAL} 4404, \mathrm{SmR}$ & $\begin{array}{l}\text { Hokema et } \\
\text { al., } 1983\end{array}$ & $\begin{array}{l}\text { Pflanzen- } \\
\text { transformation }\end{array}$ \\
\hline $\begin{array}{l}\text { Agrobacterium } \\
\text { tumefaciens } \\
\text { GV3101 }\end{array}$ & pMP90RK Rif', Gm ${ }^{r}$ & $\begin{array}{l}\text { Koncz und } \\
\text { Schell, } \\
1986\end{array}$ & $\begin{array}{l}\text { Pflanzen- } \\
\text { transformation }\end{array}$ \\
\hline
\end{tabular}




\begin{tabular}{|c|c|c|c|}
\hline $\begin{array}{l}\text { Escherichia } \\
\text { coli } \\
\text { DB3.1 }\end{array}$ & $\begin{array}{l}\text { F- gyrA462 endA1 D( sr1- recA) } \\
\text { mcrB mrr hsdS20(rB-, mB-) } \\
\text { ara-14 gupE44 } \\
\text { rpsL20(Smr) xyl-5 } \lambda \text {-leu mtl-1. }\end{array}$ & $\begin{array}{l}\text { Bernard et } \\
\text { al., } 1993\end{array}$ & $\begin{array}{l}\text { Vermehrung } \\
\text { von Gateway }{ }^{\circledR} \\
\text { Vektoren }\end{array}$ \\
\hline $\begin{array}{l}\text { Pseudomonas } \\
\text { syringae pv. } \\
\text { tomato }\end{array}$ & Pst DC3000 pLAFR3, Rif $^{r}$, Tet $^{r}$ & & $\begin{array}{l}\text { Pflanzen- } \\
\text { Infektion }\end{array}$ \\
\hline $\begin{array}{l}\text { Pseudomonas } \\
\text { syringae pv. } \\
\text { tomato }\end{array}$ & $\begin{array}{l}\text { Pst DC3000 avr Rpt2 pABL18, Rifr } \\
\text { Tet }^{r}\end{array}$ & & $\begin{array}{l}\text { Pflanzen- } \\
\text { Infektion }\end{array}$ \\
\hline $\begin{array}{l}\text { Pseudomonas } \\
\text { syringae pv. } \\
\text { tomato }\end{array}$ & $\begin{array}{l}\text { Pst DC } 3000 \text { Jl-Lux pJFLux1, Rifr', } \\
\text { Kan }^{r}\end{array}$ & $\begin{array}{l}\text { Fan et al., } \\
2008\end{array}$ & $\begin{array}{l}\text { Pflanzen- } \\
\text { Infektion }\end{array}$ \\
\hline
\end{tabular}

\subsection{Botrytis cinerea}

Tabelle 4: Verwendete $B$. cinerea Stämme

\begin{tabular}{|l|l|l|}
\hline Stamm & Eigenschaften & Referenz \\
\hline $\begin{array}{l}\text { B. cinerea } \\
\text { BH/1 }\end{array}$ & Infiziert A. thaliana Col-0 & $\begin{array}{l}\text { Bereitgestellt von Brigitte } \\
\text { Mauch-Mani, Universität } \\
\text { Neuchatel }\end{array}$ \\
\hline $\begin{array}{l}\text { B. cinerea } \\
\text { B1.26 }\end{array}$ & Infiziert A. thaliana Col-0 & $\begin{array}{l}\text { Bereitgestellt von Andreas } \\
\text { von Tiedemann, Universität } \\
\text { Göttingen }\end{array}$ \\
\hline
\end{tabular}

\subsection{Nukleinsäuren}

\subsubsection{Plasmide}

Tabelle 5: Verwendete Plasmide

\begin{tabular}{|c|c|c|}
\hline Plasmid & Eigenschaften & Referenz \\
\hline pDON223 & $\mathrm{pUC}$ ori; $\mathrm{Sm}^{R}$; attL1, CmR, ccdB, attL2 & Invitrogen, 2001 \\
\hline pDON223-AKR2A & pUC ori, Sm ${ }^{r}$, attL1, AKR2A, attL2 & diese Arbeit \\
\hline pDON223-AKR2B & pUC ori, Sm ${ }^{r}$, attL1, AKR2B, attL2 & diese Arbeit \\
\hline $\begin{array}{l}\text { pDON207- } \\
\text { AtbZIP9 }\end{array}$ & pUC ori, Kanr, attL1, AtbZIP9, attL2 & Weltmeier, 2005 \\
\hline $\begin{array}{l}\text { pDON207- } \\
\text { AtbZIP9 } \Delta N\end{array}$ & pUC ori, $\mathrm{Kan}^{\mathrm{r}}$, attL1, AtbZIP9 $\Delta \mathrm{N}$, attL2 & Weltmeier, 2005 \\
\hline $\begin{array}{l}\text { pDON201- } \\
\text { AtbZIP10 }\end{array}$ & pUC ori, Kan' ${ }^{r}$ attL1, AtbZIP10, attL2 & Weltmeier, 2005 \\
\hline $\begin{array}{l}\text { pDON201- } \\
\text { AtbZIP10 } \Delta N\end{array}$ & $\begin{array}{l}\text { pUC ori, } \mathrm{Kan}^{\mathrm{r}} \text {, attL1, AtbZIP10 } \Delta \mathrm{N} \text {, attL2; } 80 \\
\text { AS am N-Terminus deletiert }\end{array}$ & diese Arbeit \\
\hline $\begin{array}{l}\text { pDON201- } \\
\text { AtbZIP25 }\end{array}$ & pUC ori, Kanr, attL1, AtbZIP25, attL2 & Weltmeier, 2005 \\
\hline pDON201- & pUC ori, Kan', attL1, AtbZIP63, attL2 & Weltmeier, 2005 \\
\hline
\end{tabular}




\begin{tabular}{|c|c|c|}
\hline AtbZIP63 & & \\
\hline pDEST22 & $\begin{array}{l}\text { GAL4(768-881)AD, TRP1, ARS4/CEN6, } \\
\text { pUC ori, Ampr }{ }^{r} \text { attR1, Cmr, ccdB, attR2 }\end{array}$ & Invitrogen, 2001 \\
\hline pDEST32 & $\begin{array}{l}\text { GAL4(1-147)DB, LEU1, ARS4/CEN6, pUC } \\
\text { ori, CYH2S, Gmr, attR1, Cmr, ccdB, attR2 }\end{array}$ & Invitrogen, 2001 \\
\hline pDEST22-AKR2A & $\begin{array}{l}\text { GAL4(768-881)AD, TRP1, ARS4/CEN6, } \\
\text { pUC ori, Ampr }{ }^{r} \text {, attR1, AKR2A, attR2 }\end{array}$ & diese Arbeit \\
\hline pDEST22-AKR2B & $\begin{array}{l}\text { GAL4(768-881)AD, TRP1, ARS4/CEN6, } \\
\text { pUC ori, Amp }{ }^{r} \text {, attR1, AKR2B, attR2 }\end{array}$ & diese Arbeit \\
\hline pDEST32-AKR2A & $\begin{array}{l}\text { GAL4(1-147)DB, LEU1, ARS4/CEN6, pUC } \\
\text { ori, CYH2S, Gmr, attR1, AKR2A, attR2 }\end{array}$ & Invitrogen, 2001 \\
\hline pDEST32-AKR2B & $\begin{array}{l}\text { GAL4(1-147)DB, LEU1, ARS4/CEN6, pUC } \\
\text { ori, CYH2S, Gmr, attR1, AKR2B, attR2 }\end{array}$ & Invitrogen, 2001 \\
\hline pDEST22-bZIP9 & $\begin{array}{l}\text { GAL4(768-881)AD, TRP1, ARS4/CEN6, } \\
\text { pUC ori, Amp }{ }^{r}, \text { attR1, bZIP9, attR2 }\end{array}$ & \\
\hline pDEST22-bZIP10 & $\begin{array}{l}\text { GAL4(768-881)AD, TRP1, ARS4/CEN6, } \\
\text { pUC ori, Amp }{ }^{r} \text {, attR1, bZIP10, attR2 }\end{array}$ & \\
\hline pDEST22-bZIP25 & $\begin{array}{l}\text { GAL4(768-881)AD, TRP1, ARS4/CEN6, } \\
\text { pUC ori, Amp }{ }^{r} \text {, attR1, bZIP25, attR2 }\end{array}$ & \\
\hline pDEST22-bZIP63 & $\begin{array}{l}\text { GAL4(768-881)AD, TRP1, ARS4/CEN6, } \\
\text { pUC ori, Amp }{ }^{r}, \text { attR1, bZIP63, attR2 }\end{array}$ & \\
\hline $\begin{array}{l}\text { pDEST32- } \\
\text { bZIP9 } \Delta N\end{array}$ & $\begin{array}{l}\text { GAL4(1-147)DB, LEU1, ARS4/CEN6, pUC } \\
\text { ori, CYH2S, Gm², attR1, bZIP9, attR2 }\end{array}$ & $\begin{array}{l}\text { Weltmeier, } \\
\text { unveröffentlicht }\end{array}$ \\
\hline $\begin{array}{l}\text { pDEST32- } \\
\text { bZIP10 } 10 N\end{array}$ & $\begin{array}{l}\text { GAL4(1-147)DB, LEU1, ARS4/CEN6, pUC } \\
\text { ori, CYH2S, Gmr, attR1, bZIP9, attR2 }\end{array}$ & diese Arbeit \\
\hline pDEST32-bZIP25 & $\begin{array}{l}\text { GAL4(1-147)DB, LEU1, ARS4/CEN6, pUC } \\
\text { ori, CYH2S, Gm², attR1, bZIP9, attR2 }\end{array}$ & $\begin{array}{l}\text { Vicente- } \\
\text { Carbajosa, } 2002\end{array}$ \\
\hline pDEST32-bZIP63 & $\begin{array}{l}\text { GAL4(1-147)DB, LEU1, ARS4/CEN6, pUC } \\
\text { ori, CYH2S, Gmr, attR1, bZIP9, attR2 }\end{array}$ & $\begin{array}{l}\text { Vicente- } \\
\text { Carbajosa, } \\
\text { unveröffentlicht }\end{array}$ \\
\hline pDEST-GAD & $\begin{array}{l}\text { GAL4(768-881)AD, LEU2, } 2 \mu \text { ori, } \\
\text { pUC ori, Amp }{ }^{r} \text {, attR1, Cmr, ccdB, attR2 }\end{array}$ & $\begin{array}{l}\text { Barry Causier, } \\
\text { Leeds }\end{array}$ \\
\hline pDEST-GBK-T7 & $\begin{array}{l}\text { GAL4(1-147)DB, TRP1, } 2 \mu \text { ori, pUC } \\
\text { ori, CYH2S, Kan', attR1, Cmr, ccdB, attR2 }\end{array}$ & $\begin{array}{l}\text { Barry Causier, } \\
\text { Leeds }\end{array}$ \\
\hline $\begin{array}{l}\text { pDEST-GAD- } \\
\text { AKR2A }\end{array}$ & $\begin{array}{l}\text { GAL4(768-881)AD, LEU2, } 2 \mu \text { ori, } \\
\text { pUC ori, Amp }{ }^{r} \text {, attR1, AKR2A, attR2 }\end{array}$ & diese Arbeit \\
\hline $\begin{array}{l}\text { pDEST-GBK- } \\
\text { AKR2A }\end{array}$ & $\begin{array}{l}\text { GAL4(1-147)DB, TRP1, } 2 \mu \text { ori, pUC } \\
\text { ori, CYH2S, Kan'r, attR1, AKR2A, attR2 }\end{array}$ & diese Arbeit \\
\hline $\begin{array}{l}\text { pDEST-GAD- } \\
\text { AKR2B }\end{array}$ & $\begin{array}{l}\text { GAL4(768-881)AD, LEU2, } 2 \mu \text { ori, } \\
\text { pUC ori, Ampr }{ }^{r} \text { attR1, AKR2B, attR2 }\end{array}$ & diese Arbeit \\
\hline $\begin{array}{l}\text { pDEST-GBK- } \\
\text { AKR2B }\end{array}$ & $\begin{array}{l}\text { GAL4(1-147)DB, TRP1, } 2 \mu \text { ori, pUC } \\
\text { ori, CYH2S, Kan', attR1, AKR2B, attR2 }\end{array}$ & diese Arbeit \\
\hline $\begin{array}{l}\text { pDEST-GAD- } \\
\text { bZIP9 }\end{array}$ & $\begin{array}{l}\text { GAL4(768-881)AD, LEU2, } 2 \mu \text { ori, } \\
\text { pUC ori, Ampr }{ }^{r} \text { attR1, bZIP9, attR2 }\end{array}$ & diese Arbeit \\
\hline $\begin{array}{l}\text { pDEST-GBK- } \\
\text { bZIP9 }\end{array}$ & $\begin{array}{l}\text { GAL4(1-147)DB, TRP1, } 2 \mu \text { ori, pUC } \\
\text { ori, CYH2S, Kanr , attR1, bZIP9, attR2 }\end{array}$ & diese Arbeit \\
\hline $\begin{array}{l}\text { pDEST-GAD- } \\
\text { bZIP10 }\end{array}$ & $\begin{array}{l}\text { GAL4(768-881)AD, LEU2, } 2 \mu \text { ori, } \\
\text { pUC ori, Ampr }{ }^{r} \text { attR1, bZIP10, attR2 }\end{array}$ & diese Arbeit \\
\hline $\begin{array}{l}\text { pDEST-GBK- } \\
\text { bZIP10 }\end{array}$ & $\begin{array}{l}\text { GAL4(1-147)DB, TRP1, } 2 \mu \text { ori, pUC } \\
\text { ori, CYH2S, Kan'r, attR1, bZIP10, attR2 }\end{array}$ & diese Arbeit \\
\hline
\end{tabular}




\begin{tabular}{|c|c|c|}
\hline $\begin{array}{l}\text { pDEST-GAD- } \\
\text { bZIP25 }\end{array}$ & $\begin{array}{l}\text { GAL4(768-881)AD, LEU2, } 2 \mu \text { ori, } \\
\text { pUC ori, Amp }{ }^{r}, \text { attR1, bZIP25, attR2 }\end{array}$ & diese Arbeit \\
\hline $\begin{array}{l}\text { pDEST-GBK- } \\
\text { bZIP25 }\end{array}$ & $\begin{array}{l}\text { GAL4(1-147)DB, TRP1, } 2 \mu \text { ori, pUC } \\
\text { ori, CYH2S, Kan'r, attR1, bZIP25, attR2 }\end{array}$ & diese Arbeit \\
\hline $\begin{array}{l}\text { pDEST-GAD- } \\
\text { bZIP63 }\end{array}$ & $\begin{array}{l}\text { GAL4(768-881)AD, LEU2, } 2 \mu \text { ori, } \\
\text { pUC ori, Ampr } \text {, attR1, bZIP63, attR2 }\end{array}$ & diese Arbeit \\
\hline $\begin{array}{l}\text { pDEST-GBK- } \\
\text { bZIP63 }\end{array}$ & $\begin{array}{l}\text { GAL4(1-147)DB, TRP1, } 2 \mu \text { ori, pUC } \\
\text { ori, CYH2S, Kan', attR1, bZIP63, attR2 }\end{array}$ & diese Arbeit \\
\hline pAlligator2 & $\begin{array}{l}\text { 2S1:GFP, T-DNA Border Sequenzen, } \\
\text { 2x35S-Promotor, 3x HA-tag (N-terminal), } \\
\text { attR1, } \mathrm{Cm}^{r}, c c d B, \text { attR2 }\end{array}$ & $\begin{array}{l}\text { Bensmihen et al., } \\
2004\end{array}$ \\
\hline $\begin{array}{l}\text { pAlligator2- } \\
\text { AKR2A }\end{array}$ & $\begin{array}{l}\text { 2S1:GFP, T-DNA Border Sequenzen, } \\
\text { 2x35S-Promotor, 3x HA-tag (N-terminal), } \\
\text { attR1, AKR2A, attR2 }\end{array}$ & diese Arbeit \\
\hline $\begin{array}{l}\text { pAlligator2- } \\
\text { AKR2B }\end{array}$ & $\begin{array}{l}\text { 2S1:GFP, T-DNA Border Sequenzen, } \\
\text { 2x35S-Promotor, 3x HA-tag (N-terminal), } \\
\text { attR1, AKR2B, attR2 }\end{array}$ & diese Arbeit \\
\hline $\begin{array}{l}\text { pAlligator2- } \\
\text { bZIP10 }\end{array}$ & $\begin{array}{l}\text { 2S1:GFP, T-DNA Border Sequenzen, } \\
\text { 2x35S-Promotor, 3x HA-tag (N-terminal), } \\
\text { attR1, bZIP10, attR2 }\end{array}$ & diese Arbeit \\
\hline pSK-T & Klonier- und Sequenziervektor, lacZ, amp ${ }^{R}$ & $\begin{array}{l}\text { Kriete, } \\
\text { unveröffentlicht }\end{array}$ \\
\hline pFGC5941 & 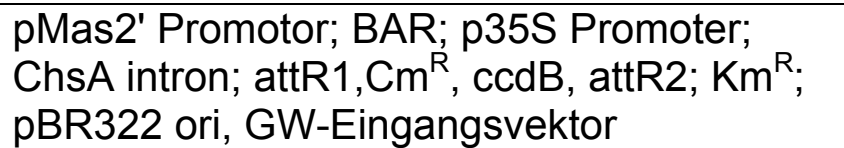 & $\begin{array}{l}\text { http://ag.arizona. } \\
\text { edu/chromatin/fg } \\
\text { c5941.html }\end{array}$ \\
\hline $\begin{array}{l}\text { pFGC5941- } \\
\text { AKR2A }\end{array}$ & $\begin{array}{l}\text { pMas2' Promotor; BAR; p35S Promoter; } \\
\text { ChsA intron; attR1, AKR2A, attR2; Km; } \\
\text { pBR322 ori }\end{array}$ & diese Arbeit \\
\hline pE-SPYCE & $\begin{array}{l}\text { pE-Vektor mit GW-Kassette des pSPYCE- } \\
\text { 35S; 35S Promotor, HA-tag, CE-tag, attR1, } \\
\mathrm{Cm}^{\mathrm{R}} \text {, ccdB, attR2, RK2 ori, Amp }{ }^{\mathrm{R}}, \mathrm{GW}- \\
\text { Expressionsvektor }\end{array}$ & $\begin{array}{l}\text { Weltmeier et al., } \\
2006\end{array}$ \\
\hline pE-SPYCE(-) & $\begin{array}{l}\text { pE-SPYCE mit deletierter GW-Kassette, 35S } \\
\text { Promotor, HAtag, CE-tag, RK2 ori, Amp }\end{array}$ & $\begin{array}{l}\text { Böttner et al., } \\
2009\end{array}$ \\
\hline pE-SPYNE & $\begin{array}{l}\text { pE-Vektor mit GW-Kassette des pSPYNE- } \\
\text { 35S; 35S Promotor, HA-tag, NE-tag, attR1, } \\
\text { Cm }^{R} \text {, ccdB, attR2, RK2 ori, Amp }{ }^{R}, G W- \\
\text { Expressionsvektor }\end{array}$ & $\begin{array}{l}\text { Weltmeier et al., } \\
2006\end{array}$ \\
\hline pE-SPYNE(-) & $\begin{array}{l}\text { pE-SPYNE mit deletierter GW-Kassette, 35S } \\
\text { Promotor, HAtag, NE-tag, RK2 ori, Amp }\end{array}$ & $\begin{array}{l}\text { Böttner et al., } \\
2009\end{array}$ \\
\hline $\begin{array}{l}\text { pE-SPYCE- } \\
\text { AKR2A }\end{array}$ & $\begin{array}{l}\text { 35S Promotor, HA-tag, CE-tag, attR1, } \\
\text { AKR2A, attR2, RK2 ori, Amp }{ }^{R}\end{array}$ & diese Arbeit \\
\hline $\begin{array}{l}\text { pE-SPYNE- } \\
\text { AKR2A }\end{array}$ & $\begin{array}{l}\text { 35S Promotor, HA-tag, NE-tag, attR1, } \\
\text { AKR2A, attR2, RK2 ori, Amp }{ }^{\mathrm{R}}\end{array}$ & diese Arbeit \\
\hline $\begin{array}{l}\text { pE-SPYCE- } \\
\text { AKR2B }\end{array}$ & $\begin{array}{l}\text { 35S Promotor, HA-tag, CE-tag, attR1, } \\
\text { AKR2B, attR2, RK2 ori, Amp }\end{array}$ & diese Arbeit \\
\hline $\begin{array}{l}\text { pE-SPYNE- } \\
\text { AKR2B }\end{array}$ & $\begin{array}{l}\text { 35S Promotor, HA-tag, NE-tag, attR1, } \\
\text { AKR2B, attR2, RK2 ori, Amp }\end{array}$ & diese Arbeit \\
\hline pE-SPYCE- & 35S Promotor, HA-tag, CE-tag, attR1, & Weltmeier et al., \\
\hline
\end{tabular}




\begin{tabular}{|c|c|c|}
\hline bZIP10 & bZIP10, attR2, RK2 ori, Amp ${ }^{R}$ & 2006 \\
\hline $\begin{array}{l}\text { pE-SPYNE- } \\
\text { bZIP10 }\end{array}$ & $\begin{array}{l}\text { 35S Promotor, HA-tag, NE-tag, attR1, } \\
\text { bZIP10, attR2, RK2 ori, Amp }\end{array}$ & $\begin{array}{l}\text { Weltmeier et al., } \\
2006\end{array}$ \\
\hline $\begin{array}{l}\text { pE-SPYCE- } \\
\text { bZIP53 }\end{array}$ & $\begin{array}{l}\text { 35S Promotor, HA-tag, CE-tag, attR1, } \\
\text { bZIP53, attR2, RK2 ori, Amp }{ }^{R}\end{array}$ & $\begin{array}{l}\text { Weltmeier et al., } \\
2006\end{array}$ \\
\hline $\begin{array}{l}\text { pE-SPYNE- } \\
\text { bZIP53 }\end{array}$ & $\begin{array}{l}\text { 35S Promotor, HA-tag, NE-tag, attR1, } \\
\text { bZIP53, attR2, RK2 ori, Amp }\end{array}$ & $\begin{array}{l}\text { Weltmeier et al., } \\
2006\end{array}$ \\
\hline pENSG-YFP & $\begin{array}{l}\text { p35SS Promotor, attR1, } \mathrm{Cm}^{\mathrm{R}} \text {, ccdB, attR2, } \\
\text { RK2 ori, Amp }{ }^{\mathrm{R}}, \mathrm{GW} \text {-Expressionsvektor }\end{array}$ & $\begin{array}{l}\text { Consonni, C } \\
2001\end{array}$ \\
\hline $\begin{array}{l}\text { pENSG-YFP- } \\
\text { AKR2A }\end{array}$ & $\begin{array}{l}\text { p35SS Promotor, attR1, AKR2A, attR2, RK2 } \\
\text { ori, Amp }\end{array}$ & diese Arbeit \\
\hline $\begin{array}{l}\text { pENSG-YFP- } \\
\text { AKR2B }\end{array}$ & $\begin{array}{l}\text { p35SS Promotor, attR1, AKR2B, attR2, RK2 } \\
\text { ori, Amp }{ }^{R}\end{array}$ & diese Arbeit \\
\hline $\begin{array}{l}\text { pENSG-YFP- } \\
\text { bZIP10 }\end{array}$ & $\begin{array}{l}\text { p35SS Promotor, attR1, bZIP10, attR2, RK2 } \\
\text { ori, Amp }\end{array}$ & diese Arbeit \\
\hline Gal4-UAS-GUS & $\begin{array}{l}\text { alter Name: pBT10-GAL4; 4x GAL4-DNA- } \\
\text { Bindestelle, pUC ori, 35S-Minimalpromotor, } \\
\text { GUS-Reportergen, Amp }\end{array}$ & $\begin{array}{l}\text { Weisshaar B, } \\
1999\end{array}$ \\
\hline pROK219-NAN & CaMV 35S-Promotor, pUC19-Derivat, Amp ${ }^{R}$ & $\begin{array}{l}\text { Kirby und } \\
\text { Kavanagh, } 2002\end{array}$ \\
\hline pHBT- $\triangle \mathrm{GFP}$ & $\begin{array}{l}\text { pHBTL-sGFP Derivat (Sheen, } \\
\text { unveröffentlicht), Entfernung des sGFP } \\
\text { Gens durch Ncol/Notl-Verdau, Klenow-'fill-in' } \\
\text { und Religation, pUC ori, Amp }{ }^{\text {R }}\end{array}$ & $\begin{array}{l}\text { Heinekamp, } \\
2002\end{array}$ \\
\hline HBT-GUS-NCO & $\begin{array}{l}\text { pUC18 Derivat, -389 bis -46 Region des } \\
\text { CaMV 35S Promotors, -188bp aus dem 5'- } \\
\text { Bereich des C4ppdkZn1-Gens (Zea mays) } \\
\text { mit der TATA-Box und Teilen des 5'-UTRs, } \\
\text { sGFP-s65T, Amp }^{R}\end{array}$ & $\begin{array}{l}\text { Thurow } \mathrm{C} \text {, } \\
\text { unveröffentlicht }\end{array}$ \\
\hline pHBTL-BDGW & $\begin{array}{l}\text { p35S-Promotor, GAL4(1-147)BD, attR1, } \\
\mathrm{Cm}^{\mathrm{R}} \text {, ccdB, attR2, pUC ori, Amp }{ }^{\mathrm{R}}, \mathrm{GW}- \\
\text { Expressionsvektor }\end{array}$ & $\begin{array}{l}\text { Ehlert et al., } \\
2006\end{array}$ \\
\hline pHBTL-ADGW & $\begin{array}{l}\text { p35S-Promotor, GAL4(768-881)AD, attR1, } \\
\text { Cm }^{\mathrm{R}} \text {, ccdB, attR2, pUC ori, Amp }{ }^{\mathrm{R}}, \mathrm{GW} \text { - } \\
\text { Expressionsvektor }\end{array}$ & $\begin{array}{l}\text { Ehlert et al., } \\
2006\end{array}$ \\
\hline pHBTL-HAGW & $\begin{array}{l}\text { p35S-Promotor, 3xHA-tag, attR1, } \mathrm{Cm}^{\mathrm{R}} \text {, } \\
\text { ccdB, attR2, pUC ori; Amp }{ }^{\mathrm{R}}, \mathrm{GW}- \\
\text { Expressionsvektor }\end{array}$ & $\begin{array}{l}\text { Ehlert et al., } \\
2006\end{array}$ \\
\hline $\begin{array}{l}\text { pHBTL-BD- } \\
\text { AKR2A }\end{array}$ & $\begin{array}{l}\text { p35S-Promotor, GAL4(1-147)BD, attR1, } \\
\text { AKR2A, attR2, pUC ori, Amp }\end{array}$ & diese Arbeit \\
\hline $\begin{array}{l}\text { pHBTL-AD- } \\
\text { AKR2A }\end{array}$ & $\begin{array}{l}\text { p35S-Promotor, GAL4(768-881)AD, attR1, } \\
\text { AKR2A, attR2, pUC ori, Amp }{ }^{R}\end{array}$ & diese Arbeit \\
\hline $\begin{array}{l}\text { pHBTL-HA- } \\
\text { AKR2A }\end{array}$ & $\begin{array}{l}\text { p35S-Promotor, 3xHA-tag, attR1, AKR2A, } \\
\text { attR2, pUC ori; Amp }\end{array}$ & diese Arbeit \\
\hline $\begin{array}{l}\text { pHBTL-BD- } \\
\text { AKR2B }\end{array}$ & $\begin{array}{l}\text { p35S-Promotor, GAL4(1-147)BD, attR1, } \\
\text { AKR2B, attR2, pUC ori, Amp }\end{array}$ & diese Arbeit \\
\hline $\begin{array}{l}\text { pHBTL-AD- } \\
\text { AKR2B }\end{array}$ & $\begin{array}{l}\text { p35S-Promotor, GAL4(768-881)AD, attR1, } \\
\text { AKR2B, attR2, pUC ori, Amp }{ }^{R}\end{array}$ & diese Arbeit \\
\hline
\end{tabular}




\begin{tabular}{|c|c|c|}
\hline $\begin{array}{l}\text { pHBTL-HA- } \\
\text { AKR2B }\end{array}$ & $\begin{array}{l}\text { p35S-Promotor, 3xHA-tag, attR1, AKR2B, } \\
\text { attR2, pUC ori; Amp }\end{array}$ & diese Arbeit \\
\hline pHBTL-BD-bZIP9 & $\begin{array}{l}\text { p35S-Promotor, GAL4(1-147)BD, attR1, } \\
\text { bZIP9, attR2, pUC ori, Amp R }\end{array}$ & $\begin{array}{l}\text { Ehlert et al., } \\
2006\end{array}$ \\
\hline pHBTL-AD- bZIP9 & $\begin{array}{l}\text { p35S-Promotor, GAL4(768-881)AD, attR1, } \\
\text { bZIP9, attR2, pUC ori, Amp }\end{array}$ & $\begin{array}{l}\text { Ehlert et al., } \\
2006\end{array}$ \\
\hline pHBTL-HA- bZIP9 & $\begin{array}{l}\text { p35S-Promotor, 3xHA-tag, attR1, bZIP9, } \\
\text { attR2, pUC ori; Amp }\end{array}$ & $\begin{array}{l}\text { Ehlert et al., } \\
2006\end{array}$ \\
\hline $\begin{array}{l}\text { pHBTL-BD- } \\
\text { bZIP10 }\end{array}$ & $\begin{array}{l}\text { p35S-Promotor, GAL4(1-147)BD, attR1, } \\
\text { bZIP10, attR2, pUC ori, Amp }\end{array}$ & $\begin{array}{l}\text { Ehlert et al., } \\
2006\end{array}$ \\
\hline $\begin{array}{l}\text { pHBTL-AD- } \\
\text { bZIP10 }\end{array}$ & $\begin{array}{l}\text { p35S-Promotor, GAL4(768-881)AD, attR1, } \\
\text { bZIP10, attR2, pUC ori, Amp }{ }^{R}\end{array}$ & $\begin{array}{l}\text { Ehlert et al., } \\
2006\end{array}$ \\
\hline $\begin{array}{l}\text { pHBTL-HA- } \\
\text { bZIP10 }\end{array}$ & $\begin{array}{l}\text { p35S-Promotor, 3xHA-tag, attR1, bZIP10, } \\
\text { attR2, pUC ori; Amp }\end{array}$ & $\begin{array}{l}\text { Ehlert et al., } \\
2006\end{array}$ \\
\hline $\begin{array}{l}\text { pHBTL-BD- } \\
\text { bZIP25 }\end{array}$ & $\begin{array}{l}\text { p35S-Promotor, GAL4(1-147)BD, attR1, } \\
\text { bZIP25, attR2, pUC ori, Amp }\end{array}$ & $\begin{array}{l}\text { Ehlert et al., } \\
2006\end{array}$ \\
\hline $\begin{array}{l}\text { pHBTL-AD- } \\
\text { bZIP25 }\end{array}$ & $\begin{array}{l}\text { p35S-Promotor, GAL4(768-881)AD, attR1, } \\
\text { bZIP25, attR2, pUC ori, Amp }{ }^{R}\end{array}$ & $\begin{array}{l}\text { Ehlert et al., } \\
2006\end{array}$ \\
\hline $\begin{array}{l}\text { pHBTL-HA- } \\
\text { bZIP25 }\end{array}$ & $\begin{array}{l}\text { p35S-Promotor, 3xHA-tag, attR1, bZIP25, } \\
\text { attR2, pUC ori; Amp }\end{array}$ & $\begin{array}{l}\text { Ehlert et al., } \\
2006\end{array}$ \\
\hline $\begin{array}{l}\text { pHBTL-BD- } \\
\text { bZIP63 }\end{array}$ & $\begin{array}{l}\text { p35S-Promotor, GAL4(1-147)BD, attR1, } \\
\text { bZIP63, attR2, pUC ori, Amp }\end{array}$ & $\begin{array}{l}\text { Ehlert et al., } \\
2006\end{array}$ \\
\hline $\begin{array}{l}\text { pHBTL-AD- } \\
\text { bZIP63 }\end{array}$ & $\begin{array}{l}\text { p35S-Promotor, GAL4(768-881)AD, attR1, } \\
\text { bZIP63, attR2, pUC ori, Amp }{ }^{R}\end{array}$ & $\begin{array}{l}\text { Ehlert et al., } \\
2006\end{array}$ \\
\hline $\begin{array}{l}\text { pHBTL-HA- } \\
\text { bZIP63 }\end{array}$ & $\begin{array}{l}\text { p35S-Promotor, 3xHA-tag, attR1, bZIP63, } \\
\text { attR2, pUC ori; Amp }\end{array}$ & $\begin{array}{l}\text { Ehlert et al., } \\
2006\end{array}$ \\
\hline $\begin{array}{l}\text { pHBTL-BD- } \\
\text { NtANK1 }\end{array}$ & $\begin{array}{l}\text { p35S-Promotor, GAL4(1-147)BD, attR1, } \\
\text { bZIP63, attR2, pUC ori, Amp }\end{array}$ & $\begin{array}{l}\text { Böttner et al., } \\
2009\end{array}$ \\
\hline $\begin{array}{l}\text { pHBTL-AD- } \\
\text { NtANK1 }\end{array}$ & $\begin{array}{l}\text { p35S-Promotor, GAL4(768-881)AD, attR1, } \\
\text { bZIP63, attR2, pUC ori, Amp }{ }^{R}\end{array}$ & $\begin{array}{l}\text { Böttner et al., } \\
2009\end{array}$ \\
\hline $\begin{array}{l}\text { pHBTL-BD- } \\
\text { NtBZI-1 }\end{array}$ & $\begin{array}{l}\text { p35S-Promotor, GAL4(1-147)BD, attR1, } \\
\text { bZIP63, attR2, pUC ori, Amp }\end{array}$ & $\begin{array}{l}\text { Böttner et al., } \\
2009\end{array}$ \\
\hline $\begin{array}{l}\text { pHBTL-AD- } \\
\text { NtBZI-1 }\end{array}$ & $\begin{array}{l}\text { p35S-Promotor, GAL4(768-881)AD, attR1, } \\
\text { bZIP63, attR2, pUC ori, Amp }\end{array}$ & $\begin{array}{l}\text { Böttner et al., } \\
2009\end{array}$ \\
\hline pBc-Act3 & $\begin{array}{l}\text { pBluescript mit 1,4 kb-Stück des Bc-Actin3- } \\
\text { Gens; Amp }\end{array}$ & $\begin{array}{l}\text { Benito et al., } \\
1998\end{array}$ \\
\hline pGEM-PDF1.2 & pGEM mit PDF1.2a inseriert; $\mathrm{Amp}^{r}$ & \\
\hline pSK-AtPR1 & pSK mit PR1 inseriert; Amp ${ }^{r}$ & Brenner, 2002 \\
\hline
\end{tabular}

\subsubsection{Primer}

Tabelle 6: Verwendete Primer

\begin{tabular}{|l|l|}
\hline Name & Sequenz $\left(\mathbf{5}^{\prime} \rightarrow \mathbf{3} \mathbf{\prime}^{\mathbf{}}\right)$ \\
\hline AKR2start & ATGGCTTCCAATTCGGAGA \\
\hline AKR_NESmutfor & CCAACAGCCAGGCGGAGGTGGCGAAGGCGCTTGAGAAGG \\
\hline AKR_NESmutrev & CCTTCTCAAGCGCCTTCGCCACCTCCGCCTGGCTGTTGG \\
\hline atphos43 & TGCCTAATTTTGTAATTCGGGC \\
\hline AtPhos43start & ATGGCTTCAAGCTCAGAGA \\
\hline AtP_NESmutfor & GGCAAACAATCAGGCAGATGTGGCGAAAGCACTTGAGAAG \\
\hline
\end{tabular}




\begin{tabular}{|c|c|}
\hline & GACG \\
\hline AtP_NESmutrev & $\begin{array}{l}\text { CGTCCTTCTCAAGTGCTTTCGCCACATCTGCCTGATTGTTT } \\
\text { GCC }\end{array}$ \\
\hline bZIP10checkinsfor & CAACCAGTTCAATCCAGTC \\
\hline bZIP10checkinsrev & GACGATCCACTAGTAACC \\
\hline bZIP10deltaN & AATCCGGACATGAATTCGGTACCGGATCCAG \\
\hline bZIP10iminsert & GGTTCTTTGATGACCCCA \\
\hline bZIP10LP & TTGAGATGAGTTCTGGTGGTTA \\
\hline bZIP10RP & GTCCACTTGATCTTCCGAGAA \\
\hline bZIP10ppsense & $\begin{array}{l}\text { CAGGTTAATGATCCAAAAGGTGAGCATTCATCACCTCTTAAA } \\
\text { CAACTG }\end{array}$ \\
\hline bZIP10ppantisense & $\begin{array}{l}\text { CAGTTGTTTAAGAGGTGATGAATGCTCACCTTTTGGATCATT } \\
\text { AACCTG }\end{array}$ \\
\hline bZIP10Spelfor & $\begin{array}{l}\text { GACTAGTTCTCCAGAAACTCAACTTCAACCAGTTCAATCCAG } \\
\text { TCCTCTTACTCAAGGTTCTTTGATGACCCCAGGAGAACTTG }\end{array}$ \\
\hline bZIP10Spelrev & GACGATCCACTAGTAACCTGCTTCA \\
\hline bZIP63.3rev & GTTTGTTTTTGGCAGGTGAAAATGGCT \\
\hline bZIP63.3revGW & $\begin{array}{l}\text { GGGGACCACTTTGTACAAGAAAGCTGGGTCTCAGCCATTTT } \\
\text { CACCTGCCAAAAACAAACA }\end{array}$ \\
\hline bZIP63forGW & $\begin{array}{l}\text { GGGGACAAGTTTGTACAAAAAAGCAGGCTTCATGGAAAAAG } \\
\text { TTTTCTCCGACGAAGAAATC }\end{array}$ \\
\hline bZIP63revGW & $\begin{array}{l}\text { GGGGACCACTTTGTACAAGAAAGCTGGGTCCTACTGATCCC } \\
\text { CAACGCTTCGAA }\end{array}$ \\
\hline GUS rev & TCGCGATCCAGACTGAATGCCCAC \\
\hline GW_F_AKR2 & $\begin{array}{l}\text { GGGGACAAGTTTGTACAAAAAAGCAGGCTTCATGGCTTCCA } \\
\text { ATTCGGAGAAAAATC }\end{array}$ \\
\hline GW_R_AKR2 & $\begin{array}{l}\text { GGGGACCACTTTGTACAAGAAAGCTGGGTCTCAAAGGAAAG } \\
\text { CATCCTTCTCAAGC }\end{array}$ \\
\hline GW_F_AtPhos43 & $\begin{array}{l}\text { GGGGACAAGTTTGTACAAAAAAGCAGGCTTCATGGCTTCAA } \\
\text { GCTCAGAGAAAACACC }\end{array}$ \\
\hline GW_R_AtPhos43 & $\begin{array}{l}\text { GGGGACCACTTTGTACAAGAAAGCTGGGTCTCAGAGGAAA } \\
\text { GCGTCCTTCTCAAGTAG }\end{array}$ \\
\hline HAtagfor & GCGGCCGCATCTTTTACCCA \\
\hline LBa1 & TGGTTCACGTAGTGGGCCATCG \\
\hline Oligo dT & TTTTTTTTTTTTTTTTTTTT \\
\hline p35S1 & ATTGATGTGATATCTCCACTGAC \\
\hline pAR1 & GAGATCTATTCCTAACGCTGGC \\
\hline pAR2 & AGCTGCCTTGGCATCTGGTGG \\
\hline pAR3 & TGCAATGCTGTCCTTCCTTCAG \\
\hline pAR4 & GGCCATTGTCTTAAACTCAGGG \\
\hline pAR5r & TGGTAAGCCAGCAACAGGCA \\
\hline pBD2 & TCATCGGAAGAGAGTAGTAAC \\
\hline PDF1.2Prom_for_Pstl & GTCTGCAGCTGATCTCTTATAATGTTCGG \\
\hline PDF1.2Prom_rev & GTCCATGGTGAAGAAATAAGCCAAAGATC \\
\hline pGADL1 & CCACTACAATGGATGATGTATA \\
\hline pGADL2 & GTGCACGATGCACAGTTGAAGT \\
\hline $\mathrm{pHOS1}$ & CTCATGAAGGAGGTCTACCTAAC \\
\hline pHOS2 & CACCAGACCGCTAGTCTTGGTG \\
\hline pHOS3 & GCAAAGCAGTCCTTCCTTCAG \\
\hline pHOS4 & AGCGTTACCAAGACGCTCAGCC \\
\hline
\end{tabular}




\begin{tabular}{|l|l|}
\hline pHOS5 & AGCTCCACCTTCACCTTCAC \\
\hline pHOS6r & ATCTAGCTGATTGTTTAGCCTG \\
\hline random nonamer & $\begin{array}{l}\text { Mix aus Oligonukleotiden, aus dem alle möglichen Nonamer- } \\
\text { Kombinationen hervorgehen. }\end{array}$ \\
\hline rev & TTCACACAGGAAACAGCTATGACC \\
\hline SeqL1pDONR & TCGCGTTAACGCTAGCATGGATCTC \\
\hline SeqL2pDONR & GTAACATCAGAGATTTTGAGACAC \\
\hline SPYCE-for & TAGCTCGAGGATGTACCCATACGATGTTCC \\
\hline SPYCE-rev & TAGAAGCTTACCTTGTACAGCTCGTCCATGC \\
\hline SPYNE-for & AGTCTCGAGGATGGAGCAAAAGTTGATTTCTG \\
\hline SPYNE-rev & TAGAAGCTTCCGGCCATGATATAGACGTTGTG \\
\hline uni & ACGACGTTGTAAAACGACGGCCAG \\
\hline
\end{tabular}

Die Schmelztemperatur wird nach Bolton und McCarthy (1962) berechnet:

$\mathrm{T}_{\mathrm{m}}\left[{ }^{\circ} \mathrm{C}\right]=69,3+0,41 \times(\% \mathrm{GC})-650 / \mathrm{n}$

$\mathrm{T}_{\mathrm{m}}=$ Schmelztemperatur, $\mathrm{n}=$ Anzahl der Basen.

\subsubsection{Hybridisierungssonden}

Tabelle 7: Verwendete Hybridisierungssonden

\begin{tabular}{|l|l|l|}
\hline Name & Eigenschaften & Referenz \\
\hline AKR2A & $\begin{array}{l}\text { PCR-Produkt mit den Primern AKR2start } \\
\text { und pAR4 auf pDONR223-AKR2 }\end{array}$ & diese Arbeit \\
\hline AKR2B & $\begin{array}{l}\text { PCR-Produkt mi den Primern } \\
\text { AtPhos43start und pHOS4 auf } \\
\text { pDONR223-AKR2B } \\
\text { B15 bp EcoRI+HindIII-Fragment aus pBc- } \\
\text { Act3 }\end{array}$ & Benito et al., 1998 \\
\hline Potrytis Actin3 & $\begin{array}{l}\text { PCR-Produkt mit den Primern uni und rev } \\
\text { auf pGEM-PDF1.2 }\end{array}$ & \\
\hline PR-1 & $\sim 500$ bp EcoRI-Fragment aus pSK-AtPR1 & Brenner, 2002 \\
\hline
\end{tabular}

\subsection{Antikörper}

Tabelle 8: Verwendete Antikörper

\begin{tabular}{|l|l|l|l|l|}
\hline Bezeichnung & Spezifität & Eigenschaft & Verdünnung & Referenz \\
\hline a-AKR2 & $\begin{array}{l}\text { Arabidopsis } \\
\text { Protein AKR2A }\end{array}$ & $\begin{array}{l}\text { polyklonal, aus } \\
\text { Kaninchen } \\
\text { (Blut 3 und 4) }\end{array}$ & $1: 20.000$ & Hong Zhang \\
\hline aHA & $\begin{array}{l}\text { HA-Epitoptag } \\
\text { (AS:YPYDVPDYA) }\end{array}$ & $\begin{array}{l}\text { polyklonal, aus } \\
\text { Kaninchen }\end{array}$ & $1: 800$ & SANTA CRUZ \\
\hline a-MYC & Myc-Epitoptag & $\begin{array}{l}\text { monoklonal, } \\
\text { aus Maus }\end{array}$ & $1: 1000$ & $\begin{array}{l}\text { CellSignalling } \\
\text { Techn. }\end{array}$ \\
\hline anti rabbit Ig & $\begin{array}{l}\text { Kaninchen- } \\
\text { Immunoglobulin }\end{array}$ & $\begin{array}{l}\text { polyklonal, aus } \\
\text { Esel, }\end{array}$ & $1: 10.000$ & AMERSHAM \\
\hline
\end{tabular}




\begin{tabular}{|l|l|l|l|l|}
\hline & & $\begin{array}{l}\text { Peroxidase } \\
\text { gekoppelt }\end{array}$ & \\
\hline $\begin{array}{l}\text { anti-mouse } \\
\text { IgG }\end{array}$ & $\begin{array}{l}\text { Maus- } \\
\text { Immunoglobulin }\end{array}$ & $\begin{array}{l}\text { Aus Schaf, } \\
\text { Peroxidase } \\
\text { gekoppelt }\end{array}$ & $1: 5000$ & AMERSHAM \\
\hline
\end{tabular}

\subsection{Nährmedien und Zusätze}

\subsubsection{Hefemedien}

SD- Medium

(Clontech, 1996)

YPD- Medium

(Clontech, 1996)
6,7 g/l Nitrogen base

0,61 g/l Complement Supplement

$20 \mathrm{~g} / \mathrm{l} \quad$ Difco Pepton

$10 \mathrm{~g} / \mathrm{l}$ Hefeextrakt

$20 \mathrm{~g} / \mathrm{l} \quad$ Glucose

mit Wasser auf 1 l auffüllen

\subsubsection{Pflanzenmedien}

MS- Medium

(Murashige und Skoog, 1962)

\begin{tabular}{|c|c|c|}
\hline 4,33 & $g / l$ & Murashige und Skoog Medium \\
\hline 10 & $g / l$ & $\begin{array}{l}\text { Saccharose } \\
\text { pH } 5,8 \text { mit } \mathrm{KOH} \text { einstellen }\end{array}$ \\
\hline & & ect Agar \\
\hline
\end{tabular}

\subsubsection{Bakterienmedien}

$\underline{\text { dYT Medium }}$

KingsB-Medium

LB- Medium

(LURIA- BERTANI Broth;

Sambrook et al., 1989)

SOC- Medium

(Sambrook et al., 1989)

$\begin{array}{lll}16 & \mathrm{~g} / \mathrm{l} & \text { Trypton } \\ 10 & \mathrm{~g} / \mathrm{l} & \text { Hefeextrakt } \\ 5 & \mathrm{~g} / \mathrm{l} & \mathrm{NaCl}\end{array}$
$12,3 \mathrm{~g} / \mathrm{l} \quad$ Glycerin (87\%)
$1,5 \mathrm{~g} / \mathrm{l} \quad \mathrm{K}_{2} \mathrm{HPO}_{4}{ }^{*} 3 \mathrm{H}_{2} \mathrm{O}$
$20 \mathrm{~g} / \mathrm{l} \quad$ Protease Pepton 3 $\mathrm{pH} 7,2$ mit $\mathrm{HCl}$
$5 \mathrm{ml} / \mathrm{l} \quad \mathrm{M} \mathrm{MgSO}_{4}$ zum Flüssigmedium zufügen

$\begin{array}{lll}10 & \mathrm{~g} / \mathrm{l} & \text { Trypton } \\ 5 & \mathrm{~g} / \mathrm{l} & \text { Hefeextrakt } \\ 5 & \mathrm{~g} / \mathrm{l} & \mathrm{NaCl} \\ & & \mathrm{pH} 7,4\end{array}$

$20 \mathrm{~g} / \mathrm{l} \quad$ Trypton

$5 \mathrm{~g} / \mathrm{l}$ Hefeextrakt

$10 \mathrm{ml} \quad 1 \mathrm{M} \mathrm{NaCl}$

$2,5 \mathrm{ml} \quad 1 \mathrm{M} \mathrm{KCl}$

$\mathrm{pH} 7,0$ 
$\underline{\text { YEB-Medium }}$

$10 \mathrm{~g} /$

nach dem Autoklavieren steril hinzufügen:

$10 \quad \mathrm{ml} \quad 1 \mathrm{M} \mathrm{MgCl}_{2}$

$10 \mathrm{ml} \quad \mathrm{MM} \mathrm{MgSO}_{4}$

$10 \mathrm{ml}$ 2M Glucose

$2 \mathrm{~g} / \mathrm{l}$ Hefeextrakt

5 g/l Pepton

$5 \mathrm{~g} / \mathrm{l}$ Saccharose

$0,5 \mathrm{~g} / \mathrm{l} \quad \mathrm{MgSo}_{4}$

pH 7 einstellen

Agrobakterium-Minimal-Medium (AMM) (Sambrook et al., 1989)

$20 \times$ T-Puffer

$210 \mathrm{~g} / \mathrm{l} \quad \mathrm{K}_{2} \mathrm{HPO}_{4}$

$20 \times$ T-Salze

$4 \mathrm{~g} / \mathrm{l} \quad \mathrm{MgSO}_{4} \times 7 \mathrm{H}_{2} \mathrm{O}$

$0,2 \quad \mathrm{~g} / \mathrm{l} \quad \mathrm{CaCl}_{2}$

$0,1 \quad \mathrm{~g} / \mathrm{l} \quad \mathrm{FeSO}_{4}$

$0,04 \mathrm{~g} / \mathrm{l} \quad \mathrm{MnCl}_{2}$

$20 \mathrm{~g} / \mathrm{l} \quad \mathrm{NH}_{4} \mathrm{Cl}$

AMM

$50 \mathrm{ml} 20 \times \mathrm{T}$-Puffer

$50 \mathrm{ml} 20 \times \mathrm{T}$-Salze

$5 \mathrm{~g} / \mathrm{l} \quad$ Glucose

\subsubsection{Pilzmedium}

PDB-Medium (Sigma)

$12 \mathrm{~g} / \mathrm{l} \quad$ Potato dextrose broth

\subsubsection{Agar}

Die Festmedien für Bakterien enthalten zusätzlich $14 \mathrm{~g} / \mathrm{l} \mathrm{Kobe-Agar.} \mathrm{Dieser} \mathrm{wird} \mathrm{nach}$ dem Einstellen des pH- Wertes und vor dem Autoklavieren zugegeben.

\subsubsection{Aminosäuren}

Tabelle 9: Aminosäuren für Hefe-Medien

\begin{tabular}{|l|c|c|}
\hline Aminosäuren & Stammlösung (40x) & Endkonzentration \\
\hline Adenin & $400 \mathrm{mg} / \mathrm{l}$ & $10 \mathrm{mg} / \mathrm{l}$ \\
\hline Histidin & $800 \mathrm{mg} / \mathrm{l}$ & $20 \mathrm{mg} / \mathrm{l}$ \\
\hline Leucin & $4000 \mathrm{mg} / \mathrm{l}$ & $100 \mathrm{mg} / \mathrm{l}$ \\
\hline Uracil & $800 \mathrm{mg} / \mathrm{l}$ & $20 \mathrm{mg} / \mathrm{l}$ \\
\hline Tryptophan & $2000 \mathrm{mg} / \mathrm{l}$ & $50 \mathrm{mg} / \mathrm{l}$ \\
\hline
\end{tabular}




\subsubsection{Antibiotika}

Tabelle 10: Eingesetzte Antibiotika

\begin{tabular}{|l|c|c|}
\hline Antibiotikum & Stammlösung & Endkonzentration \\
\hline Ampicillin & $100 \mathrm{mg} / \mathrm{ml} \mathrm{H}_{2} \mathrm{O}$ & $100 \mathrm{mg} / \mathrm{l}$ \\
\hline Chloramphenicol & $100 \mathrm{mg} / \mathrm{ml} \mathrm{H}_{2} \mathrm{O}$ & $50 \mathrm{mg} / \mathrm{l}$ \\
\hline Gentamycin & $25 \mathrm{mg} / \mathrm{ml} \mathrm{H}_{2} \mathrm{O}$ & $6,25 \mathrm{mg} / \mathrm{l}$ \\
\hline Kanamycin & $50 \mathrm{mg} / \mathrm{ml} \mathrm{H}_{2} \mathrm{O}$ & $50 \mathrm{mg} / \mathrm{l}$ \\
\hline Rifampicin & $10 \mathrm{mg} / \mathrm{ml} \mathrm{Methanol}$ & $50 \mathrm{mg} / \mathrm{l}$ \\
\hline Spectinomycin & $100 \mathrm{mg} / \mathrm{ml} \mathrm{H}_{2} \mathrm{O}$ & $100 \mathrm{mg} / \mathrm{l}$ \\
\hline
\end{tabular}

\subsubsection{Medienzusätze}

Tabelle 11: Medienzusätze

\begin{tabular}{|l|c|c|}
\hline Zusatz & Stammlösung & Endkonzentration \\
\hline IPTG (Isopropylthiogalactosid) & $26 \mathrm{mg} / \mathrm{ml} \mathrm{DMF}$ & $50 \mu \mathrm{l}$ pro Platte \\
\hline $\begin{array}{l}\text { X-Gal (5-Brom-4-chlor-3-indolyl- } \\
\beta \text {-D-galactopyranosid) }\end{array}$ & $20 \mathrm{mg} / \mathrm{ml}$ DMF & $50 \mu \mathrm{l}$ pro Platte \\
\hline $\begin{array}{l}\text { Paraquat } \\
\text { (Dimethylbipyridiniumchlorid) }\end{array}$ & $10 \mathrm{mM} \mathrm{H}_{2} \mathrm{O}$ & $0,75-2,5 \mu \mathrm{M}$ \\
\hline
\end{tabular}

\subsection{Lösungen und Puffer}

Alle Lösungen und Puffer werden, soweit nicht anders beschrieben, mit ultra pure $\mathrm{H}_{2} \mathrm{O}$ angesetzt und anschließend autoklaviert (15 min, 2 bar, $121^{\circ} \mathrm{C}$ ).

\section{Ammoniumacetat-Lösung}

AS-Medium $(100 \mathrm{ml})$

Church

CTAB-Lösung

Entfärbebad (Coomassie)

Enzymlösung
8 M Ammoniumacetat

$1 \mathrm{ml} \quad 1 \mathrm{M} \mathrm{MgCl}_{2}$

$1 \mathrm{ml} \quad 1 \mathrm{M}$ MES-KOH pH5,6

$0,1 \mathrm{ml} 150 \mathrm{mM}$ Acetosyringone

$7 \%$ SDS

$250 \mathrm{mM}$ NaPhosphat-Puffer $(\mathrm{pH} 7,0)$

$1 \mathrm{mM}$ EDTA

\section{$2 \% \quad \mathrm{CTAB}$}

$100 \mathrm{mM}$ Tris- $\mathrm{HCl}, \mathrm{pH} 8,0$

$20 \mathrm{mM}$ EDTA, $\mathrm{pH} 8,0$

$1.4 \mathrm{M} \quad \mathrm{NaCl}$

$10 \% \quad(\mathrm{v} / \mathrm{v}) \quad$ Essigsäure

$\begin{array}{lll}1,25 & \% & \text { Cellulase R-10 } \\ 0,3 & \% & \text { Macerozyme R-10 } \\ 0,4 & \mathrm{M} & \text { Mannitol } \\ 20 & \mathrm{mM} & \mathrm{KCl} \\ 20 & \mathrm{mM} & \text { MES }\end{array}$


$10 \mathrm{mM} \quad \mathrm{CaCl}_{2}$

steril filtrieren und bei $4^{\circ} \mathrm{C}$

lagern

Ethidiumbromidbad

Farbmix (Proteinbestimmung)

GUS-Extraktionspuffer

mit ß-Mercaptoethanol

GUS-Stop-Puffer

Fällungspuffer

Färbelösung für Proteine

auf Nitrocellulosemembranen

Färbelösung (Coomassie)

Fixierlösung (Coomassie)

$\underline{\text { Harnstoffextraktionspuffer }}$

Heringssperma-DNA

Kontrastmittel

1x Laufpuffer (SDS-PAGE)

Ladepuffer für Agarosegele
$0,5 \mu \mathrm{g} / \mathrm{ml}$ Ethidiumbromid in $\mathrm{H}_{2} \mathrm{O}$

$750 \mathrm{ml} \quad \mathrm{H}_{2} \mathrm{O}$

$100 \mathrm{ml} \quad 85 \%(\mathrm{v} / \mathrm{v}) \mathrm{H}_{3} \mathrm{PO}_{4}$

$70 \mathrm{mg}$ Coomassie Brilliantblue G-250 in $50 \mathrm{ml}$ absol. EtOH gelöst

$50 \quad \mathrm{mM}$ Na-Phosphatpuffer

$10 \mathrm{mM}$ EDTA

$0,1 \% \quad(v / v)$ Triton X100

$0,1 \% \quad(v / v)$ Sarkosyl

0,05\% (v/v) ß-Mercaptoethanol

$200 \mathrm{mM} \quad \mathrm{Na}_{2} \mathrm{CO}_{3}$

$1,2 \quad \mathrm{M} \quad \mathrm{NaCl}$

0,8 M tri-Natrium-Citrat

$0,02 \% \quad(w / v)$ Ponceau S

$3 \% \quad$ Trichloressigsäure

0,006\%(w/v) Coomassie Brilliant Blue G-250

$10 \% \quad(\mathrm{v} / \mathrm{v})$ Essigsäure

$25 \% \quad(\mathrm{v} / \mathrm{v})$ Isopropanol

$10 \%$ (v/v) Essigsäure

$4 \quad \mathrm{M}$ Harnstoff

$16,6 \%(v / v)$ Glycerin

$5 \% \quad(\mathrm{v} / \mathrm{v}) \quad$ ß-Mercaptoethanol

$5 \% \quad(w / v) \quad$ SDS

$0,5 \%$ (w/v) Bromphenolblau

$10 \mathrm{mg} / \mathrm{ml}$ in TE durch Rühren (1h)

lösen falls nötig: mit

Ultraschall behandeln

bei $-20{ }^{\circ} \mathrm{C}$ lagern

vor Verwendung 20 min bei $95^{\circ} \mathrm{C}$

$0,2 \% \quad$ Uranylacetat in $\mathrm{H}_{2} \mathrm{O}$

$25 \mathrm{mM}$ Tris

$190 \mathrm{mM}$ Glycin

$0,1 \%(w / v)$ SDS

$40 \quad \mathrm{mM}$ Tris/Acetat, $\mathrm{pH} \mathrm{8,3}$

$2 \mathrm{mM}$ EDTA 
Lösung I für alkalische Lyse

Lösung II für alkalische Lyse

Lösung III für alkalische Lyse

\section{Lösung A}

Lösung B

Lösung $\mathrm{C}$

MEN-Puffer 10x

$\underline{\mathrm{MMg}}$

MUG-Gebrauchslösung

oNPG-Lösung

P1-Puffer (Qiagen)

P2-Puffer (Qiagen)
$50 \% \quad(\mathrm{v} / \mathrm{v}) \quad$ Glycerin (87\%)

$0,4 \%$ (w/v) Orange G

$\begin{array}{lll}50 & \mathrm{mM} & \text { Glucose } \\ 10 & \mathrm{mM} & \text { EDTA } \\ 25 & \mathrm{mM} & \text { Tris-HCl }(\mathrm{pH} \mathrm{8,0)} \\ 100 & \mathrm{mg} / \mathrm{l} & \text { Rnase }\end{array}$

$0,2 \quad \mathrm{M} \quad \mathrm{NaOH}$

$2 \% \quad$ SDS

$294 \mathrm{~g} \quad \mathrm{KAc}$

$50 \mathrm{ml} \quad \mathrm{HCOOH}$

$2,5 \mathrm{mg} / \mathrm{ml}$ Lyticase mit $\mathrm{H}_{2} \mathrm{O}$ auf 1 I auffüllen $\mathrm{pH} 7,4$, bei $-20^{\circ} \mathrm{C}$ lagern

$10 \mathrm{mM}$ Bicine 1 M Sorbitol

$3 \% \quad(\mathrm{v} / \mathrm{v})$ Ethylenglycol $\mathrm{pH} 8,35$ mit $\mathrm{KOH}$ einstellen

$200 \mathrm{mM}$ Bicine

$40 \% \quad(w / v)$ Peg 1000 $\mathrm{pH} \mathrm{8,35} \mathrm{mit} \mathrm{KOH}$ einstellen

$10 \mathrm{mM}$ Bicine

$150 \mathrm{mM} \mathrm{NaCl}$

$\mathrm{pH}$ 8,35 mit $\mathrm{KOH}$ einstellen

$200 \mathrm{mM}$ MOPS

$50 \mathrm{mM}$ Natriumacetat

$10 \mathrm{mM}$ EDTA $\mathrm{pH}$ 7,0 mit $\mathrm{NaOH}$

0,4 M Mannitol

$15 \mathrm{mM} \quad \mathrm{MgCl}_{2}$

$4 \mathrm{mM}$ MES

steril filtrieren

4 mM 4-MUG (4-

Methylumbeliferylß-D-Glucoronid) in GUSExtraktionspuffer mit ßMercaptoethanol

$4 \mathrm{mg} / \mathrm{ml}$ oNPG, gelöst in Z-Puffer

$50 \quad \mathrm{mM}$ Tris- $\mathrm{HCl}(\mathrm{pH} 8,0)$

$10 \mathrm{mM}$ EDTA

0,1 g/l RNase A

$200 \mathrm{mM} \quad \mathrm{NaOH}$

$1 \% \quad$ SDS 
$\underline{\text { P3-Puffer (Qiagen) }}$

PEG-Lösung (40\%)

Primärfixativ

$\underline{\text { RNA-Probenpuffer }(2,5 \mathrm{x})}$

Sammelgel (SDS-PAGE)

Sekundärfixativ

Spurr

$\operatorname{SSC} 20 x$

Stripp-Lösung

$20 \times$ TAE

$\underline{\text { TB-Puffer }}$

$\begin{array}{lll}294 & \mathrm{~g} & \mathrm{KAc} \\ 50 & \mathrm{ml} & \mathrm{HCOOH}\end{array}$

4 g PEG 4000

$3 \mathrm{ml} \quad \mathrm{H}_{2} \mathrm{O}$

2,5 $\mathrm{ml}$ 0,8M Mannitol

$1 \mathrm{ml} \quad 1 \mathrm{M} \mathrm{CaCl}_{2}$

$\leq 10 \mathrm{ml}$ PEG-Lösung

steril filtrieren

1,5\% Paraformaldehyd

$0,25 \% \quad$ Glutaraldehyd in Waschpuffer

$\begin{array}{lll}20 & \% & \text { MEN } \\ 8 & \% & \text { Glycerin } \\ 56,7 & \% & \text { Formamid } \\ 5 & \% & \text { Formaldehyd } \\ 0,001 & \% & \text { Bromphenolblau } \\ 0,1 & \% & \text { Ethidiumbromid } \\ 4 & \mathrm{mM} & \text { EDTA pH } 7,5\end{array}$

$5 \% \quad$ (w/v) Acrylamid/ BIS (19:1)

$125 \mathrm{mM}$ Tris/ HCL pH 6,8

$0,1 \% \quad(w / v)$ SDS

$0,1 \% \quad(w / v)$ APS

$0,2 \% \quad(v / v)$ TEMED

$0,5 \% \quad$ Osmium in Waschpuffer

ergibt ca. $160 \mathrm{ml}$ Kunstharz, in $100 \mathrm{ml}$ Tropfflasche, später eingefroren.

$45 \mathrm{~g} \quad$ ERL (4221) (3,4-

Epoxcylcyclohexyl-methyl-3,4epoxycyclohexylcarboxylate)

$27 \mathrm{~g} \quad$ DER 736

$117 \mathrm{~g} \quad$ NSA (Nonenylsuccinic anhydride)

$1,8 \mathrm{~g} \quad$ Dimethylaminoethanol

$\begin{array}{lll}2 & \mathrm{M} & \mathrm{NaCl} \\ 0,3 & \mathrm{M} & \text { Natriumcitrat } \\ & & \mathrm{pH} 7,0 \text { mit } \mathrm{HCl}\end{array}$

$0,1 \quad \% \quad$ SDS

$0,8 \quad \mathrm{M} \quad$ Tris- $\mathrm{HCl}$

$0,2 \quad \mathrm{M} \quad \mathrm{NaAc}$

$20 \mathrm{mM}$ EDTA

pH 7,8 mit Essigsäure einstellen

$10 \mathrm{mM}$ PIPES-KOH, $\mathrm{pH} \mathrm{6,7}$ 
$\underline{\text { TBS }}$

$\begin{array}{lll}15 & \mathrm{mM} & \mathrm{CaCl}_{2} \\ 250 & \mathrm{mM} & \mathrm{KCl} \\ 55 & \mathrm{mM} & \mathrm{MnCl}_{2} \text { (Filter sterilisiert) }\end{array}$

$50 \mathrm{mM}$ Tris

$150 \mathrm{mM} \mathrm{NaCl}$

$\mathrm{pH} \mathrm{7,6} \mathrm{mit} \mathrm{HCl}$

$\underline{\text { TBS-T }}$

$\begin{array}{lll} & & \text { TBS } \\ 0,1 \% & (\mathrm{v} / \mathrm{v}) & \text { Tween20 } \\ 100 & \mathrm{mM} & \text { Tris-HCl } \\ 10 & \mathrm{mM} & \text { EDTA } \\ & & \text { pH 7,5 }\end{array}$

15\%iges Trenngel (SDS-PAGE)

$20 \%$ (w/v) Acrylamid/ BIS (19:1)

$0,4 \quad M \quad$ Tris/ HCL pH 8,8

$0,1 \% \quad(w / v)$ SDS

$0,1 \%(w / v)$ APS

$0,1 \% \quad(\mathrm{v} / \mathrm{v})$ TEMED

$\underline{\text { Transferpuffer }}$

$\begin{array}{lll}192 & \mathrm{mM} & \text { Glycin } \\ 25 & \mathrm{mM} & \text { Tris } \\ 20 \% & (\mathrm{v} / \mathrm{v}) & \text { Methanol } \\ 0,01 \% & (\mathrm{w} / \mathrm{v}) & \text { SDS }\end{array}$

$\underline{\text { Trizolpuffer }}$

$380 \mathrm{ml} / \mathrm{l}$ Phenol mit 0,1 M Citrat-Puffer gesättigt

0,8 M Guanidiniumthiocyanat

$0,4 \quad M \quad$ Ammoniumthiocyanat

$33,4 \mathrm{ml} / \mathrm{l} \quad$ Na-Acetat $(3 \mathrm{M} \mathrm{pH} \mathrm{5,2} \mathrm{mit}$ Essigsäure)

$5 \%$ Glycerin

Waschpuffer

$0,1 \mathrm{M}$

PIPES

$2 \mathrm{mM}$

$\mathrm{CaCl}_{2}$ in bidest

mit $\mathrm{NaOH}$ auf $\mathrm{pH} 7$

$\underline{\mathrm{W} 5}$

$154 \mathrm{mM} \quad \mathrm{NaCl}$

$125 \mathrm{mM} \quad \mathrm{CaCl}_{2}$

$5 \mathrm{mM} \mathrm{KCl}$

$2 \mathrm{mM}$ MES

steril filtrieren

$\underline{\text { WI }}$

0,5 M Mannitol

4 mM MES

$20 \mathrm{mM} \mathrm{KCl}$

steril filtrieren

Z-Puffer
$16.1 \mathrm{~g} / \mathrm{l}$
$\mathrm{Na}_{2} \mathrm{HPO}_{4} \times 7 \mathrm{H}_{2} \mathrm{O}$
$5.50 \mathrm{~g} / \mathrm{l}$
$\mathrm{NaH}_{2} \mathrm{PO}_{4} \times \mathrm{H}_{2} \mathrm{O}$
$0.75 \mathrm{~g} / \mathrm{l}$
$\mathrm{KCl}$
$0.246 \mathrm{~g} / \mathrm{l}$
$\mathrm{MgSO}_{4} \times 7 \mathrm{H}_{2} \mathrm{O}$ 
$\mathrm{pH} 7,0$ mit $\mathrm{NaOH}$ einstellen

Z-Puffer/ß-Mercaptoethanol

$0,27 \mathrm{ml}$

$\beta$-Mercaptoethanol

$100 \mathrm{ml}$

Z-Puffer

Z-Puffer + oNPG

$40 \quad \mathrm{mg}$ oNPG

$10 \mathrm{ml}$ Z-Puffer

\subsection{Geräte}

Tabelle 12: Geräte

\begin{tabular}{|c|c|c|}
\hline Gerät & Modell & Hersteller \\
\hline Autoklav & $3870 \mathrm{ELV}$ & Tuttnauer \\
\hline Bioimager (Phosphoimager) & BAS-1000 & Fuji \\
\hline Elektroporationsgerät & Gene Pulser & Bio Rad \\
\hline Eismaschine & AF-20 & Scotman \\
\hline Fluoreszenzmikroskop & BX60 & Olympus \\
\hline Fluorometer & Cytofluor $^{T M}$ II & Perseptive \\
\hline Gefriertruhe $-80^{\circ} \mathrm{C}$ & C54285 & New Brunswick Scientific \\
\hline Geldokumentationsanlage & RS1 & Kaiser, Deutschland \\
\hline Gelelektrophoresekammer & & $\begin{array}{l}\text { Werkstatt der Universität } \\
\text { Göttingen }\end{array}$ \\
\hline Heizblock & Boekel & Scientific \\
\hline Heizrührer & RCT basic & IKA Labortechnik \\
\hline Hybridisierungsschrank & Hy-St-1 & Bachofer \\
\hline Hybridisierungswasserbad & Belly Dancer & Sorvall \\
\hline Inkubationsschrank & & WTC Binder \\
\hline Klimaschrank & & Percival Scientific \\
\hline Konfokales Mikroskop & TCS SP2 AOBS & Leica \\
\hline Kühlschränke & & Liebherr \\
\hline Kühlzentrifuge & Sorvall RC 5B Plus & DuPont \\
\hline $\begin{array}{l}\text { Lumineszenz-Imaging } \\
\text { System }\end{array}$ & $\begin{array}{l}\text { C4742-98 gekühlte CCD- } \\
\text { Kamera }\end{array}$ & Hamamatsu Photonics \\
\hline Luminometer & & BMG Labtech \\
\hline Netzgeräte & E 323 & Benedikt Heinemann \\
\hline Netzgeräte & EC 105 EC & Apparatus Corporation \\
\hline PCR-Gerät, MiniCycler ${ }^{\mathrm{TM}}$ & PTC-150 & MJ Research, USA \\
\hline $\mathrm{pH}-$ Meter & $\mathrm{HI} 9321$ & Hanna Instruments \\
\hline Photometer & Unikon 720 LC & Kontron \\
\hline Polyacrylamid-Gelkammer & & AGS \\
\hline Real-time-PCR-Gerät & iCycler MylQ & BioRad \\
\hline RNA-/ DNA-Calculator & Nanovue & $\mathrm{GE}$ \\
\hline Scanner & & Epson \\
\hline Schüttler & 3005 & GFL \\
\hline Semi-Dry-Blot-Apparatur & & $\begin{array}{l}\text { Werkstatt der Universität } \\
\text { Bielefeld }\end{array}$ \\
\hline Sequenziergerät & ABI PRISM 310 & Perkin-Elmer Corporation \\
\hline $\begin{array}{l}\text { Spektralphotometer für } \\
\text { Mikrotiterplastten }\end{array}$ & MRX Dynex Plate Reader & Dynex \\
\hline
\end{tabular}




\begin{tabular}{|l|l|l|}
\hline Sterilbank & Microflow & Nunc \\
\hline Tischzentrifuge & 5414 & Eppendorf \\
\hline Tischzentrifuge, gekühlt & 5403 & Eppendorf \\
\hline Ultrazentrifuge & Centrikon T-1065 & Kontron \\
\hline UV-Transilluminator & FLX-20 M & Vilber Lourmat \\
\hline Vortex & L46 & Labinco BV, Niederlande \\
\hline Waagen & SPO51, SAC62, 1207 & Scaltec \\
Feinwaage & MP2 & Sartorius \\
\hline Wasseraufbereitungsanlage & Option 4, Maxima & ELGA \\
\hline Wasserbäder & 1086 & GFL \\
\hline Zentrifuge, Ausschwingrotor & & Universal 16 A Hettich \\
\hline
\end{tabular}

\subsection{Verbrauchsmittel}

Tabelle 13: Verbrauchsmittel

\begin{tabular}{|l|l|}
\hline Produkt & Hersteller \\
\hline Alufolie & Roth \\
\hline Elektroporationsküvetten & BioRad \\
\hline Fließpapier & Whatman \\
\hline $\begin{array}{l}\text { Glasmaterialien: Flaschen, Pasteurpipetten, } \\
\text { Erlenmeyerkolben usw. }\end{array}$ & Brand, Schott \\
\hline Haushaltsfolie & Tip \\
\hline Hybond ${ }^{\text {MMN / -N+ }}$ & Amersham \\
\hline Immobilon-P, PVDF-Transfer Membranen & Millipore \\
\hline $\begin{array}{l}\text { Kunststoff-Einwegmaterial: Spitzen, Pipetten, } \\
\text { Reaktionsgefäße, Röhrchen, Petrischalen usw. }\end{array}$ & Eppendorf, Brand, \\
\hline Microtiterplatten & Greiner, Sarstedt \\
\hline Objektträger, Deckgläschen & Nunc, Roth \\
\hline Parafilm N & Roth \\
\hline Röntgenfilme & American National Can ${ }^{\mathrm{TM}}$ \\
\hline Sephadex G50 & Kodak \\
\hline
\end{tabular}

\subsection{Chemikalien}

Tabelle 14: Chemikalien

\begin{tabular}{|l|l|}
\hline Produkt & Hersteller \\
\hline Agar Bacteriological & GIBCO BRL Life technologies \\
\hline Agarose & SeaKem LE Biozym \\
\hline Aminosäuren & Sigma \\
\hline Ampicillin & Sigma \\
\hline BASTA & Hoechst \\
\hline Bradfordreagenz & Roth \\
\hline Bromphenolblau-Natriumsalz & Roth \\
\hline BSA & Roth \\
\hline Calciumcarbonat $\left(\mathrm{CaCl}_{2}\right)$ & Roth \\
\hline Chloroform & Merck \\
\hline Complete Supplement Mixture (CSM) & Bio 101 \\
\hline
\end{tabular}




\begin{tabular}{|c|c|}
\hline Difco Pepton & Difco \\
\hline Dimethylsulfoxid (DMSO) & Sigma \\
\hline$\left[\alpha-{ }^{32} \mathrm{P}\right] \mathrm{dATP}, 800 \mathrm{Ci} / \mathrm{mmol}$ & Hartmann Analytic \\
\hline dNTPs & Fermentas \\
\hline EDTA & AppliChem \\
\hline Essigsäure & Roth \\
\hline Ethanol absolut & Merck \\
\hline Ethidiumbromidlösung $1 \%$ & Roth \\
\hline Formaldehyd & Roth \\
\hline Formamid & Roth \\
\hline Glucose & Roth \\
\hline Glycerin (87\%) & Roth \\
\hline Harnstoff & Roth \\
\hline Heringssperma-DNA (HSP) & Boehringer \\
\hline $\begin{array}{l}\text { Hydroxyethyl-Cellulose medium vis. } \\
\text { (HEC) }\end{array}$ & Fluka \\
\hline IPTG & BioTech Trade \\
\hline Kaliumacetat (KAc) & Merck \\
\hline Kaliumchlorid (KCl) & Roth \\
\hline Kanamycin & Duchefa \\
\hline Leptomycin B (LMB) & LC Laboratories \\
\hline Leupeptin & Sigma \\
\hline Lithiumacetat & Sigma \\
\hline Lyticase & Sigma \\
\hline Magnesiumchlorid $\left(\mathrm{MgCl}_{2}\right)$ & AppliChem \\
\hline $\begin{array}{l}\text { Magnesiumsulfat-Heptahydrat }\left(\mathrm{MgSO}_{4} \mathrm{X}\right. \\
\left.\mathrm{H}_{2} \mathrm{O}\right)\end{array}$ & AppliChem \\
\hline Magermilchpulver & Glücksklee \\
\hline Mannitol & Roth \\
\hline 4-Methylumbelliferyl (4-MU) & Sigma \\
\hline $\mathrm{NaOH}$ & Merck \\
\hline Natriumcarbonat & Merck \\
\hline Natriumchlorid $(\mathrm{NaCl})$ & Roth \\
\hline Natriumhypochlorit & Roth \\
\hline Natriumlaurylsulfat (SDS) & Roth \\
\hline $\begin{array}{l}\text { o-Nitrophenyl ß-D-Galactosidase } \\
\text { (oNPG) }\end{array}$ & Sigma \\
\hline Orange G & Sigma \\
\hline $\begin{array}{l}\text { Polyacrylamid (PAA)-Mix: } 30 \% \text { PAA + } \\
\text { Bisacrylamid }(37,5: 1)\end{array}$ & Roth \\
\hline Polyethylenglycol (PEG) 4000 & Fluka \\
\hline Pepton & Roth \\
\hline Phenol & AppliChem \\
\hline Ponceau rot & Sigma \\
\hline Rifampicin & Duchefa \\
\hline Röntgenfilmentwickler LX24 & Kodak \\
\hline Röntgenfilm Fixierer AL4 & Kodak \\
\hline Saccharose & Roth \\
\hline Salzsäure & Merck \\
\hline Select Agar & Life Technologies \\
\hline
\end{tabular}




\begin{tabular}{|l|l|}
\hline Select Yeast Extract & Life Technologies \\
\hline Silwet L77 & Lehle Seeds \\
\hline $\begin{array}{l}\text { TEMED (N,N,N',N'- } \\
\text { Tetramethylethylendiamidin) }\end{array}$ & Roth \\
\hline Trishydroxymethylaminomethan (Tris) & Roth \\
\hline Triton X-100 & Roth \\
\hline Trypton & Oxoid \\
\hline Tween & Sigma \\
\hline Yeast nitrogen base without amino acids & Difco \\
\hline B-Mercaptoethanol & Roth \\
\hline
\end{tabular}

Nicht aufgeführte Standardchemikalien wurden von den Firmen Merck, Roth, Boehringer, Fluka oder Sigma bezogen.

\subsection{Enzyme}

Tabelle 15: Enzyme

\begin{tabular}{|l|l|}
\hline Enzym & Hersteller \\
\hline Advantage cDNA Polymerase Mix (50x) & Clontech \\
\hline Alkalische Phosphatase (CIAP) & Fermentas \\
\hline Cellulase „Onozuka R-10“ & Serva \\
\hline DNasel & Fermentas \\
\hline Klenow Exo- Polymerase & Fermentas \\
\hline Mazerocym R-10 & Sigma \\
\hline PfuTurbo DNA Polymerase & Fermentas \\
\hline Proteinase K & Fermentas \\
\hline Restriktionsenzyme & Fermentas \\
\hline Reverse Transkriptase H' M-MulV & Fermentas \\
\hline RiboLock RNase Inhibitor & Fermentas \\
\hline T4 DNA-Ligase & Fermentas \\
\hline Taq DNA Polymerase & Molzym \\
\hline
\end{tabular}

\subsection{Kits}

Tabelle 16: Kits

\begin{tabular}{|l|l|}
\hline Kit & Hersteller \\
\hline Amino Allyl MessageAmpll aRNA-Kit & Ambion \\
\hline BigDye Terminator Ready Reaction Kit & Perkin-Elmer Corporation \\
\hline Gateway Cloning Kit & Invitrogen \\
\hline Invisorb Spin Plant RNA Mini Kit & Invitek \\
\hline NucleoBond Maxiprep Kit & Macherey-Nagel \\
\hline NucleoSpin Plasmid Miniprep Kit & Macherey-Nagel \\
\hline NucleoSpin Extraction II Kit & Macherey-Nagel \\
\hline QuikChange Site-directed mutagenesis kit & Stratagene \\
\hline
\end{tabular}




\subsection{Größenstandards}

\subsubsection{DNA-Größenstandard}

Als Fragmentlängenstandard wurde bei der Gelelektrophorese folgende DNAGrößenmarker verwendet:

\section{NPstI}

$(\lambda$-DNA mit

Pstl gespalten)

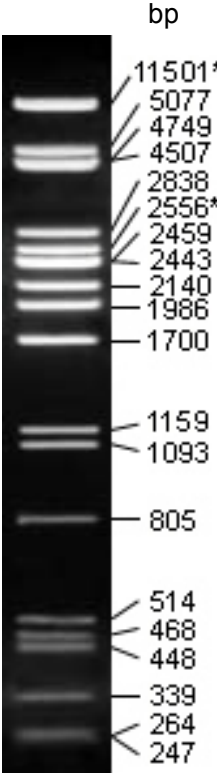

GeneRuler

DNA Ladder Mix

(Fermentas)

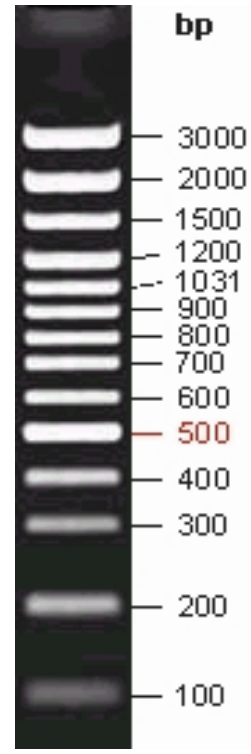

\subsubsection{Protein- Größenstandard}

Zur Ermittlung des Molekulargewichtes von Proteinen wurde die „PageRuler ${ }^{\mathrm{TM}}$ Prestained Protein Ladder“ (Fermentas) verwendet. 


\section{Methoden}

\subsection{Pflanzenanzucht und Transformation}

\subsubsection{Pflanzenanzucht}

Die A. thaliana Pflanzen wurden angezogen in T25-Erde (Fa. Fruhstorfer Erde, Lauterbach), oder nach der Sterilisation auf MS-Medium (Murashige \& Skoog) ausgelegt. Nach zwei Tagen bei $4^{\circ} \mathrm{C}$ im Kühlraum zur Stratifizierung wurden die ausgelegten Samen in die Langtag-Klimakammer bei $22^{\circ} \mathrm{C}$ gestellt mit 16 Stunden Licht und 8 Stunden Dunkel.

N. benthamiana L. Pflanzen wuchsen in der Klimakammer bei 16 Stunden Licht und 8 Stunden Dunkel.

\subsubsection{Floral Dip Transformation}

Ein klassischer Weg zur Transformation von Pflanzen ist der Agrobakterienvermittelte Gentransfer. Agrobacterium tumefaciens hat die Fähigkeit einen durch zwei Border-Sequenzen definierten Abschnitt des so genannten Ti-Plasmids in eine Pflanzenzelle zu transportieren und dort an einer zufälligen Stelle eines PflanzenChromosoms einzufügen (Herrera-Estrella et al., 1992).

Das Ti-Plasmid wurde speziell für die gezielte Integration von Genen in das pflanzliche Genom modifiziert. So werden z.B. die für den Transfer notwendigen Funktionen auf zwei Plasmide aufgeteilt. Die zu übertragenden DNA-Sequenzen lassen sich mit molekularbiologischen Methoden zwischen die Border-Sequenzen inserieren. A. tumefaciens ist so zu einem hervorragenden Hilfsmittel geworden, um Pflanzen gezielt zu transformieren.

Für die Agrobakterien-vermittelte Transformation von Arabidopsis thaliana wurde eine sehr einfache Methode entwickelt (Clough und Bent, 1998). Pflanzen, die gerade begonnen haben zu blühen, werden in Medium mit den entsprechenden Agrobakterien und einem Benetzungsmittel getaucht. Dabei scheinen sich entwickelnde Eizellen das bevorzugte Ziel produktiver Transformationen zu sein (Bent, 2000). Aus diesen Zellen entstehen hemizygote Samen. Für die Transformation werden pro Topf $(\varnothing 6 \mathrm{~cm})$ bis zu 20 Samen ausgesät. Gesunde und kräftige Pflanzen erhöhen die Transformationsrate. Durch das Abschneiden der ersten Blütenstände lässt sich die Bildung vieler sekundärer Blütenstände anregen, was die Ausbeute an transgenen Samen erhöhen kann.

1) Mit einer $25 \mathrm{ml}$ Vorkultur $400 \mathrm{ml}$ YEB + entsprechende Antibiotika animpfen und bis zu einer OD600 von 2.0 wachsen lassen

2) Die Agrobakterien 10 min. bei $1000 x g$ abzentrifugieren und bis zum Erreichen einer $\mathrm{OD}_{600}$ von etwa 0,8 in Transformationsmedium resuspendieren

3) Pflanzen für einige Sekunden bis zur Rosette in die Agrobakterien-Lösung dippen, anschließend zurück in die Klimakammer stellen und 1-2 Tage mit einer Haube abdecken.

Die Pflanzen werden bis zur Samenreife (2-3 Wochen) weiterkultiviert. Die Blütenstände lässt man dann in Papiertüten trocknen. Die trockenen Pflanzen werden vorsichtig mit den Fingern zerrieben um die Schötchen aufzubrechen, und 
die Samen durch sieben grob von den übrigen Pflanzenteilen getrennt. Sie können bei $4^{\circ} \mathrm{C}$ trocken gelagert werden.

\subsubsection{Selektion auf Basta $^{\circledR}$-Resistenz}

Die Samen werden zunächst wie gewohnt auf Erde ausgesät und kultiviert. Wenn die Pflanzen 2-4 vegetative Blätter gebildet haben werden sie mit $1 \mathrm{mM}$ Basta besprüht (etwa $1 \mathrm{ml} /$ Topf). Basta bzw. Phosphinothricin (auch Glufosinat = L-Homoanalin-4yl-(methyl)-phosphinsäure) wirkt als Strukturanalogon des L-Glutamat und inhibiert dadurch die Glutaminsynthetase. Die Pflanzen können bei Behandlung mit Basta Glutamat nicht mehr in Glutamin umwandeln. Dadurch häuft sich Ammonium zu einer letalen Konzentration in der Pflanze an und führt zusammen mit dem Glutaminmangel zum raschen Absterben der behandelten Pflanzen. Pflanzen, die als Resitenzmarker das bar-Gen tragen, sind unempfindlich gegenüber Phosphinothricin (White et al., 1990).

Nach 3-4 Tagen sind die nicht resistenten Pflanzen abgestorben. Um auszuschließen, dass nicht resistente Pflanzen überleben, werden die Pflanzen noch einmal nach 3-4 Tagen mit Basta besprüht.

\subsection{Anzucht und Lagerung von Bakterien und Hefen}

\subsubsection{Anzucht von Escherichia coli}

Die Anzucht von E. coli erfolgt entweder auf LB-Festmedium oder in LBFlüssigmedium über Nacht bei $37^{\circ} \mathrm{C}$ mit einem geeigneten Antibiotikum zur Selektion (Sambrook et al., 1989).

\subsubsection{Anzucht von Agrobacterium tumefaciens}

Die Anzucht von Agrobacterium tumefaciens erfolgt entweder auf YEB-Festmedium oder in YEB-Flüssigmedium im Schüttler bei $30^{\circ} \mathrm{C}$ mit geeigneten Antibiotika zur Selektion.

\subsubsection{Anzucht von Pseudomonas syringae}

Die Anzucht von Pseudomonas syringae erfolgt entweder auf KingsB-Festmedium oder in KingsB-Flüssigmedium im Schüttler bei $29^{\circ} \mathrm{C}$ mit geeigneten Antibiotika zur Selektion.

\subsubsection{Anzucht von Saccharomyces cerevisiae}

Die Anzucht von Saccharomyces cerevisiae erfolgt bei $30{ }^{\circ} \mathrm{C}$. Stämme ohne Plasmide werden auf YPD-Medium angezogen. Stämme, die Plasmide enthalten, werden auf den entsprechenden SD-Medien angezogen.

\subsubsection{Lagerung der Bakterien}

Die Bakterien können auf den Platten bei $4{ }^{\circ} \mathrm{C}$ mittelfristig gelagert werden. Für längere Lagerung müssen Gefrierkulturen angelegt werden.

Anlage einer Gefrierkultur:

1) $750 \mu$ l einer frischen ü.N.-Kultur mit $250 \mu \mathrm{l} 87 \%$ Glycerin versetzen

2) kräftig vortexen 
3) schockgefrieren in Flüssigstickstoff

4) Lagerung bei $-80{ }^{\circ} \mathrm{C}$

\subsubsection{Lagerung der Hefen}

Die Hefen können auf den entsprechenden Platten mit Parafilm bis zu einem Monat bei $4{ }^{\circ} \mathrm{C}$ gelagert werden. Für das Arbeiten mit Hefe sollten die Platten aber frisch sein. Um Hefen längerfristig zu lagern, müssen Gefrierkulturen angelegt werden. Anlage einer Gefrierkultur:

1) $750 \mu \mathrm{l}$ einer frischen Kultur im entsprechenden SD-Medium mit $250 \mu \mathrm{l} 87 \%$ Glycerin versetzen

2) kräftig vortexen

3) langsam bei $-80^{\circ} \mathrm{C}$ einfrieren

4) Lagerung bei $-80^{\circ} \mathrm{C}$

\subsection{Methoden zur Präparation von Nukleinsäuren}

\subsubsection{Isolierung von RNA}

Die Isolierung von RNA aus $A$. thaliana erfolgte nach der Trizol-Methode.

Die Methode basiert auf einer Phenol/Chloroform Extraktion, die die Tatsache ausnutzt, dass RNA sich besser in der hydrophilen, wässrigen Phase löst, während Chlorophyll und andere Bestandteile besser in der hydrophoben Chloroform-Phase gelöst werden. Die beiden Thiocyanat-Salze im Extraktionspuffer inhibieren RNasen und verhindern damit eine Degradation der RNA (Chomczynski, 1993; Chomczynski und Sacchi, 1987).

$0,2 \mathrm{~g}$ Blattmaterial wird in $\mathrm{N}_{2}$ aufgemörsert und in ein 1,5 ml- Reagiergefäß überführt. $1,5 \mathrm{ml}$ Trizolpuffer werden hinzugeben und das Gefäß wird auf dem Vortexer fixiert und 5 Minuten geschüttelt. Dann werden $300 \mu \mathrm{l}$ Chloroform hinzugeben und erneut 5 Minuten geschüttelt. Anschließend wird 30 Minuten bei $4^{\circ} \mathrm{C} / 10.000 \mathrm{~g}$ abzentrifugiert. Der Überstand wird in ein neues Gefäß überführt, es werden $420 \mu \mathrm{l}$ Fällungspuffer und $420 \mu \mathrm{l}$ Isopropanol zugegeben. Nach mehrmaligem Invertieren wird 10 Minuten bei RT inkubiert und 15 Minuten bei $4^{\circ} \mathrm{C} / 10.000 \mathrm{~g}$ abzentrifugiert. Der Überstand wird abgenommen, das Pellet mit $70 \%$ EtOH gewaschen, 10 Minuten bei $4^{\circ} \mathrm{C} / 10.000 \mathrm{~g}$ abzentrifugiert, $30 \mathrm{sec}$ bei $95^{\circ} \mathrm{C}$ luftgetrocknet und in $50 \mu \mathrm{l} \mathrm{H}_{2} \mathrm{O}$ gelöst $(10 \mathrm{~min}$ Schütteln bei $\left.65^{\circ} \mathrm{C}\right)$.

Für Microarray-Analysen wurde so isolierte RNA noch über eine Säule des "Invisorb Spin Plant RNA Mini Kit" nach Angaben des Herstellerprotokolls aufgereinigt.

\subsubsection{Isolierung von genomischer DNA}

Zur Analyse der T-DNA-Insertionsmutanten von $A$. thaliana wurde genomische DNA aus Blättern isoliert. Es wurde eine modifizierte Cetyltrimethylammoniumbromid(CTAB-) Methode nach Rogers und Bendich (1988) angewandt.

Ein kleines Blatt wurde in einem Eppendorf-Reaktionsgefäß mit flüssigem Stickstoff gemösert. $200 \mu \mathrm{l}$ CTAB-Lösung wurden zugefügt und für $15 \mathrm{~min}$ bei $65^{\circ} \mathrm{C}$ inkubiert. Dann wurde das gleiche Volumen Chloroform:Isoamylalkohol (24:1) zugegeben und in einer Eppendorfzentrifuge $3 \mathrm{~min}$ bei $7.500 \mathrm{~g}$ zentrifugiert. Die obere wässrige Phase wurde in ein neues Reaktionsgefäß überführt. Ein gleiches Volumen Isopropanol wurde zugegeben und durch Invertieren des Gefäßes gemischt. Nach einer Inkubation von $30 \mathrm{~min}$ bei $-20^{\circ} \mathrm{C}$, um die DNA zu fällen, wurde die Probe bei $20.000 \mathrm{~g}$ für $10 \mathrm{~min}$ bei $4^{\circ} \mathrm{C}$ zentrifugiert. Der Überstand wurde abgenommen und 
das Pellet mit 70\% Ethanol gewaschen. Der Ethanol wurde entfernt, das Pellet kurz getrocknet und in $50 \mu \mathrm{l}$ Wasser resuspendiert. Hiervon wurden $2 \mu \mathrm{l}$ für einen PCRAnsatz eingesetzt.

\subsubsection{Isolierung von Plasmid-DNA aus E. coli}

$5 \mathrm{ml}$ LB-Medium mit dem geeigneten Antibiotikum wurden mit einer positiven Kolonie, die durch Kolonie-PCR identifiziert worden war, angeimpft und über Nacht bei $37^{\circ} \mathrm{C}$ im Schüttler inkubiert. Zur Isolierung der DNA wurde das Nucleospin Plasmid Miniprep Kit verwendet. Die Plasmid-DNA wurde von der Säule mit $50 \mu l$ Wasser eluiert.

\subsubsection{Bestimmung der Nukleinsäurekonzentration}

$2 \mu \mathrm{l}$ Nukleinsäurelösung wurden im NanoVue laut Herstellerangaben gemessen. Der Quotient der Extinktionswerte (260/280 nm) stellt ein Maß für die Verunreinigung der Lösung mit UV-absorbierenden Stoffen (Proteinen) dar. Idealerweise sollte der Wert zwischen 1,8 und 2,0 liegen. Die Nukleinsäurekonzentrationen wurden vom Photometer berechnet. Die Formeln dazu lauten:

$$
\begin{aligned}
& \text { RNA }[\mu \mathrm{g} / \mathrm{ml}]=E_{260}{ }^{*} 42{ }^{*} V_{\text {Küvette }}{ }^{*} V_{\text {Aliquot }}{ }^{-1} \\
& \text { DNA }[\mu \mathrm{g} / \mathrm{ml}]=E_{260}{ }^{*} 50{ }^{*} V_{\text {Küvette }}{ }^{*} V_{\text {Aliquot }}{ }^{-1}
\end{aligned}
$$

Alternativ wurden die Konzentrationen von DNA und RNA auch anhand bekannter Mengen Gesamt-DNA und -RNA als Standard bei der TAEAgarosegelelektrophorese abgeschätzt.

\subsection{DNA-Amplifikation durch Polymerase-Kettenreaktion (PCR)}

\subsubsection{Synthese von cDNA}

Die reverse Transkription (RT) von mRNA-Vorlagen in cDNA („copy DNA“) Kopien ermöglicht es, indirekt RNA als Ausgangspunkt einer PCR zu verwenden (= RTPCR) und so bestimmte mRNA-Spezies spezifisch nachzuweisen oder die transkribierte Sequenz eines Gens frei von Introns zu erhalten. Ein Gemisch aus „random Nonamer"-Primer (neun zufällige Basen) und einem an das PolyA-Ende von eukaryotischen mRNA bindender $\mathrm{dT}_{20}$-Primer diente dabei als unspezifische Primer für die Reverse Transkriptase.

Zuerst wurde ein DNase-Verdau durchgeführt, um evtl. mit isolierte genomische DNA zu entfernen: $1 \mu \mathrm{g}$ RNA wurden mit $1 \mu \mathrm{l}$ DNase-Puffer, $1 \mu \mathrm{l}$ Dnasel und 0,25 $\mu \mathrm{l}$ RNase-Inhibitor gemischt, mit Wasser auf $10 \mu$ laufgefüllt und 30 min bei $37^{\circ} \mathrm{C}$ inkubiert. Danach wurde $1 \mu \mathrm{ll} 25 \mathrm{mM}$ EDTA zugegeben und $10 \mathrm{~min}$ bei $65^{\circ} \mathrm{C}$ inkubiert, zur Enzyminaktivierung.

Für die cDNA-Synthese wurden noch $1 \mu \mathrm{l}$ random Nonamer Primer und 0,2 $\mu$ l oligo dT-Primer zugegeben und $10 \mathrm{~min}$ bei $70^{\circ} \mathrm{C}$ inkubiert, danach die Gefäße sofort auf Eis gestellt. Als Mastermix wurden zugegeben: $2 \mu \mathrm{dNTP}, 4 \mu \mathrm{RT}$-Puffer, $1 \mu \mathrm{l}$ RNase-Inhibitor und $10 \mathrm{~min}$ bei $37^{\circ} \mathrm{C}$ inkubiert. Als letztes erfolgte die Zugabe von 1 ul 1:4 verdünnter M-MuLV (Moloney Murine Leukemia Virus) $\mathrm{H}$ minus Reverse Transkriptase und Inkubation für $70 \mathrm{~min}$ bei $42^{\circ} \mathrm{C}$. Bei $70^{\circ} \mathrm{C}$ wurde in $10 \mathrm{~min}$ das Enzym inaktiviert. 


\subsubsection{Ableitung von Oligonukleotid-Primern}

Für die Amplifikation spezifischer DNA-Sequenzen durch PCR sind kurze, einzelsträngige DNA-Sequenzen (Primer) nötig, die sich mit einem komplementären Strang der DNA paaren und ein freies 3'OH-Ende zur Verfügung stellen, an dem die DNA-Polymerase mit der DNA-Synthese beginnen kann. Durch Knüpfung einer Phosphodiesterbindung zwischen $\mathrm{OH}$-Gruppe des Primers und einem freien Nukleotid erfolgt die Kettenverlängerung in 3'-Richtung. Bei der PolymeraseKettenreaktion sind zwei Primer, ein 5'- und ein 3'-Primer, erforderlich. Durch die Auswahl der Primer lassen sich Anfang und Ende des amplifizierten DNA-Stranges definieren. Die abgeleiteten Primer waren zwischen 18 und 30 Nukleotiden lang, hatten einen GC-Gehalt von 40-60\% und enthielten in den letzten fünf Nukleotiden am 3'-Ende mindestens drei A oder T, endeten aber nicht auf T. Aus der abgeleiteten Sequenz ergab sich $\mathrm{T}_{\mathrm{m}}$, die Schmelztemperatur, bei der $50 \%$ der Primer an der komplementären DNA-Sequenz angelagert bzw. abgelöst sind. Der $\mathrm{T}_{\mathrm{m}}$-Wert der Primer ist ein wichtiges Kriterium für die Wahl der Annealing-Temperatur im PCRProgramm, um eine falsche Anlagerung der Primer und Amplifikation falscher Sequenzen zu begrenzen. $T_{m}$ sollte für ein Primer-Paar dicht beieinanderliegen und wurde nach folgender Formel berechnet:

$\mathrm{T}_{\mathrm{m}}\left[{ }^{\circ} \mathrm{C}\right]=69,3+0,41$ * $[\mathrm{GC}-$ Gehalt in \%] - 650/Nukleotidanzahl

Die Primer sollten nicht miteinander oder mit sich selbst komplementär sein oder Sekundärstrukturen bilden. Das wurde mit dem Programm VectorNTI überprüft.

\subsubsection{PCR}

Gene wurden mit Hilfe der Polymerase-Kettenreaktion (PCR, Mullis und Faloona, 1987) amplifiziert. Dabei handelt es sich um eine Methode, bei der gezielt spezifische DNA-Sequenzen mehr als $10^{6}$-fach vermehrt werden. Die DNA wird zyklisch immer wieder thermisch denaturiert und mit Primern hybridisiert, die von hitzestabiler DNAPolymerase verlängert werden. Die Taq DNA Polymerase wurde zur. Sie ist die billigste DNA Polymerase und amplifiziert schneller als die „proofreading“ (Korrekturlese) DNA Polymerasen, die normalerweise zur Klonierung verwendet werden. Diese haben eine 3' $\rightarrow 5$ ' Exonuklease Korrekturlese-Funktion und dadurch eine zehnfach höhere Genauigkeit (Fehlerrate etwa $2 \times 10^{-3}$ ) als Taq Polymerase. Von den Korrekturlese-Polymerasen wurden im Laufe der Zeit drei verschiedene benutzt, die alle „blunt ended“ PCR-Produkte (mit stumpfen Enden) erstellen: PfuUltra ${ }^{\mathrm{TM}}$ High-Fidelity DNA Polymerase (Fa. Stratagene), SAWADY Pwo-DNAPolymerase (Fa. Peqlab) und Pfu DNA Polymerase (Fa. Fermentas). Taq Polymerase stammt aus Thermophilus aquaticus, Pfu aus Pyrococcus furiosus und Pwo aus Pyrococcus woesei.

Standardansätze bestanden aus folgenden Komponenten:

10x Reaktionspuffer
(zum Enzym passend)
$50 \mathrm{mM} \mathrm{MgCl}$
$10 \mathrm{mM} \mathrm{dNTP}$
$10 \mu \mathrm{M}$ 5'-Primer
$10 \mu \mathrm{M}$ 3'-Primer
DNA-Matrize
DNA Polymerase
dd $\mathrm{H}_{2} \mathrm{O}$

10x Reaktionspuffer

$50 \mathrm{mM} \mathrm{MgCl}_{2}$

$10 \mathrm{mM}$ dNTP

$10 \mu \mathrm{M}$ 5'-Primer

DNA-Matrize dd $\mathrm{H}_{2} \mathrm{O}$
Taq Polymerase Korrekturlese-Polymerase

$2,5 \mu \mathrm{l} \quad 5 \mu \mathrm{l}$

$1 \mu \mathrm{l}$

$0,5 \mu \mathrm{l}$

$0,5 \mu \mathrm{l}$

$0,5 \mu \mathrm{l}$

$2 \mu \mathrm{l}$

$0,25 \mu l(1,25 \mathrm{U})$ ad $25 \mu \mathrm{l}$
$1 \mu \mathrm{l}$
$1 \mu \mathrm{l}$
$1 \mu \mathrm{l}$
$2 \mu \mathrm{l}$

$1 \mu \mathrm{l}(1 \mathrm{U})$

ad $50 \mu \mathrm{l}$ 
Ein Standardprogramm war folgendermaßen:

\begin{tabular}{|l|l|l|}
\hline Zyklen & Temperatur & Dauer \\
\hline 1 & $95^{\circ} \mathrm{C}$ & $2 \mathrm{~min}$ \\
\hline \multirow{3}{*}{35} & $95^{\circ} \mathrm{C}$ & $30 \mathrm{sec}$ \\
\cline { 2 - 3 } & Annealing-Temperatur & $30 \mathrm{sec}$ \\
\cline { 2 - 3 } & $72^{\circ} \mathrm{C}$ & $1: 30 \mathrm{~min}$ \\
\hline 1 & $72^{\circ} \mathrm{C}$ & $10 \mathrm{~min}$ \\
\hline
\end{tabular}

Die Annealing-Temperatur lag $5^{\circ} \mathrm{C}$ niedriger als die Schmelztemperatur, die spezifisch für jedes Primerpaar war. Von beiden Primern wurde immer die niedrigere Temperatur gewählt. Durch TAE-Agarose-Gelelektrophorese wurden die Amplifikationsprodukte analysiert.

\subsubsection{Quantitative realtime PCR}

Es wurde das iCycler System der Fa. BioRad zur Amplifizierung und Quantifizierung von cDNA verwendet. Ein PCR-Ansatz bestand aus $1 \times \mathrm{NH}_{4}$-Reaktionspuffer, $2 \mathrm{mM}$ $\mathrm{MgCl}_{2}, 100 \mu \mathrm{M}$ dNTPs, 0,4 $\mu \mathrm{M}$ Primer, 0,25 u BIOTaq DNA, $10 \mathrm{nM}$ Fluoresceine, 100.000 fach verdünnte SYBR Green I Lösung, $1 \mu \mathrm{l}$ von 1:10 verdünnter cDNA als Template und $\mathrm{H}_{2} \mathrm{O}$ bis zu einem Volumen von $25 \mu \mathrm{l}$. Das PCR-Programm lief folgendermaßen ab: 6 min $95^{\circ} \mathrm{C}, 40$ Zyklen: $20 \mathrm{sec}$ bei $95^{\circ} \mathrm{C}, 20 \mathrm{sec}$ bei $55^{\circ} \mathrm{C}$ und 40 sec bei $72^{\circ} \mathrm{C}$.

\subsection{Klonierungsmethoden}

\subsubsection{TAE-Agarose-Gelelektrophorese}

Um den Erfolg einer PCR zu überprüfen, wurden die PCR-Produkte durch eine TAEAgarose-Gelelektrophorese aufgetrennt. Es wurden 1\%ige (w/v) TAE-Agarosegele gegossen mit der gewünschten Anzahl Taschen. Vor dem Probenauftrag wurde den Proben jeweils $1 / 6$ Volumen Probenpuffer zugesetzt. Die Gele wurden bei 140 Volt in $1 \mathrm{x}$ TAE-Puffer für $40 \mathrm{~min}$ laufen gelassen und dann für $10 \mathrm{~min}$ in ein Ethidiumbromidbad gelegt (50 $\mu \mathrm{l} \%$ Ethidiumbromid in Wasser verdünnt). Die DNABanden konnten dann durch UV-Licht sichtbar gemacht und fotografiert werden.

\subsubsection{Isolierung von DNA-Fragmenten aus Agarosegelen}

Vor der Ligation eines bestimmten DNA-Fragments in ein Plasmid musste dieses DNA-Stück von den Primern und anderen im Versuchsansatz vorhandenen DNAFragmenten getrennt werden. Dies ist zum einen bei dem Produkt einer PCR erforderlich, da dort oft auch unerwünschte Amplifikationsprodukte entstehen, zum anderen bei einem Restriktionsverdau, bei dem i.d.R. mindestens zwei DNAFragmente entstehen. Die Trennung des gewünschten DNA-Fragments von den unerwünschten erfolgte durch eine präparative TAE-Agarose-Gelelektrophorese. Die Auftrennung erfolgte bei einer Spannung von 140 Volt. Die gesuchte DNA-Bande wurde dann unter UV-Licht aus dem Gel herausgeschnitten, wobei sie dem UV-Licht möglichst kurz ausgesetzt werden sollte, um UV-induzierte Mutationen zu vermeiden. Die DNA wurde von der Agarose und dem gebundenen Ethidiumbromid durch den NucleoSpin Gel Extraction Kit der Firma Macherey-Nagel eluiert. Dieses Kit beruht auf der selektiven Bindung von Nukleinsäuren an Kieselgel-Partikel bei hohen Salzkonzentrationen. Im letzten Schritt der Elution wurde die DNA in $30 \mu \mathrm{l} \mathrm{H}_{2} \mathrm{O}$ 
aufgenommen. Um den Erfolg der Elution zu überprüfen, wurde wiederum eine TAEAgarose-Gelektrophorese mit $5 \mu \mathrm{l}$ des Eluats durchgeführt.

\subsubsection{Ligation}

Bei der Ligation wird ein eluiertes DNA-Fragment in einen Vektor ligiert, wenn sie die gleichen überhängenden Enden haben. Das ist der Fall, wenn sie mit dem gleichen Restriktionsenzym geschnitten wurden, oder bei der T/A-Klonierung. Für die Ligation ist das molare Verhältnis von DNA-Fragment (Insert) zu Vektor wichtig, es muss immer mehr Insert als Vektor vorliegen, z.B. im Verhältnis 3:1. Berechnung der einzusetzenden Insert-Menge:

$n g$ Insert $=\frac{n g \text { Vektor } * k b \text { Größe des Inserts }}{k b \text { Größe des Vektors }} *$ molares Verhältnis $\frac{\text { Insert }}{\text { Vektor }}$

Für einen Standardligationsansatz wurde die errechnete Menge Insert mit 0,5 $\mu$ l Vektor $(50 \mathrm{ng} / \mu \mathrm{l}), 1 \mu \mathrm{l} 10 \mathrm{x}$ T4-DNA-Ligase-Puffer und $1 \mu \mathrm{l}$ T4-DNA-Ligase mit Wasser auf $10 \mu \mathrm{l}$ aufgefüllt, gemischt und über Nacht bei $16^{\circ} \mathrm{C}$ inkubiert.

\subsubsection{PCR-Produkte in pSK-T}

PCR-Produkte wurden zuerst in den Vektor pSK-T ligiert, bei dem die sogenannte T/A-Klonierung genutzt werden konnte. Mit Taq-DNA-Polymerase amplifizierte PCRProdukte haben an ihren 3'-Enden ein überhängendes A. Der Vektor besitzt korrespondierend dazu ein überhängendes $T$ an seinen 3'-Enden, so dass solche PCR-Produkte ohne weitere Modifizierung mit der Ligase-Reaktion eingefügt werden konnten. PCR-Produkte, die mit Korrekturlese- DNA-Polymerasen amplifiziert worden sind, haben keine solchen Überhänge und mussten diese erst durch „A-tailing“ erhalten.

„A-tailing“ Methode:

1-7 $\mu$ I PCR-Produkt

$1 \mu \mathrm{l} 10 x$ Reaktionspuffer mit $\mathrm{MgCl}_{2}$

dATP bis zu einer Endkonzentration von $0,2 \mathrm{mM}$

0,5 $\mu \mathrm{l}$ Taq-DNA-Polymerase

mit $\mathrm{ddH}_{2} \mathrm{O}$ auf $10 \mu \mathrm{l}$ auffüllen und alles mischen. Inkubation bei $70^{\circ} \mathrm{C}$ für $15-30 \mathrm{~min}$.

Davon wurden 2-5 $\mu$ in einer Ligationsreaktion eingesetzt.

\subsubsection{Gateway-Rekombination}

Bei Gateway-Klonierungen werden DNA-Segmente über ortsspezifische Rekombination zwischen verschiedenen Plasmiden transferiert. Das System basiert auf der ortsspezifischen Integration des Phagen Lambda in das Genom von E.coli. Um für die Rekombination verfügbar zu sein, müssen Erkennungssequenzen an das gewünschte DNA-Segment angefügt werden. Dies geschieht, indem man das gewünschte DNA Stück mit Primern amplifiziert, die an den 5'-Enden die Erkennungssequenzen enthalten. Bei Gateway-Klonierungen werden zwei Reaktionen verwendet. Das DNA Segment kann aus dem PCR-Produkt in der BPReaktion in einen Eingangs-Vektor rekombiniert werden. Von dort aus kann es in der LR-Reaktion in verschiedene Ziel- Vektoren transferiert werden. Außerdem besteht die Möglichkeit, das DNA-Segment aus dem Ziel-Vektor in einer weiteren BPReaktion in einen anderen Eingangs-Vektor zu transferieren. 


\subsection{Aufreinigung von attB-PCR Produkten}

Die Aufreinigung des PCR-Produktes ist notwendig, um Primer-Dimere zu entfernen, die in den Eingangs-Vektor rekombiniert werden könnten.
1) zu einem $50 \mu \mathrm{l} \mathrm{PCR}$-Ansatz $150 \mu \mathrm{l}$ TE zugeben
2) $100 \mu \mathrm{l} 30 \%$ PEG $8000 / 30$ mM MgCl 2 zugeben
3) gründlich vortexen und sofort 15 Minuten bei 10.000xg und RT abzentrifugieren
4) Pellet in TE aufnehmen

\subsection{BP-Reaktion}

Die BP-Reaktion dient dazu, den DNA-Abschnitt zwischen den attB-sites in einen Donor-Vektor mit attP-sites zu transferieren. Dabei entsteht ein Eingangsplasmid mit attL-sites.

1) $50-200 \mathrm{ng}$ attB-PCR-Produkt (oder linearisierter Ziel-Vektor) in ein $1,5 \mathrm{ml}$ Eppendorfgefäß geben

2) 150 ng Eingangs-Vektor zugeben

3) $2 \mu \mathrm{l}$ 5x BP Reaktions-Puffer zugeben

4) mit TE auf $9 \mu$ auffüllen

5) $1 \mu \mathrm{l} \mathrm{BP}$ ClONASE Enzym Mix zugeben

6) kurz vortexen und ü.N. bei $25^{\circ} \mathrm{C}$ inkubieren

7) $1 \mu \mathrm{l}$ Proteinase $\mathrm{K}$ zugeben und 10 Minuten bei $37^{\circ} \mathrm{C}$ inkubieren

$5 \mu \mathrm{l}$ des Ansatzes werden in $100 \mu \mathrm{l}$ chemisch kompetente DH5a-Zellen transformiert.

\subsection{LR-Reaktion}

Die LR-Reaktion dient dazu, die DNA zwischen den attL-sites eines Eingangsplasmids in einen Ziel-Vektor mit attR-sites zu transferieren. Sie läuft am effizientesten $a b$, wenn beide Vektoren linearisiert werden.

1) 100-200 ng Eingangs-Vektor in ein 1,5 ml Eppendorfgefäß geben

2) $200 \mathrm{ng}$ Ziel-Vektor zugeben

3) 2 l 5x LR Reaktions-Puffer zugeben

4) mit TE auf $9 \mu$ auffüllen

5) $1 \mu \mathrm{l}$ LR ClONASE Enzym Mix zugeben

6) kurz vortexen und ü.N. bei $25^{\circ} \mathrm{C}$ inkubieren

7) $1 \mu \mathrm{l}$ Proteinase $\mathrm{K}$ zugeben und 10 Minuten bei $37^{\circ} \mathrm{C}$ inkubieren

Anschließend werden $5 \mu \mathrm{l}$ des Ansatzes in $100 \mu$ l chemisch kompetente DH5aZellen transformiert.

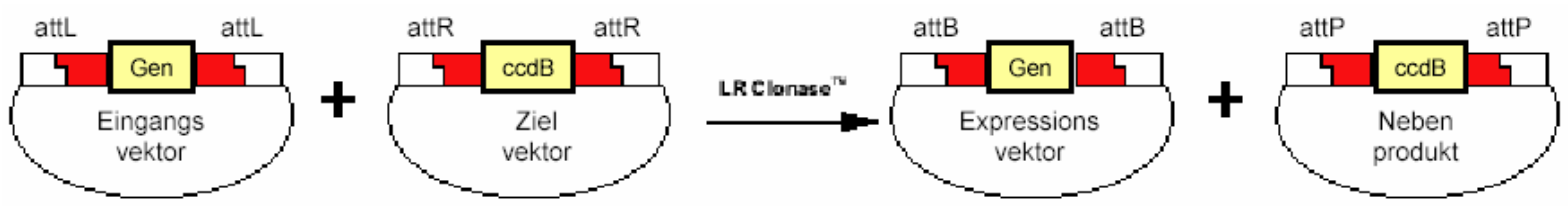

Abbildung 7: Schema der LR Clonase ${ }^{\mathrm{TM}}$ Reaktion, bei der "Gen" eine cDNA in einen Expressionsvektor transferiert wird, wobei durch die Kombination von Anitbiotikazusatz und ccdB-Gen nur das gewünschte Plasmid Kolonien bildet. 


\subsubsection{Transformation von E. coli}

\subsubsection{Präparation kompetenter E. coli Zellen}

Für die Präparation kompetenter E. coli Zellen wurde die Methode von Inoue et al. (1990) modifiziert. Diese Methode erzeugt kompetente Zellen mit hoher Transformationseffizienz, die bei $-70^{\circ} \mathrm{C}$ lange Zeit gelagert werden können.

$100 \mathrm{ml}$ LB-Medium wurden mit einigen Kolonien E. coli Zellen angeimpft und im Schüttler für $2 \mathrm{~h}$ bei $37^{\circ} \mathrm{C}$, dann bei $16^{\circ} \mathrm{C}$ bis zu einer $\mathrm{OD}_{600 \mathrm{~nm}}$ von 0,4 wachsen gelassen. Dann wurden sie für 10 min auf Eis inkubiert und für $10 \mathrm{~min}$ bei $4.000 \mathrm{Upm}$ und $4^{\circ} \mathrm{C}$ in einer Eppendorfzentrifuge sedimentiert. Nach der Resuspension in $30 \mathrm{ml}$ eiskaltem TB-Puffer wurden sie wieder für $10 \mathrm{~min}$ auf Eis inkubiert und sedimentiert. Danach erfolgte eine Resuspension in $8 \mathrm{ml}$ eiskaltem TB-Puffer. Es wurden $560 \mu \mathrm{l}$ DMSO zugegeben und 10 min auf Eis inkubiert. Danach wurden die Zellen zu $200 \mu \mathrm{l}$ aliquotiert und in flüssigem Stickstoff eingefroren.

\subsubsection{Transformation kompetenter E. coli Zellen}

Nachdem $200 \mu$ l kompetente Zellen langsam auf Eis aufgetaut worden waren, wurde der Ligationsansatz zugegeben, vorsichtig gemischt und 30 min auf Eis inkubiert. Es folgte ein Hitzeschock für $45 \mathrm{sec}$ bei $42^{\circ} \mathrm{C}$. Der Ansatz wurde für 5 min auf Eis gekühlt und $1 \mathrm{ml}$ SOC-Medium zugegeben. Danach wurden die Bakterien für $1 \mathrm{~h}$ unter Schütteln bei $37^{\circ} \mathrm{C}$ inkubiert.

Die transformierten Zellen wurden auf LB-Agar-Platten mit geeignetem Antibiotikum ausgestrichen und über Nacht bei $37^{\circ} \mathrm{C}$ inkubiert. Wenn pSK-T benutzt wurde, wurden vorher $40 \mu \mathrm{l} 100 \mathrm{mM}$ IPTG und $40 \mu \mathrm{l} 2 \%$ x-Gal pro Platte ausgestrichen. Diese Zusätze sind für die Blau/Weiß-Selektion notwendig, bei der nur Bakterien mit einem Vektor mit Insert weiße Kolonien bilden, da die kodierende Region für das $\alpha$ Peptid der $\beta$-Galaktosidase durch die Insertion unterbrochen ist. Bakterien mit einem Vektor ohne Insert bilden blaue Kolonien, da ihr lacZ-Gen ( $=\beta$-Galaktosidase) nicht unterbrochen ist. Die $\beta$-Galaktosidase bewirkt die Umsetzung des farblosen Stoffes $x$-Gal zu einem blauen Derivat.

\subsubsection{Einfügen von Punktmutationen}

Zur spezifischen Mutagenese eines Gens wurden mutagenisierende Primer verwendet, die spezifische Punktmutationen in die Gensequenz einfügen. Verwendet wurde hierfür das Protokoll QuikChange ${ }^{\circledR}$ Site-Directed Mutagenesis Kit des Herstellers Stratagene.

\subsubsection{Kolonie-PCR}

Um positive Kolonien zu identifizieren, d.h. solche mit dem gewünschten Insert, wurde eine Kolonie-PCR durchgeführt. Dafür wurde ein Master-Mix mit allen Bestandteilen für eine PCR-Reaktion außer der DNA-Matrize auf Eis zusammenpipettiert und dann in PCR-Reaktionsgefäße verteilt. Als Primer wurden entweder die genspezifischen Primer verwendet, oder, wenn die Richtung des Inserts überprüft werden sollte, der "forward" Primer des Vektors und der genspezifische „reverse" Primer. Mit sterilen Zahnstochern wurden ca. 10 Kolonien gepickt, jeweils in ein Reaktionsgefäß getaucht und auf einer neuen LB-Agarplatte ausgestrichen, die über Nacht bei $37^{\circ} \mathrm{C}$ inkubiert wurde. Das verwendete PCR-Programm begann mit 5 min bei $95^{\circ} \mathrm{C}$ und bestand aus 35 Zyklen. Bei positiven Kolonien entstand eine 
Bande in der Größe des Gens. Von bis zu drei positiven Kolonien wurde das Plasmid isoliert und weiter analysiert.

\subsubsection{Restriktionsverdau}

Für Klonierungen und zur Überprüfung von positiven Kolonien wurde ein Restriktionsverdau durchgeführt. Es konnten z.B. Restriktionsenzyme gewählt werden, die im Vektor vor oder hinter der Insertionsstelle schneiden und solche, die im Gen schneiden. Die erhaltenen Banden konnten mit der erwarteten Größe verglichen werden.

Für einen Restriktionsansatz wurden 2 - 8,5 $\mu$ l Plasmid-DNA (je nach Konzentration, ca. $1 \mu \mathrm{g}$ DNA) mit $1 \mu \mathrm{l}$ 10x Reaktionspuffer und 0,5 $\mu$ l Restriktionsenzym (5 U) gemischt und gegebenenfalls mit Wasser auf $10 \mu \mathrm{l}$ aufgefüllt. Soweit nicht anders angegeben, wurde der Ansatz $1 \mathrm{~h}$ bei $37^{\circ} \mathrm{C}$ inkubiert und dann auf ein TAE-AgaroseGel aufgetragen.

DNA konnte auch gleichzeitig mit zwei Restriktionsenzymen verdaut werden (Doppelverdau), sofern es einen Puffer gab, in dem beide Enzyme mehr als 50\% Aktivität aufwiesen. Welcher Puffer der beste war, konnte in einer Tabelle von Fermentas überprüft werden. Der Ansatz, der beide Restriktionsenzyme, Puffer und DNA enthielt, sollte ein Gesamtvolumen von $20 \mu \mathrm{l}$ haben, um die Glycerin Konzentration gering zu halten.

\subsubsection{DNA-Sequenzierung}

Die DNA-Sequenzierung erfolgte nach Sanger et al. (1977). Dazu wurde ein Kit benutzt, der mit dRhodamin markierte Didesoxynukleotide enthielt („ABI PRISM BigDye Terminator Cycle Sequencing Ready Reaction Kit"). Die verschiedenen markierten ddNTPs haben Absorptions- und Emissionsspektren von 450-650 nm. Folgender Ansatz wurde für die Kettenverlängerungsreaktion verwendet:

$1 \mu$ Terminator Ready Reaction Mix

$1,5 \mu \mathrm{l}$ T-Puffer

150-300 ng Plasmid-DNA

5 pmol Sequenzierungs-Primer

ad $10 \mu \mathrm{l} \quad \mathrm{H}_{2} \mathrm{O}$

Als Sequenzierungs-Primer dienten Abschnitte, die auf dem Vektor in der Nähe der Insertionsstelle liegen.

Die Kettenverlängerung erfolgte unter folgenden Bedingungen:

\begin{tabular}{|l|l|l|}
\hline Zyklen & Temperatur & Dauer \\
\hline 1 & $95^{\circ} \mathrm{C}$ & $1 \mathrm{~min}$ \\
\hline \multirow{3}{*}{30} & $95^{\circ} \mathrm{C}$ & $10 \mathrm{sec}$ \\
\cline { 2 - 3 } & $50^{\circ} \mathrm{C}$ & $5 \mathrm{sec}$ \\
\cline { 2 - 3 } & $60^{\circ} \mathrm{C}$ & $3 \mathrm{~min}$ \\
\hline
\end{tabular}

Nach dieser Reaktion mussten die nicht eingebauten ddNTPs durch eine DNAFällung entfernt werden. Dazu wurde der PCR-Ansatz mit 9,5 $\mu$ l Wasser aufgefüllt und mit 30,5 $\mu \mathrm{l}$ abs. Ethanol versetzt und durch Invertieren gemischt. Die Probe wurde für 30-60 min bei Raumtemperatur inkubiert und nach einer 30-minütigen Zentrifugation bei 13.000 Upm der Überstand entfernt. Das Pellet wurde zum Waschen in $125 \mu \mathrm{l} 70 \%$ Ethanol aufgenommen. Nach einer weiteren Zentrifugation wurde der Überstand abgenommen und das Pellet für $30 \mathrm{sec}$ bei $65^{\circ} \mathrm{C}$ getrocknet. 
Anschließend wurde das Pellet in $10 \mu \mathrm{HiDi}$ gelöst. Die Probe konnte nun im ABI Prism 3100 Genetic Analyzer sequenziert werden.

\subsection{Transformation von Agrobakterien und Hefe}

\subsubsection{Herstellung kompetenter Agrobakterien}

$5 \mathrm{ml}$ einer Agrobakterienflüssigkultur werden abzentrifugiert (5 min, $5000 \mathrm{rpm}$, RT) und dreimal durch Resuspendieren und erneutes Abzentrifugieren in sterilem Wasser gewaschen. Das Pellet wird in $500 \mu$ l sterilem Wasser aufgenommen und in $100 \mu \mathrm{l}$ Aliquots in flüssigem $\mathrm{N}_{2}$ eingefroren.

\subsubsection{Transformation von Agrobacterium tumefaciens}

Durch Erzeugen kurzer Spannungspulse wird die Membran kompetenter Bakterienzellen permeabilisiert. Dadurch wird die Aufnahme von freier DNA aus dem Medium in die Zelle ermöglicht. Nach der Zugabe der zu transformierenden DNA zu den kompetenten Zellen wird der Transformationsansatz in sterile Elektroporationsküvetten (Elektrodenabstand: $2 \mathrm{~mm}$ ) überführt. Die Elektroporation

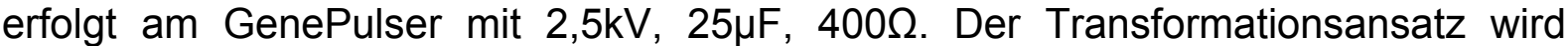
anschließend in ein Eppendorfgefäß überführt und mit $1 \mathrm{ml}$ LB-Medium aufgefüllt. Die Regeneration der Agrobakterien erfolgte für 2 Stunden bei $28^{\circ} \mathrm{C}$, danach werden sie auf YEB-Selektionsmedium ausplattiert.

\subsubsection{Herstellung kompetenter Hefezellen}

Die Kompetenz von Hefezellen zur DNA-Aufnahme läßt sich durch das Alkalimetallion $\mathrm{Li}^{+}$induzieren. Dabei ist desweiteren PEG (Polyethylenglykol) erforderlich.

Wahrscheinlich kommt es zu Spannungsänderungen an der Membran durch Wechselwirkungen zwischen dem negativ geladenen PEG, dem monovalenten lon $\mathrm{Li}^{+}$und der Zelloberfläche. Die höchste Transformationseffizienz läßt sich in Zellen erreichen, die sich in der Mitte der logarithmischen Wachstumsphase befinden (Ito et al., 1983). Durch Zugabe von DMSO lässt sich die Transformationseffizienz deutlich steigern (Hill et al., 1991).

1) animpfen von $20 \mathrm{ml}$ YPD-Medium mit den Hefezellen einer einzelnen Kolonie

2) Wachstum ü.N. bei $30^{\circ} \mathrm{C}$ bis zu einer $\mathrm{OD} 600$ von etwa 1,5

3) ü.N.-Kultur in $100 \mathrm{ml}$ YPD überimpfen, die OD600 sollte etwa 0,2 betragen

4) Hefen bis zu einer OD600 von 0,4-0,6 anziehen

5) Zentrifugation: 5 Minuten / 1000 x g / RT

6) Überstand verwerfen

7) Pellet in $10 \mathrm{ml}$ Lösung A resuspendieren

8) Zentrifugation: 5 Minuten / 1000 x g / RT

10) Überstand verwerfen

11) Pellet in $2 \mathrm{ml}$ Lösung $A$ resuspendieren

12) in $100 \mu \mathrm{l}$ Aliquots abfüllen, langsam bei $-70^{\circ} \mathrm{C}$ einfrieren

\subsubsection{Transformation der kompetenten Hefezellen}

1) $100 \mu \mathrm{l}$ kompetente Hefezellen (gefroren) auf Eis

2) Heringssperma-DNA (HSP) für 20 Minuten abkochen, dann auf Eis 
3) jeweils ca. $0,5 \mu \mathrm{g}$ der jeweiligen Plasmid DNA, $50 \mu \mathrm{g}$ HSP sowie $100 \mu \mathrm{l}$ kompetenter Zellen mischen

4) 5 min bei $37^{\circ} \mathrm{C}$ in den Roller

5) $1 \mathrm{ml}$ Lösung $\mathrm{B}$ dazu geben und vorsichtig mischen

6) Inkubation: 60 Minuten / $30^{\circ} \mathrm{C}$, unter Schütteln (200 rpm)

7) $20 \mathrm{~s}$ bei $13000 \mathrm{rpm}$ bei RT abzentrifugieren und Überstand verwerfen

8) Pellet in $800 \mu l$ Lösung $C$ vorsichtig waschen

9) $20 \mathrm{~s}$ bei $13000 \mathrm{rpm}$ bei RT abzentrifugieren und Überstand verwerfen

10) Pellet in $100 \mu$ l Lösung $C$ vorsichtig resuspendieren

11) Transformationsansatz auf dem entsprechenden SD-Medium ausplattieren

\subsection{Transiente Expression}

\subsubsection{Transiente Expression in Arabidopsis Mesophyll-Protoplasten}

\subsubsection{Protoplastengewinnung}

Von 3-4 Wochen alten Pflanzen werden das 2te oder 3te Blattpaar entnommen und von der Blattunterseite fein eingeritzt. Mit der angeritzten Unterseite werden die Blätter auf die Enzymlösung in eine Petrischale gelegt (10-20 Blätter auf 5-10 ml Enzymlösung) und über Nacht verdaut. Durch leichtes schwenken der Petrischale fallen die Protoplasten in die Enzymlösung. Die Protoplastensuspension wird mit einem Metallnetz $(35-75 \mu \mathrm{m})$ filtriert und bei $100 \mathrm{~g}$ für $1 \mathrm{~min}(\mathrm{RT})$ zentrifugiert. Das Protoplastenpellet wird vorsichtig zweimal durch leichtes Schwenken in $10 \mathrm{ml}$ kalte W5- Lösung resuspendiert und für ca. $5 \mathrm{~h}$ auf Eis inkubiert (max. 24h).

\subsubsection{Protoplasten- PEG- Transformation}

Vor der Transformation erfolgt ein erneutes Resuspendieren der abgesetzten Protoplasten und anschließendes Auszählen der Lebendzellzahl mit Hilfe einer Zählkammer. Nach Zentrifugation bei $100 \mathrm{~g}$ für $1 \mathrm{~min}$ (RT) wird das Pellet in 1-2 ml MMg-Lösung je $10^{5}$ Zellen vorsichtig durch Schwenken resuspendieren. In $2 \mathrm{ml}$ Eppendorfgefäße mit rundem Boden werden $20 \mu \mathrm{l}$ DNA (20-40 $\mu \mathrm{g})$ vorgelegt und $200 \mu l$ Protoplasten vorsichtig mit einer abgeschnittenen blauen Spitze hinzugefügt.

Nach vorsichtigem mischen werden $220 \mu \mathrm{l}$ PEG-Lösung hinzufügt und erneut vorsichtig gemischt. Dann folgte eine Inkubation für 30 Minuten bei RT. Es werden $800 \mu \mathrm{l}$ W5-Lösung hinzugefügt und nach vorsichtigem mischen folgt eine Zentrifugation bei $100 \mathrm{~g}$ für $1 \mathrm{~min}$ (RT). Mit einer blauen Spitze wird vorsichtig $1 \mathrm{ml}$ vom Überstand abgenommen. Nach einer weiteren Zentrifugation bei $100 \mathrm{~g}$ für $1 \mathrm{~min}$ (RT) werden mit einer gelben Spitze vorsichtig ca. $200 \mu \mathrm{l}$ vom Überstand abgenommen. Der restliche Überstand wird nach einer weiteren Zentrifugation bei $100 \mathrm{~g}$ für $1 \mathrm{~min}$ (RT) mit einer Insulin-Spritze abgenommen. $250 \mu \mathrm{l}$ WI- Lösung werden vorsichtig hinzugefügt und dabei wird das Protoplastenpellet resuspendiert. Nach Inkubation für 8-16 h im Klimaschrank werden $200 \mu \mathrm{l}$ des Überstandes mit einer gelben Spitze entfernt. Nach Zentrifugation bei $100 \mathrm{~g}$ für $1 \mathrm{~min}$ (RT) wird der restliche Überstand mit einer Insulinspritze vorsichtig entfernt.

\subsubsection{Messung der ß-Glucuronidase (GUS)-Aktivität}

Die ß-Glucuronidase (GUS) ist das Genprodukt des GUS-Reportergens. Das GUSEnzym ist in der Lage ß-Glucuronide in D-Glucuronsäuren und einem aglyconischen 
Rest zu spalten. Setzt man das künstliche Substrat 4-Methylumbeliferyl-ß-DGlucuronid (4-MUG) ein, so erhält man nach der Hydrolyse das fluoreszierende Molekül Methylumbeliferon (MU). Die Anregung des MU erfolgt bei $360 \mathrm{~nm}$, die Emission bei $460 \mathrm{~nm}$.

Die transformierten Protoplasten werden in $70 \mu \mathrm{l}$ GUS-Extraktionspuffer mit ßMercaptoethanol aufgenommen und 2 Proben werden vereinigt. $100 \mu \mathrm{l} \mathrm{der}$ Proteinsuspension werden in ein Well einer Mikrotiterplatte überführt. $100 \mu \mathrm{l}$ MUGGebrauchslösung werden zugeben. Nach mischen wird 10 min bei $37^{\circ} \mathrm{C}$ inkubiert. $100 \mu \mathrm{l}$ des Reaktionsansatzes in ein neues Well überführen und die Reaktion durch Zugabe von $100 \mu$ l GUS-Stop-Puffer abgestopt $\left(\mathrm{t}_{0}\right)$.

Weitere $100 \mu$ des Reaktionsansatzes werden für $60 \mathrm{~min}$ bei $37^{\circ} \mathrm{C}$ inkubiert, und dann ebenfalls gestoppt $\left(\mathrm{t}_{60}\right)$. Die Quantifizierung der Fluoreszenz erfolgt im CytoFluor II Plate Reader, die GUS-Aktivität wird nach folgender Formel berechnet.

GUS-Aktivität $\left[\mathrm{pmol} /\left(\mathrm{min}^{*} \mathrm{mg}\right)\right]=\Delta \mathrm{F} / 10 /\left(\mathrm{t}^{*} \mathrm{mg}\right)$

$\Delta \mathrm{F}=$ Differenz der Floureszenz $\mathrm{t}_{60}-\mathrm{t}_{0}$

10 Fluoreszenzeinheiten entsprechen 1 pmol MUG-Umsatz.

$\mathrm{t}=60 \mathrm{~min}$

$\mathrm{mg}=$ eingesetzte Gesamtproteinmenge in $\mathrm{mg}$

\subsubsection{Messung der Neuraminidase (NAN)-Aktivität}

Zur Korrektur der Variation der einzelnen Ansätzen in einem Experiment, wurde zusätzlich das Pro 35 s:NAN (Neuraminidase) Plasmid eingeführt (Kirby und Kavanagh, 2002; Ehlert et al., 2006). Die Neuraminidase (NAN) ist das Genprodukt des NAN-Reportergens. NAN ist ein codon-optimiertes nanH aus Clostridium perfringens. Das NAN-Enzym setzt das künstliche Substrat ,2`-(4-Methylumbelliferyl)alpha-D-N-acetylneuraminic acid' (MUN) um und man erhält nach der Hydrolyse das fluoreszierende Molekül Methylumbelliferon (MU). Durch die Stärke der Fluoreszenz in den Ansätzen lässt sich die umgesetzte Menge MU quantifizieren und die Aktivität des NAN-Enzyms bestimmen. Die Anregung des MU erfolgt bei $360 \mathrm{~nm}$, die Emission bei 460 nm (Kirby und Kavanagh, 2002; Ehlert et al., 2006). Die MUNMessung erfolgt parallel zu der MUG-Messung:

$10 \mu \mathrm{l}$ der Proteinsuspension in GUS-Extraktions-Puffer mit ß-Mercaptoethanol werden in ein Well einer Mikrotiterplatte überführt. $10 \mu \mathrm{l}$ MUN-Gebrauchslösung werden zugeben. Nach mischen wird $10 \mathrm{~min}$ bei $37^{\circ} \mathrm{C}$ inkubiert. $3,3 \mu \mathrm{l}$ des Reaktionsansatzes in ein neues Well überführen und die Reaktion durch Zugabe von $200 \mu \mathrm{l}$ NAN-Stop-Puffer abgestoppt $\left(\mathrm{t}_{0}\right)$.

Die restlichen $16,7 \mu \mathrm{l}$ des Reaktionsansatzes werden für $60 \mathrm{~min}$ bei $37^{\circ} \mathrm{C}$ weiter inkubiert, und dann davon ebenfalls 3,3 $\mu$ labgestoppt $\left(t_{60}\right)$. Die Quantifizierung der Fluoreszenz erfolgt im CytoFluor II Plate Reader, die NAN-Aktivität wird entsprechend der GUS-Aktivität berechnet.

Das Verhältnis zwischen den GUS- und NAN-Aktivitäten wird als relative GUS/NANAktivitäten in ,units' angegeben. Die relativen GUS/NAN-Aktivitäten werden wie folgt berechnet:

GUS/NAN-Aktivitäten [units] = GUS-Aktivität/NAN-Aktivität

\subsubsection{Transiente Expression in Nicotiana benthamiana}

\section{,Bimolecular Fluorescence Complementation' (BiFC)}

Eine Bestimmung der Proteininteraktion wurde mit der BiFC Methode durchgeführt (Walter et al., 2004; Hu et al., 2002). Das YFP-Protein (,Yellow Fluorescence Protein') ist in diesem System in ein amino- und ein carboxyterminales Fragment 
geteilt, die einzeln nicht fluoreszieren. Diese Fragmente werden an die zu untersuchenden Proteine fusioniert. Wenn die YFP-Fragmente durch eine ProteinProtein Interaktion der an sie fusionierten Proteine wieder in räumliche Nähe gebracht werden, so wird die Funktion des YFP rekonstituiert. Die Fusionsproteine werden durch Agrobacterium Infiltration in Nicotiana benthamiana Blättern transient exprimiert. Die Expressionsvektoren (pE-SPYNE-GW und pE-SPYCE-GW) wurden mit Hilfe des Gateway ${ }^{\circledR}$ Systems hergestellt. Für die Transformation wurde der $A$. tumefaciens Stamm GV3101 RK verwendet, der auf AMM-Platten (Rif50, Gent25, Kan50, Carb50) kultiviert wurde. Es wurde immer zusätzlich das p19k-Protein ( $A$. tumefaciens p19k) tansformiert. Das p19k-Protein des ,bushy stunt virus' wird zur Unterdrückung des, gene silencing' verwendet. Die Tabakpflanzen sollten 2-3 Wochen alt sein. In älteren Pflanzen sinkt die Transformationsrate.

Die transformierten Agrobakterien-Stämme wurden in YEB (Rif50, Gent 25, Kan50, Carb50) und zusätzlich das $A$. tumefaciens p19k in YEB (Rif50, Gent 25, Kan50) angeimpft und ü.N. bei $29^{\circ} \mathrm{C}$ im Schüttler wachsen gelassen. Bei einer $\mathrm{OD}_{600 \mathrm{~nm}}$ von 0,8 wurden die Kulturen bei $4000 \mathrm{rpm} 15 \mathrm{~min}$ abzentrifugiert und in AS-Medium resuspendiert. Die Agrobakterien und $A$. tumefaciens $\mathrm{p} 19 \mathrm{k}$ wurden im gleichen Verhältnis gemischt $(1: 1: 1)$ und $4 \mathrm{~h}$ bei RT inkubiert. Die wurden Pflanzen in der Inkubationszeit gut gewässert, dann mit einer Spritze (Omnifix(R) 40 Solo, Ref $9161306 \mathrm{~V})$ in die Unterseite der Blätter mit den Lösungen infiltriert. Nach $48 \mathrm{~h}$ Inkubation in der Klimakammer wurde die Expression analysiert.

Bestimmung der Lokalisation von YFP-Fusionsproteinen

YFP-Fusionsproteine werden entsprechend der BiFC Methode transient in $N$. benthamiana exprimiert. Verwendet wurde der Gateway kompatible Expressionsvektor pENSG-YFP.

\subsection{Detektion fluoreszenzmarkierter Proteine}

Die Analysen der in Arabidopsis Mesophyllprotoplasten transient exprimierten YFPProteine wurde mit dem Fluoreszenzmikroskop BX60 der Firma Olympus und mit dem konfokalen Mikroskop TCS SP2 AOBS der Firma Leica durchgeführt. Die Analysen der transienten Expression von BiFC-Konstrukten in $N$. benthamiana wurden ausschließlich mit dem konfokalen Mikroskop mit folgenden Einstellungen durchgeführt:

BX60: Anregungsfilter 460- $495 \mathrm{~nm}$

Detektion YFP: Sperrfilter (U-WIBA) 510- $550 \mathrm{~nm}$

Detektion YFP und Chlorophyllanregung: Sperrfilter (U-NWB) $510 \mathrm{~nm}$

TCS SP2 AOBS:

YFP-Anregung mit einem Argon Laser: $488 \mathrm{~nm}$

Detektion: 510- $580 \mathrm{~nm}$

Chlorophyll-Anregung (Argon-Laser): $514 \mathrm{~nm}$

Detektion: 650-700 nm

\subsection{Infektion mit Pseudomonas syringae}

Zur Infektion mit Pseudomonas werden Pflanzen entweder in die Bakteriensuspension gedippt, wofür mehrere Samen auf Torfquelltöpfe ausgelegt wurden und ca. 3 Wochen alt waren, oder 4-5 Wochen alte Pflanzen werden auf der Blattunterseite durch die Stomata infiltriert. Die Infiltration wurde nur für Pseudomonas mit dem lux-Gen verwendet, wobei die Infektion über Lumineszenz sichtbar gemacht bzw. quantifiziert wurde. 


\subsubsection{Dipping}

Dazu wird eine $10 \mathrm{ml}$ ü.N.-Bakterienkultur mit $10 \mathrm{mM} \mathrm{MgCl} 2$ gewaschen und mit Hilfe des Photometers mit $10 \mathrm{mM} \mathrm{MgCl}_{2}$ auf eine $\mathrm{OD}_{600 \mathrm{~nm}}$ von 0,2 verdünnt. Diese Suspension wird wiederum auf eine $\mathrm{OD}_{600 \mathrm{~nm}}$ von 0,002 verdünnt und mit $0,02 \%$ Silvett versetzt. In $150 \mathrm{ml}$ dieser Lösung werden die Pflanzen $30 \mathrm{sec}-1$ min gedippt, so dass die Blätter ganz untergetaucht sind, dann $1 \mathrm{~h}$ stehen gelassen zum Trocknen und Erholen. Pro Pflanzenlinie werden $3 \times 3$ kleine Blätter abgetrennt und in abgewogene $2 \mathrm{ml}$ Eppendorfgefäße mit $1 \mathrm{ml} 10 \mathrm{mM} \mathrm{MgCl}_{2} / 0,2 \%$ Silvett gelegt. Nach nochmaligem Abwiegen zur Frischgewichtsbestimmung werden die Bakterien 10 min ausgeschüttelt (Eppendorf-Schüttler) und $100 \mu \mathrm{l}$ der Suspension auf KingsBPlatten ausgestrichen. An Tag 0: unverdünnt, Tage 3 und 5: Verdünnungen von $10^{-3}$ und $10^{-4}$ werden ausplattiert und 3 Tage später die Kolonien ausgezählt.

\subsubsection{Infiltration}

Die Bakteriensuspension wird ebenfalls auf eine $\mathrm{OD}_{600 \mathrm{~nm}}$ von 0,002 verdünnt und mit einer Spritze in die Blattunterseite von mehreren Blättern pro Pflanze infiltriert. Nach einer ca. einstündigen Erholungsphase und mind. 10 min im Dunkeln, wird die Lumineszenz aller Pflanzen mit der sensitiven CCD-Kamera fotografiert.

Zur Quantifizierung werden Blattscheiben der infiltrierten Gebiete ausgestanzt $(\varnothing 5$ $\mathrm{mm}$ ) und auf $50 \mu \mathrm{l}$ Wasser in eine weiße Mikrotiterplatte verteilt, so dass die Lumineszenz im Luminometer gemessen werden kann.

\subsubsection{Lumineszenz-Imaging}

Arabidopsis-Pflanzen wurden in die "dark box" des Luciferase-Imaging-Systems platziert. Nach der Fokussierung des Bildes im live-Image-Modus des Kamerasystems wurde eine Schwarzweiß-Aufnahme erstellt und die "dark box“ anschließend verschlossen. Vor dem Aufnahmestart des Lumineszenz-Bildes mussten die Pflanzen acht Minuten zur Abstrahlung der Autophosphoreszenz der photosynthetisch aktiven Pflanzenteile in der Dunkelkammer verbleiben. Danach wurden mit der „high gain“-Einstellung der Kamera je nach Stärke der LuciferaseExpression Bilder mit einer Belichtungszeit von 5-60 Minuten erstellt. Da es bei langen Belichtungszeiten zu Bildstörungen durch Umgebungsstrahlung kommt, wurden die Bilder mit der „spot noise reduction“-Einstellung gemacht. Mit der Kamerasoftware Wasabi ${ }^{\circledR}$ konnten die Schwarzweiß- und Lumineszenz-Aufnahmen anschließend durch Bildüberlagerung vereint werden.

\subsection{Infektion mit Botrytis cinerea}

\subsubsection{Anzucht}

Stücke des Mycels auf einer PDA-Platte (Wachstumsplatte) oder Sporen aus einem Glycerin-Stock $\left(-80^{\circ} \mathrm{C}\right)$ werden auf frische Malz-Extrakt-Platten (Sporulationsplatte) umgesetzt. Das Pilzwachstum findet im Dunkeln bei RT für 7-12 Tage statt. Die Sporulation wurde durch 24stündige UV-Bestrahlung initiiert. Danach wurden die Platten bis zur vollständigen Sporulation noch 4-7 Tage im Dunkeln bei RT inkubiert. Gesammlte Sporen wurden als Glycerin-Stocks (30\%) in $50 \mu \mathrm{l}$-Aliquots bei $-80^{\circ} \mathrm{C}$ eingefroren. 


\subsubsection{Sammeln der Sporen}

Fünf ml PDB-Medium wurden auf eine vollständig sporulierte Platte gegeben. Die Pilzhyphen wurden mit einem Drigalskispatel abgeschabt und das Medium mit den Hyphen und Sporen wurde durch 3 Lagen Mull gefiltert. Die Sporen wurden in einer Thomma-Zählkammer gezählt und mit PDB auf eine Konzentration von $1^{*} 10^{6}$ Sporen/ml verdünnt.

\subsubsection{Infektion}

Die Sporenlösung wurde im Licht bei RT 2-3 h inkubiert. Pflanzen wurden infiziert, indem $5 \mu \mathrm{l}$ der Sporenlösung auf mehrere voll entfaltete Blätter gegeben wurde. Für $24 \mathrm{~h}$ nach der Infektion wurde die Haube über den Pflanzen gelassen, damit der Pilz optimale Wachstumsbedingungen hatte (hohe Luftfeuchtigkeit).

\subsection{Northernblot / Kapillarblot}

Im Northernblot-Verfahren wird die zu analysierende RNA durch eine denaturierende Agarosegelelektrophorese aufgetrennt. Nach Kontrolle des Gellaufs auf dem Transilluminator erfolgt der Transfer der RNA auf eine Nylonmembran mittels Kapillarblot. Durch Hybridisierung des Filters mit radioaktiv markierten einzelsträngigen DNA-Sonden ist es möglich diejenigen RNA-Transkripte durch Autoradiographie sichtbar zu machen, die komplementär zu der eingesetzten Sonde sind.

\subsubsection{Denaturierende Agarosegelelektrophorese von RNA-Molekülen}

Um die elektrophoretische Grössenauftrennung von RNA-Molekülen zu ermöglichen muss die Elektrophorese unter denaturierenden Bedingungen stattfinden, da sonst die Sekundärstrukturen das Laufverhalten beeinflussen. Die Elektrophorese findet in einem Formaldehyd-haltigen Agarosegel (1 \% (w/v) Agarose, 5,5\% (v/v) Formaldehyd in 1 x MEN-Puffer, $200 \mathrm{mM}$ MOPS, $50 \mathrm{mM}$ NaAc, $10 \mathrm{mM}$ EDTA, pH 7,0 mit $\mathrm{NaOH}$ ) statt, wobei 1 x MEN als Laufpuffer dient. Die je 10-20 $\mu \mathrm{g}$ der RNAProben werden auf das gleiche Volumen abgeglichen und mit 2,5 $x$ RNAProbenpuffer versetzt. Die Denaturierung der Proben erfolgt bei $65^{\circ} \mathrm{C}$ für $10 \mathrm{~min}$. Bis zum Auftragen der Proben werden diese auf Eis gehalten. Die Elektrophorese erfolgt bei $120 \mathrm{~V}$ bis die BPB-Bande 2-3 cm vom unteren Gelrand entfernt ist. Die Kontrolle und Dokumentation der RNA erfolgt am UVTransilluminator mit Hilfe der Geldokumentationsanlage.

\subsubsection{Kapillarblot}

Mittels Kapillar-Blot wird die durch eine denaturierende Agarosegelektrophorese aufgetrennte RNA auf eine Nylonmembran transferiert. Dazu werden zwei Lagen Fließpapier mit 10 x SSC äquilibriert und so auf einer ebenen Glasplatte aufgebracht, dass die Enden in ein 10 x SSC-Pufferreservoir tauchen. Das RNA-Gel wird luftblasenfrei mit der Oberseite nach unten auf das Fließpapier gelegt. Die Kanten und Taschen des Gels werden mit Haushaltsfolie abgedeckt. Die Nylonmembran wird luftblasenfrei auf das Gel aufgelegt, mit zwei Lagen Fließpapier und Papiertüchern bedeckt und mit einem Gewicht (ca. $500 \mathrm{~g}$ ) gleichmäßig beschwert. Der Kapillarblot erfolgt für mindestens $14 \mathrm{~h}$. Die RNA wird durch kurze UV- 
Bestrahlung auf dem Transilluminator und durch zweistündige Inkubation bei $80^{\circ} \mathrm{C}$ auf der Filteroberfläche fixiert.

\subsubsection{Herstellen einer radioaktiv markierten DNA-Sonde}

Für die Herstellung radioaktiv markierter Hybridisierungssonden wird ein DNA Fragment nach Restriktionsspaltung oder ein PCR-Produkt aus einem Agarosegel eluiert. Die Markierungsreaktion erfolgt nach der Random-Prime-Labeling-Methode nach (Feinberg und Vogelstein, 1983; Feinberg und Vogelstein, 1984), bei der Hexanukleotide zufälliger Sequenz an die Matrizen-DNA binden: Die gebundenen Hexanukleotide dienen dann als Primer für die Neusynthese eines komplementären Stranges durch die Klenow-Polymerase unter Einbau von radioaktiven Nukleotiden. Die verwendete Klenow-Polymerase ist modifiziert, so dass sie keine Exonucleaseaktivität (exo-) mehr besitzt. Die Markierungsreaktion wird mit Hilfe des Megaprime DNA labeling system Kits von Amersham Pharmacia vorgenommen. Die Durchführung erfolgt nach dem Protokoll des Herstellers.

\subsubsection{Hybridisierung der Northern Blot Membran}

Durch Hybridisierung der Membran mit radioaktiv markierten, einzelsträngigen DNA Sonden lassen sich komplementäre RNA-Transkripte auf der Membran lokalisieren. Die Spezifität, mit der die Sonde an die RNA bindet, ist abhängig von der Salzkonzentration und der Temperatur. Bei hoher Salzkonzentration und niedriger Temperatur ist die Stabilität unspezifischer DNA-RNA-Hybride größer als in Lösungen niederer Salzkonzentration und höherer Temperatur. Durch die Absenkung der Salzkonzentration in den Waschlösungen erhöht man die Stringenz. Bei einer detektierbaren Strahlung auf dem Filter von ca. $100 \mathrm{cps}$ ist der Filter auswertbar. Die Methode ist modifiziert nach Church und Gilbert (1984). Die zu analysierende Membran wird in einer Hybridisierungsröhre 30 Minuten bei $65{ }^{\circ} \mathrm{C}$ in einer Hybridisierungslösung (0,5 M Na-Phosphatpuffer, $1 \mathrm{mM}$ EDTA, 7 \% SDS) inkubiert.

Die Sonden-DNA wird 10 Minuten bei $100{ }^{\circ} \mathrm{C}$ denaturiert und 5 Minuten auf Eis inkubiert. Nach der Zugabe der Sonden-DNA zu ca. $10 \mathrm{ml}$ Hybridisierungslösung in der Hybridisierungsröhre erfolgt die Hybridisierung bei $65^{\circ} \mathrm{C}$ ü.N. im Roller. Zur Abtrennung unspezifisch gebundener Sonden-DNA wird die Membran zweimal mit 2x SSC / 0,1\% SDS und einmal mit 1x SSC / 0,1\% SDS und optional mit 0,5x SSC / $0,1 \%$ SDS für $15-30$ Minuten gewaschen. Für den Nachweis der Radioaktivität wird die Membran in Folie eingeschweißt und mit einem IP-Screen exponiert. Die Dauer der Exposition hängt von der Menge der nachweisbaren Radioaktivität ab. Die Auswertung erfolgt mit Hilfe des Bioimagers (BAS-1000 von Fuji). Zur Quantifizierung werden die Programme PCBAS ${ }^{\circledR} 2.09$ und TINA ${ }^{\circledR} 2.0$ der Firma Raytest verwendet. Die Normalisierung der detektierten Signale wird über den Vergleich mit der dokumentierten Ethidiumbromid-Färbung der RNA erreicht.

\subsubsection{Rehybridisierung}

Die auf der Filteroberfläche fixierte RNA kann nacheinander mit mehreren verschiedenen Sonden hybridisiert werden. Dazu müssen die auf dem Filter befindlichen radioaktiven Sonden aus der vorhergehenden Hybridisierung durch Denaturierung der RNA-DNA-Hybride in Waschlösungen mit geringer Salzkonzentration bei hoher Temperatur abgelöst werden. Die Membran wird durch 
Zugabe kochendheißer 0,1\%iger SDS-Lösung für 1 Stunde bei $65{ }^{\circ} \mathrm{C}$ gewaschen. Danach war der Filter für eine erneute Hybridisierung einsetzbar.

\subsection{Transkriptomanalyse mit „ARIZONA whole genome arrays“}

Die für die Transkriptomanalysen verwendeten Microarrays stammen von der Abteilung Pflanzenwissenschaften der Universität Arizona, und werden durch das Spotten des für diesen Zweck von der Firma Operon käuflichen OligonukleotidSatzes 'Arabidopsis Genome Oligo Set Version 3.0' auf Glasträger erstellt. Die für die Hybridisierung dieser Microarrays verwendete RNA wird zunächst mit Ambions 'Amino Allyl MessageAmp ${ }^{\mathrm{TM}}$ II aRNA Amplification Kit' zu aRNA amplifiziert und dabei indirekt fluoreszenzmarkiert. Die gesamte Analyse wurde im Transkriptomanalyselabor der Humanmedizin Uni Göttingen durchgeführt.

\subsubsection{Amplifikation der eingesetzten RNA}

Die Amplifikation der RNA wird mit dem Kit der Firma Ambion im Wesentlichen nach Herstellerangaben, jedoch mit kleineren Ansätzen durchgeführt. 2,75 $\mu$ l RNA (454 $\mathrm{ng} / \mu \mathrm{l})$ wird mit $0,25 \mu \mathrm{l} \mathrm{T7}$ Oligo(dT) Primer im PCR-tube für 10 Minuten auf $70^{\circ} \mathrm{C}$ erhitzt, kurz abzentrifugiert, und auf Eis gestellt. Für die reverse Transkription wird ein Mastermix $(0,5 \mu \mathrm{l}$ 10x First strand buffer/1 $\mu \mathrm{l}$ dNTP Mix/0,25 $\mu$ l RNase Inhibitor/0,25 $\mu$ l Arrayscript Polymerase pro Ansatz) angesetzt, davon jeweils $2 \mu \mathrm{l} z \mathrm{u}$ den RNA Proben gegeben, durch Pipettieren gemischt und $2 \mathrm{~h}$ bei $42^{\circ} \mathrm{C}$ inkubiert.

Für die Zweitstrang Synthese wird ein Mastermix $(15,75 \mu \mathrm{l}$ RNase-freies Wasser/2,5 $\mu \mathrm{l}$ 10x Second strand buffer/1 $\mu \mathrm{l}$ dNTP mix/0,5 $\mu$ l DNA Polymerase/0,25 $\mu \mathrm{l}$ RNase $\mathrm{H}$ pro Ansatz) angesetzt, davon jeweils $20 \mu \mathrm{l}$ zu den Proben geben, durch Pipettieren gemischt und $2 \mathrm{~h}$ bei $16^{\circ} \mathrm{C}$ inkubiert. Die Proben werden mit $75 \mu \mathrm{RNase}$ freiem Wasser aufgefüllt, die Aufreinigung der cDNA fand mit den dafür vorgesehenen Säulen nach Herstellerprotokoll statt. Die Elution der cDNA findet mit zwei mal $10 \mu \mathrm{l}$ auf $55^{\circ} \mathrm{C}$ vorgewärmtem Wasser statt, und die eluierte cDNA wird in der Vakuumzentrifuge auf ein Volumen von 3,75 $\mu$ l eingeengt.

Für die in vitro Transkription wird ein Mastermix (0,75 $\mu$ Aminoallyl-UTP/1 $\mu \mathrm{l}$ ATP Lösung/1 $\mu$ l CTP Lösung/1 $\mu$ l GTP Lösung/0,5 $\mu$ l UTP Lösung/1 $\mu$ l 10x reaction buffer/1 $\mu \mathrm{l}$ T7 Enzym Mix pro Ansatz) angesetzt, davon werden jeweils 6,25 $\mu \mathrm{l}$ zu den Proben geben, durch Pipettieren gemischt und $16 \mathrm{~h}$ bei $37^{\circ} \mathrm{C}$ inkubiert. Die Proben werden mit $90 \mu \mathrm{l}$ RNase-freiem Wasser aufgefüllt und die aRNA wird mit den dafür vorgesehenen Säulen nach Herstellerprotokoll aufgereinigt. Die Elution der aRNA findet mit zwei mal $50 \mu$ l auf $60^{\circ} \mathrm{C}$ vorgewärmtem Wasser statt.

Die Konzentration der eluierten aRNA wird mit dem Nanodrop gemessen, und die Qualität der aRNA wird im Bioanalyzer getestet.

\subsubsection{Indirekte Markierung der aRNA}

Während der folgenden Arbeitsschritte werden die Proben vor Licht geschützt um ein Ausbleichen der Fluoreszenzfarbstoffe zu verhindern. Für die indirekte Markierung werden je 7,5 $\mu \mathrm{g}$ der Aminoallyl-aRNA auf ein Volumen von $14 \mu \mathrm{l}$ gebracht und mit 2 ul $1 \mathrm{M} \mathrm{Na}_{2} \mathrm{CO}_{3}(\mathrm{pH}$ 9) und $4 \mu \mathrm{l}$ Cy5 bzw. Cy3 für 1 Stunde im Dunkeln bei Raumtemperatur inkubiert. Die Kopplungsreaktion wird dann durch Zugabe von $35 \mu \mathrm{l}$ $100 \mathrm{mM}$ Natriumacetat (pH 5,2) gestoppt. Die Proben werden mit $45 \mu \mathrm{l}$ Rase-freiem Wasser aufgefüllt und die fluoreszenzmarkierte aRNA wird mit den dafür vorgesehenen Säulen nach Herstellerprotokoll aufgereinigt. Die Elution der fluoreszenzmarkierten aRNA findet mit 2 mal $50 \mu \mathrm{l}$ auf $60^{\circ} \mathrm{C}$ vorgewärmtem Wasser 
statt. Anschließend werden am Nanodrop gemessen wie viel pmol Fluorophore pro $\mu \mathrm{l}$ eingebaut werden. Je nach Ausbeute werden für die Hybridisierung Proben mit 150300 pmol Fluoreszenzfarbstoff eingesetzt, wobei darauf geachtet wird, dass von beiden auf einen Array hybridisierten Proben beide gleichviel picomol Fluoreszenzfarbstoffe enthielten. Die für einen Array verwendeten Volumen Cy3 und Cy5 markierter aRNA werden vereinigt, $1 \mu \mathrm{l}$ polyA $(20 \mu \mathrm{g} / \mu \mathrm{l})$ und $1 \mu \mathrm{l}$ tRNA $(20 \mu \mathrm{g} / \mu \mathrm{l})$ zugegeben, und das ganze wird in einer Vakuumzentrifuge zur Trockne eingeengt.

\subsubsection{Hybridisierung der „ARIZONA whole genome arrays“}

Vor der Verwendung werden die ARIZONA „whole genome arrays“ „hydratisiert“, das heißt, sie werden dreimal kurz über ein $60^{\circ} \mathrm{C}$ Wasserbad gehalten, so dass ihre Oberfläche leicht beschlagen. Dabei laufen die aufgrund von Pufferresten hygroskopischen Spots etwas auseinander, werden dadurch größer und lassen sich später besser auswerten. Anschließend werden die Oligonukleotide durch Bestrahlung mit 120 Millijoule UV-Licht kovalent an die Oberfläche des Glasträgers gebunden. Danach werden die Arrays 4 Minuten mit 0,1\% SDS, dreimal 2 Minuten mit $\mathrm{H}_{2} \mathrm{O}$ (demin) und dann 30 Sekunden in 100\% Ethanol gewaschen und anschließend durch Abzentrifugieren oder Abpusten getrocknet.

Die Vorhybridisierungslösung besteht aus $300 \mu \mathrm{l} 20 \mathrm{x}$ SSC, $575 \mu_{\mathrm{l} \mathrm{H}} \mathrm{O}, 100 \mu \mathrm{l} 10 \%$ BSA und $25 \mu \mathrm{l} 20 \%$ SDS. Zur Vorhybridisierung werden $80 \mu \mathrm{l}$ Vorhybridisierungslösung auf ein Deckglas gegeben, der Array umgedreht an das Deckglas gehalten und mit dem nun durch Adhäsion anhaftenden Deckglas angehoben. Anschließend wird der Array mit Deckglas in die Hybridisierungskassette geschlossen und $1 \mathrm{~h}$ bei $42^{\circ} \mathrm{C}$ inkubiert.

In der Zwischenzeit wird die getrocknete aRNA in $9 \mu \mathrm{H}_{2} \mathrm{O}$ resuspendiert und $1 \mu \mathrm{l} 10 \mathrm{x}$ fragmentation buffer wird zugegeben. Dann wird $15 \mathrm{~min}$ bei $70^{\circ} \mathrm{C}$ inkubiert und $1 \mu \mathrm{l}$ fragmentation stop zugegeben. $\mathrm{Zu}$ jeder Probe werden 56,4 $\mu \mathrm{l}$ einer Hybridisierungslösung (350 $\mu \mathrm{l}$ Formamid, $210 \mu \mathrm{l}$ 20x SSC, $70 \mu \mathrm{l}$ 50X Denhardts, $17,5 \mu \mathrm{l} 20 \%$ SDS und $52,5 \mu \mathrm{H}_{2} \mathrm{O}$ ) gegeben, das ganze gevortext, 5 Minuten auf $95^{\circ} \mathrm{C}$ erhitzt und 5 Minuten bei $10.000 \mathrm{~g}$ abzentrifugiert.

Die vorhybridisierten Glasträger werden mit $\mathrm{H}_{2} \mathrm{O}$ gewaschen, und die in der Hybridisierungslösung aufgenommene aRNA wird zwischen den Glasträger und einen darauf platzierten Liftslip laufengelassen. Der Glasträger mit Probe wird in wasserdichte Hybridisierungsgefäße eingeschlossen und anschließend über Nacht bei $37^{\circ} \mathrm{C}$ in einem Wasserbad inkubiert. Nach der Inkubation wird der Glasträger 5 Minuten bei $37^{\circ} \mathrm{C}$ mit $0,5 x$ SSC $+1 \%$ SDS, zweimal 5 Minuten bei RT mit $0,5 x$ SSC + $1 \%$ SDS, viermal 5 Minuten bei RT mit 0,5x SSC und 5 Minuten bei RT mit 0,1x SSC gewaschen und anschließend durch Abzentrifugieren oder Abpusten getrocknet.

Das Auslesen der Fluoreszenzsignale sowie die Integration der erhaltenen Datensätze wurde von den Mitarbeitern des Transkriptomanalyselabors der Universität Göttingen übernommen.

\subsection{Proteinbestimmung und Proteinfällung}

\subsubsection{Proteinbestimmung nach Bradford}

Die Bestimmung des Gehalts an löslichem Protein erfolgte nach Bradford (1976). Der bei dieser Methode verwendete Farbstoff Coomassie Brilliantblue G-250 liegt in saurer Lösung in zwei Formen vor, einer blauen und einer orangefarbenen Form. 
Proteine binden bevorzugt die blaue Form, wobei ein Komplex entsteht, dessen Extinktionskoeffizient viel höher ist als der des freien Farbstoffs. Der Farbtest wird durch Detergenzien, alkalische Medien und Ampholine gestört. Hochvernetzte Proteine oder Proteine mit niedrigem isoelektrischen Punkt zeigen nur eine geringe Farbreaktion.

$50 \mu \mathrm{l}$ der Probe, die zwischen 5 und $10 \mu \mathrm{g}$ Protein enthalten sollte, wurde mit $950 \mu \mathrm{l}$ Farbmix versetzt. Nach 5 min wurde am Photometer (Ultrospec 1100 pro; Fa. Amersham Biosciences) die Extinktion bei $595 \mathrm{~nm}$ gemessen. Als Nullwert diente eine Probe mit $50 \mu \mathrm{l}$ Wasser, die in gleicher Weise behandelt worden war. Zur Kalibrierung wurde eine Eichreihe aus entfettetem BSA hergestellt und anstelle der Probe eingesetzt. Diese Eichreihe war über längere Zeit stabil.

\subsubsection{Proteinfällung nach Wessel und Flügge}

Die Proteinfällung nach Wessel und Flügge (1984) kann sowohl für lösliche als auch für hydrophobe Proteine in wässrigen Lösungen verwendet werden.

$\mathrm{Zu} \mathrm{0,1} \mathrm{ml}$ Proteinprobe wurden 0,4 $\mathrm{ml}$ Methanol zugegeben und gemischt. Dazu wurden noch $0,1 \mathrm{ml}$ Chloroform gegeben und ebenfalls gemischt. Zur Phasentrennung wurden $0,3 \mathrm{ml}$ Wasser zugefügt und durch vortexen gut gemischt. Nach einer einminütigen Zentrifugation bei $12.000 \mathrm{Upm}$ und $4^{\circ} \mathrm{C}$ in einer Eppendorfzentrifuge wurde die obere Phase vorsichtig mit einer Pasteurpipette mit ausgezogener Spitze abgenommen und verworfen (die Proteine befanden sich in der Interphase). Die untere Chloroform-Phase wurde mit 0,3 ml Methanol gemischt und 2 min bei $12.000 \mathrm{Upm}$ und $4^{\circ} \mathrm{C}$ zentrifugiert. Nun wurde der Überstand abgenommen und das Pellet an der Luft getrocknet.

\subsubsection{Proteinfällung mit Aceton}

$\mathrm{Zu}$ einer wässrigen Proteinlösung wurde das zehnfache Volumen $-20^{\circ} \mathrm{C}$ kaltes Aceton zugegeben, gut gemischt und 5 min auf Eis inkubiert. Danach wurde die Probe für $5 \mathrm{~min}$ bei $4^{\circ} \mathrm{C}$ und $10.000 \mathrm{Upm}$ zentrifugiert und der Überstand abgenommen. Nachdem das Pellet an der Luft getrocknet war, wurde es in Probenpuffer (für SDS-PAGE) oder Wasser resuspendiert.

\subsection{Western-Blot Analyse}

\subsubsection{Herstellung denaturierender Gesamtzellextrakte aus Pflanzen}

Das Blattgewebe wird unter flüssigem Stickstoff aufgemörsert, 50 - $200 \mathrm{mg}$ des Pulvers im gefrorenen Zustand in ein Eppendorfgefäß eingewogen, in der doppelten Menge (w/v) Harnstoffextraktionspuffer aufgenommen, gevortext und bei $65^{\circ} \mathrm{C}$ für 10 Minuten inkubiert. Nach 5 Minuten Inkubation werden die Eppendorfgefäße mehrmals invertiert. Anschließend wird der Rohextrakt 10 Minuten bei 13000 rpm und RT zentrifugiert um Zelltrümmer und DNA abzutrennen. 2/3 Volumen des Überstandes werden in ein neues Eppendorfgefäß überführt. Die Proteinextrakte werden bis zur weiteren Verwendung bei $-80^{\circ} \mathrm{C}$ gelagert. Vor Auftragung in der SDSPAGE werden sie 5 Minuten bei $65^{\circ} \mathrm{C}$ inkubiert. Die Proben können direkt auf das Gel appliziert werden. 


\subsubsection{SDS-Polyacrylamidgelelektrophorese}

Die SDS-Polyacrylamidgelelektrophorese (SDS-PAGE, (Laemmli, 1970)) dient der Auftrennung von Proteinen nach ihrer Molekularmasse. Die Polyacrylamidmatrix wird durch Polymerisation von Acrylamid mit dem Quervernetzer N,N'Methylenbisacrylamid (BIS) hergestellt. Die Porengröße im Gel kann durch die Wahl der Acrylamidkonzentration sowie des Verhältnisses Acrylamid/BIS verändert werden. Die Polymerisation wird durch Zugabe von Ammoniumpersulfat (APS) durch Erzeugung freier Radikale gestartet. Als Katalysator wird N,N,N',N'Tetramethylethylendiamin (TEMED) zugefügt. Es wurde zuerst das Trenngel in die vorbereitete Apparatur gegossen, während des Festwerdens mit Isobutanol überschichtet (ca. $2 \mathrm{ml}$ ), nach ca. $30 \mathrm{~min}$, wenn das Trenngel fest geworden ist, konnte das Sammelgel darüber gegossen werden und der Kamm für die Taschen eingeschoben werden. Die Elektrophorese erfolgte in Laufpuffer ca. 30' bei $80 \mathrm{~V}$ zum Durchlaufen der Proteine durch das Sammelgel und anschließend bei $120 \mathrm{~V}$ bis die BPB-Bande das untere Ende des Gels erreicht hat.

\subsubsection{Coomassie-Färbung}

Um Proteinbanden in SDS-PAGE-Gelen sichtbar zu machen, werden diese mit dem Farbstoff Coomassie Brilliant Blue G-250 angefärbt. Hierfür wird das Gel 30 Minuten in der Fixierlösung geschwenkt. Nach Verfärbung des Bromphenolblau ins Gelbliche wird das Gel in der Färbelösung 30 bis 60 Minuten inkubiert. Die Entfärbung des Gels erfolgt in dem Entfärbebad unter wiederholtem Wechsel der Lösung für mehrere Stunden. Optional kann der Vorgang durch kurzes Erwärmen in der Mikrowelle beschleunigt werden.

\subsubsection{Proteintransfer auf PVDF-Membranen}

Der Transfer der im SDS-Gel aufgetrennten Proteine auf eine PVDF-Membran erfolgt mittels der „Semi-Dry-Blotting“-Methode (Kyhse-Anderson, 1984). Dazu werden drei Lagen Fließpapier in Transferpuffer angefeuchtet und auf die Blottingapparatur aufgelegt. Die PVDF Membran wird in Methanol aktiviert, mit Transferpuffer äquilibriert und luftblasenfrei auf die Schicht Fließpapier gelegt. Das PAA-Gel wird auf dem Filter positioniert und mit drei Lagen in Transferpuffer äquilibriertem Fließpapier bedeckt. Der Elektrotransfer läuft für 45 Minuten bei $5 \mathrm{~mA} / \mathrm{cm}^{2}$ Filterfläche. Nach dem Transfer wird der Filter kurz in TBS gewaschen und zwischen zwei Lagen Fließpapier getrocknet. Die Membran wird vor der Weiterbehandlung wieder mit Methanol aktiviert.

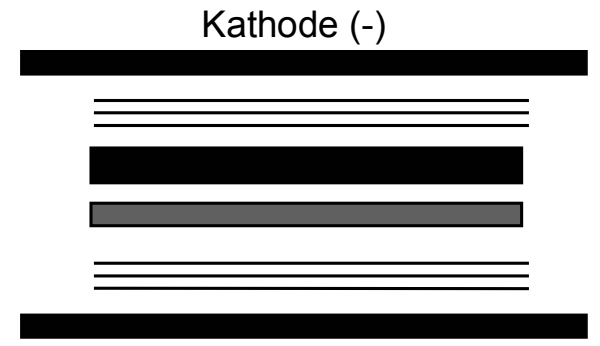

Anode (+)
3 Lagen 3 MM Whatman Papier

SDS-Gel

PVDF-Membran

3 Lagen 3 MM Whatman Papier

Abbildung 8: Aufbau eines Western-Blot. 


\subsubsection{Immunodetektion mit dem ECL+ System}

Bei der hier angewendeten indirekten Nachweismethode werden die auf der Membran immobilisierten Proteine zuerst mit einem Primärantikörper immunodetektiert. Dieser Antikörper ist spezifisch gegen ein Epitop des nachzuweisenden Proteins gerichtet. Unter Verwendung eines Peroxidasegekoppelten zweiten Antikörpers wird der Primärantikörper erkannt. Der Nachweis erfolgt mit Hilfe des ECL+-Kits der Firma Amersham. Nach Inkubation des Filters mit einem Substrat-Mix kann die bei der Peroxidase-katalysierten Oxidation des Substrates Luminol entstehende Chemilumineszenz durch Exposition eines Röntgenfilms nachgewiesen werden. Das Absättigen freier Stellen auf der Membran (Blocken) erfolgt durch 1 Stunde Inkubation mit $5 \%$ Milchpulver in TBST. Danach erfolgt für 2 Stunden die Inkubation mit $5 \%$ Milchpulver in TBST und Primärantikörper. Die Membran wird dreimal 10 Minuten mit 1 x TBST zum Entfernen von nicht gebundenem Antikörper gewaschen. Die Inkubation mit dem Sekundärantikörper erfolgte in $5 \%$ Milchpulver in TBST für $1 \mathrm{~h}$. Nichtgebundener Antikörper wird wieder entfernt durch 5 × 5 Minuten Waschen mit 1 x TBS. Das ECLSubstratmix wird frisch aus den Lösungen 1 und $2 \mathrm{im}$ Verhältnis 1:1 angesetzt, für eine Membran $(9,5 \times 6,5 \mathrm{~cm})$ werden $3 \mathrm{ml}$ Substratmix benötigt. Die Membran wird mit der Proteinseite nach oben auf ein Stück Haushaltsfolie gelegt, und mit dem Substratmix 1 Minuten inkubiert. Überschüssiger Substratmix wird abgeschüttet und die Membran in Haushaltsfolie eingeschlagen. Die Detektion der Chemilumineszenssignale erfolgt durch Exposition eines Röntgenfilms, je nach Signalstärke für $15 \mathrm{~s}$ bis $10 \mathrm{~min}$. Der Autoradiographiefilm wird dann für 1-5 Minuten entwickelt, kurz gewässert und 3 Minuten fixiert.

\subsection{Einbettung von Proben für Elektronenmikroskopie}

Diese Methode wurde von Andrea Olbrich durchgeführt.

Ernte: Waschpuffer wurde in eine Petrischale auf Eis gegeben, von den Blättern wurden Mittelrippe und Rand verworfen, $2 \times 2 \mathrm{~mm}$ große Stücke mit scharfer Klinge geschnitten und in Primärfixativ überführt.

Durch Evakuieren und erneut belüften, wurde Austausch und Durchdringen des Primärfixativs ins Gewebe erzielt.

$\begin{array}{lll}\text { Primärfixativ } & 4 \mathrm{~h} \text { bei RT (incl. Evakuieren) } & \\ & \text { ü. N. bei } 4{ }^{\circ} \mathrm{C} & \\ \text { Waschpuffer } & 2 \times 10 \text { min bei RT } & 7.00 \\ \text { Sekundärfixativ } & 4 \mathrm{~h} \mathrm{bei} \mathrm{RT} & 8.00 \\ \text { Waschpuffer } & 2 \times 10 \text { min bei RT } & 12.00 \\ \mathrm{H}_{2} \mathrm{O} \text { bidest. } & 2 \times 10 \text { min bei RT } & \\ \text { Kontrastmittel } & 4 \mathrm{~h} \text { bei RT } & 13.40 \\ \mathrm{H}_{2} \mathrm{O} \text { bidest. } & 2 \times 10 \text { min bei RT } & 17.40 \\ 25 \% \text { Aceton } & \text { ü.N. bei RT } & 18.15 \\ 50 \% \text { Aceton } & 45 \mathrm{~min} \text { bei RT } & 7.00 \\ 75 \% \text { Aceton } & 45 \mathrm{~min} \text { bei RT } & 8.00 \\ 95 \% \text { Aceton } & 45 \mathrm{~min} \text { bei RT } & 9.00 \\ 100 \% \text { wasserfreies Aceton } & 2 \times 45 \text { min bei RT } & 10.00\end{array}$

Infiltration erst ab Zugabe von Spurr unter Bewegung auf dem Rotor. 
Kunstharzinfiltration und Polymerisation:

$25 \%(v / v)$

$50 \%(\mathrm{v} / \mathrm{v})$

$75 \%(\mathrm{v} / \mathrm{v})$

$100 \%(\mathrm{v} / \mathrm{v})$

$100 \%(v / v)$
Spurr in wasserfreiem Aceton p.a. Spurr in wasserfreiem Aceton p.a. Spurr in wasserfreiem Aceton p.a. Spurr Spurr

Die Proben werden in Flacheinbettungsformen aus weichem Gummi eingebettet und zur Polymerisation des Harzes für mindestens 24 Stunden in einen $60{ }^{\circ} \mathrm{C}$ warmen Trockenschrank gestellt.

\subsection{Bestimmung des Chlorophyllgehalts}

100 mg Blattmaterial wurden in flüssigem Stickstoff gemörsert und in ein EppendorfGefäß überführt. $1 \mathrm{ml}$ Methanol wurden zugegeben und für 30 min bei $60^{\circ} \mathrm{C}$ inkubiert. Es wurde für $10 \mathrm{~min}$ bei $13.000 \mathrm{rpm}$ zentrifugiert und die Extinktion des Überstandes (evtl. 1:10 verdünnt) im Photometer bei $650 \mathrm{mn}$ und $665 \mathrm{~nm}$ gemessen. Berechnung: $\mathrm{E}_{650}{ }^{*} 0,025+\mathrm{E}_{665}{ }^{*} 0,005=\mathrm{mg}$ Chlorophyll pro ml Messlösung mit $\mathrm{E}=$ Extinktion

\subsection{Stressbedingungen für $\mathrm{A}$. thaliana}

Um die Pflanzen mit oxidativem Stress zu behandeln, wurde das Herbizid Paraquat verwendet. Von der $10 \mathrm{mM}$ Stammlösung, die bei $-80^{\circ} \mathrm{C}$ gelagert werden konnte, wurden verschiedene Mengen eingesetzt, um die im Ergebnisteil angegebenen Konzentrationen in MS-Medium zu erhalten. Es wurde MS-Medium mit 1x MS-Salzen und ohne Zucker verwendet. Die sterilisierten $A$. thaliana Samen wurden auf den Agarplatten ausgelegt, 2 Tage bei $4^{\circ} \mathrm{C}$ vernalisiert und für 10 Tage in der LangtagKlimakammer angezogen. Dann wurden die nicht gekeimten Samen, die grünen Keimlinge und die weißen Keimlinge ausgezählt und als Prozent der grünen Keimlinge im Diagramm aufgetragen.

\subsection{Analyse von T-DNA-Insertionsmutanten von A. thaliana}

Die Salk T-DNA Linien (Alonso et al., 2003) wurden nach Erhalt angezogen und homozygote Mutanten identifiziert, d.h. solche bei denen beide Chromosomen eine T-DNA-Insertion im interessierenden Gen aufweisen. Dafür wurden ein linker genomischer Primer (Primer LP) und ein rechter genomischer Primer (Primer RP) abgeleitet, die auf beiden Seiten der Insertion liegen. Einen Vorschlag für diese

Primer konnte auf der Internetseite http://signal.salk.edu/tdnaprimers.html angefordert werden. 


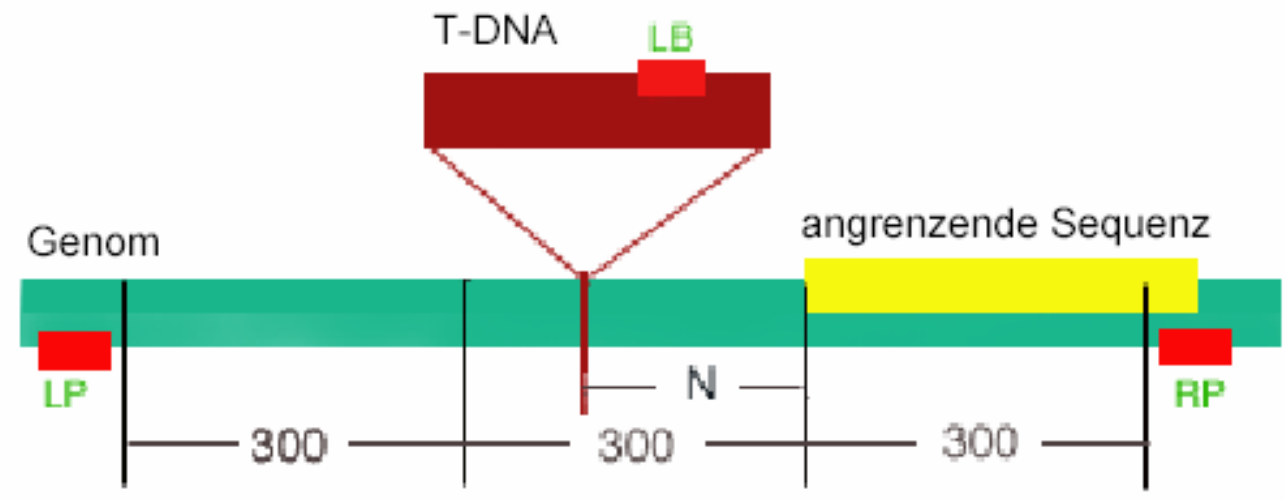

Abbildung 9: Anordnung der T-DNA-Insertion und der Primer bei SALK-Mutanten (aus: http://signal.salk.edu/tdnaprimers.html).

$\mathbf{N}$ : Unterschied der eigentlichen Insertionsstelle und der Stelle der angrenzenden Sequenz (0 - 300 Basen), LB: "Left border" (linker Rand) Primer der T-DNA-Sequenz

Homozygote Mutanten wurden über PCRs identifiziert. Bei der PCR mit LP und RP sollte bei Wildtyp- und heterozygoten Pflanzen ein PCR-Produkt von ca. 900 bp amplifiziert werden, bei homozygoten dagegen nichts. Bei Verwendung der Primer RP und LB sollte bei homo- und heterozygoten Pflanzen ein PCR-Produkt von $410+\mathrm{N}$ bp (110 bp von LB zum linken Rand der T-DNA) amplifiziert werden und bei Wildtyppflanzen nichts.

Das erhaltene PCR-Produkt von homozygoten Pflanzen wurde in PSK-T Easy kloniert und sequenziert.

Homozygote Pflanzen wurden zu weiteren Analysen vermehrt.

\subsection{Verwendete Computerprogramme}

- VectorNTI 10.1.1 (Invitrogen Corporation) - Bearbeitung von DNA- und Proteinsequenzen

- Geneious v4.7 (Drummond et al., 2009) - Bearbeitung von DNA- und Proteinsequenzen

- Chromas1.55 (Technelysium, 1998) - Analyse von Sequenzierdaten

- Blast (Altschul et al., 1997; Schäffer et al., 2001) - Programme zur Suche von ähnlichen DNA- oder Proteinsequenzen

- EasyGO (Zhou und Su, 2007) - Analyse der Microarraydaten

- ExPASy (Gasteiger et al., 2003) - Proteomic Server zur Analyse von Proteinsequenzen und Strukturen und Server für viele andere nützliche Programme

- Genevestigator (Zimmermann et al., 2004) - Analyse der Microarraydaten

- NetPhos 2.0 (Blom et al., 1999) - Voraussage von eukaryotischen ProteinPhosphorylierungsstellen

- MicrosoftOffice 2003

- PcBAS $^{\circledR} 2.09$ (Raytest)

- Tina ${ }^{\circledR} 2.0$ (Raytest)

- Wasabi 1.5 (Hamamatsu Photonics) - zur Auswertung der Lumineszenzfotos

- Blattfläche 


\section{Ergebnisse}

\subsection{Eine Interaktion von AKR2A und AKR2B mit Gruppe C bZIP-} Transkriptionsfaktoren sollte überprüft werden

In Tabak interagieren das Ankyrin-repeat Protein NtANK1 und der bZIPTranskriptionsfaktor NtBZl-1 miteinander, was in verschiedenen in vivo und in vitro Systemen gezeigt worden ist (Kuhlmann et al., 2003; Böttner et al., 2009). Im Rahmen dieser Arbeit sollten homologe Proteine aus Arabidopsis auf eine Interaktion getestet werden, wegen der Vorteile, die dieses verbreitete Modellsystem bietet. Microarrays können einfacher durchgeführt werden, da fertige "Chips" erhältlich sind und T-DNA-Insertionsmutanten stehen zur Verfügung, die komplementiert werden können, was bei RNAi-Pflanzen schwieriger ist.

\subsubsection{In zwei verschiedenen Two-Hybrid-Systemen wurde die Interaktion zwischen AKR2A/B und Gruppe C-bZIP-Faktoren getestet}

Dazu wurde ein $\mathrm{Y} 2 \mathrm{H}$-Experiment durchgeführt, das ein klassisches System zur Analyse von in vivo Protein-Protein Interaktionen ist. Es basiert auf dem modularen Aufbau des Transkriptionsfaktors GAL4 aus einer DNA-Bindedomäne (BD) und einer Aktivierungsdomäne (AD) (Brent und Ptashne, 1985; Ma und Ptashne, 1987). Die GAL4-BD interagiert mit der GAL4-UAS („upstream activating sequence“), so dass der Transkriptionsfaktor an dieser Stelle an die DNA bindet, die GAL4-AD wird benötigt, um die Transkription durch Interaktion mit dem RNA-Polymerase II Komplex einzuleiten (Giniger et al., 1985).

In $\mathrm{Y} 2 \mathrm{H}$ Tests untersucht man die Interaktion zwischen zwei Proteinen, indem man das eine Protein an die GAL4-BD und den putativen Partner an die GAL4-AD fusioniert. Wenn die Proteine miteinander interagieren, wird der GAL4 Transkriptionsfaktor rekonstituiert und aktiviert die Expression eines lacZReportergens, das unter der Kontrolle eines GAL4-UAS abhängigen Promotors steht (Fields und Song, 1989).

Um quantitative Werte für die Interaktion zu erhalten, wurden oNPG-Tests mit jeweils drei unabhängigen Kolonien durchgeführt. Der oNPG-Test erlaubt eine quantitative Bestimmung der Aktivität der vom lacZ-Reportergen kodierten $\beta$-Galaktosidase, was 
ein $M a ß$ für Protein-Protein Interaktionen ist. Als Negativ-Kontrolle wurden der leere BD-Vektor pDEST32 und der leere AD-Vektor pDEST22 verwendet (Abb. 10).

Einige Proteine haben zu starke Auto-Aktivierungseigenschaften, um sinnvoll als BDFusion verwendet zu werden. Daher wurden die Ankyrin-repeat Proteine AKR2A und B aus Arabidopsis sowie NtANK1 aus Tabak nur als AD-Fusionen verwendet. Von bZIP9 und NtBZI-1 lagen Deletionsderivate vor, bZIP9 $\Delta N$ und NtBZI-1 $\Delta N$, die reduzierte Aktivierungseigenschaften zeigen (Kuhlmann et al., 2003; Ehlert et al., 2006). Für bZIP10 wurde analog hierzu ein bZIP10 $\Delta$ N-Derivat hergestellt, bei dem die N-terminalen 80 Aminosäuren deletiert worden sind. Die Aktivierungseigenschaft von bZIP10 konnte so bis auf den Wert der Leervektoren reduziert werden (Abb. 10). Im Y2H-Ansatz wurden die Kombinationen aus dem Tabak-Protein NtBZI-1 $\Delta \mathrm{N}$ als BD-Fusion zusammen mit NtANK1 aus Tabak und AKR2A/B aus Arabidopsis als ADFusionen getestet. Die Interaktion von NtANK1 und NtBZI-1 $\Delta N$ ist deutlich zu erkennen, während die Werte von AKR2A und B mit NtBZI-1 nur etwa das 0,5- bzw. 0,25-fache betragen (Abb. 10). Da sie noch deutlich über dem Hintergrund des Leervektors liegen, ist von einer schwachen Interaktion bei der Kombination dieser Proteine auszugehen. Desweiteren wurden die bZIP-Transkriptionsfaktoren der Gruppe $C$ aus Arabidopsis als BD-Fusionen eingesetzt und mit AKR2A und $B$ als ADFusionen kombiniert. Bei diesen Kombinationen zeigte sich keine Interaktion, die Zugabe von AKR2A oder AKR2B führte in keinem Fall zu einer Erhöhung der Reportergenaktivierung gegenüber dem AD-Leervektor (Abb. 10). Die Kombination des Tabak-Proteins NtANK1 mit den Arabidopsis bZIP-Proteinen ergab ebenfalls keine Interaktion (Abb. 33 im Anhang).

Die Interaktion von AKR2A/B und den Gruppe C bZIPs aus Arabidopsis wurde ebenfalls im „Protoplasten-Two-Hybrid“ (P2H)-System getestet, welches analog zum Y2H mit Gal4-BD- und AD-Fusionen durchgeführt wird (Ehlert et al., 2006). In Arabidopsis-Protoplasten konnte jedoch auch keine Interaktion gefunden werden (Abb. 34 im Anhang). Tabak-Protoplasten wurden ebenfalls getestet, weil es einen Kofaktor geben könnte, der für die Interaktion nötig ist, in Arabidopsis aber evtl. fehlt (Abb. 35 im Anhang). Da hier auch keine Interaktion detektiert wurde, ist davon auszugehen, dass die Arabidopsis Gruppe C bZIP-Proteine nicht mit AKR2A und B interagieren. 


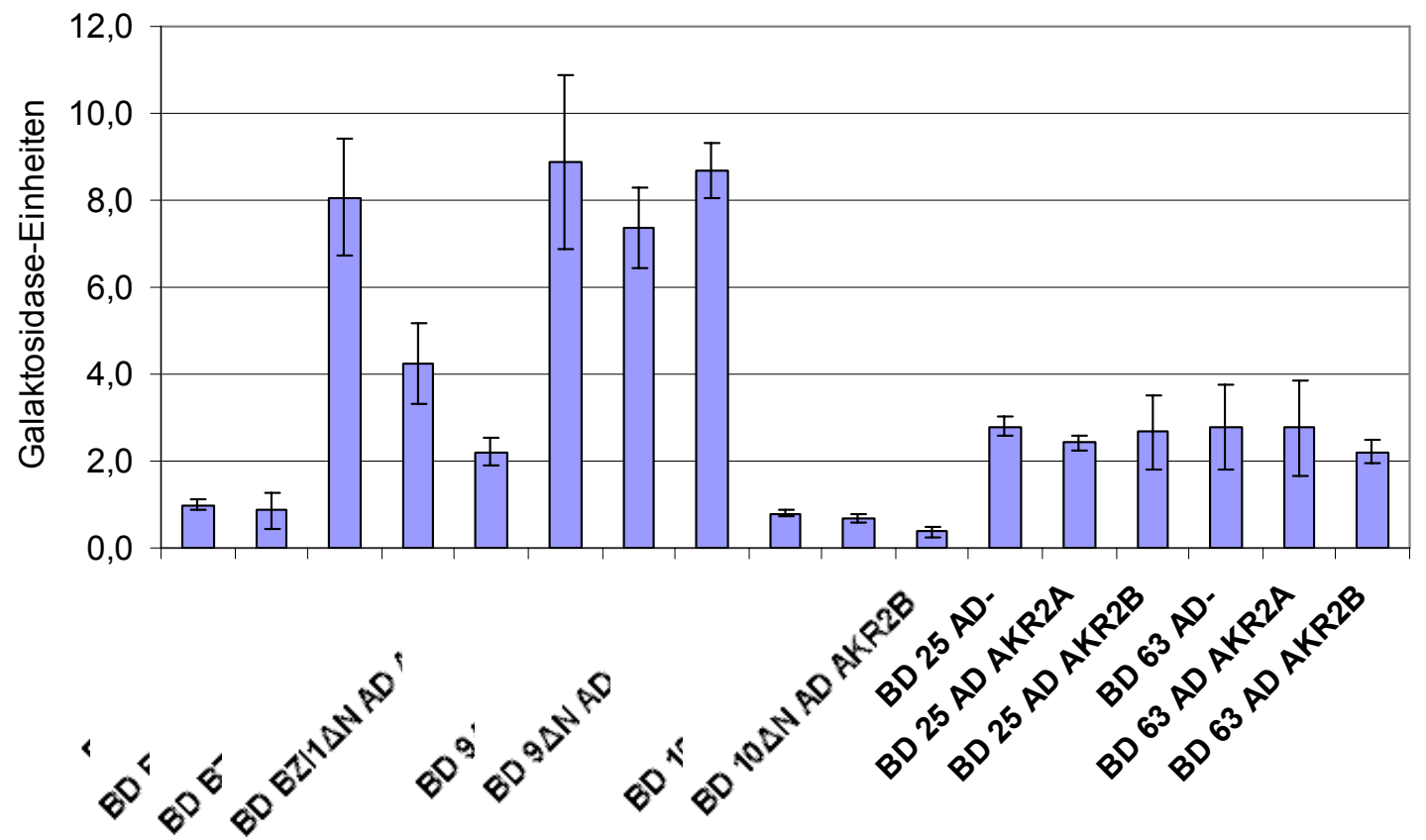

Abbildung 10: oNPG-Test verschiedener Protein-Protein-Interaktionen im Y2H-System. Gal4Bindedomäne (BD)- und Gal4-Aktivierungsdomäne (AD)-Fusionen wurden verwendet, mit pDEST22 $(A D)$ und pDEST32 (BD) als Ausgangsvektoren. -: Leervektoren als Kontrollen, BZI1 $\triangle N$ und ANK1: Proteine aus Tabak, $9 \Delta \mathrm{N}, 10 \Delta \mathrm{N}, 25,63$ : bZIP-Faktoren aus Arabidopsis. Der Mittelwert wurde jeweils aus den Ergebnissen von 3 unabhängigen Kolonien gebildet.

\subsubsection{Test auf Interaktion mit „,bimolecular fluorescence complementation" (BiFC)}

Für „bimolecular fluorescence complementation“ (BiFC)-Analysen wurden im Rahmen dieser Arbeit Gateway-kompatible Vektoren erstellt. Als Grundlage dienten die Vektoren pSPYNE-35S und pSPYCE-35S (,split YFP $\underline{\mathrm{N}}$-terminal/ㅡ-terminal fragment expression“; YFP: „yellow fluorescent protein“; Walter et al., 2004). Mithilfe dieser Vektoren können zu untersuchende Proteine entweder an die N-terminalen 155 Aminosäuren $\left(\mathrm{YFP}_{\mathrm{N}}\right.$ ) oder an die C-terminalen 86 Aminosäuren (YFP $)$ des YFP-Proteins fusioniert werden (Hu et al., 2002). Die Fusionsproteine enthalten außerdem einen c-myc- (pSPYNE-35S) oder einen HA- (pSPYCE-35S) Anhang, mit dem die Proteine im Western-Blot detektiert werden können. Wenn die zu untersuchenden Proteine miteinander interagieren, wird das YFP-Protein rekonstituiert und die Fluoreszenz ist im Mikroskop detektierbar. Von den Vektoren wurde jeweils der Abschnitt mit $\mathrm{YFP}_{\mathrm{N} / \mathrm{C}}$ und c-myc-/HA-Anhang amplifiziert und so in den binären Gateway-Destination-Vektor $\mathrm{pE}$ inseriert, dass Fusionsproteine mit YFP $_{\mathrm{N} / \mathrm{C}}$ am N-Terminus entstehen (Abb. 11; Abb. 37 im Anhang). Die Vektoren 
wurden pE-SPYNE-GW und pE-SPYCE-GW benannt, sowie die Leerkontrollen, in denen ein Teil der Gateway-Kassette mit dem ccdB-Gen entfernt wurde: $p E-$ SPYNE(-) und pE-SPYCE (-) (Abb. 37 im Anhang).

A

\begin{tabular}{|l|l|}
\hline YFP $_{\mathrm{N}}$ & 1 \\
\hline
\end{tabular}

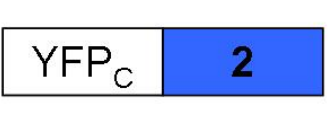

1 und 2

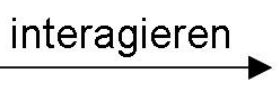

\begin{tabular}{|l|l|}
\hline $\mathrm{YFP}_{\mathrm{N}}$ & $\mathbf{1}$ \\
\hline $\mathrm{YFP}_{\mathrm{C}}$ & $\mathbf{2}$ \\
\hline
\end{tabular}

B

\begin{tabular}{|l|c|}
\multicolumn{2}{c}{$c-m y c$} \\
\hline MCS & YFP \\
\hline pSPYNE-35S
\end{tabular}

C

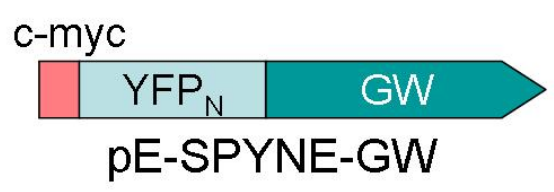

Abbildung 11: Schematische Übersicht über die Funktionsweise und die Vektoren des BiFC. A: Die synthetisierten Fusionsproteine mit 1 und 2 als zu untersuchende Proteine. Gelb eingefärbt ist das rekonstituierte YFP mit detektierbarer Fluoreszenz. B: Die vorliegenden Vektoren pSPYNE-35S und pSPYCE-35S, MCS: multiple cloning site. C: Die in dieser Arbeit erstellten Vektoren pE-SPYNE-GW und pE-SPYCE-GW, GW: Gateway, c-myc und HA: Anhang zur Detektion im Western-Blot.

Zum Test der Vektoren wurde die gut charakterisierte Interaktion zwischen bZIP10 und bZIP53 reproduziert (Weltmeier et al., 2006). Es wurden Agrobakterien mit den pE-SPYNE/SPYCE-Vektoren transformiert um verschiedene Kombinationen in Nicotiana benthamiana Blättern transient zu exprimieren. In Abb. $12 \mathrm{~A}$ ist bei der

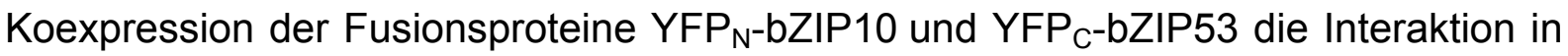
den Kernen der Epidermiszellen zu sehen. Bei Koexpression von $\mathrm{YFP}_{\mathrm{N}}$ und $\mathrm{YFP}_{\mathrm{C}^{-}}$ bZIP53 als Kontrolle ist keine Fluoreszenz detektierbar. Die Interaktion von $\mathrm{YFP}_{\mathrm{N}^{-}}$ AKR2A und YFP $_{\mathrm{C}}-\mathrm{bZIP10}$ sowie $\mathrm{YFP}_{\mathrm{N}}$-bZIP10 und YFPC $_{\mathrm{C}}$-AKR2A konnte nicht nachgewiesen werden, da keine Fluoreszenz detektierbar war, obwohl die Proteine exprimiert wurden (Abb. $12 \mathrm{~B}$ und $\mathrm{C}$ ). Als einziges Fusionsprotein konnte im Western

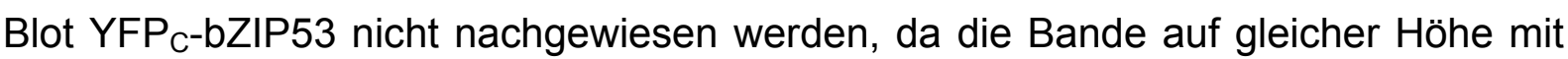
einer Hintergrundbande des HA-Antikörpers ist. YFP N-bZIP53, YFP $_{N}-A K R 2 A$ und YFP $_{N^{-}-b Z I P 10}$ sind mit dem c-myc-Antikörper gut nachweisbar, genauso wie YFP $_{C^{-}}$ 
AKR2A und YFPc-bZIP10 mit dem HA-Antikörper (Abb. 12 C). Deshalb und aufgrund der sichtbaren Interaktion ist davon auszugehen, dass YFP $_{\mathrm{C}}$-bZIP53 ebenfalls in ausreichender Menge exprimiert wird.
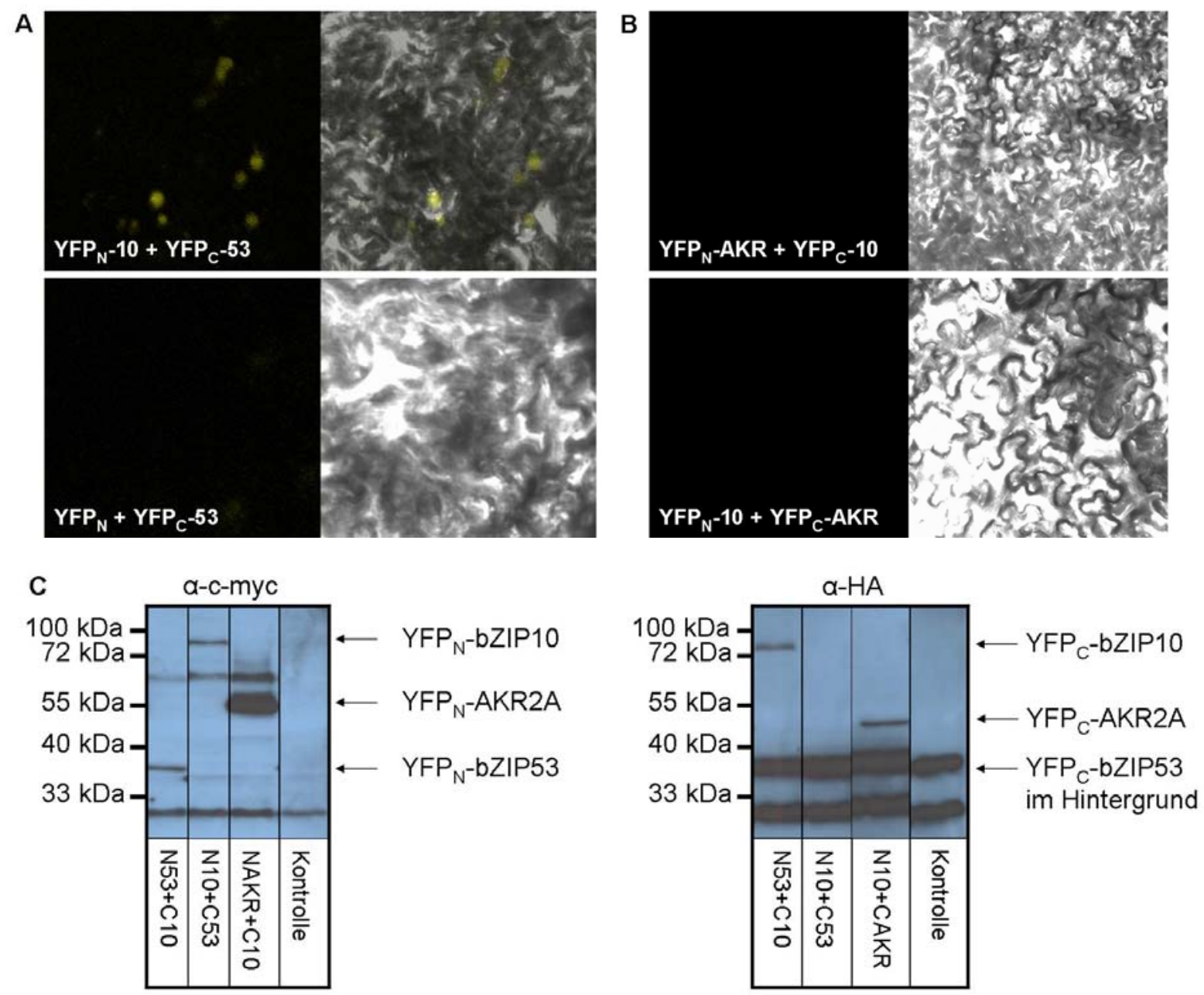

Abbildung 12: BiFC-Analysen in transient transformierten N. benthamiana Blättern. A: Koexpression der Fusionsproteine YFP $_{\mathrm{N}}$-bZIP10 und YFP $_{\mathrm{C}}$-bZIP53 (oben), die Fluoreszenz ist in den Kernen zu sehen (links), rechts ist die Überlagerung mit dem Durchlichtbild zu sehen. Bei der Kontrolle YFP (unfusioniert) und YFP ${ }_{C}$-bZIP53 ist keine Fluoreszenz detektierbar (unten links); Durchlicht (rechts). B: Koexpression der Fusionsproteine YFP $_{\mathrm{N}}-$ AKR2A und YFP $_{\mathrm{C}}$-bZIP10 (oben), sowie YFP $_{\mathrm{N}}$-bZIP10 und YFP $_{\mathrm{C}}$-AKR2A (unten): es ist keine Fluoreszenz zu sehen; Durchlichtbilder rechts. C: Western Blot mit Proben der infiltrierten Blätter und den Antikörpern gegen c-myc und HA: N53+C10: YFP ${ }_{N}-b Z I P 53$ und

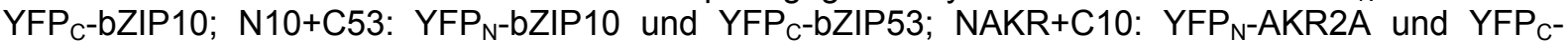
bZIP10; Kontrolle: Transformation mit leerem Vektor. Die detektierbaren Fusionsproteine sind

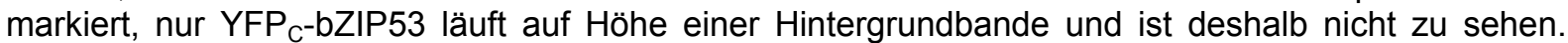
YFP $_{\mathrm{N}}$ : die N-terminalen 155 Aminosäuren des YFP-Proteins; YFP $_{\mathrm{C}}$ : die C-terminalen 86 Aminosäuren des YFP-Proteins 


\subsubsection{Die Zugabe von AKR2A oder AKR2B im Protoplasten-System steigert bZIP-Heterodimer-induzierte Reportergenaktivierung}

In Alonso et al. (2009) ist beschrieben, dass im Protoplasten-System die durch das Heterodimer bZIP10/bZIP53 induzierte Reportergen-Aktivierung durch Zugabe eines dritten Proteins $(A B \mid 3)$ erhöht werden kann. Analog zu diesem Ansatz wurden ebenfalls im Protoplasten-System zum bZIP10/bZIP53 Heterodimer AKR2A und B zugegeben (Abb. 13). Dabei lag bZIP53 als BD-Fusion vor, bZIP10 als AD-Fusion und $A K R 2 A / B$ als HA-Fusion. Es ist eine deutliche Steigerung der Aktivierung des Heterodimers um das 1,5fache bei Zugabe von AKR2A oder AKR2B zu sehen. Diese drei Proteine bilden also möglicherweise einen trimeren Komplex auf der DNA, dabei würde AKR2A/B mit dem Heterodimer aus bZIP10 und bZIP53 interagieren. Jedoch konnte dieser mutmaßliche Komplex weder in Hefe noch im BiFC nachgewiesen werden (Abb. 36 im Anhang).

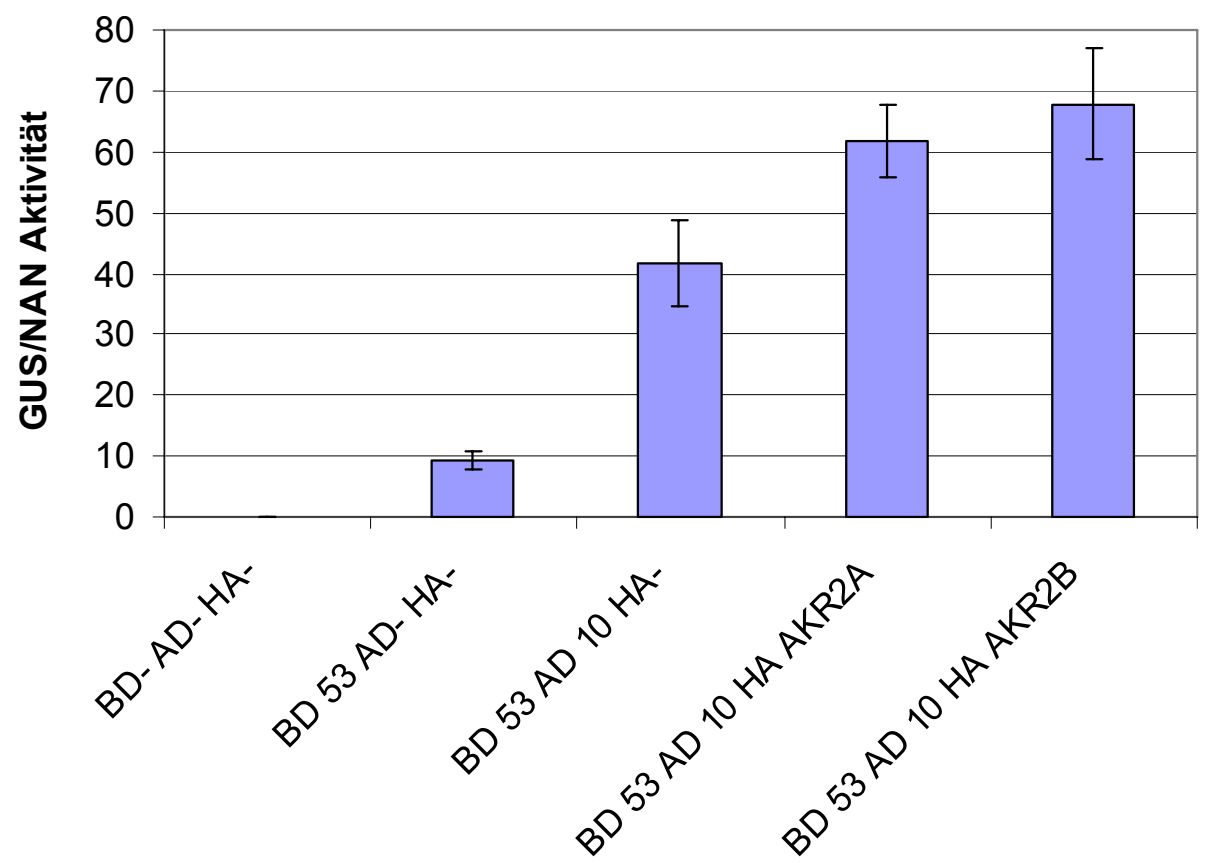

Abbildung 13: Steigerung der Reportergenaktivierung des Heterodimers bZIP10/bZIP53 durch die Zugabe von AKR2A/B im Protoplasten-System. BD: GAL-4 Bindedomäne; AD: GAL-4 Aktivierungsdomäne, -: Leervektoren als Kontrolle. In den Ansätzen wurden $9 \mu \mathrm{g}$ GAL4-UAS4:GUS und $3 \mu \mathrm{g} \mathrm{PrO}{ }_{355}:$ NAN als Reporterplasmide sowie $5 \mu \mathrm{g}$ der Plasmide mit bZIP53 und bZIP10 und 9,3 $\mu \mathrm{g}$ der Plasmide mit AKR2A und B eingesetzt. Die Standardabweichungen beziehen sich auf 2 unabhängige Transformationen. Bei Einsetzen von gleichen Mengen DNA aller drei Plasmide konnte nur eine geringere Steigerung erzielt werden als in diesem Experiment. 


\subsection{Lokalisation von YFP-AKR2A/AKR2B}

\subsubsection{AKR2A und AKR2B sind im Cytoplasma lokalisiert}

Zur Analyse eines Proteins ist auch die zelluläre Lokalisation wichtig, denn daraus ergeben sich potentielle Funktionsbereiche. Sowohl für NtANK1 aus Tabak, als auch für AKR2A aus Arabidopsis wurde eine cytosolische Lokalisation festgestellt, die hier für AKR2A und AKR2B reproduziert werden konnte (Abb. 14; Kuhlmann et al., 2003; Bae et al., 2008). Dazu wurden Arabidopsis-Protoplasten transient mit den Fusionsproteinen YFP-AKR2A/B und ARR2-RFP (Arabidopsis response regulator 2 red fluorescent protein als Kernkontrolle, Hass et al., 2004) kotransformiert. Das Fluoreszenzsignal von YFP-AKR2A/B ist nur im Cytoplasma, nicht aber im Kern zu sehen, die Proteine befinden sich also nur im Cytoplasma. In den Überlagerungsbildern ist deshalb der Kern rot eingefärbt, wie die Kernkontrolle.

Zusätzlich wurden $N$. benthamiana Epidermiszellen durch Infiltration mit transformierten $A$. tumefaciens transient transformiert. Die Fluoreszenz der YFPAKR2A/B Fusionsproteine ist ebenfalls im Cytoplasma und nicht im Kern zu sehen (Abb. 14 B, Pfeile deuten auf die ausgesparten Kerne). 
A
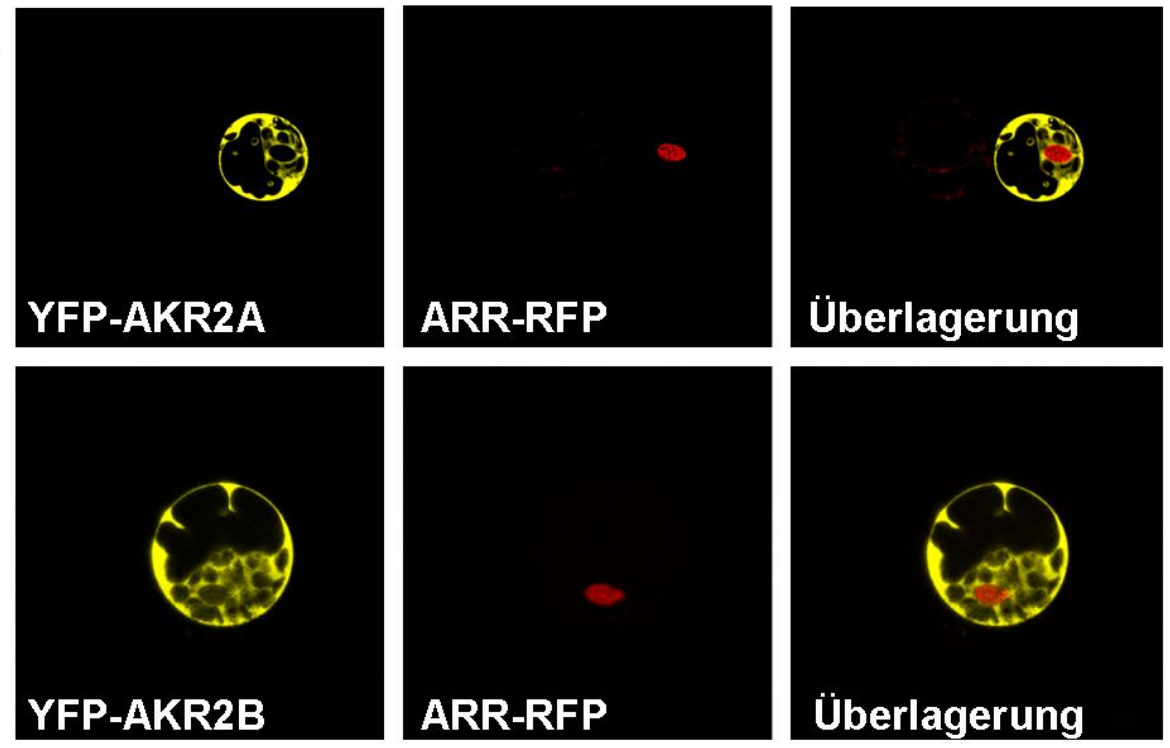

B
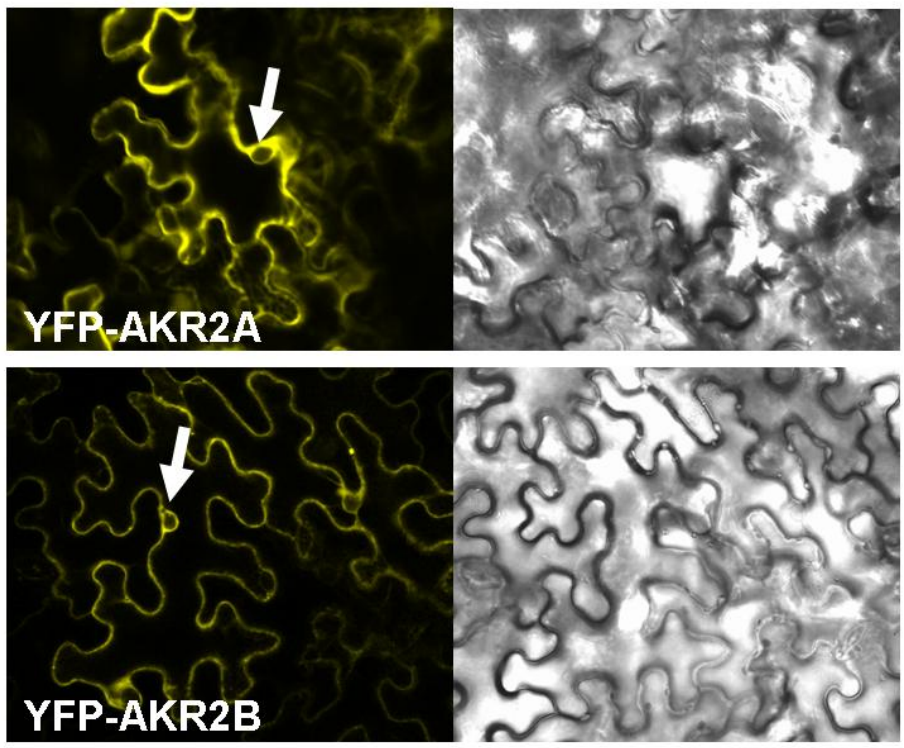

Abbildung 14: Zelluläre Lokalisation von AKR2A/B. A: Arabidopsis-Protoplasten wurden mit YFPAKR2A/B und ARR2-RFP kotransformiert und die Fluoreszenz im konfokalen Mikroskop detektiert. YFP-Fluoreszenz ist im Cytoplasma zu sehen und nicht im Kern, die Fluoreszenz der Kernkontrolle ARR-RFP ist nur im Kern zu sehen. 1. Spalte: YFP-Kanal, 2. Spalte: RFP-Kanal, 3. Spalte: Überlagerung. B: $N$. benthamiana Epidermiszellen wurden durch Infiltration mit transformierten $A$. tumefaciens Zellen transformiert. Die YFP-Fluoreszenz von YFP-AKR2A/B ist im Cytoplasma zu sehen, nicht aber im Kern. Kerne sind mit Pfeilen markiert. Rechts: Durchlichtbilder der Epidermiszellen.

\subsubsection{Nach pharmakologischer Inhibierung des Kernexports sind AKR2A und AKR2B auch im Kern lokalisiert}

In Böttner et al. (2009) wird gezeigt, dass NtANK1 aus Tabak unter bestimmten Bedingungen im Kern akkumuliert. Dazu gehört die Hemmung des Kernexports durch den Inhibitor LMB (Haasen et al., 1999). LMB inhibiert die Interaktion von Exportin 1 (XPO1) aus Arabidopsis mit der Leucin-reichen NES ("nuclear export 
sequence") in Proteinen, die aus dem Kern exportiert werden sollen. Sowohl AKR2A als auch AKR2B besitzen eine solche putative NES, wie der Vergleich mit NtANK1 aus Tabak, RanBP1a und c und der in Haasen et al. (1999) postulierten NES zeigt (Abb. 15; Böttner et al., 2009; Haasen et al., 1999).

$\begin{array}{lll}\text { AKR2A } & (325) & \text { KLNSQLEVVKLLEKDAFL } \\ \text { AKR2B } & (327) & \text { RLNNQLDVVKLLEKDAFL } \\ \text { ANK1 } & (333) & \text { KLNNQQEVLKLLEKDVFL } \\ & & \\ \text { RanBP1a } & (171) & \text { DTAGLLEKLTVEETKTEE } \\ \text { RanBP1C } & (170) & \text { EAAGLIENLSVEENISEE } \\ \text { NES } & & \text { LXXXLXXLXL }\end{array}$

Abbildung 15: Vergleich der Aminosäuresequenzen der putativen NES am C-Terminus der Proteine. AKR2A und B aus Arabidopsis, NtANK1 aus Tabak (Böttner et al., 2009), RanBP1a und c aus Arabidopsis und NES nach Haasen et al. (1999). Konservierte Aminosäuren sind fett gedruckt.

Zur LMB-Behandlung wurden Arabidopsis Protoplasten mit YFP-AKR2A/B und ARR2-RFP kotransformiert und 0,5 - 4 Stunden vor der Betrachtung im Mikroskop wurde das LMB $(2 \mu \mathrm{M})$ hinzugegeben. Dies führte in ca. 25\% der Fälle zu einer deutlichen Akkumulation der Ankyrin-repeat Proteine im Kern (Abb. 16). In transformierten, aber nicht mit LMB behandelten Zellen war eine Kernlokalisation nie detektierbar.

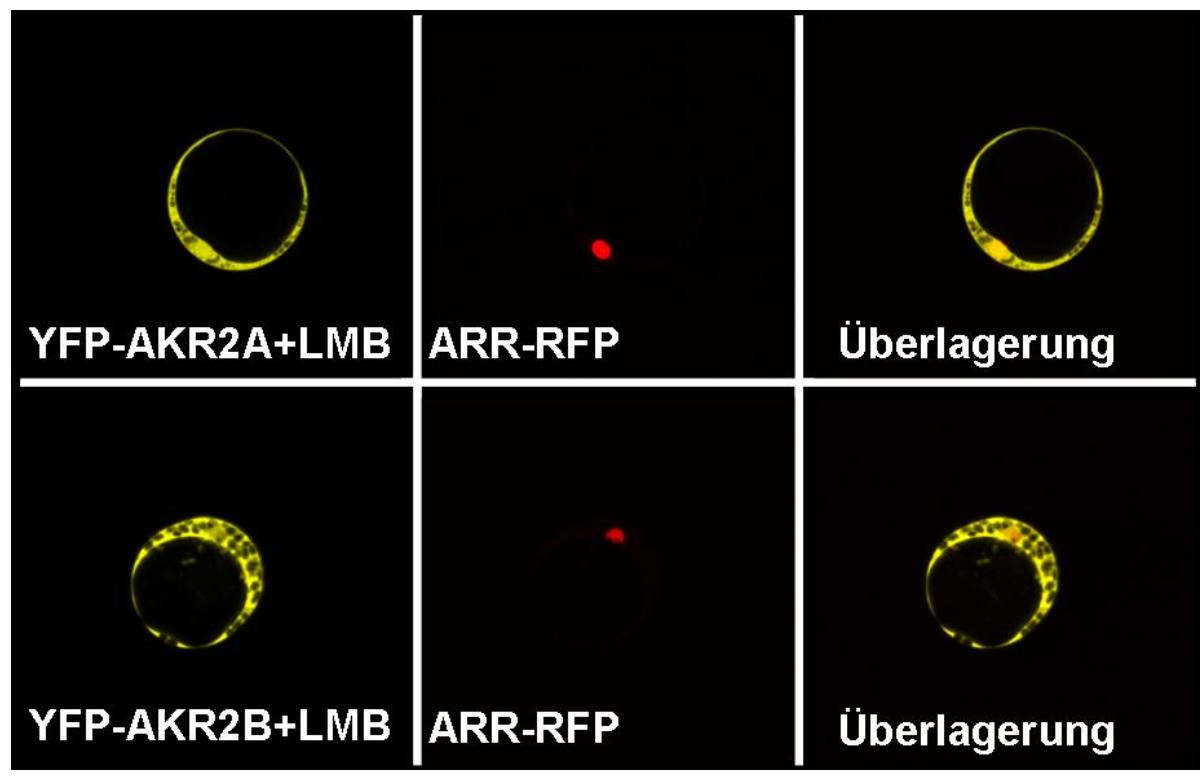

Abbildung 16: Zelluläre Lokalisation von AKR2A/B nach LMB-Behandlung. Arabidopsis-Protoplasten wurden mit YFP-AKR2A/B und ARR2-RFP kotransformiert, 0,5 - 4 Stunden mit $2 \mu \mathrm{M}$ LMB inkubiert und die Fluoreszenz im konfokalen Mikroskop detektiert. YFP-Fluoreszenz ist im Cytoplasma und im Kern zu sehen, die Fluoreszenz der Kernkontrolle ARR-RFP ist nur im Kern zu sehen. 1. Spalte: YFPKanal, 2. Spalte: RFP-Kanal, 3. Spalte: Überlagerung 


\subsubsection{Mutation der putativen NES von AKR2A und AKR2B führt ebenfalls zur Kernlokalisation}

Um die Funktionalität der NES zu überprüfen wurden in AKR2A und $B$ die vier konservierten, hydrophoben Aminosäuren mutiert und durch Alanin ersetzt (Abb. 17; Böttner et al., 2009).

\begin{tabular}{lcc} 
AKR2A & (325) & \multicolumn{2}{c}{ KLNSQLEVVKLLEKDAFL } \\
NES $_{\text {mut }}$ & & A A A A \\
& & \\
AKR2B & (327) & RLNNQLDVVKLLEKDAFL \\
NES $_{\text {mut }}$ & & A A A A \\
NES & & LXXXLXLXL
\end{tabular}

Abbildung 17: Übersicht über die mutierten Aminosäuren, um die Funktionalität der NES zu überprüfen. Alle 4 konservierten Aminosäuren wurden durch Alanin ersetzt.

In transformierten Arabidopsis-Protoplasten führte die Mutation der NES zur Lokalisation der Proteine im Kern und im Cytoplasma in ca. 25\% der Fälle, ähnlich wie nach der LMB-Behandlung (Abb. 18). Diese Ergebnisse deuten darauf hin, dass AKR2A und B eine funktionelle NES besitzen, die dafür sorgt, dass die Proteine sich unter normalen Bedingungen nur im Cytoplasma befinden und keine Akkumulation im Kern stattfindet. Nur unter Bedingungen, in denen die NES außer Funktion ist, akkumulieren AKR2A/B auch im Kern.

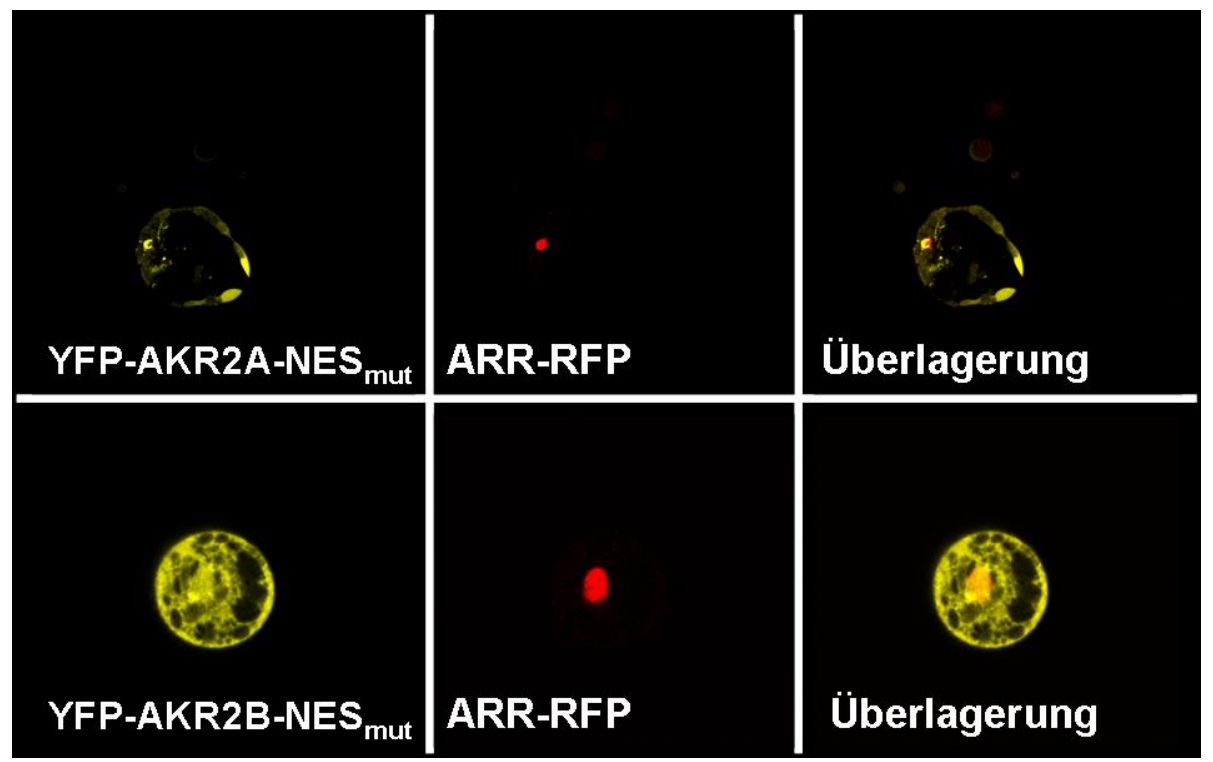

Abbildung 18: Zelluläre Lokalisation von AKR2A/B-NES mut. Arabidopsis-Protoplasten wurden mit YFP-AKR2A/B-NES mut und ARR2-RFP kotransformiert und die Fluoreszenz im konfokalen Mikroskop detektiert. YFP-Fluoreszenz ist im Cytoplasma und im Kern zu sehen, die Fluoreszenz der Kernkontrolle ARR-RFP ist nur im Kern zu sehen. 1. Spalte: YFP-Kanal, 2. Spalte: RFP-Kanal, 3. Spalte: Überlagerung 


\subsection{Erzeugung von transgenen Pflanzen zur funktionalen Analyse von AKR2A und AKR2B}

Zur Analyse von Proteinfunktionen stehen mehrere Methoden zur Verfügung, dazu gehört auch die Analyse von transgenen Pflanzen mit erhöhter oder reduzierter Transkriptmenge des zu untersuchenden Proteins. Deshalb wurden im Rahmen dieser Arbeit Pro ${ }_{35 s}: A K R 2 A-$ und Pro ${ }_{35 s}$ :AKR2B- (Überexpressions-) Pflanzen und AKR2-RNAi-Pflanzen erzeugt.

\subsubsection{Erzeugung von Pro $_{35 s}$ :AKR2A und Pro $_{35 s}$ :AKR2B Pflanzen}

Zur Erzeugung von Überexpressionspflanzen wurden in den GatewayExpressionsvektor pAlligator2 die Gene AKR2A und $B$ inseriert (Bensmihen et al., 2004). Die zu übertragende T-DNA in diesem Vektor enthält neben der GatewayKassette mit dem 35S-Promotor zur Überexpression auch das GFP-Gen (grün fluoreszierendes Protein) unter Kontrolle eines Samen-spezifischen Promotors. Dies führt dazu, dass die nach der "floral dip“-Transformation erhaltenen ArabidopsisSamen unter einem Fluoreszenz-Mikroskop selektioniert werden konnten, so dass nur grün fluoreszierende Samen, die die T-DNA enthielten, zur weiteren Verwendung ausgelegt wurden. Mit Blättern dieser Pflanzen wurde ein Western-Blot mit einem Antikörper gegen AKR2A durchgeführt, um zu überprüfen welche Pflanzen eine starke Überexpression zeigen. Der Antikörper erkennt sowohl AKR2A als auch AKR2B aufgrund der hohen Sequenzidentität. Das Signal der endogenen Proteine entspricht einem Molekulargewicht von ca. $37 \mathrm{kDa}$, die überexprimierten Proteine sind Fusionsproteine mit HA-Anhang, weshalb deren Signal einem Molekulargewicht von ca. $43 \mathrm{kDa}$ entspricht (Abb. 19). Trotz der deutlichen Überexpression unterschieden sich die Pflanzen phänotypisch nicht vom Wildtyp. 


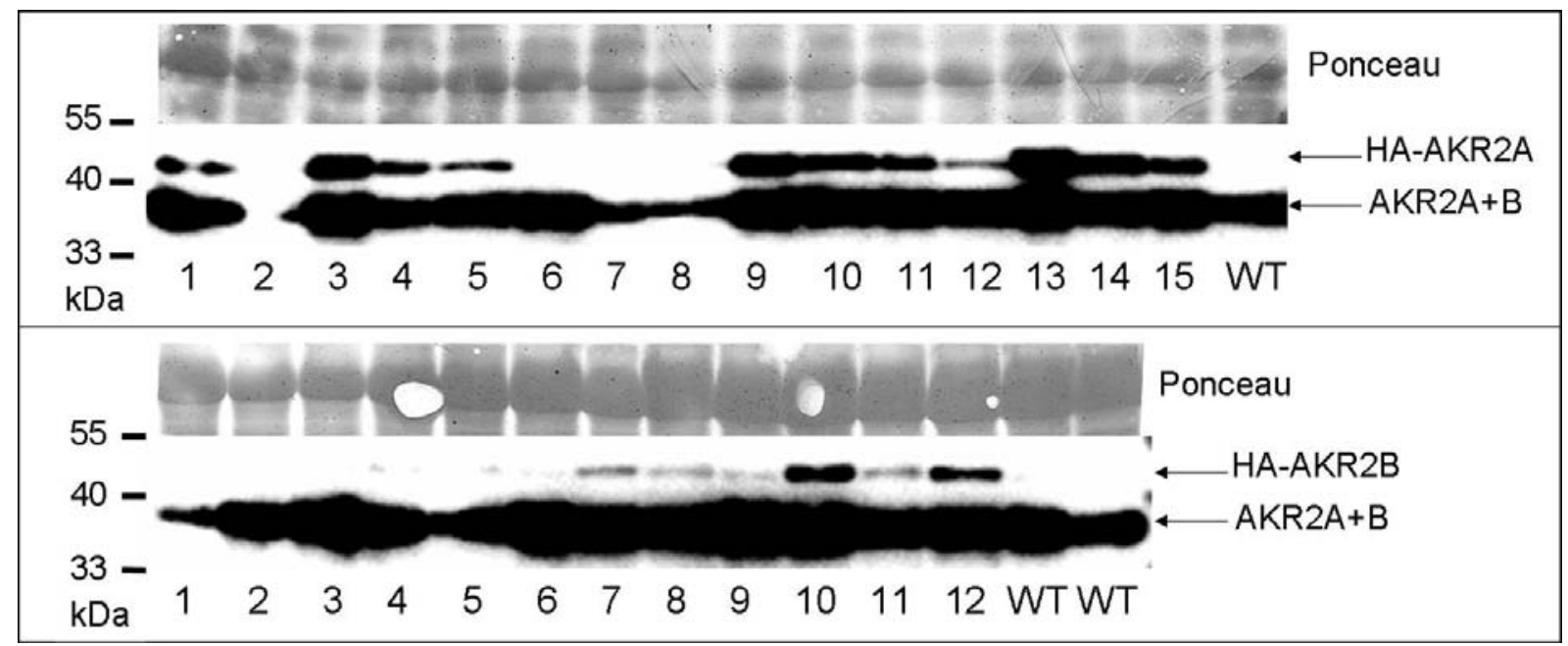

Abbildung 19: Western Blot von Pro $_{35}$ :AKR2A (oben) und Pro ${ }_{35 s}$ :AKR2B (unten) Pflanzen der $\mathrm{F}_{1-}$ Generation mit dem $\alpha$-AKR2A-Antikörper. AKR2A + B: Signal der endogenen Proteine; HA-AKR2A bzw. B: Signale des Fusionsproteins mit HA-Anhang in überexprimierenden Pflanzen. Ponceau: Färbung aller Proteine auf der Membran zur Ladungskontrolle.

\subsubsection{Identifizierung von $a k r 2 b$ Mutanten}

In der öffentlichen Datenbank des SIGnAL (Salk Institute Genomic Analysis Laboratory) konnte nach T-DNA-Insertionsmutanten recherchiert werden, die dann auf reduzierte Transkriptmenge und evtl. Phänotypen untersucht werden konnten. Es standen T-DNA-Insertionsmutanten der Linie SALK_039330 zu Verfügung, bei der die Insertion im 7. (vorletzten) Exon von $A K R 2 B$ liegt. Durch PCR auf genomische DNA konnten die Pflanzen auf Homozygotie überprüft werden (Abb. 20). Es wurden 8 Pflanzen getestet, bei 5 davon konnte durch eine Bande mit den Primern LBa1 und pHOS6 die Insertion der T-DNA bestätigt werden. Bei diesen 5 Pflanzen fehlt die Bande in der zweiten PCR (pHOS2 und pHOS6), sie sind also homozygot (Abb. 20 A). In der Übersicht (Abb. 20 B) ist zu erkennen, wo die Primer binden im Verhältnis zum Insertionsort der T-DNA. Bei Mutanten mit Insertion entsteht kein PCR-Produkt mit den Primern pHOS2 und pHOS6, weil diese dann zu weit auseinander liegen. Andererseits entsteht kein PCR-Produkt mit LBa1 und pHOS6, wenn die Insertion fehlt (z.B. im Wildtyp). 
A

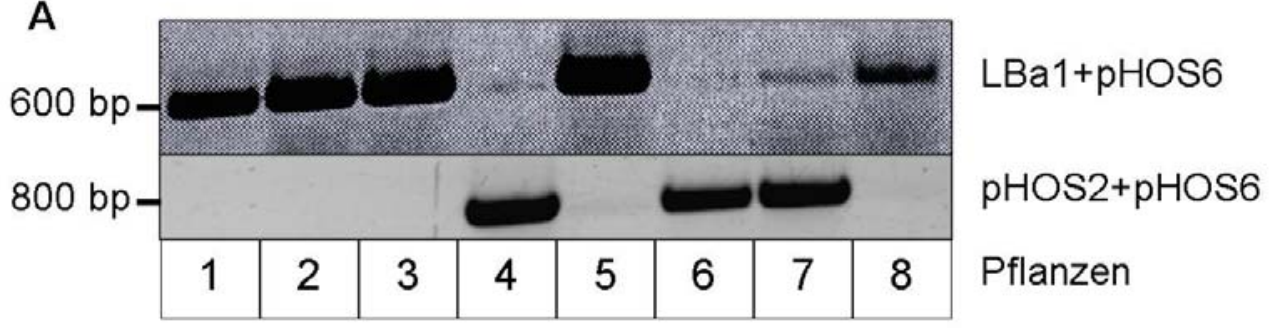

B

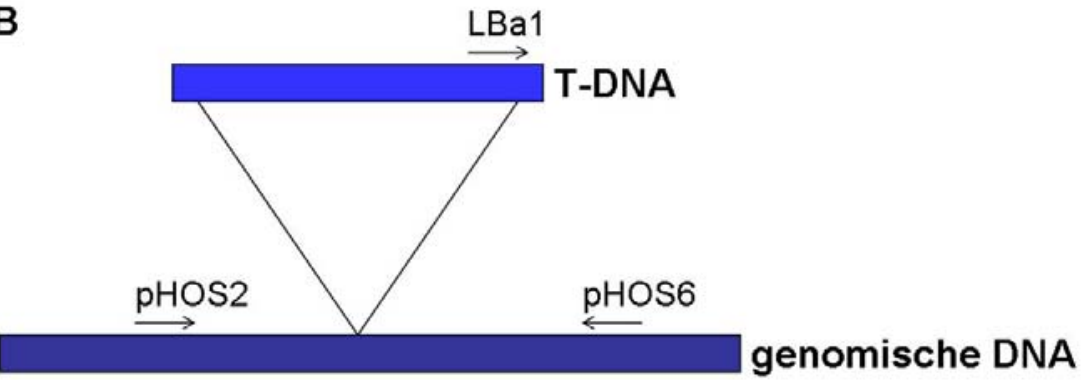

Abbildung 20: Test der SALK_039330-Mutanten auf Homozygotie bezüglich der T-DNA-Insertion. A: Gelbild der PCRs auf genomische DNA von 8 verschiedenen SALK_039330-Pflanzen mit den angegebenen Primern. B: Schema der T-DNA-Insertion mit den zugehörigen und in (A) verwendeten Primern. pHOS2: linker genomischer Primer; pHOS6: rechter genomischer Primer; LBa1: „left border“ Primer der T-DNA

Die akr2b-Mutante wurde im Northern Blot untersucht, ob die Transkriptmenge von $A K R 2 B$ reduziert ist (Abb. 21). Die Nachkommen von zwei verschiedenen Pflanzen (2 und 5) zeigen keine RNA für $A K R 2 B$, wohingegen beim Wildtyp eine Bande zu sehen ist und in einer Pro ${ }_{35}$ :AKR2B Linie ein stärkeres Signal zu sehen ist. Die Signale für $A K R 2 A$ sind in allen Pflanzen gleich. Die Mutante ist also ein akr2bknock-out, zeigt aber keinen veränderten Phänotyp im Vergleich zum Wildtyp.

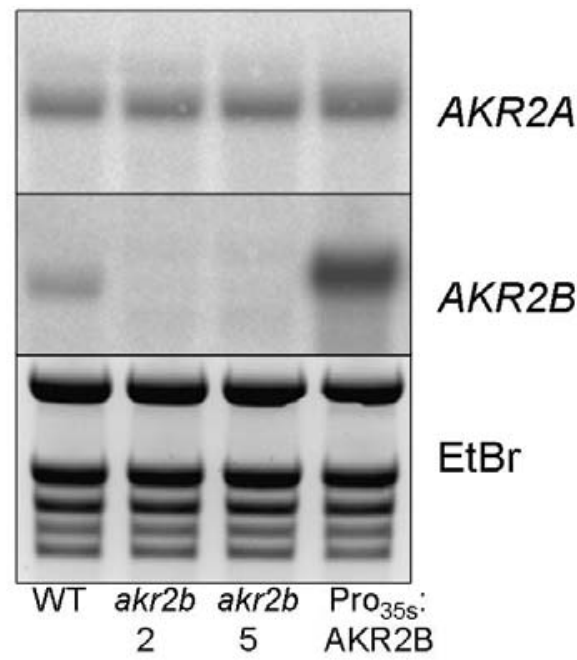

Abbildung 21: Northern Blot von transgenen Pflanzen mit veränderter AKR2B Expression. oben: alle Pflanzen zeigen ein gleich starkes Signal für $A K R 2 A$, Mitte: Pflanzen 2 und 5 der akr2b-Mutante zeigen kein Signal für $A K R 2 B, P_{3}{ }_{35 s}: A K R 2 B$ Pflanzen zeigen ein stärkeres Signal als der Wildtyp (WT), unten: Ethidium Bromid (EtBr) Ladungskontrolle. 


\subsubsection{Erzeugung von AKR2-RNAi Pflanzen}

Um die Expressionsmenge von $A K R 2 A$ und $B$ zu reduzieren, wurden RNAi-Pflanzen erzeugt, in denen beide Proteine nicht oder nur wenig synthetisiert werden. Dafür wurde $A K R 2 A$ in den RNAi-Vektor pFGC rekombiniert und für "floral dip" verwendet. Positive Transformanten konnten mit BASTA ${ }^{\circledR}$ selektiert werden. Im Western Blot ist zu erkennen, dass die ARK2A/B-Proteinmenge in einigen Pflanzen stark reduziert ist (Abb. 22). Aufgrunddessen wurden die Linien 6, 8, 18 und 21 weiter verwendet und analysiert.

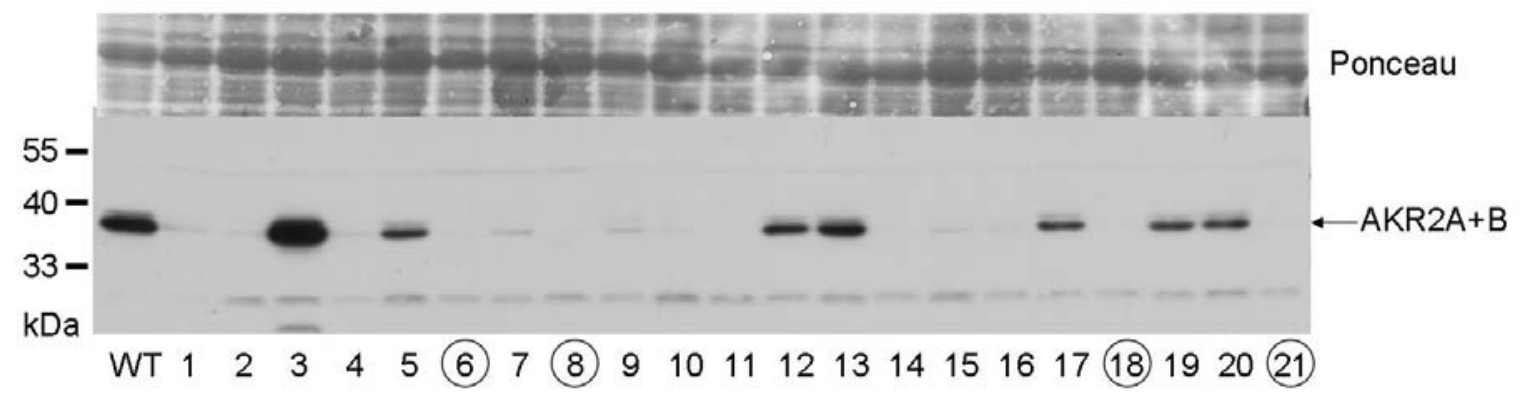

Abbildung 22: Western Blot der AKR2-RNAi-Pflanzen der $F_{1}$-Generation mit dem $\alpha$-AKR2AAntikörper. AKR2A + B: Signal der endogenen Proteine, das aufgrund des RNAi-Effekts in einigen Pflanzen fehlt. Ponceau: Färbung aller Proteine auf der Membran zur Ladungskontrolle.

In der Veröffentlichung Yan et al. (2002) sind Antisense Pflanzen von AKR2A beschrieben, die nekrotische Flecken auf den Blättern zeigen. Diese Pflanzen wurden im C24-Hintergrund erstellt, während in dieser Arbeit Columbia (Col-0) als Hintergrund für die transgenen Pflanzen verwendet wurde und die Col-0-AKR2-RNAi Pflanzen zeigen keine nekrotischen Flecken. Um den von Yan et al. (2002) beschriebenen Phänotyp zu reproduzieren, wurden ebenfalls AKR2-RNAi Pflanzen und auch Pro $35 s$ :AKR2A Pflanzen im C24-Hintergrund erzeugt (Abb. 23).

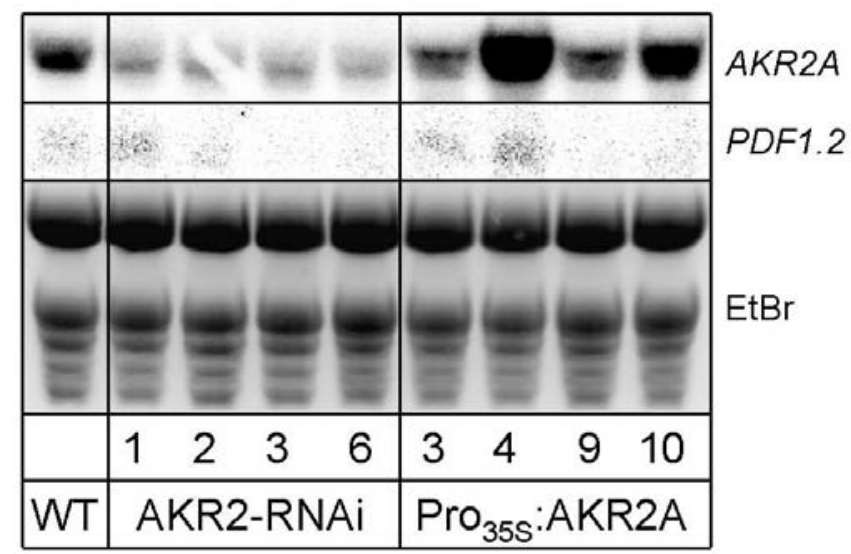

Abbildung 23: Northern Blot von RNA aus ganzen Keimlingen mehrerer Linien der transgenen AKR2A-Pflanzen im C24-Hintergrund. AKR2A ist in den RNAi Pflanzen deutlich reduziert, in den Pro $_{35 s}$ :AKR2A Pflanzen in Linien 4 und 10 deutlich stärker als im Wildtyp exprimiert, PDF1.2 ist nicht deutlich exprimiert. Die Pflanzen wuchsen in Sterilkultur auf MS-Medium und waren ca. 2 Wochen alt. EtBr: Ladungskontrolle, WT: Wildtyp. 
Dazu wurden die gleichen Methoden und Vektoren benutzt wie schon beschrieben. Die AKR2A-Expression ist in den AKR2-RNAi Pflanzen deutlich reduziert und in zwei der getesteten Pro $_{355}: A K R 2 A$ Linien (4 und 10) deutlich verstärkt (Abb. 23). Die Pflanzen zeigten allerdings keine nekrotischen Flecken oder andere phänotypische Auffälligkeiten, weder in Sterilkultur noch bei Wachstum in Erde.

In den folgenden Kapiteln werden als AKR2-RNAi Pflanzen immer die Pflanzen im Col-0-Hintergrund bezeichnet.

\subsubsection{AKR2-RNAi Pflanzen unterscheiden sich phänotypisch vom Wildtyp}

Bei der Anzucht der AKR2-RNAi Pflanzen in Erde war nach 3-4 Wochen gut zu erkennen, dass sie kleiner und heller sind als der Wildtyp. Dies war besonders beim Wachstum der Blütenstände zu sehen (Abb. 24 A), der Wildtyp hatte deutlich höhere Blütenstände als die RNAi-Pflanzen. Interessanterweise gibt es bei den RNAiPflanzen bei allen gemessenen Parametern eine Abstufung in Abhängigkeit der AKR2A/B-Proteinmenge (Abb. 24 B). In den RNAi-Pflanzen \#6 und \#8 ist kein Protein detektierbar und sie sind die Linien mit der geringsten Wuchshöhe. Bei \#18 ist etwas Protein im Western Blot detektierbar und bei \#21 ist das Signal fast so stark wie im Wildtyp. Dementsprechend wächst der Blütenstand von \#18 höher als bei \#6 und \#8, und der von \#21 ist noch höher. Es wurde auch die Blattfläche gemessen (Abb. $24 \mathrm{C}$ ), wobei sich das gleiche Muster ergibt: \#6 und \#8 haben die kleinste Blattfläche, dann \#18, und \#21 zeigt hier die gleiche Blattfläche wie der Wildtyp.

Das Samengewicht wurde bestimmt, indem 100 Samen auf der Feinwaage ausgewogen wurden, und es zeigte sich, dass \#6 und \#8 ein reduziertes Samengewicht aufweisen (Abb. 24 D). Wie oben erwähnt war nicht nur die reduzierte Größe der RNAi-Pflanzen auffällig, sondern sie sahen auch heller aus. Deshalb wurde der Chlorophyllgehalt der Blätter gemessen und der optische Eindruck wurde dadurch bestätigt, dass die RNAi-Linien weniger Chlorophyll enthalten (Abb. 24 E). Dabei wurde \#18 nicht mit getestet, die anderen Linien zeigen die Ausprägung wieder in Abhängigkeit der AKR2A/B-Proteinmenge, \#6 und \#8 haben die geringste Menge Chlorophyll und \#21 etwas mehr, jedoch weniger als der Wildtyp. 


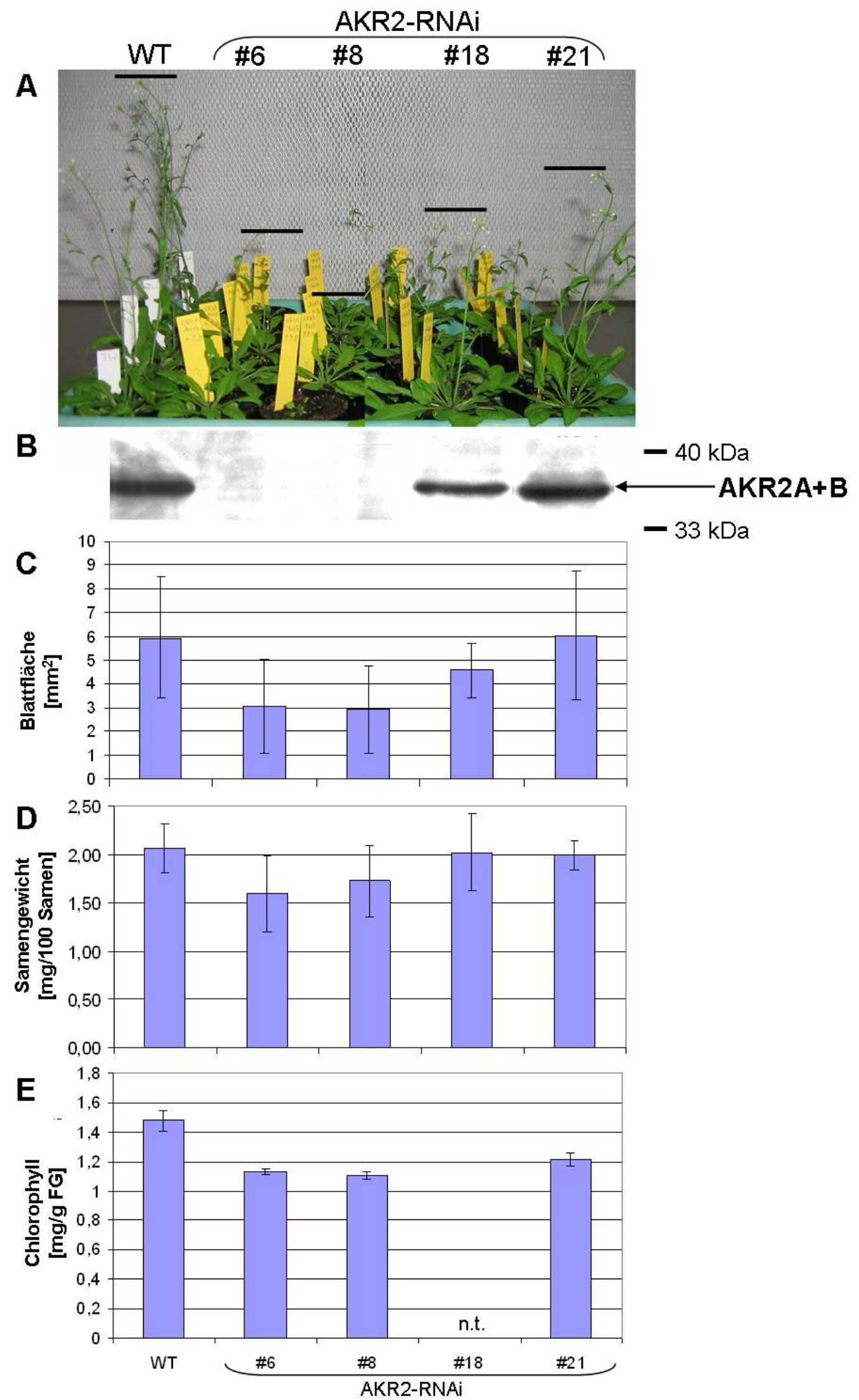

Abbildung 24: AKR2-RNAi Pflanzen zeigen Unterschiede im Phänotyp verglichen mit dem Wildtyp. A: Die Blütenstände des Wildtyps (WT) sind höher als die der RNAi Pflanzen, in Abhängigkeit der Proteinmenge im Western Blot (B). C: Die Blattfläche wurde mithilfe des Programms "Blattfläche“ von Fotos gleichaltriger Pflanzen, die noch nicht blühten, bestimmt. D: Für das Samengewicht wurden 100 Samen auf der Feinwaage ausgewogen. E: Chlorophyllgehalt der Blätter wurde photometrisch in Methanollösung bestimmt (s. Material und Methoden). Linie \#18 wurde nicht getestet (n.t.). 


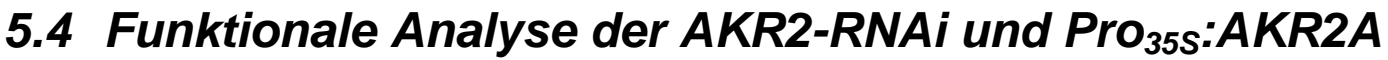 Pflanzen und der akr2b Mutante}

\subsubsection{Microarray zur Analyse der AKR2-RNAi und Pro $_{355}$ :AKR2A Pflanzen}

Aufgrund des beobachteten Phänotyps der RNAi Pflanzen wurden diese zur weiteren Untersuchung für ein Microarray-Experiment eingesetzt. Beim Microarray-Experiment kann das gesamte Transkriptom einer Pflanze untersucht werden, es wurden dafür "Arizona whole-genome microarrays" verwendet. Das Transkriptom der RNAi Pflanzen konnte so mit dem des Wildtyps verglichen werden. Außerdem wurden Pro $_{35 s}$ :AKR2A Pflanzen in diesem Microarray-Experiment eingesetzt, so dass deren Transkriptom ebenfalls mit dem des Wildtyps verglichen werden konnte. Die Pflanzen mussten dazu unter gleichen, möglichst reproduzierbaren Bedingungen, die wenigen Schwankungen unterliegen, angezogen werden. Aufgrund von Erfahrungen im Labor wurde die sterile Anzucht auf Agarplatten mit 1xMS-Salzen und 2\% Saccharose im Langtag gewählt. 2 Wochen alte Keimlinge von 2 Agarplatten wurden vereinigt und 2 Replikate von jeder Probe zur RNA-Extraktion verwendet.

\subsubsection{Ergebnisse der Transkriptomanalyse der AKR2-RNAi Pflanzen}

Die kompletten Listen mit den in AKR2-RNAi Pflanzen stärker und schwächer exprimierten Genen, verglichen mit dem Wildtyp, sind im Anhang. Insgesamt sind 115 Gene stärker in den RNAi Pflanzen exprimiert als im Wildtyp („hochreguliert“) und 102 schwächer („herunterreguliert"), wobei der Schwellenwert für den P-Wert als 0,02 definiert wurde und für das Signal $\log ($ RNAi/WT) als 3. In Tabelle 17 sind jeweils die ersten 20 Gene dieser Listen aufgezeichnet. Dabei stehen AKR2A und $A K R 2 B$ an erster Stelle der herunterregulierten Gene, was nochmals die Funktionalität des RNAi-Effektes bestätigt. Außerdem sind keine anderen, homologen Ankyrin-repeat Proteine unter den herunterregulierten Genen, d.h. dass der RNAi-Effekt spezifisch ist.

Ein ebenfalls stark hochreguliertes Gen ist WRKY40, für das ebenfalls eine Rolle in der Pathogenabwehr beschrieben ist. Die wrky18/wrky40-Doppelmutante und die wrky18/wrky40/wrky60-Triplemutante sind resistenter gegenüber $P$. syringae, aber anfälliger gegenüber einer Infektion mit B. cinerea als der Wildtyp (Xu et al., 2006). 
Tabelle 17: Gene, die laut Microarray in den AKR2-RNAi Pflanzen stärker, bzw. schwächer exprimiert wurden als im Wildtyp. Davon sind jeweils die 20 am stärksten regulierten Gene aufgeführt. Ein negatives Vorzeichen bedeutet schwächere Expression in der transgenen Pflanze, je kleiner der PWert, desto signifikanter sind die Expressionsdaten.

\begin{tabular}{|c|c|c|c|}
\hline Gen AGI & $\begin{array}{c}\log \\
(\mathrm{RNAi} / \mathrm{WT})\end{array}$ & P-Wert & Annotation \\
\hline At1g75830 & 10.8 & 0.00317 & plant defensin protein, (PDF1.1) \\
\hline At5g44420 & 10.6 & 0.00333 & plant defensin protein, (PDF1.2a) \\
\hline At5g59320 & 10.6 & 0.00557 & lipid transfer protein 3 (LTP3) \\
\hline At5g59310 & 10.4 & 0.00852 & lipid transfer protein 4 (LTP4) \\
\hline At5g44430 & 8.5 & 0.00328 & plant defensin protein, (PDF1.2c) \\
\hline At2g26020 & 7.3 & 0.00681 & plant defensin protein, (PDF1.2b) \\
\hline At1g80840 & 6.5 & 0.00246 & WRKY40 \\
\hline At4g22690 & 6.5 & 0.00247 & cytochrome P450 family protein flavonoid, CYP706A1 \\
\hline At4g24570 & 6.4 & 0.00232 & mitochondrial substrate carrier protein \\
\hline At2g41100 & 6.2 & 0.00275 & touch-responsive protein ( $\mathrm{TCH} 3)$ \\
\hline At5g08680 & 5.9 & 0.00297 & ATP synthase beta chain, mitochondrial, putative \\
\hline At3g55980 & 5.8 & 0.00547 & zinc finger ( $\mathrm{CCCH}$-type) family protein \\
\hline At2g26010 & 5.7 & 0.00415 & plant defensin-fusion protein (PDF1.3) \\
\hline At4g30270 & 5.6 & 0.00264 & endo-xyloglucan transferase, MERI-5(B) (SEN4) \\
\hline At5g67480 & 5.4 & 0.00254 & $\begin{array}{l}\text { TAZ zinc finger family protein / BTB/POZ domain- } \\
\text { containing protein (BT4) }\end{array}$ \\
\hline At2g18193 & 5.4 & 0.00232 & AAA-type ATPase family protein \\
\hline At1g24260 & 5.4 & 0.00315 & MADS-box protein (AGL9) (SEP3) \\
\hline At4g23600 & 5.3 & 0.00477 & $\begin{array}{l}\text { coronatine-responsive tyrosine aminotransferase / } \\
\text { tyrosine transaminase (CORI3, JR2) }\end{array}$ \\
\hline At2g28630 & 5.2 & 0.00204 & $\begin{array}{l}\text { beta-ketoacyl-CoA synthase family protein } \\
\text { (Very-long-chain fatty acid condensing enzyme 12) }\end{array}$ \\
\hline At5g33355 & 5.0 & 0.00216 & defensin-like (DEFL) family protein \\
\hline At4g38860 & -4.8 & 0.00233 & auxin-responsive protein, putative \\
\hline At4g12545 & -4.8 & 0.00258 & protease inhibitor/seed storage/LTP family protein \\
\hline At2g39800 & -4.8 & 0.00232 & P5CS1: delta1-pyrroline-5-carboxylate synthase \\
\hline At4g26530 & -4.8 & 0.00264 & fructose-bisphosphate aldolase, cytoplasmic \\
\hline At3g22600 & -4.9 & 0.00221 & protease inhibitor/seed storage/LTP family protein \\
\hline At4g19690 & -5.1 & 0.00232 & $\mathrm{Fe}(\mathrm{II})$ transport protein (IRT1) \\
\hline At1g32080 & -5.2 & 0.00246 & membrane protein, putative \\
\hline At5g48000 & -5.3 & 0.00301 & cytochrome P450 family protein, CYP708A2 \\
\hline At2g05510 & -5.3 & 0.00276 & glycine-rich protein \\
\hline At2g33790 & -5.8 & 0.00226 & pollen Ole e 1 allergen protein \\
\hline At3g25830 & -6.3 & 0.00424 & monoterpene 1,8-cineole synthase, atTPS-Cin \\
\hline At4g11320 & -6.5 & 0.00232 & cysteine proteinase, putative \\
\hline At3g25820 & -6.6 & 0.00276 & monoterpene 1,8-cineole synthase, atTPS-Cin \\
\hline At2g14610 & -6.7 & 0.00427 & PR1 \\
\hline At2g02120 & -6.8 & 0.00226 & plant defensin-fusion protein, putative (PDF2.1) \\
\hline At5g47450 & -7.2 & 0.00232 & Tonoplast intrinsic protein (TIP2;3) (DELTA-TIP3) \\
\hline At4g33550 & -7.4 & 0.00248 & protease inhibitor/seed storage/LTP family protein \\
\hline At3g53980 & -8.2 & 0.00252 & protease inhibitor/seed storage/LTP family protein \\
\hline At4g35450 & -10.6 & 0.0161 & AKR2A \\
\hline At2g17390 & -10.6 & 0.00204 & AKR2B \\
\hline
\end{tabular}


Bei den hochregulierten Genen fällt außerdem auf, dass mehrere PDF (PflanzenDefensin) Gene darunter sind. Pflanzliche Defensine inhibieren das Wachstum von vielen Pilzen, sind aber für tierische und pflanzliche Zellen nicht toxisch (Thomma et al., 2002). Sie gehören deshalb zur Abwehr der Pflanze gegen pilzliche, nekrotrophe Pathogene, wie z.B. Botrytis cinerea (Leon-Reyes et al., 2009). In Tabelle 18 sind alle PDF-Gene und deren Regulation in den AKR2-RNAi Pflanzen aufgelistet. Es ist zu sehen, dass alle signifikant regulierten PDF1.x Gene hochreguliert sind und alle signifikant regulierten PDF2.x Gene herunterreguliert sind. Die drei Gene mit einem $\mathrm{P}$-Wert von 1 sind nicht signifikant reguliert gegenüber dem Wildtyp.

Tabelle 18: PDF-Gene und deren Regulation in den AKR2-RNAi Pflanzen.

\begin{tabular}{|r|l|l|l|}
\hline Gen AGI & \multicolumn{1}{|c|}{ Name } & $\begin{array}{c}\text { log } \\
\text { (RNAi/WT) }\end{array}$ & \multicolumn{1}{c|}{ P-Wert } \\
\hline At1g75830 & PDF1.1 & 10.8 & 0.0031 \\
\hline At5g44420 & PDF1.2a & 10.6 & 0.00333 \\
\hline At2g26020 & PDF1.2b & 7.3 & 0.0068 \\
\hline At5g44430 & PDF1.2c & 8.5 & 0.0032 \\
\hline At2g26010 & PDF1.3 & 5.7 & 0.0041 \\
\hline At1g19610 & PDF1.4 & 1.4 & 0.0036 \\
\hline At1g55010 & PDF1.5 & -1.0 & 1 \\
\hline At2g02120 & PDF2.1 & -6.8 & 0.0022 \\
\hline At2g02100 & PDF2.2 & -4.0 & 0.0020 \\
\hline At2g02130 & PDF2.3 & -3.3 & 0.0027 \\
\hline At1g61070 & PDF2.4 & -0.1 & 1 \\
\hline At5g63660 & PDF2.5 & -3.0 & 0.0035 \\
\hline At2g02140 & PDF2.6 & -0.09 & 1 \\
\hline
\end{tabular}

Um die Daten des Microarrays weiter zu analysieren standen noch die GO (Gene Ontology)-Annotationen zur Verfügung, die jedes Gen einer Zellkomponente, molekularen Funktionen und biologischen Prozessen zuordnen, soweit bekannt bzw. prognostiziert (Ashburner et al., 2000). Es ist möglich zu überprüfen, welche GOAnnotationen im Microarray-Datensatz im Vergleich mit dem gesamten Arabidopsis Genom überrepräsentiert sind (http://bioinformatics.cau.edu.cn/easygo/; Zhou and Su, 2007). In Tabelle 19 ist aufgezeichnet, welche GO-Annotationen in den Genen, die in den RNAi Pflanzen hochreguliert sind, häufiger vorkommen als im gesamten Arabidopsis Genom. Es sind jeweils die Prozentsätze der Gene angegeben, die diese Annotation haben. Demnach befinden sich mehr Genprodukte im Mitochondrium (14\% statt 4,6\%) und in der Zellwand (10,3\% statt 1,1\%) als erwartet. In der Kategorie "molekularen Funktionen“ ist nur die Transferase Aktivität überrepräsentiert. Dagegen sind die Antworten auf mehrere Stimuli 
überrepräsentiert, z.B. Antwort auf ABA, Abwehrreaktion, Antwort auf oxidativen und biotischen Stress und Antwort auf Kälte.

Tabelle 19: Überrepräsentierte GO-Annotationen der laut Microarry in den RNAi Pflanzen hochregulierten Gene nach Zhou and Su (2007). Zum Vergleich steht in der dritten Spalte der Prozentsatz der so annotierten Gene aus dem gesamten Arabidopsis Genom.

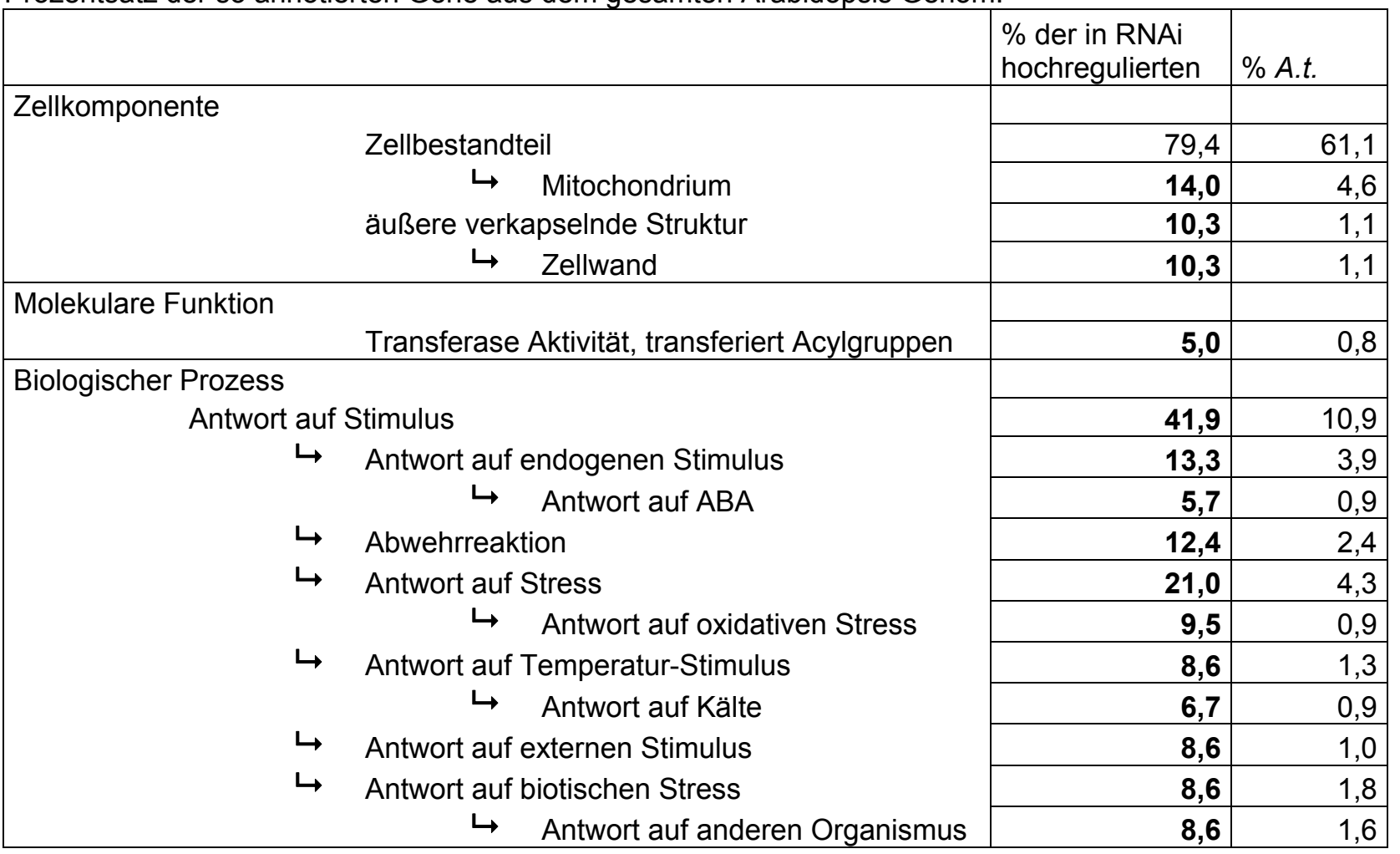

In Tabelle 20 ist für die in den RNAi Pflanzen herunterregulierten Gene angegeben, welche GO-Annotationen häufiger vorkommen als im gesamten Arabidopsis Genom. Hierbei befinden sich ungewöhnlich viele Genprodukte im Endomembransystem, dazu gehören das Endoplasmatische Reticulum, der Golgi Apparat, Vesikel, die Zellmembran und die Kernmembran. Die überrepräsentierte molekulare Funktion ist in diesem Fall Lipidbindung, da in den RNAi Pflanzen viele „protease inhibitor/seed storage/LTP (lipid transfer protein)"-Gene herunterreguliert sind. Diese führen auch zur Überrepräsentation des Lipidtransports in Tabelle 20. Außerdem sind, wie bei den hochregulierten Genen auch die Antworten auf Stimuli (Abwehrreaktion, Stress, Auxin) überrepräsentiert. 
Tabelle 20: Überrepräsentierte GO-Annotationen der laut Microarry in den RNAi Pflanzen herunterregulierten Gene nach Zhou and Su (2007). Zum Vergleich steht in der dritten Spalte der Prozentsatz der so annotierten Gene aus dem gesamten Arabidopsis Genom.

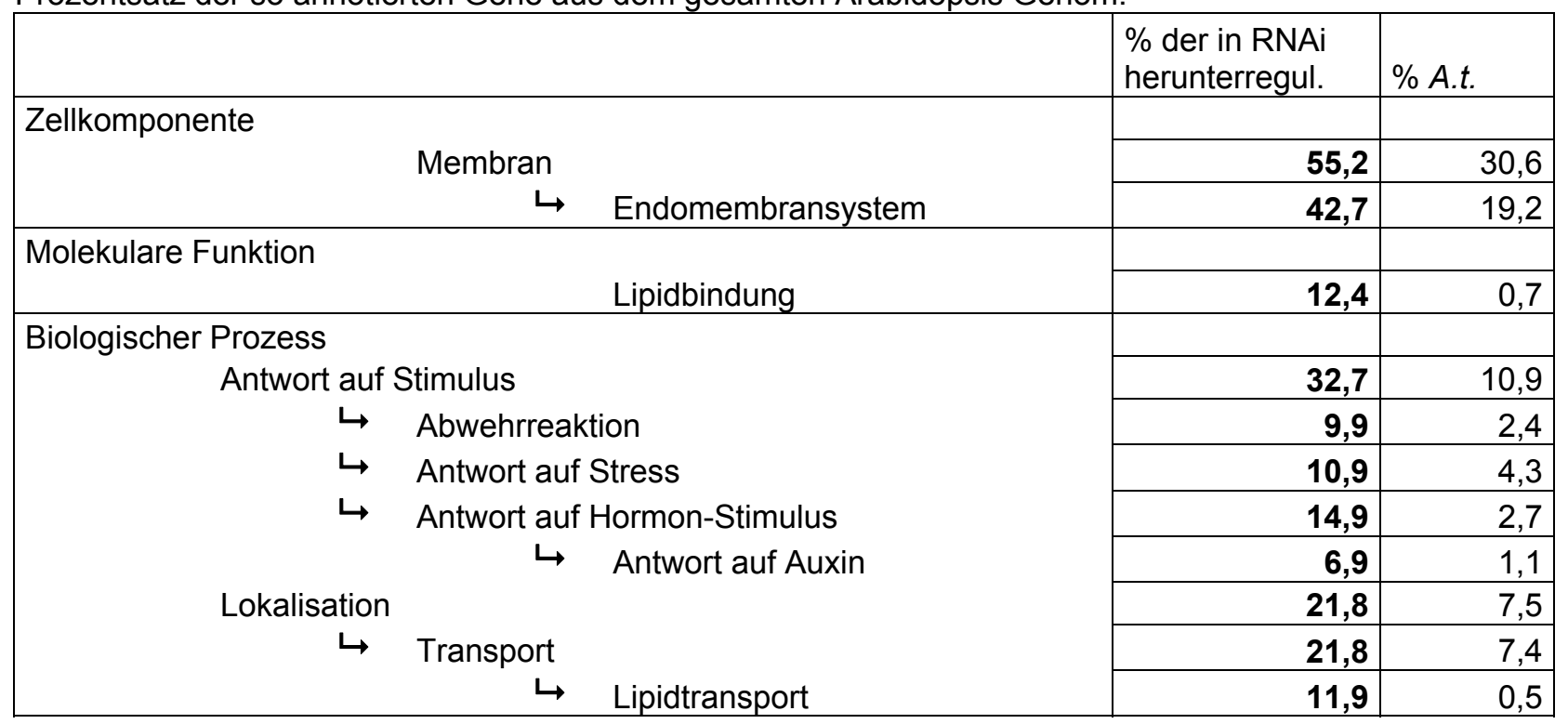

\subsubsection{AKR2-RNAi Pflanzen zeigen eine beeinträchtigte Chloroplasten- Biogenese}

In einer Arbeit aus Korea, die während der Anfertigung dieser Arbeit veröffentlicht wurde, wurde AKR2A als Vermittler für den Import von chloroplastidären Membranproteinen identifiziert (Bae et al, 2008). Es wird dort beschrieben, dass AKR2A im Cytoplasma an OEPs bindet, sie transportiert und ihre Insertion in die Membran vermittelt. Die Arbeitsgruppe hat Dexamethason-induzierbare AKR2ARNAi Pflanzen im akr2b-Hintergrund hergestellt, die beim Wachstum auf Dexamethason gelbe oder weiße Blätter zeigen und ein stark reduziertes Wachstum haben. Außerdem war in diesen Pflanzen die Menge von mehreren Chloroplastenproteinen reduziert und die Chloroplasten enthielten statt Thylakoidmembranen mehrere Vesikel (Bae et al, 2008).

Aufgrund dieser Daten wurden die hier analysierten AKR2-RNAi Pflanzen elektronenmikroskopisch untersucht. Alle elektronenmikroskopischen Aufnahmen und die vorherige Einbettung der Proben in Kunstharz (Spurr) wurden von Andrea Olbrich durchgeführt. Auch in diesem Fall unterscheiden sich die Chloroplasten der AKR2-RNAi Pflanzen von denen des Wildtyps, allerdings nicht so drastisch wie in der Veröffentlichung beschrieben. Die Thylakoidmembranen bilden Grana und es sind auch Stärkekörner zu sehen, wie im Wildtyp (Abb. 25 A, B). Allerdings sind die Thylakoidmembranen lockerer gepackt und es gibt einige leere Zwischenräume, die 
Vesikeln ähneln, allerdings von keiner Membran umgeben sind (Pfeile, Vergrößerung in Abb. $25 \mathrm{C}$ ). Interessanterweise sind die gleichen Veränderungen in Tabak (Nicotiana tabacum) NtANK1-RNAi Pflanzen zu sehen (Abb. 25 D-F). Die NtANK1RNAi Pflanzen zeigen Läsionen, insbesondere in der Nähe der Blattadern, die sich durch eine reduzierte Mesophyllschicht und damit auch einen reduzierten Chlorophyllgehalt auszeichnen (Böttner et al., 2009). Elektronenmikroskopische Aufnahmen wurden von Chloroplasten aus dem grünen, unauffälligen Teil eines Blattes gemacht (Abb. $25 \mathrm{E}$ ) und von Chloroplasten aus einer gelblichen Läsion (Abb. $25 \mathrm{~F}$ ). In beiden Fällen sind Stärkekörner zu sehen und die lockere Packung der Thylakoide mit Leerräumen dazwischen (Pfeile). In Abb. $25 \mathrm{~F}$ ist die große Anzahl von Vesikeln auffällig, die sich innerhalb der Chloroplastenmembran, jedoch außerhalb des Thylakoidnetzwerks befinden.

Trotz der Überrepräsentation von mitochondrialen Proteinen (Tabelle 19), waren die Mitochondrien der AKR2-RNAi Pflanzen in den elektronenmikroskopischen Aufnahmen unauffällig im Vergleich zum Wildtyp.
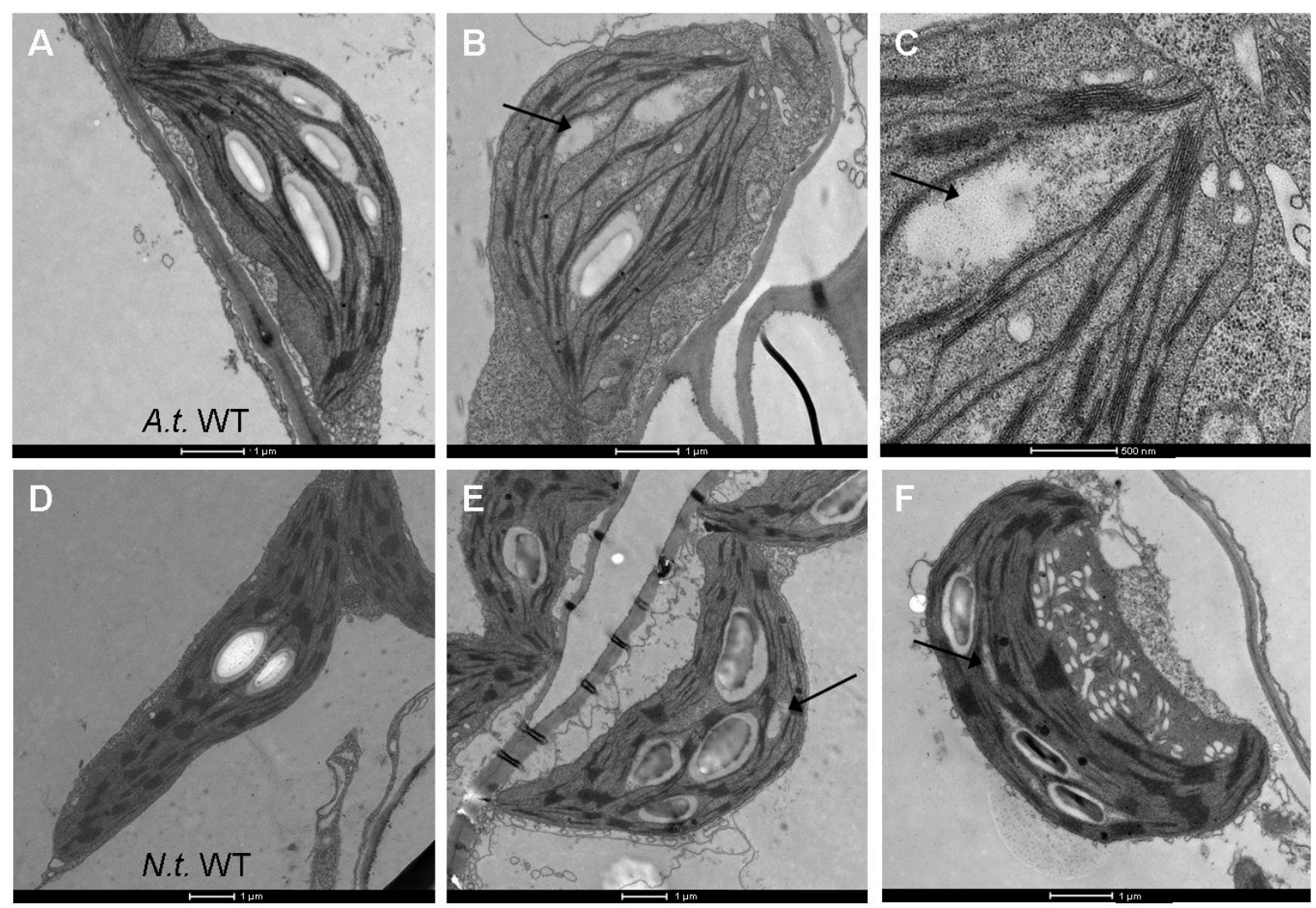

Abbildung 25: Elektronenmikroskopische Aufnahmen von Chloroplasten aus verschiedenen Pflanzen. A: Arabidopsis Wildtyp (A.t. WT), B: Arabidopsis AKR2-RNAi, C: Vergrößerung aus B, D: Tabak Wildtyp (N.t. WT), E: Tabak NtANK1-RNAi grünes Blattstück, F: Tabak NtANK1-RNAi gelbes Blattstück (,Läsion“). Pfeile deuten auf Leerräume zwischen den Thylakoidmembranen, die nicht von einer Membran umgeben sind. Die Balken unter den Bildern entsprechen $1 \mu \mathrm{m}$, außer in C: $500 \mathrm{~nm}$. 
Chloroplastidäre Proteine sind nach den Microarraydaten weder bei den hoch- noch bei den herunterregulierten Genen überrepräsentiert. Es sind allerdings einige Gene dabei, deren Genprodukt sich laut Annotation im Chloroplasten befindet, diese sind in Tabelle 21 zusammengestellt.

Tabelle 21: Gene, die im Microarray der AKR2-RNAi Pflanzen hoch- (positive Zahl) bzw. herunterreguliert (negatives Vorzeichen) waren und denen die GO-Annotation "Chloroplast" zugeordnet ist.

\begin{tabular}{|l|l|l|}
\hline Gen AGI & $\begin{array}{c}\text { log } \\
\text { (RNAi/WT) }\end{array}$ & \multicolumn{1}{c|}{ Annotation } \\
\hline At4g25100 & 4.4 & $\begin{array}{l}\text { superoxide dismutase [Fe], chloroplast (SODB) / iron superoxide } \\
\text { dismutase (FSD1) }\end{array}$ \\
\hline At1g73540 & 3.9 & Nudix hydrolase 21, chloroplast precursor (NUDT21) \\
\hline At5g61440 & 3.9 & thioredoxin family protein \\
\hline At4g08390 & 3.9 & L-ascorbate peroxidase, stromal (sAPX) \\
\hline At1g60950 & 3.3 & ferredoxin, chloroplast (PETF) (AtFD2) (FEDA) \\
\hline At2g22880 & 3.3 & VQ motif-containing protein \\
\hline At2g45180 & 3.2 & protease inhibitor/seed storage/LTP family protein \\
\hline At5g01600 & 3.2 & ferritin 1 (FER1) \\
\hline At1g48570 & 3.0 & zinc finger (Ran-binding) family protein \\
\hline At2g42540 & -3.8 & cold-responsive protein (cor15a) \\
\hline At4g19170 & -3.8 & 9-cis-epoxycarotenoid dioxygenase, putative (NCED4) \\
\hline At1g32080 & -5.2 & membrane protein, putative \\
\hline
\end{tabular}

\subsubsection{Ergebnisse der Transkriptomanalyse der Pro ${ }_{355}$ :AKR2A Pflanzen}

Die kompletten Listen mit den in Pro $_{355}: A K R 2 A$ Pflanzen stärker und schwächer exprimierten Genen, verglichen mit dem Wildtyp, sind im Anhang. Insgesamt sind 45 Gene stärker in den Pro 35 s:AKR2A Pflanzen exprimiert als im Wildtyp (,hochreguliert“) und 17 schwächer („herunterreguliert"), wobei hier ebenfalls der Schwellenwert für den P-Wert als 0,02 definiert wurde und für das Signal log (Pro ${ }_{355} / \mathrm{WT}$ ) als 3. In Tabelle 22 sind jeweils die ersten 20 bzw. alle (17) Gene dieser Listen aufgezeichnet. Dabei fällt auf, dass es sich bei ca. der Hälfte der Gene um dieselben handelt, die auch in den AKR2-RNAi Pflanzen hoch- bzw. herunterreguliert sind (Abb. 26). 
Tabelle 22: Gene, die laut Microarray in den Pro 35 :AKR2A Pflanzen stärker, bzw. schwächer exprimiert wurden als im Wildtyp. Davon sind jeweils die 20 am stärksten regulierten bzw. alle 17 Gene aufgeführt. Ein negatives Vorzeichen bedeutet schwächere Expression in der transgenen Pflanze, je kleiner der P-Wert, desto signifikanter sind die Expressionsdaten. Reg. wie RNAi: die angekreuzten Gene sind in den AKR2-RNAi Pflanzen ebenfalls hoch- bzw. herunterreguliert.

\begin{tabular}{|c|c|c|c|c|}
\hline Gen AGI & $\begin{array}{c}\log \\
\left(\mathrm{PrO}_{35 \mathrm{~S}} / \mathrm{WT}\right)\end{array}$ & P-Wert & Annotation & $\begin{array}{c}\text { reg. wie } \\
\text { RNAi }\end{array}$ \\
\hline At5g59320 & 14.9 & 0.00561 & lipid transfer protein 3 (LTP3) & $\mathrm{X}$ \\
\hline At5g59310 & 14.9 & 0.0065 & lipid transfer protein 4 (LTP4) & $\mathrm{X}$ \\
\hline At1g75830 & 9.0 & 0.00636 & plant defensin-fusion protein (PDF1.1) & $\mathrm{X}$ \\
\hline At4g23600 & 8.0 & 0.00518 & $\begin{array}{l}\text { coronatine-responsive tyrosine aminotransferase / } \\
\text { tyrosine transaminase (CORI3, JR2) }\end{array}$ & $\mathrm{X}$ \\
\hline At4g15210 & 7.9 & 0.00621 & $\begin{array}{l}\text { beta-amylase (BMY1)/1,4-alpha-D-glucan } \\
\text { maltohydrolase }\end{array}$ & $\mathrm{X}$ \\
\hline At5g44420 & 7.7 & 0.00773 & plant defensin protein (PDF1.2a) & $\mathrm{X}$ \\
\hline At4g35295 & 6.7 & 0.00737 & homoserine kinase, putative / HSK & $\mathrm{X}$ \\
\hline At5g44430 & 6.5 & 0.00731 & plant defensin-fusion protein, (PDF1.2c) & $\mathrm{X}$ \\
\hline At4g35610 & 6.2 & 0.00651 & zinc finger (C2H2 type) family protein & \\
\hline At4g24570 & 5.9 & 0.00476 & mitochondrial substrate carrier family protein & $\mathrm{X}$ \\
\hline At2g26020 & 5.5 & 0.0157 & plant defensin-fusion protein, putative (PDF1.2b) & $\bar{X}$ \\
\hline At1g80840 & 4.4 & 0.00578 & WRKY40 & $\mathrm{X}$ \\
\hline At5g51190 & 4.4 & 0.0055 & ERF protein subfamily B-3 of ERF/AP2 & \\
\hline At1g72910 & 4.3 & 0.00515 & $\begin{array}{l}\text { disease resistance protein (TIR-NBS class), } \\
\text { putative }\end{array}$ & $\mathrm{X}$ \\
\hline At2g37770 & 4.3 & 0.00625 & aldo/keto reductase family protein & $\bar{X}$ \\
\hline At1g66100 & 4.2 & 0.00476 & probable thionin-2.4 precursor & \\
\hline At1g27730 & 4.1 & 0.0055 & $\begin{array}{l}\text { zinc finger (C2H2 type) family protein (ZAT10) / } \\
\text { salt-tolerance zinc finger protein (STZ) }\end{array}$ & $\mathrm{X}$ \\
\hline At2g26010 & 4.1 & 0.01 & plant defensin-fusion protein, putative (PDF1.3) & $\mathrm{X}$ \\
\hline At3g28290 & 4.1 & 0.00515 & integrin-related protein $14 a$ & \\
\hline At3g55980 & 4.1 & 0.0142 & zinc finger (CCCH-type) family protein & $\mathrm{X}$ \\
\hline At5g57240 & -3.0 & 0.0113 & oxysterol-binding family protein & \\
\hline At1g18400 & -3.0 & 0.00476 & BR enhanced expression 1 (BEE1) & \\
\hline At5g39110 & -3.0 & 0.00513 & germin-like protein, putative & \\
\hline At5g48485 & -3.1 & 0.00611 & $\begin{array}{l}\text { protease inhibitor/seed storage/LTP family protein; } \\
\text { DIR1: DEFECTIVE IN INDUCED RESISTANCE } 1\end{array}$ & \\
\hline At3g56980 & -3.1 & 0.00518 & OBP3-responsive gene 3 (ORG3) (BHLH039) & \\
\hline At2g05510 & -3.2 & 0.00837 & glycine-rich protein & $\mathrm{X}$ \\
\hline At3g05950 & -3.6 & 0.0065 & $\begin{array}{l}\text { Germin-like protein subfamily } 1 \text { member } 7 \\
\text { precursor }\end{array}$ & \\
\hline At3g56970 & -3.6 & 0.00511 & OBP3-responsive gene 2 (ORG2) (BHLH038) & \\
\hline At1g65960 & -3.9 & 0.00515 & glutamate decarboxylase 2 (GAD 2) & \\
\hline At3g25830 & -4.0 & 0.0128 & monoterpene 1,8-cineole synthase, atTPS-Cin & $\mathrm{X}$ \\
\hline At3g25820 & -4.2 & 0.00756 & monoterpene 1,8-cineole synthase, atTPS-Cin & $\mathrm{X}$ \\
\hline At2g47270 & -4.6 & 0.00601 & transcription factor/ transcription regulator & $\mathrm{X}$ \\
\hline At1g49570 & -5.0 & 0.00862 & Peroxidase 10 precursor (PER10) & $\mathrm{X}$ \\
\hline At1g23730 & -5.8 & 0.0055 & $\begin{array}{l}\text { carbonic anhydrase/carbonate dehydratase, } \\
\text { putative }\end{array}$ & $\mathrm{X}$ \\
\hline At5g19890 & -6.4 & 0.00515 & peroxidase, putative & \\
\hline At4g33720 & -6.9 & 0.00431 & pathogenesis-related protein, putative & \\
\hline At2g14610 & -7.0 & 0.00627 & PR1 & $\mathrm{X}$ \\
\hline
\end{tabular}



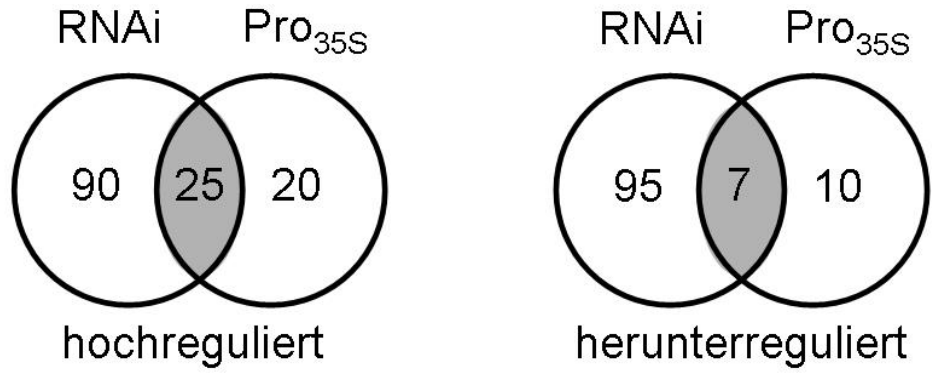

Abbildung 26: Venn-Diagramme der signifikant hoch- bzw. herunterregulierten Gene in den Microarrays der RNAi und Pro $_{35 s}$ Pflanzen. Grau hinterlegt ist die Anzahl der Gene, die in beiden Pflanzenlinien hochreguliert (links) oder in beiden herunterreguliert (rechts) sind. Auf weißem Grund steht die Anzahl der Gene, die in den Pflanzenlinien unterschiedlich reguliert sind. Die Schwellenwerte sind: P-Wert 0,02, log(ratio): 3.

Diese gleich regulierten Gene sind in Tabelle 24 aufgeführt, in der log $\left(\mathrm{PrO}_{35 \mathrm{~s}} / \mathrm{WT}\right)$ und log (RNAi/WT) zum Vergleich nebeneinander stehen. Die relative Expressionsstärke stimmt oft bei beiden Pflanzenlinien überein, z.B. gehören LTP3, LTP4 und PDF1.1 zu den am stärksten hochregulierten Genen. Es sind bei den hochregulierten Genen viele durch Stress induzierte Gene dabei, wie z.B. die PDF1Gene, das Pathogen-induzierte WRKY40 und "disease resistance proteins“. Auch aus Tabelle 23 lässt sich anhand der überrepräsentierten GO-Annotationen entnehmen, dass in den Pro $_{35 s}$ :AKR2A Pflanzen, genau wie in den AKR2-RNAi Pflanzen, ungewöhnlich viele Stress-induzierte Gene exprimiert werden, verglichen mit dem Wildtyp (Abwehrreaktion, Antwort auf Stress, Antwort auf abiotischen Stimulus). Außerdem sind Transkriptionsfaktoren überrepräsentiert von den in Pro $_{35 s}$ :AKR2A Pflanzen hochregulierten Genen. Von den in diesen Pflanzen herunterregulierten Genen ist keine GO-Annotation überrepräsentiert.

Tabelle 23: Überrepräsentierte GO-Annotationen der laut Microarry in den Pro ${ }_{35 s}$ :AKR2A Pflanzen hochregulierten Gene nach Zhou and Su (2007). Zum Vergleich steht in der dritten Spalte der Prozentsatz der so annotierten Gene aus dem gesamten Arabidopsis Genom.

\begin{tabular}{|c|c|c|}
\hline 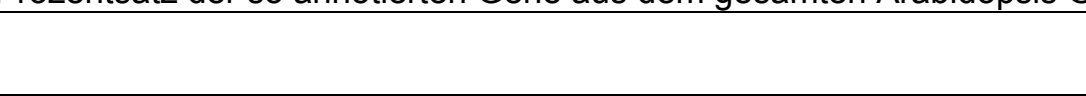 & $\begin{array}{l}\text { \% der in } \mathrm{PrO}_{35 s} \\
\text { hochregulierten }\end{array}$ & $\%$ A.t. \\
\hline \multicolumn{3}{|l|}{ Zellkomponente } \\
\hline Zellwand & 13,6 & 1,1 \\
\hline \multicolumn{3}{|l|}{ Molekulare Funktion } \\
\hline \multirow{2}{*}{$\begin{array}{c}\text { DNA-Bindung } \\
\stackrel{\text { T }}{\hookrightarrow} \text { Transkriptionsfaktor-Aktivität }\end{array}$} & 21,7 & 9,1 \\
\hline & 21,7 & 6,9 \\
\hline \multicolumn{3}{|l|}{ Biologischer Prozess } \\
\hline \multirow{2}{*}{ Antwort auf Stimulus } & 47,7 & 10,9 \\
\hline & 27,3 & 2,4 \\
\hline 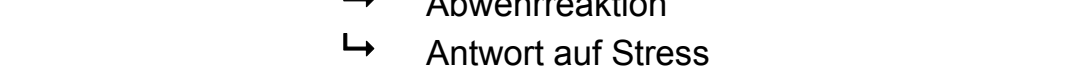 & 15,9 & 4,3 \\
\hline$\hookrightarrow \quad$ Antwort auf abiotischen Stimulus & 15,9 & 3,6 \\
\hline \multirow{2}{*}{$\begin{array}{l}\stackrel{\hookrightarrow}{\text { Antwort auf Hormon-Stimulus }} \\
\text { Regulierung eines zellulären metabolischen Prozesses }\end{array}$} & 20,5 & 2,7 \\
\hline & 20,5 & 7,5 \\
\hline$\hookrightarrow \quad$ Regulierung der Transkription & 20,5 & 7,1 \\
\hline
\end{tabular}


Tabelle 24: Gene, die in den Pro $_{355}: A K R 2 A$ und in den AKR2-RNAi Pflanzen gleich reguliert werden, d.h. in beiden Pflanzenlinien stärker oder in beiden schwächer als im Wildtyp exprimiert werden.

\begin{tabular}{|c|c|c|c|}
\hline Gen AGI & $\begin{array}{c}\log \\
\left(\text { Pro }_{35 \mathrm{~S}} / \mathrm{WT}\right) \\
\end{array}$ & $\begin{array}{c}\log \\
(\text { RNAi/WT) }\end{array}$ & Annotation \\
\hline At5g59320 & 14.9 & 10.6 & lipid transfer protein 3 (LTP3) \\
\hline At5g59310 & 14.9 & 10.4 & lipid transfer protein 4 (LTP4) \\
\hline At1g75830 & 9.0 & 10.8 & plant defensin-fusion protein (PDF1.1) \\
\hline At4g23600 & 8.0 & 5.3 & $\begin{array}{l}\text { coronatine-responsive tyrosine aminotransferase / } \\
\text { tyrosine transaminase (CORI3, JR2) }\end{array}$ \\
\hline At4g15210 & 7.9 & 4.1 & $\begin{array}{l}\text { beta-amylase (BMY1)/1,4-alpha-D-glucan } \\
\text { maltohydrolase }\end{array}$ \\
\hline At5g44420 & 7.7 & 10.6 & plant defensin protein (PDF1.2a) \\
\hline At4g35295 & 6.7 & 3.3 & homoserine kinase, putative / HSK \\
\hline At5g44430 & 6.5 & 8.5 & plant defensin-fusion protein (PDF1.2c) \\
\hline At4g24570 & 5.9 & 6.4 & mitochondrial substrate carrier family protein \\
\hline At2g26020 & 5.5 & 6.2 & plant defensin-fusion protein, putative (PDF1.2b) \\
\hline At1g80840 & 4.4 & 6.5 & WRKY40 \\
\hline At1g72910 & 4.3 & 3.3 & disease resistance protein (TIR-NBS class), putative \\
\hline At2g37770 & 4.3 & 3.4 & aldo/keto reductase family protein \\
\hline At1g27730 & 4.1 & 3.2 & $\begin{array}{l}\text { zinc finger (C2H2 type) family protein (ZAT10) / salt- } \\
\text { tolerance zinc finger protein (STZ) }\end{array}$ \\
\hline At2g26010 & 4.1 & 5.7 & plant defensin-fusion protein, putative (PDF1.3) \\
\hline At3g55980 & 4.1 & 5.8 & zinc finger (CCCH-type) family protein \\
\hline At1g72900 & 3.7 & 3.2 & disease resistance protein (TIR-NBS class) \\
\hline At1g72940 & 3.7 & 3.5 & disease resistance protein (TIR-NBS class) \\
\hline At2g41100 & 3.5 & 6.2 & $\begin{array}{l}\text { touch-responsive protein / calmodulin-related protein } 3 \text {, } \\
\text { touch-induced }(\mathrm{TCH} 3)\end{array}$ \\
\hline At1g24260 & 3.3 & 5.4 & MADS-box protein (AGL9) (SEP3) \\
\hline At1g07135 & 3.1 & 3.5 & glycine-rich protein \\
\hline At2g40140 & 3.1 & 3.3 & zinc finger (CCCH-type) family protein (CZF1/ZFAR1) \\
\hline At5g06320 & 3.0 & 3.5 & harpin-induced (HIN1, NDR1) family protein (NHL3) \\
\hline At1g75900 & 3.0 & 3.0 & family II extracellular lipase 3 (EXL3) \\
\hline At2g05510 & -3.2 & -5.3 & glycine-rich protein \\
\hline At3g25830 & -4.0 & -6.3 & monoterpene 1,8-cineole synthase, atTPS-Cin \\
\hline At3g25820 & -4.2 & -6.6 & monoterpene 1,8-cineole synthase, atTPS-Cin \\
\hline At2g47270 & -4.6 & -4.1 & transcription factor/ transcription regulator \\
\hline At1g49570 & -5.0 & -4.2 & Peroxidase 10 precursor (PER10) \\
\hline At1g23730 & -5.8 & -4.4 & carbonic anhydrase/carbonate dehydratase, putative \\
\hline At2g14610 & -7.0 & -6.7 & PR1 \\
\hline
\end{tabular}




\subsubsection{AKR2-RNAi Pflanzen sind stressanfälliger als der Wildtyp}

Die Ergebnisse des Microarrays deuteten darauf hin, dass die Reduktion von AKR2A und $A K R 2 B$ in Arabidopsis zu einer veränderten Stressantwort führt. Insbesondere die Hochregulierung der PDF1-Gene und die in Tabelle 19 gezeigte Häufung von „Antwort auf Stimulus"-Annotationen implizieren dies. Deshalb wurden die AKR2RNAi Pflanzen mit verschiedenen Methoden Stress unterzogen.

\subsubsection{AKR2-RNAi Pflanzen sind anfälliger gegenüber oxidativem Stress als der Wildtyp}

Pflanzen sind in ihrer normalen Entwicklung oxidativem Stress ausgesetzt. Trockenheit, zu hohe Belichtung oder Kälte führen zu oxidativem Stress, bei dem „reaktive Sauerstoffspezies“ (ROS, reactive oxygen species) entstehen (Grene, 2002). Auch das Herbizid Paraquat (Methylviologen) induziert oxidativen Stress. Das angeregte Photosystem I überträgt ein Elektron auf Paraquat, welches dann Sauerstoff zum chemisch aggressiven Superoxidradikal reduziert. Zudem konkurriert Paraquat mit Dehydroascorbat um die durch Photosystem I bereitgestellten Reduktionsäquivalente, so dass Dehydroascorbat nicht zu Ascorbat reduziert wird. Deshalb kann die Reaktion der Ascorbat-Peroxidase nicht ablaufen, durch die sonst $\mathrm{H}_{2} \mathrm{O}_{2}$ eliminiert wird. Die vermehrte Bildung von Superoxid und die verminderte Entgiftung von $\mathrm{H}_{2} \mathrm{O}_{2}$ führt Paraquat zu sehr schweren Schäden der Mesophyllzellen, wie man durch das Ausbleichen der Blätter erkennen kann (Heldt, 1999).

Zur Applikation von oxidativem Stress wurden Samen vom Wildtyp, von 2 AKR2RNAi Linien (\#6 und \#8) und akr2b Pflanzen auf Agarplatten mit Paraquat-haltigem MS-Medium ausgelegt. Nach 2 Wochen in der Langtag-Klimakammer konnten die Keimlinge ausgezählt werden. Ohne Paraquat waren alle Keimlinge grün, mit steigender Paraquat-Konzentration stieg der Anteil der weißen Keimlinge und der nicht gekeimten Samen. Dies ist in Abb. 27 als \% der grünen Keimlinge aufgetragen. Es ist zu erkennen, dass die Keimlinge der AKR2-RNAi Linien deutlich sensitiver auf Paraquat reagieren, da bei der gleichen Paraquat-Konzentration der Anteil grüner Keimlinge geringer ist als im Wildtyp. Die akr2b Mutante ist anfälliger als der Wildtyp, allerdings nicht in so hohem Maße wie die AKR2-RNAi Pflanzen. 


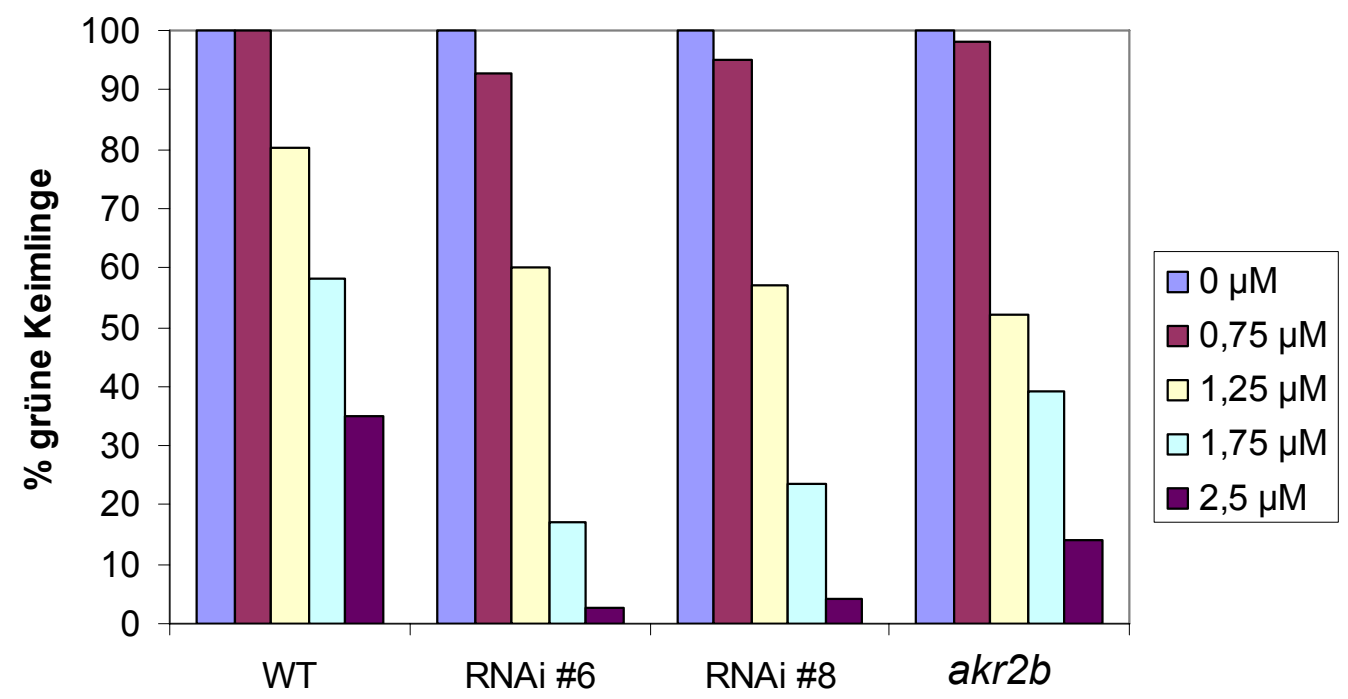

Abbildung 27: Wachstum von Keimlingen des Wildtyps, der AKR2-RNAi Pflanzen und der akr2bMutante auf MS-Medium mit verschiedenen Konzentrationen Paraquat. Samen wurden auf MSAgarplatten mit den rechts angegebenen Konzentrationen Paraquat ausgelegt und nach 2 Wochen in der Klimakammer wurde der Anteil der grünen Keimlinge an den gesamten ausgelegten Samen ausgezählt. Die AKR2-RNAi Linien \#6 und \#8 sind sensitiver als der Wildtyp, akr2b zeigt einen moderaten Phänotyp. Das Experiment wurde dreimal mit ähnlichen Ergebnissen wiederholt.

\subsubsection{AKR2-RNAi Pflanzen sind suszeptibler gegenüber Pseudomonas syringae als der Wildtyp}

In den Ergebnissen des Microarray (Tab. 19) sind auch Gene mit der Annotation „Antwort auf biotischen Stress“ überrepräsentiert. Um zu testen, ob die AKR2-RNAi Pflanzen anders auf biotischen Stress reagieren als der Wildtyp, wurde eine Infektion mit dem Bakterium Pseudomonas syringae DC3000 durchgeführt. Es wurde ein Stamm verwendet, der den LuxCDABE Operon aus Photorhabdus luminescens mit einem konstitutiven Promoter enthält, was zur konstitutiven Lumineszenz der Bakterien führt (Fan et al., 2008). Dieser Stamm wurde zur Infektion von Arabidopsis Pflanzen durch Infiltration in die Blätter verwendet. Die Lumineszenz der Bakterien kann in den Blättern der Pflanzen nachgewiesen werden (Abb. 28 A). An Tag 3 nach der Infektion kann auf dem Lumineszenz-Bild schon mit bloßem Auge ein Unterschied zwischen den Pflanzenlinien gesehen werden. Die AKR2-RNAi Linien \#6 und \#8 zeigen die stärkste Lumineszenz (in Falschfarben: rot), die RNAi Linie \#21 etwas weniger und die akr2b-Mutante so wie der Wildtyp am wenigsten (Abb. 28 A). In einem anderen Experiment wurden Wildtyp, AKR2-RNAi \#6 und akr2b mit einem nicht-lumineszenten Pseudomonas syringae DC3000 Stamm durch Eintauchen der Blätter in Bakteriensuspension infiziert. Die Auswertung erfolgte nach der klassischen Titer-Methode. Auch bei dieser Methode konnte die Suszeptibilität der RNAi Pflanzen 
gezeigt werden (Abb. 28 B). An Tag 3 sind in den RNAi Pflanzen eine Zehnerpotenz mehr Bakterien gewachsen als im Wildtyp, an Tag 5 ist es fast eine Zehnerpotenz.

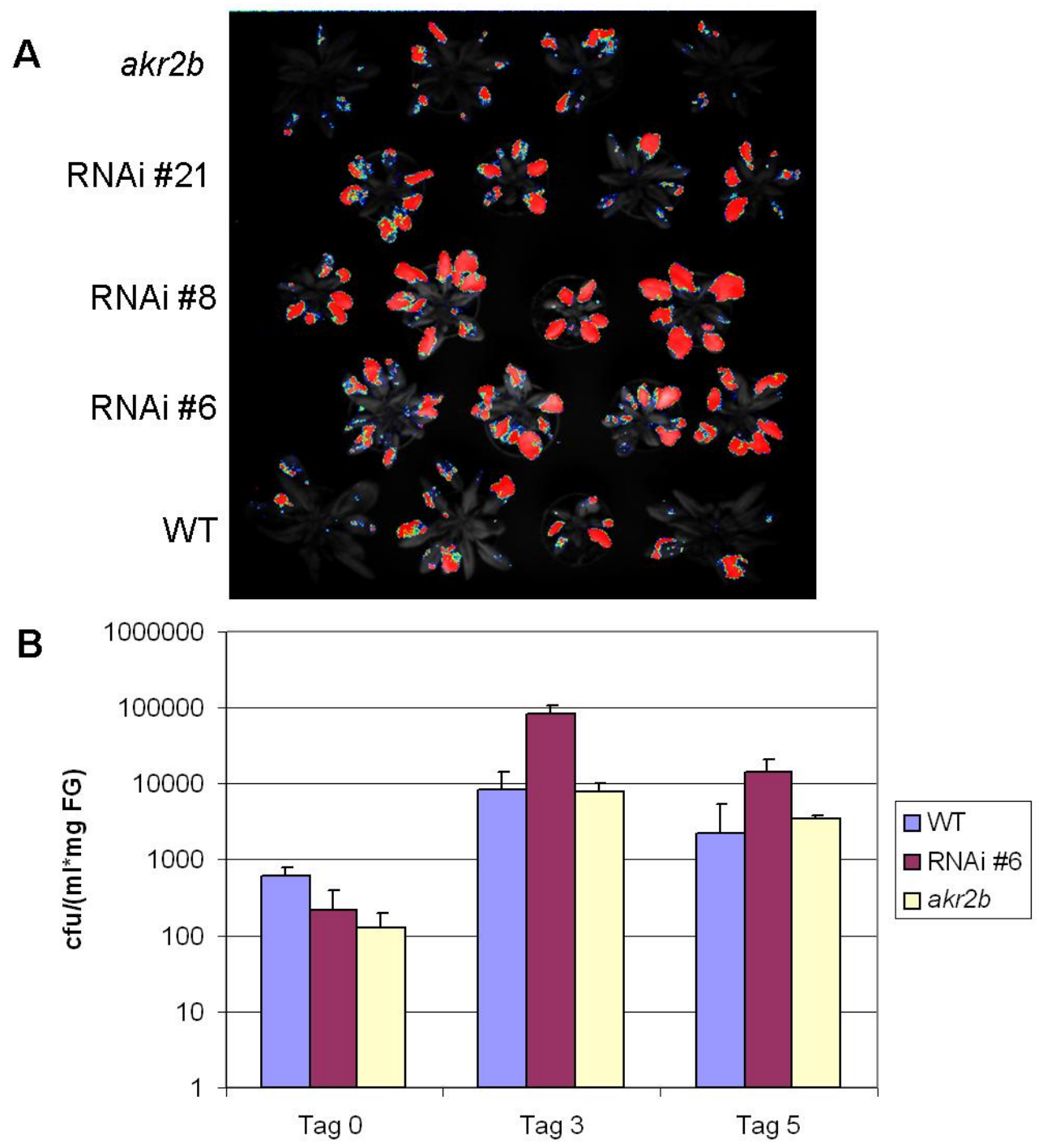

Abbildung 28: Infektion von Wildtyp, AKR2-RNAi Linien und der akr2b-Mutante mit Pseudomonas syringae und Messung der Bakterien mit zwei verschiedenen Methoden. A: Tag 3 nach der Infiltration mit $P$. syringae DC3000 JI Lux, einem konstitutiv lumineszenten Bakterienstamm. Aufnahme der Lumineszenz mit einer sensitiven CCD-Kamera, die Lumineszenz ist in Falschfarben wiedergegeben (rot-grün-blau). Von jeder Pflanzenlinie sind 5 Pflanzen zu sehen, WT: Wildtyp, AKR2-RNAi Linien \#6, \#8, \#21 und akr2b-Mutante. B: Klassische P. syringae Infektion durch eintauchen der Pflanzen in Bakteriensuspension und ausstreichen und auszählen der Kolonien an den angegebenen Tagen nach Infektion. Infizierte Pflanzenlinien: WT: Wildtyp, AKR2-RNAi \#6 und akr2b-Mutante. 


\subsubsection{AKR2-RNAi Pflanzen sind anfälliger gegenüber einer Infektion mit Botrytis cinerea als der Wildtyp}

Neben der Infektion mit $P$. syringae wurde als weiterer biotischer Stress die Infektion mit dem nekrotrophen Pilz Botrytis cinerea durchgeführt. Befall mit diesem Pilz verursacht die Grauschimmelfäule, die zum Absterben der Wirtspflanze führt. Der nekrotrophe Pilz assimiliert die Nährstoffe aus den toten Zellen (van Kan, 2006). Die Infektion mit Botrytis induziert die pflanzliche Abwehrreaktion, unter anderem die Expression von JA-abhängigen Genen, wie z.B. PDF1.2 (Ferrari et al., 2003). In der coi1-Mutante, die einen Defekte in vielen JA-abhängigen Funktionen hat, wird PDF1.2 nach Botrytis-Infektion nicht exprimiert (Feys et al., 1994). Außerdem ist die coi1-Mutante suszeptibler für eine Infektion mit Botrytis verglichen mit dem Wildtyp (Thomma et al., 1998). Aufgrunddessen wurde in den AKR2-RNAi Pflanzen, in denen PDF1.2 konstitutiv exprimiert wird, eine veränderte Resistenz gegenüber Botrytis erwartet.

In Abb. 29 A sind Blätter der infizierten Pflanzen 6 Tage nach der Infektion gezeigt und es ist deutlich zu erkennen, dass die AKR2-RNAi Linien, insbesondere \#6, suszeptibler gegenüber dem Pilz sind, ihre Blätter sind deutlich mehr beschädigt. Für das Foto wurden jeweils die am wenigsten befallenen Blätter der Pflanzen verwendet.

Auch bei der Quantifizierung des Pilzes in den Pflanzen mithilfe eines Northern Blots, für den jeweils um $13 \mathrm{Uhr}$ an Tag 0-5 nach der Infektion Proben genommen wurden, ist anhand des Signals der Botrytis Actin 3-Sonde zu sehen, dass die RNAi Pflanzen suszeptibler sind als der Wildtyp (Abb. 29 B). Bei AKR2-RNAi \#6 ist an Tag 3, 4 und 5 das Signal für Botrytis Actin 3 deutlich stärker als im Wildtyp. Bei AKR2-RNAi \#8 ist dies an Tag 5 und bei \#21 an Tag 4 und 5 ebenfalls der Fall. Das Signal für $P R 1$ ist in AKR2-RNAi \#6 ab Tag 2 erhöht, für PDF1.2 schon ab Tag 1, verglichen mit dem Wildtyp. 
A

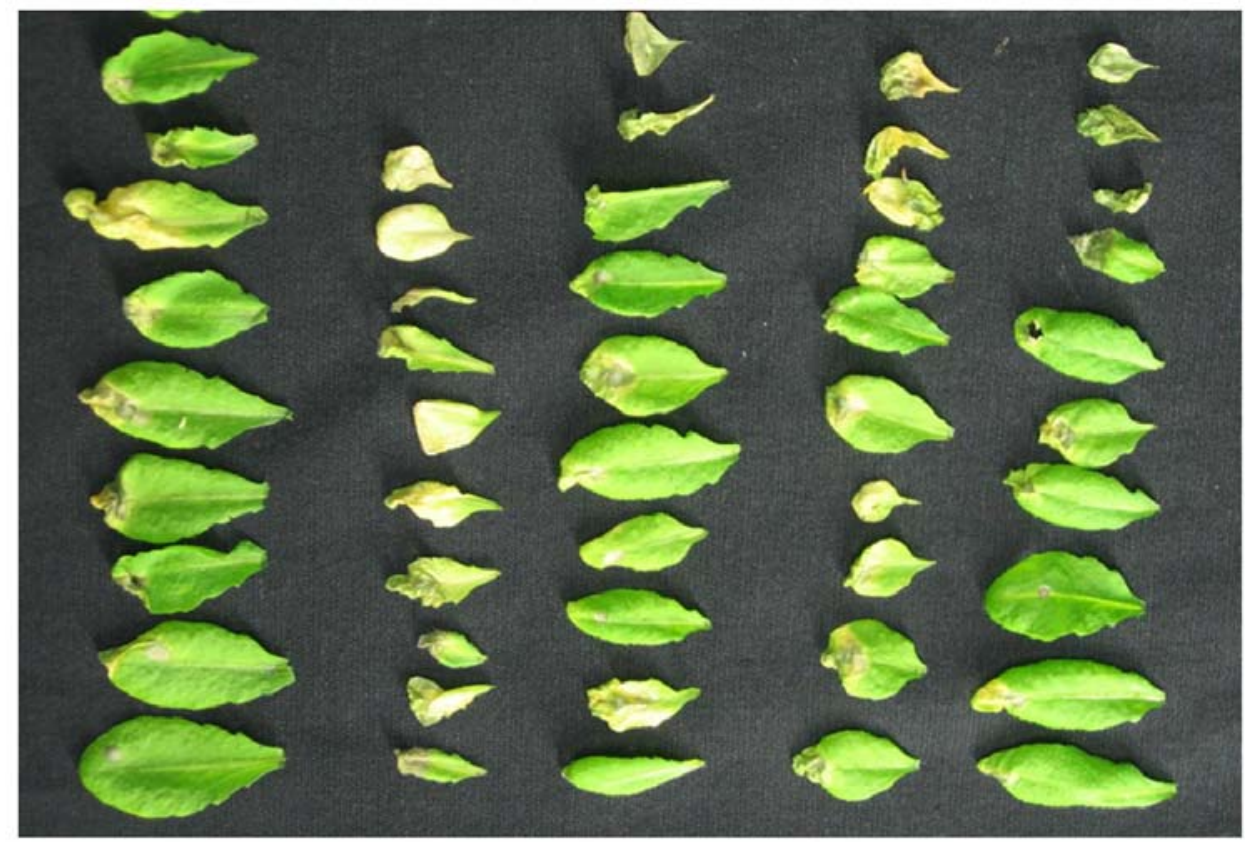

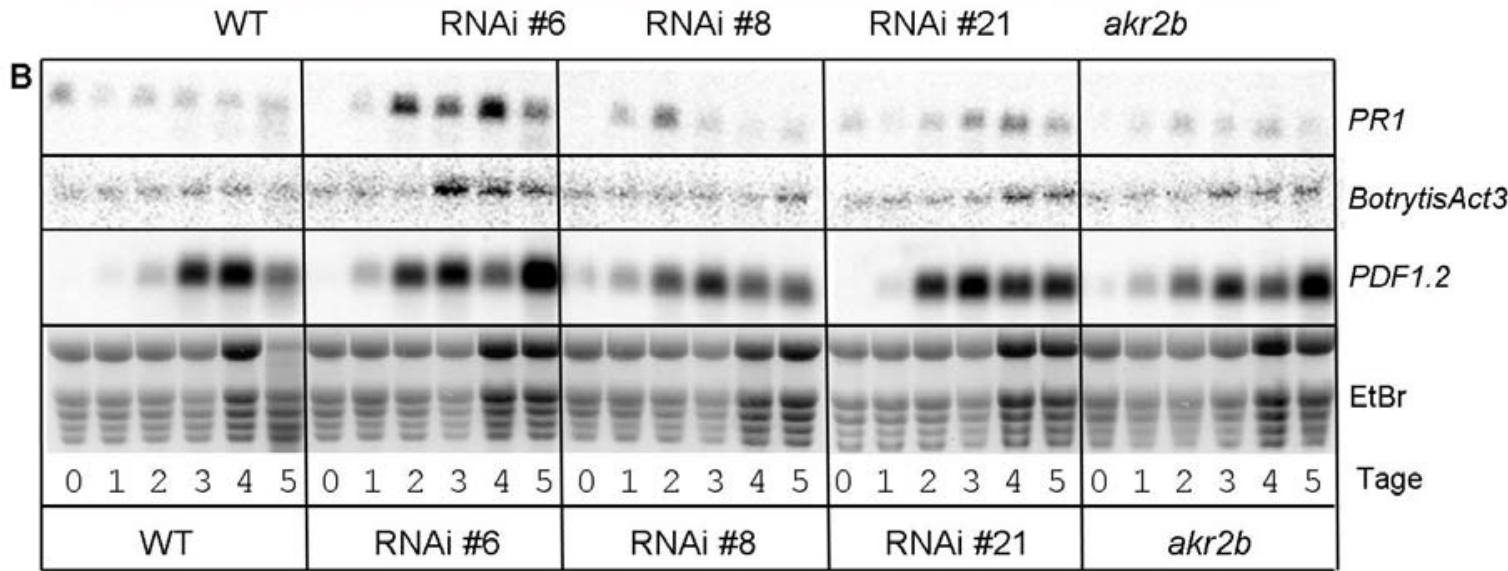

Abbildung 29: Vergleich der Infektion von Wildtyp, AKR2-RNAi Linien und akr2b-Mutante mit Botrytis cinerea mit infizierten Blättern und Änderungen der Gen-Expression. A: Die am wenigsten beschädigten Blätter 6 Tage nach der Infektion. B: Northern Blot mit den angegebenen Sonden, Probennahme an Tag 0-5 nach der Infektion, jeweils um 13 Uhr. Die Ethidium Bromid (EtBr) Kontrolle an Tag 4 und 5 ist stärker gefärbt, da neuer Ladepuffer verwendet wurde, dies ist kein Hinweis auf höhere RNA-Konzentrationen. Verwendete Pflanzenlinien: WT: Wildtyp, AKR2-RNAi Linien \#6, \#8, \#21 und akr2b-Mutante.

Die aufgrund der Ergebnisse des Microarrays erwartete konstitutive Expression von PDF1.2 ist hier nicht zu erkennen (Tag 0). Deshalb wurde ein Northern Blot durchgeführt, bei dem zu verschiedenen Tageszeitpunkten Proben von Wildtyp- und von AKR2-RNAi Pflanzen aus Erdkultur genommen wurden. Es wurde die Expression von $A K R 2 A$ und von den beiden Pathogen-induzierten Genen PR1 und $P D F 1.2 a$ überprüft (Abb. 30). Wie erwartet werden in den AKR2-RNAi Pflanzen weder $A K R 2$ noch $P R 1$ exprimiert, jedoch ergab sich für PDF1.2a ein Tageszeiten abhängiges Expressionsmuster. Kurz nach Einschalten des Lichts (7:05 Uhr und 8 Uhr) ist die Expression schwach, um 9 Uhr sehr stark und nimmt dann bis mittags 
(13:30 Uhr) wieder ab. In einem zweiten, unabhängigen Experiment war eine ähnliche Regulation zu sehen. Es handelt sich also nicht um eine konstitutive Expression von PDF1.2, sondern um eine Tageszeiten abhängige Regulation. Diese Regulation erklärt das Ausbleiben des PDF1.2-Signals an Tag 0 der B. cinerea Infektion, da die Proben um 13 Uhr genommen wurden, ein Zeitpunkt, an dem die PDF1.2-Expression herunterreguliert ist.

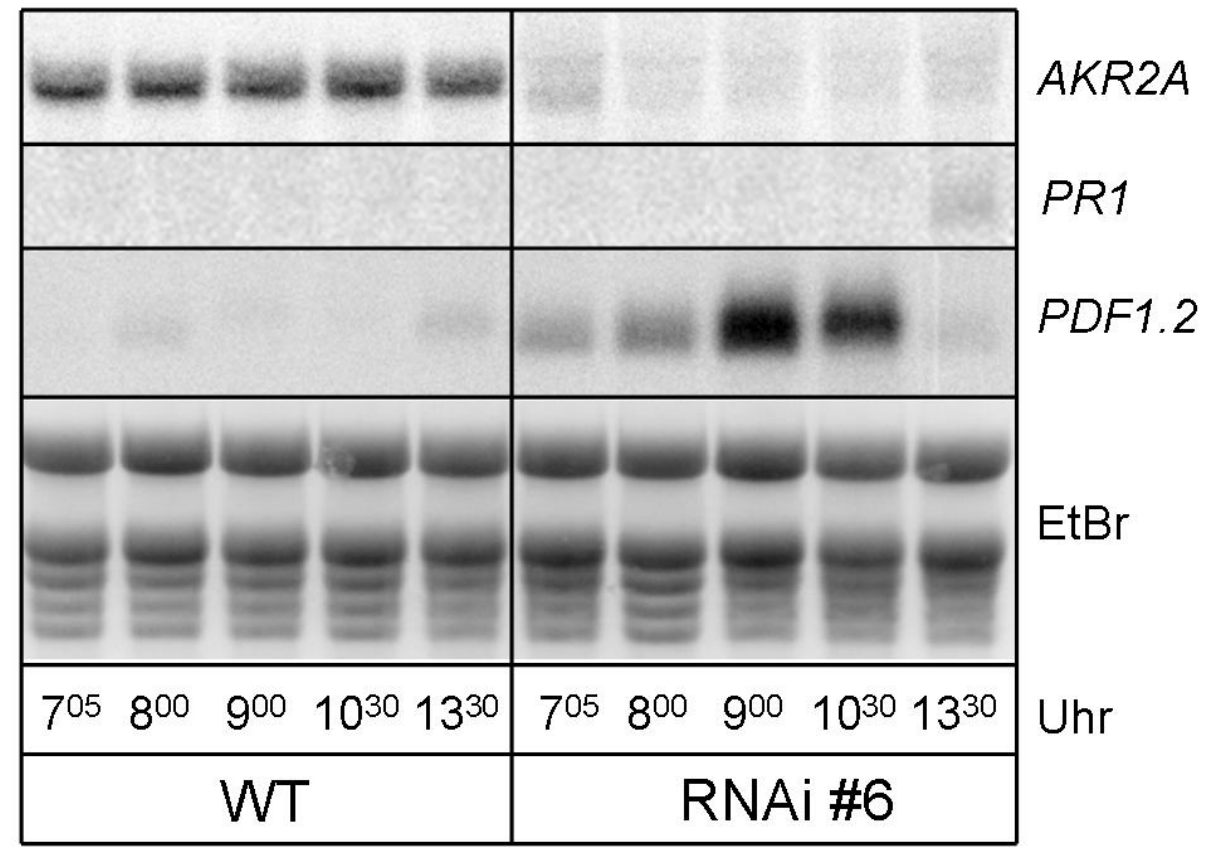

Abbildung 30: Northern Blot mit RNA aus Blättern von Wildtyp und AKR2-RNAi Pflanzen zur Analyse von tageszeitlichen Schwankungen der Genexpression. Die Probennahme erfolgte zu verschiedenen Tageszeiten („Uhr"), das Licht wurde um $7^{00} \mathrm{Uhr}$ angeschaltet. AKR2A und PR1 sind nicht tageszeitlich reguliert, PDF1.2 wird in den RNAi Pflanzen am Vormittag hochreguliert, bis mittags wieder herunterreguliert. Die Pflanzen wuchsen in Erde im Klimaschrank und waren ca. 3 Wochen alt. EtBr: Ladungskontrolle. WT: Wildtyp, RNAi \#6: AKR2-RNAi Linie 6. 


\section{Diskussion}

\subsection{Interaktionen zwischen einem Ankyrin-repeat Protein und einem bZIP-Transkriptionsfaktor unterscheiden sich in Tabak und Arabidopsis}

Die Ankyrin-repeat Proteindomäne kommt in Prokaryoten, Eukaryoten und einigen Viren vor und vermittelt Protein-Protein-Interaktionen (Sedgwick und Smerdon, 1999). Für das Arabidopsis Ankyrin-repeat Protein AKR2A wurden Interaktionen mit einem 14-3-3-Protein (At5g10450) und mit der Ascorbat Peroxidase 3 (APX3) gefunden (Yan et al., 2002). Es konnte außerdem gezeigt werden, dass AKR2A und AKR2B mit chloroplastidären Membranproteinen interagieren (Bae et al., 2008). In Tabak ist die Interaktion zwischen dem homologen Ankyrin-repeat Protein NtANK1 und dem bZIP-Transkriptionsfaktor NtBZI-1 gut charakterisiert (Böttner et al., 2009; Kuhlmann et al., 2003). In dieser Arbeit sollte getestet werden, ob in Arabidopsis AKR2A und AKR2B mit einem zu NtBZI-1 homologen bZIP-Transkriptionsfaktor interagieren, da das Modellsystem Tabak Limitierungen hat im Vergleich zu Arabidopsis. Da das Genom nicht vollständig sequenziert ist, stehen keine T-DNAInsertionsmutanten zur Komplementierung zur Verfügung, ebensowenig wie Microarrays zur Durchführung von Transkriptomanalysen.

Die Arabidopsis Proteine, die die höchste Homologie zu NtBZI-1 zeigen, sind die bZIP-Transkriptionsfaktoren der Gruppe C (bZIP9, bZIP10, bZIP25, bZIP63). Um die Interaktion zwischen den bZIP-Faktoren und den Ankyrin-repeat Proteinen in allen möglichen Kombinationen zu testen, wurden verschiedene experimentelle Systeme verwendet, und zwar $\mathrm{Y} 2 \mathrm{H}, \mathrm{P} 2 \mathrm{H}$ und BiFC. Die beiden letzten Methoden haben den Vorteil, dass sie in planta Methoden sind, bei allen drei Methoden ist der Nachteil, dass Fusionsproteine getestet werden müssen. Durch die Fusion kann sich die dreidimensionale Struktur des zu untersuchenden Proteins ändern, oder der Anhang könnte die Interaktionsdomäne beeinflussen. Deshalb wurde beispielhaft für bZIP10 auch die C-terminale Fusion im BiFC getestet, sonst waren alle Proteine mit Nterminalen Fusionen versehen. Eine alternative Methode, bei der keine Fusionsproteine benötigt werden, ist z.B. Co-Immunpräzipitation (Co-IP), bei der Proteinkomplexe mithilfe eines an festes Substrat gebundenen Antikörpers aus dem Zellextrakt gefällt werden können. 
Für die Arabidopsis Proteine konnte keine Interaktion detektiert werden. Da die Tabak Proteine in allen drei oben beschriebenen experimentellen Systemen miteinander interagieren, stellte sich die Frage, ob es in Tabak spezielle Bedingungen geben könnte, wie z.B. pH-Wert, andere Proteine oder Proteinmodifizierungen, die für die Interaktion essentiell sind, in Arabidopsis aber fehlen. Dies konnte nicht bestätigt werden, da die Arabidopsis Proteine nicht im P2HSystem mit Tabak-Mesophyll-Protoplasten interagieren, die Tabak Proteine jedoch auch in Arabidopsis-Mesophyll-Protoplasten interagieren. Die Kombination von Tabak und Arabidopsis Proteinen in Arabidopsis-Protoplasten zeigte, dass die Arabidopsis Ankyrin-repeat Proteine AKR2A und AKR2B mit NtBZI-1 interagieren können, die Arabidopsis bZIP-Faktoren der Gruppe C jedoch nicht mit NtANK1 interagieren können. Das zeigt, dass sich insbesondere die bZIP-Proteine aus Tabak und Arabidopsis unterscheiden und unterschiedliche Funktionen ausüben können. Da Proteine oft mehrere Funktionen haben, ist nicht auszuschließen, dass es auch übereinstimmende Funktionsbereiche gibt. Ein anderer Grund für die verschiedenen Interaktionseigenschaften könnten verschiedene Proteinmodifikationen in den beiden Pflanzen sein.

In der Literatur ist ein trimerer Komplex beschrieben aus dem Heterodimer bZIP10/bZIP53 und ABI3, der in drei Systemen (P2H, Y2H und BiFC) nachgewiesen werden konnte (Alonso et al., 2009). Um die Bildung eines trimeren Komplexes mit den AKR2-Proteinen zu testen, wurden AKR2A und AKR2B zu bZIP10 und bZIP53 im Protoplasten-System zugegeben. Die starke Reportergenaktivierung durch das Heterodimer bZIP10/bZIP53 (Ehlert et al., 2006) konnte durch Zugabe von AKR2A oder AKR2B verstärkt werden. Allerdings konnte diese potentielle Komplexbildung weder in Hefe noch mit BiFC reproduziert werden, was die Entstehung eines trimeren Komplexes unwahrscheinlich macht.

Die Protein-Protein-Interaktionen zwischen den beschriebenen Ankyrin-repeat Proteinen und den bZIP-Transkriptionsfaktoren unterscheiden sich also in Tabak und Arabidopsis. Daraus wird ersichtlich, dass Daten, die in einer Pflanzenspezies gewonnen wurden, nicht ohne weiteres auf homologe Proteine einer anderen Pflanzenspezies übertragen werden können. Die in Tabak für den Proteinkomplex NtBZI-1/NtANK1 beschriebene Funktion in der Auxin-vermittelten Transkriptionskontrolle wird in Arabidopsis unterschiedlich reguliert. 


\subsection{Mehrere zelluläre Lokalisationen von AKR2A und AKR2B} (Cytoplasma, Kern und Chloroplastenmembran) deuten auf multiple Funktionen hin

Die Lokalisation von AKR2A und AKR2B im Cytoplasma konnte durch Expression von YFP-Fusionsproteinen bestätigt werden, wie es schon für NtANK1 beschrieben wurde (Böttner et al., 2009). Dazu wurden sowohl Arabidopsis-Protoplasten als auch Nicotiana benthamiana Epidermiszellen transient transformiert. Dabei ist deutlich zu erkennen, dass sich die AKR2-Proteine nicht im Kern befinden. Da für das homologe Protein NtANK1 eine Stimulus-abhängige Lokalisation auch im Kern beschrieben ist (Böttner et al., 2009), wurde dies für AKR2A und AKR2B ebenfalls getestet. Ein Sequenzvergleich zeigte, dass AKR2A und AKR2B eine Leucin-reiche Sequenz am C-Terminus besitzen, wie sie in Haasen et al. (1999) als NES beschrieben ist. In Arabidopsis bindet Exportin 1 (XPO1) an eine solche NES und vermittelt den Kernexport des Proteins mit der NES. Der Inhibitor LMB kann diese Bindung verhindern und so den XPO1-vermittelten Kernexport hemmen (Haasen et al., 1999). Sowohl nach Zugabe des Kernexport-Inhibitors LMB, als auch durch Mutation der putativen NES akkumulieren AKR2A und AKR2B im Kern. Das YFP-Signal war deutlich sowohl im Kern als auch im Cytoplasma zu erkennen. Daraus lässt sich schließen, dass beide Proteine eine funktionsfähige NES besitzen, die unter normalen Bedingungen dafür sorgt, dass die Proteine effektiv aus dem Kern exportiert werden und deshalb dort nicht akkumulieren können.

Welche natürlichen Bedingungen könnten zu einer Akkumulation im Kern führen?

In Tabak führte auch die Zugabe von Auxin zu einer Anhäufung von NtANK1 im Kern (Böttner et al., 2009). Für AKR2A und AKR2B konnte das in Protoplasten nicht bestätigt werden. In Peck et al. (2001) ist beschrieben, dass AKR2B innerhalb von wenigen Minuten nach Zugabe des bakteriellen Elicitors flg22 oder Chitin, einem pilzlichen Elicitor, phosphoryliert wird. Auch NtBZI-1, der Interaktionspartner von NtANK1, wird phosphoryliert, und zwar nach Infektion mit Pseudomonas syringae (Kuhlmann et al., 2002). Eine Phosphorylierung als Proteinmodifikation von AKR2A und AKR2B nach einem natürlichen Stimulus ist also nicht unwahrscheinlich. Laut dem Programm NetPhos 2.0 (http://www.cbs.dtu.dk/services/NetPhos/) gibt es im AKR2A-Protein mehrere putative Phosphorylierungsstellen: 15 mal Serin, 3 mal Threonin, 2 mal Tyrosin. Diejenigen mit der höchsten Wahrscheinlichkeit sind mehrere Serin-Aminosäuren am N-Terminus des Proteins. Dort befindet sich die 
PEST-Domäne, die schon als Phosphorylierungsort beschrieben wurde (Verma und Stevenson, 1997). Da die Phosphorylierung eines Proteins aufgrund der Polarität des Phosphatrests oft eine Konformationsänderung zur Folge hat, wäre es denkbar, dass beim phosphorylierten Protein die NES nicht mehr funktionstüchtig ist (Poirier und Bucher, 2002). Somit könnte eine Phosphorylierung von AKR2A und AKR2B unter natürlichen Bedingungen ein Grund für deren Kernlokalisation sein. Um diese These experimentell zu bestätigen, könnten potentielle Phosphorylierungsstellen mutiert werden und die Lokalisation der erhaltenen Proteine überprüft werden.

In der Veröffentlichung Bae et al. (2008) wird gezeigt, dass AKR2A an die äußere Chloroplastenmembran bindet. Dazu wurden verschiedene Experimente durchgeführt. Bei der Aufreinigung von Chloroplasten aus dem ArabidopsisGesamtzellextrakt, konnte AKR2A in der Chloroplastenfraktion detektiert werden. Transformierte Protoplasten, die T7-AKR2A exprimierten, zeigten nach Immundetektion mit dem T7-Antikörper eine Färbung in der Chloroplastenmembran, und zwar die gleiche Färbung wie das chloroplastidäre Membranprotein Toc159. Fluoreszenzbilder zur Lokalisation von YFP-AKR2A/B wurden von Bae et al. (2008) nicht gezeigt, so dass nicht auszuschließen ist, dass sie mit einem solchen experimentellen Ansatz die gleiche cytoplasmatische Lokalisation, wie oben beschrieben, erhalten hätten. Bae et al. (2008) schlussfolgern aus ihren Ergebnissen, dass AKR2A und AKR2B im Cytoplasma an neu synthetisierte OEPs binden, sie zum Chloroplasten transportieren und deren Insertion in die Membran unterstützen. AKR2A/B haben dabei auch eine Chaperon-Funktion, um Aggregation der OEPs zu verhindern (Bae et al., 2008). Um allgemein die Fähigkeit von AKR2A zu zeigen, andere Proteine zu einem Organell zu transportieren wurde interessanterweise der Kerntransport verwendet: Das Chloroplastenmembranprotein OEP7 zeigte als GFP-Fusion keine Organellen-spezifische Lokalisation. Wenn aber gleichzeitig AKR2A als NLS-Fusion exprimiert wurde, waren beide Proteine, OEP7 und AKR2A, kernlokalisiert (Bae et al., 2008). Anstelle der NLS-Fusion könnte diese Aufgabe evtl. auch von der außer Funktion gesetzten NES von AKR2A übernommen werden, wodurch AKR2A ebenfalls im Kern lokalisiert wäre.

Für AKR2A und AKR2B wurden also verschiedene zelluläre Lokalisationen gezeigt: im Cytosol verteilt, gebunden an die äußere Chloroplastenmembran und nach Inhibierung des Kernexports im Kern. Die Proteine könnten also multiple Funktionen an den multiplen Lokalisationen ausführen. Dafür spricht auch, dass in der Literatur 
verschiedene Protein-Interaktionspartner für AKR2A/B beschrieben worden sind: die chloroplastidären Membranproteine OEP7 und OEP64 (Bae et al., 2008); das 14-3-3 Protein At5g10450, 14-3-3 Proteine haben oft regulatorische Funktionen durch Protein-Protein-Interaktion mit phosphorylierten Partnern (Yan et al., 2002; Van Heusden, 2009; Oecking und Jaspert, 2009); die Ascorbat-Peroxidase 3 (APX3; Yan et al., 2002); Transkriptionsfaktoren, die im Y2H gefunden wurden (I. Hwang (Pohang, Korea), persönliche Mitteilung); und das homologe Tabak-Protein NtANK1 interagiert mit dem bZIP-Transkriptionsfaktor NtBZI-1 (Böttner et al., 2009). In einer Veröffentlichung, die direkt vor der Fertigstellung dieser Arbeit erschien, wurden noch andere Interaktionspartner von AKR2A und AKR2B identifiziert, und zwar 5 weitere Membranproteine: APX5 (Peroxisom), Toc34 (Chloroplast), CB5 und CB5R (Cytochrom $b_{5}$ (Reduktase), Mikrosom), Tom20 (,translocase of the outer mitochondrial membrane“, Mitochondrium) (Shen et al., 2010, dieselbe Arbeitsgruppe wie Yan et al., 2002). Die Bindestelle bei all diesen Proteinen ist die Transmembrandomäne, jeweils mit einigen basischen Aminosäuren direkt folgend. Es liegt keine Sequenzhomologie dieser Bindestelle in den verschiedenen Proteinen vor, sondern die Struktur ist die gleiche. Die bZIP-Transkriptionsfaktoren der Gruppe C, die aufgrund inrer Homologie zu NtBZI-1 als potentielle Interaktionspartner in Frage kamen, besitzen keine ähnlich strukturierte Bindestelle, da sie keine Transmembrandomäne haben.

Während Bae et al. (2008) Chaperonfunktion und den Transport OEPs zur äußeren Chloroplastenmembran als Funktionen für AKR2A/B postulieren, folgern Shen et al. (2010) aus ihren Ergebnissen, dass AKR2A auch als molekulares Chaperon für andere Membranproteine fungiert und diese zu den Membranen der verschiedenen Organellen transportiert (Peroxisom, ER, Mitochondrium). Außerdem wurde eine Kernlokalisation von AKR2A bei konstitutiver Expression von GFP-AKR2A in transgenen Pflanzen, sowohl unter Kontrolle des 35S- als auch des endogenen AKR2A-Promotors, gezeigt (Shen et al., 2010). Da in dieser Arbeit ebenfalls eine Lokalisation von AKR2A und AKR2B im Kern detektiert werden konnte, könnten AKR2A/B auch Proteine zur Kernmembran oder in den Kern transportieren. Das macht eine Funktion im Kern für AKR2A/B plausibel. Im Kern könnten AKR2A/B z.B. mit einem Transkriptionsfaktor interagieren, und dadurch die Transkriptionskontrolle regulieren (Transkriptionsfaktoren als Interaktionspartner wurden gefunden, s.o.). 
Eine weitere Spekulation wäre, dass die multiplen Lokalisationen auf eine Rolle von AKR2A/B im retrograden Signalweg vom Chloroplasten zum Kern hindeuten. Darunter versteht man die Kommunikation zwischen Chloroplast und Kern, bei der der Chloroplast seinen Status dem Kern vermittelt. Das ist nötig, weil 95\% der Chloroplastenproteine kernkodiert sind und deren Genexpression dem Bedarf entsprechend koordiniert werden muss (Pesaresi et al., 2007). Nach dem Import in den Chloroplast bilden die kernkodierten Plastidenproteine zusammen mit plastidenkodierten Proteinen Multiproteinkomplexe, wie z.B. Photosysteme und metabolische Enzyme. Bisher sind drei chloroplastidäre Prozesse beschrieben, die retrograde Chloroplastensignale auslösen:

(1) Störungen im Tetrapyrrol-Biosyntheseweg, der u.a. zur Bildung von Chlorophyll führt, ausgelöst z.B. durch das Herbizid Norflurazon, führen zur reduzierten Expression von kernkodierten Chlorophyll-bindenden Proteinen (LHCA und LHCB, „light harvesting complex"). Es ist noch nicht geklärt, ob ein Intermediat aus dem Tetrapyrrol-Syntheseweg (Mg-ProtoporphyrinIX) nach Norflurazon-Behandlung im Chloroplasten akkumuliert und als retrogrades Signal dient (Strand et al., 2003), oder das Signal indirekt durch ROS und einen veränderten Redoxstatus (s.u. (3)) im Chloroplasten initiiert wird (Moulin et al.; 2008). Denn von Moulin et al. (2008) konnte keine Akkumulation einer Tetrapyrrol-Zwischenstufe nach Norflurazon-Behandlung nachgewiesen werden.

(2) Hemmung der Plastidengen-Expression durch das Herbizid Lincomycin führt zur Repression der kernkodierten Phosynthesegen-Expression. Diese Antwort auf Plastidengen-Expression erfolgt nur an den ersten 3 Tagen der Keimlingentwicklung und ist lichtabhängig (Beck, 2005).

(3) Der chloroplastidäre Redox-Status, z.B. in Form des reduzierten oder oxidierten Plastochinon (PQ)-Pools oder ROS $\left(\mathrm{H}_{2} \mathrm{O}_{2}\right)$, sind Signale, die zur Expression der gleichen kernkodierten Gene führen wie Starklicht (reduzierter PQ-Pool) und Schwachlicht (oxidierter PQ-Pool) (Nott et al., 2006).

Im Allgemeinen entstehen diese Signale bei abnormaler Chloroplastenentwicklung und bei Stressbedingungen aus der Umwelt. Alle drei Signale führen zur Aktivierung des Proteins GUN1 („GENOMES UNCOUPLED1“), das im Chloroplast lokalisiert ist. Ein unbekannter Signalweg führt dann zur Aktivierung des Transkriptionsfaktors ABI4 („ABA INSENSITIVE4“) im Kern, der die Expression der Zielgene des retrograden Signalwegs blockiert (Koussevitzky et al., 2007; Abb. 31). Durch einen unabhängigen 
Signalweg reguliert GUN1 die Expression des Transkriptionsfaktors GLK1 („GOLDEN2-LIKE1“) im Kern herunter, so dass die kernkodierten Photosynthesegene reprimiert werden (Kakizaki et al., 2009). GLK1 ist also ein positiver Regulator des retrograden Signalwegs (Kakizaki et al., 2009; Abb. 31).

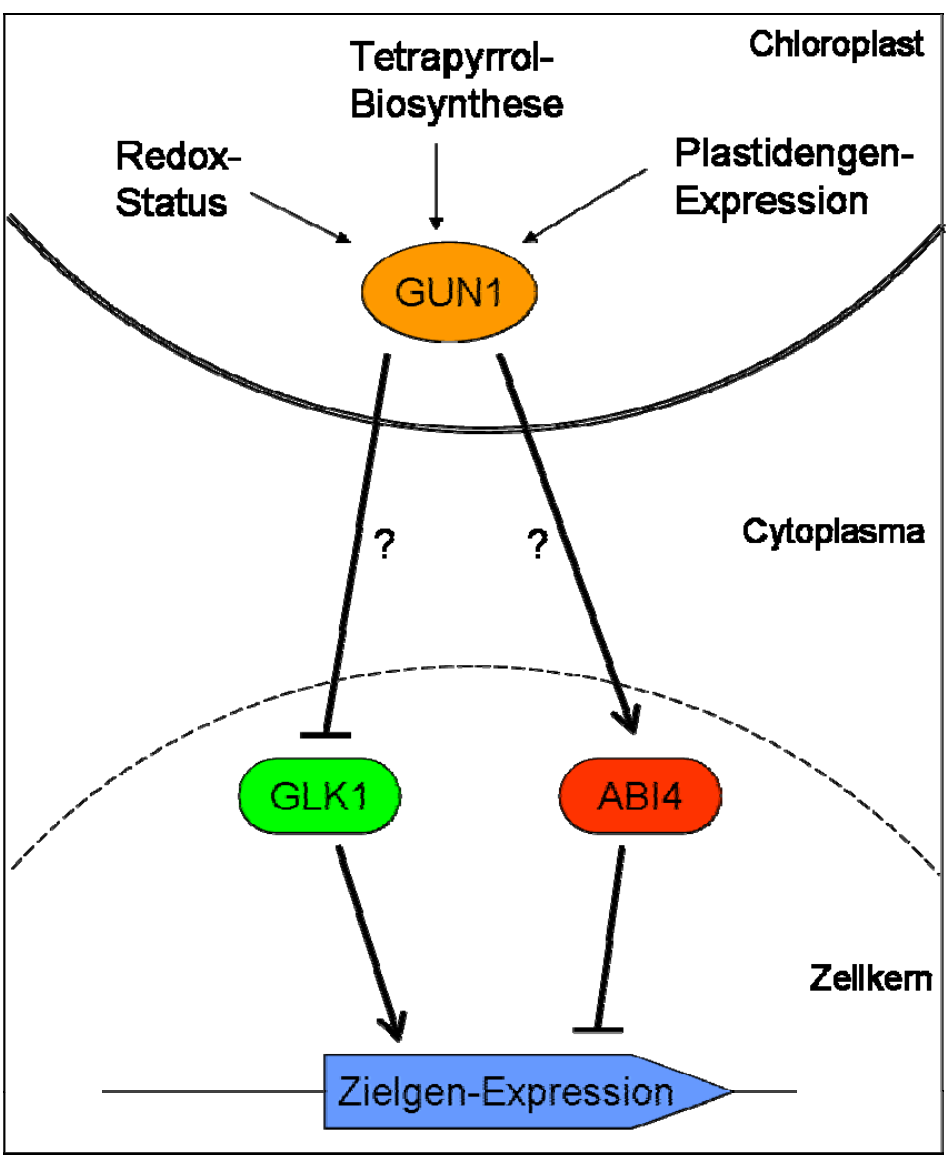

Abbildung 31: Modell zur Zielgen-Expression des retrograden Transports vom Chloroplasten zum Zellkern. Drei verschiedene Signale, die bei beeinträchtigter Chloroplastenentwicklung oder Stressbedingungen entstehen, aktivieren GUN1 im Chloroplasten. GUN1 teilt diesen Status auf unbekanntem Weg (?) dem Zellkern mit, wodurch die Transkriptionsfaktoren GLK1 und ABI4 reprimiert bzw. aktiviert werden und die Zielgen-Expression regulieren (modifiziert nach Zhang, 2007; Kakizaki et al., 2009).

Aufgrund der oben diskutierten Ergebnisse zur Lokalisation von AKR2A und AKR2B, kann spekuliert werden, dass AKR2A/B Signalüberträger des retrograden Transports von der Chloroplastenmembran bis in den Zellkern sind, wo die Transkriptionsfaktoren reguliert werden (? in Abb. 31). Dabei könnten sie entweder selbst das Signal übertragen, oder ein Signalprotein transportieren, wie es für die chloroplastidären Membranproteine gezeigt wurde.

Ein Experiment zur Prüfung dieser These könnte die Schädigung der Chloroplasten sein, um dann zu testen, ob sich die AKR2-Proteine im Kern anreichern. Dazu könnten z.B. die Herbizide Norflurazon oder Lincomycin verwendet werden, die speziell Abläufe im Chloroplasten inhibieren (Tetrapyrrol-Biosynthese bzw. Protein 
Translation). Ein weiterer methodischer Ansatz, bei dem direkt die Funktion von AKR2A und AKR2B im Kern getestet werden könnte, wäre eine Überexpression von AKR2A/B mit mutierter NES in Pflanzen, die dann für Microarrays genutzt werden könnten, und deren Phänotyp untersucht werden könnte.

\subsection{Die Überexpression von AKR2A führt zu keiner deutlichen phänotypischen Veränderung}

Es wurden im Rahmen dieser Arbeit verschiedene transgene Pflanzen hergestellt: Pro $_{35 s}: A K R 2 A, P_{35}: A K R 2 B, A K R 2-R N A i$ und $a k r 2 b$ Mutanten. Diejenigen, die einen sichtbaren Phänotyp zeigten, waren nur die AKR2-RNAi-Pflanzen.

Die Pro ${ }_{35 s}$ :AKR2A Pflanzen wurden zum Vergleich mit für das Microarray eingesetzt, zeigten aber wesentlich weniger signifikant regulierte Gene als in den RNAi Pflanzen. Obwohl auch in diesem Fall besonders viele Gene hochreguliert sind, die der Annotation "Antwort auf einen Stimulus" zugeordnet sind, konnte bei den Pro $_{35 s}: A K R 2 A$ Pflanzen keine veränderte Antwort auf die getesteten Stressbedingungen festgestellt werden (Daten nicht gezeigt). Über den Grund, weshalb viele Gene in den RNAi und den Pro $_{355}$ Pflanzen gleich reguliert sind, kann hier nur spekuliert werden. Es scheint, als ob eine bestimmte Menge an AKR2AProtein in der Pflanze benötigt wird, und wenn diese Menge weit über- oder unterschritten wird, führt dies zu einer Deregulation der Genexpression.

\subsection{AKR2-RNAi Pflanzen zeigen reduziertes Wachstum und eine beeinträchtigte Chloroplasten-Biogenese}

Die AKR2-RNAi-Pflanzen zeigen einen sichtbaren Phänotyp. Sie sind kleiner, sowohl die Blattfläche als auch die Höhe des Blütenstandes, ihr Blattgrün ist heller als im Wildtyp, und sie haben ein reduziertes Samengewicht, jeweils in Abhängigkeit der Proteinmenge. Bei zwei verwendeten Linien konnte kein AKR2A/B-Protein im Western-Blot nachgewiesen werden, zwei andere Linien zeigen eine geringe Proteinmenge, d.h. deutlich weniger als der Wildtyp. Im Microarray ist zusätzlich noch zu erkennen, dass der RNAi-Effekt spezifisch ist, da die beiden am stärksten herunterregulierten Gene $A K R 2 A$ und $A K R 2 B$ sind und keine weiteren homologen Ankyrin-repeat Proteine herunterreguliert sind. In der Veröffentlichung Yan et al. (2002) werden AKR2-Antisense Pflanzen beschrieben, die einen ganz anderen Phänotyp zeigen. Die Pflanzen zeigen, ebenfalls in Abhängigkeit der verbliebenen 
AKR2A/B-Proteinmenge, einen Nekrose-Phänotyp, d.h. die Blätter zeigen nekrotische Flecken, die auf eine Überproduktion von $\mathrm{H}_{2} \mathrm{O}_{2}$ zurück zu führen sind. Außerdem wurden erhöhte Transkripte von PR-1 und GST6 detektiert und die Pflanzen zeigten erhöhte Resistenz gegen eine Infektion mit $P$. syringae. Der von Yan et al. (2002) verwendete Arabidopsis-Ökotyp ist C24, während in dieser Arbeit der Ökotyp Col-0 verwendet wurde. Beim Versuch die Daten von Yan et al. (2002) zu reproduzieren, wurden ebenfalls AKR2-RNAi Pflanzen im C24-Hintergrund hergestellt, diese zeigten allerdings keinen sichtbaren Phänotyp. Da außerdem eine Infektion der AKR2-RNAi Pflanzen mit $P$. syringae das Gegenteil, nämlich eine höhere Suszeptibilität, zeigte und Interaktionsdaten von Yan et al. (2002) nicht reproduziert werden konnten (Daten nicht gezeigt), wurden die Daten von Yan et al. (2002) nicht weiter zu Rate gezogen.

Ein Grund für die Herstellung von AKR2-RNAi Pflanzen war, dass nur eine akr2bMutante erhältlich ist, und keine akr2a-Mutante, so dass auch keine Doppelmutanten, in denen die beiden homologen Gene nicht exprimiert werden, erstellt werden konnten. Die hohe Homologie lässt eine Redundanz der Gene vermuten, was durch den unauffälligen Phänotyp der akr2b-Mutante (wie Wildtyp) bestätigt wird. Das Fehlen einer akr2a-Mutante legt allerdings nahe, dass eine solche Mutation letal ist und $A K R 2 B$ nicht das Fehlen von AKR2A komplementieren kann. Die beiden Proteine haben also wahrscheinlich auch unterschiedliche Funktionen (Shen et al., 2010).

In einer anderen Arbeitsgruppe wurden ebenfalls AKR2-RNAi Pflanzen hergestellt. In Bae et al. (2008) werden Dexamethason-induzierbare AKR2-RNAi beschrieben. Im Wildtyp-Hintergrund zeigten diese Pflanzen keinen sichtbaren Phänotyp, im akr2bHintergrund führt Wachstum auf Dexamethason jedoch zu einem schwerwiegenden Phänotyp: die Pflanzen haben gelbe oder weiße Blätter und bleiben sehr klein. In elektronenmikroskopischen Aufnahmen dieser Blätter sind stark beeinträchtigte Chloroplasten zu sehen, in denen statt Thylakoidmembranen mehrere Vesikel zu sehen sind (Bae et al., 2008). Es verwundert allerdings nicht, dass Pflanzen mit einem so ausgeprägten Phänotyp auch auf zellulärer Ebene stark beeinträchtigt sind. Pflanzen mit einem weniger stark ausgeprägten Phänotyp, wie die in dieser Arbeit hergestellten AKR2-RNAi Pflanzen, könnten sich besser eignen, um die zelluläre Organisation zu untersuchen. Tatsächlich zeigen elektronenmikroskopische Aufnahmen von Blättern dieser AKR2-RNAi Pflanzen, dass sich die Chloroplasten 
von denen im Wildtyp unterscheiden. Die Thylakoidmembranen in den AKR2-RNAi Pflanzen sind lockerer gepackt und dazwischen befinden sich Vesikel-ähnliche Strukturen (ohne Membran). Die Chloroplasten-Biogenese scheint also beeinträchtigt zu sein und spiegelt sich im reduzierten Chlorophyllgehalt und der helleren Farbe der AKR2-RNAi Pflanzen wider.

Zur Analyse der Funktionsfähigkeit der Chloroplasten könnten Messungen der Photosyntheserate durchgeführt werden. Dazu kann ein Gaswechselanalysegerät verwendet werden, oder die Chlorophyll-Fluoreszenz mithilfe eines „Imaging-PAM“ Fluorometers gemessen werden (Oxborough 2004).

Es wurden auch elektronenmikroskopische Aufnahmen von Blättern der Tabak NtANK1-RNAi Pflanzen gemacht, in denen eine ganz ähnliche lockere Packung der Thylakoidmembranen mit Vesikel-ähnlichen Strukturen zu sehen ist. Deshalb kann vermutet werden, dass NtANK1 ebenfalls eine Rolle in der Chloroplasten-Biogenese spielt und somit NtANK1 und AKR2A/B eine ähnliche Funktion in Tabak bzw. Arabidopsis ausüben. Es könnte sein, dass NtANK1 die in Böttner et al. (2009) beschriebene Funktion in der Auxin-vermittelten Transkriptionskontrolle zusammen mit NtBZI-1 zusätzlich zu der Rolle in der Chloroplasten-Biogenese hat. Wenn $A K R 2 A$ und $A K R 2 B$ in allen Bereichen eine ähnliche Funktion haben sollten wie NtANK1, dann könnten andere Transkriptionsfaktoren, die nicht homolog zu NtBZI-1 sind und hier deshalb nicht getestet wurden, mit AKR2A und AKR2B interagieren (im Y2H identifiziert, I. Hwang, persönliche Mitteilung). Es wäre auch möglich, dass es in Arabidopsis einen zusätzlichen Proteinpartner für die Interaktion mit den Gruppe C bZIP-Transkriptionsfaktoren gibt, der bisher noch nicht gefunden wurde, aber essentiell für die zu Tabak homologe Interaktion ist.

Bae et al. (2008) erklären die Beeinträchtigung der Chloroplasten-Biogenese damit, dass bei reduzierter AKR2A/B-Proteinmenge die chloroplastidären Membranproteine nicht mehr in ausreichender Menge zur äußeren Chloroplastenmembran transportiert werden können. Dadurch kann die Membranintegrität geschädigt werden und der Import in den Chloroplasten könnte nicht mehr ausreichend funktionieren.

Die AKR2-RNAi Pflanzen aus dieser Arbeit zeigen einen ähnlichen Phänotyp wie die in Bae et al. (2008) beschriebenen. Obwohl dies auch auf eine beeinträchtigte Chloroplasten-Biogenese schließen lässt, waren im Microarray mit den AKR2-RNAi Pflanzen keine entsprechenden Gene herunterreguliert. Auch bei den GOAnnotationen sind Chloroplasten nicht überrepräsentiert. Dazu wäre evtl. eine 
stärkere Reduktion der AKR2-Proteine nötig, wie sie in Bae et al. (2008) erzielt wurde, obwohl im Western Blot in den AKR2-RNAi Linien \#6 und \#8 schon kein Protein detektierbar ist. Es sind allerdings besonders viele mitochondriale Gene hochreguliert, was durch den Stress erklärt werden kann, dem die Pflanzen aufgrund der beeinträchtigten Chloroplasten unterliegen. Dafür spricht auch, dass viele Stressoder Stimulus-induzierte Gene heraufreguliert sind.

Besonders viele der herunterregulierten Gene sind in der Membran annotiert, allerdings gehören die meisten davon zum Endomembransystem und nicht zur Chloroplastenmembran. Es kann also sein, dass AKR2A/B auch für den Transport zu anderen Membranen als der Chloroplastenmembran zuständig sind. Bae et al. (2008) haben hierzu nur gezeigt, dass AKR2A/B nicht mit zwei mitochondrialen und einem peroxisomalen Membranprotein interagieren, Proteine des Endomembransystems wurden nicht getestet. Die Überrepräsentation von Lipidbindung und Lipidtransport bei den herunterregulierten Genen deutet zusätzlich auf eine Beteiligung an Membranabläufen hin. Deshalb besteht die Möglichkeit, dass Proteine von AKR2A/B auch zu anderen als der äußeren Chloroplastenmembran transportiert werden. Dafür kommen aufgrund der im Microarray regulierten Gene die Mitochondrienmembran und das Endomembransystem (mit Endoplasmatischem Reticulum, Golgi Apparat, Vesikel, Zellmembran, Kernmembran) infrage, insbesondere also die Kernmembran, da AKR2A und AKR2B auch im Kern lokalisiert sein können. Um diese Möglichkeit zu testen, wäre es sinnvoll, einen $\mathrm{Y} 2 \mathrm{H}-$ „,Screen“ durchzuführen, bei dem mögliche Interaktionspartner, d.h. auch zu transportierende Proteine, gefunden werden könnten. Dabei müsste allerdings erst ein Derivat von AKR2A oder AKR2B gefunden werden, das keine so hohe Autoaktivierung in Hefe zeigt, oder ein anderer Hefestamm, in dem BD-AKR2-Fusionen keine Autoaktivierung zeigen.

Dass auch die Antwort auf Auxin besonders häufig herunterreguliert ist, passt zu den Daten von NtANK1 aus Tabak (Böttner et al., 2009). Jedoch konnte für die AKR2RNAi Pflanzen nie eine abweichende Reaktion auf Auxin festgestellt werden, verglichen mit dem Wildtyp (Daten nicht gezeigt). Dazu war das Wurzellängenwachstum auf verschiedenen Auxinkonzentrationen getestet worden und die Zugabe von Auxin zu Protoplasten bei Lokalisationsuntersuchungen. 


\subsection{Die erhöhte Stressanfälligkeit der AKR2-RNAi Pflanzen könnte ein sekundärer Effekt sein}

Es gibt in der Literatur verschiedene Hinweise, dass AKR2A und AKR2B an der Antwort auf Stress beteiligt sind: für AKR2A-Antisense Pflanzen wurde erhöhte Resistenz gegenüber $\mathrm{P}$. syringae und $\mathrm{H}_{2} \mathrm{O}_{2}$-Produktion in Blättern beschrieben (Yan et al., 2002); für AKR2B wurde eine Phosphorylierung nach flg22- oder ChitinStimulus nachgewiesen (Peck et al., 2001).

Auch die Ergebnisse des Microarrays lassen eine Beteiligung an der Stress-Antwort vermuten, da sehr viele Stimulus-induzierte Gene, insbesondere die PDF1.x-Gene heraufreguliert sind. Deshalb wurden die AKR2-RNAi Pflanzen verschiedenen Stressbedingungen unterzogen: oxidativer Stress (Wachstum in Sterilkultur mit verschiedenen Konzentrationen des Herbizids Paraquat), Infektion mit dem biotrophen Bakterium P. syringae und Infektion mit dem nekrotrophen Pilz B. cinerea. Zusammenfassend lässt sich sagen, dass die Pflanzen anfälliger gegenüber allen drei Bedingungen waren als der Wildtyp. Die akr2b-Mutante zeigte meist eine etwas erhöhte Anfälligkeit, jedoch nicht so stark wie die RNAi Pflanzen. Eine erhöhte Anfälligkeit gegenüber $P$. syringae widerspricht den Ergebnissen von Yan et al. (2002), die eine erhöhte Resistenz ihrer AKR2A-Antisense Pflanzen beschreiben. Diese Diskrepanz wurde weiter oben bereits diskutiert.

Für die Infektion mit $B$. cinerea wurde anfangs eine höhere Resistenz erwartet, da eine erhöhte Expression des JA-Markergens PDF1.2 im Microarray der AKR2-RNAi Pflanzen detektiert worden war. Allerdings führt eine Überexpression von PDF1.2 in Arabidopsis nicht zu einer veränderten Resistenz gegenüber nekrotrophen Pathogenen (J. Sels (Heverlee, Belgien), persönliche Mitteilung). Bei der näheren Analyse von PDF1.2 in den AKR2-RNAi Pflanzen stellte sich heraus, dass es sich um keine konstitutive PDF1.2-Expression handelt, sondern dass diese im Tagesverlauf schwankt und vormittags deutlich stärker ist. Daher kann angenommen werden, dass die erhöhte PDF1.2-Expression zu Beginn der Lichtphase stattfindet, weil die Pflanzen dann Stress durch die beginnende Belichtung unterliegen. Damit können sowohl die erhöhte PDF1.2-Expression als auch die erhöhte Anfälligkeit gegenüber den drei getesteten Stressbedingungen sekundärere Effekte zu sein, die sich aus der beeinträchtigten Chloroplasten-Biogenese ergeben. Dadurch wären die AKR2-RNAi Pflanzen in ihrer allgemeinen Fitness herabgesetzt sind, was sich in deren geringerem Samengewicht widerspiegelt. Die andere Möglichkeit ist, dass es 
sich bei PDF1.2-Expression und erhöhter Anfälligkeit um einen direkten Effekt der reduzierten AKR2A/B-Proteinmenge handelt. In Wildtyp Pflanzen führen PAMPs (,pathogen associated molecular patterns“) zur Phosphorylierung von AKR2B (Peck et al., 2001). Diese Phosphorylierung könnte die pflanzliche Pathogenabwehr aktivieren, evtl. durch Modifikation von Membranen mithilfe von Membranproteinen. In AKR2-RNAi Pflanzen kann AKR2B (und AKR2A) nicht phosphoryliert werden, so dass die potentielle Aktivierung der Abwehr nicht stattfinden kann, weshalb die Pflanzen suszeptibler gegenüber Pathogenen sind.

\subsection{Modell der potentiellen Funktionen von AKR2A und AKR2B}

Aus den oben diskutierten Ergebnissen konnte ein Modell erstellt werden, welche Funktionen AKR2A und AKR2B in der Zelle haben (Abb. 32). Demnach haben AKR2A/B eine Chaperonfunktion für Membranproteine und transportieren sie zu verschiedenen zellulären Kompartimenten (Bae et al., 2008; Shen et al., 2010). In Peck et al. (2001) wird eine Phosphorylierung von AKR2B nach flg22 oder ChitinBehandlung beschrieben.

Abb. 32 zeigt, dass PAMPs von einem Rezeptor ( $R$, orange) erkannt werden und ein Signal (gestrichelter Pfeil) führt zur Phosphorylierung $(P)$ von AKR2 (steht für AKR2A und/oder AKR2B).

Desweiteren kann AKR2 an ein Protein (Pr, grün) im Cytoplasma binden, und daraufhin dieses $\mathrm{zu}$ verschiedenen Organellen transportieren: Peroxisomen, Mitochondrium, ER, Kern und Chloroplast. Experimentell bestätigt wurde der Transport zum Peroxisom und zum Chloroplast (Bae et al., 2008; Shen et al., 2010), die anderen Transportwege sind mit einem ? versehen. Am Chloroplast wird gezeigt, dass das Protein nach dem Transport in die äußere Chloroplastenmembran inseriert wird (Abb. 32). Aufgrund der bestätigten Kernlokalisation von AKR2A/B ist für den Kern auch in Co-Transport eines Proteins in den Kern hinein denkbar, nicht nur in die Membran.

Eine weitere putative Funktion von AKR2A/B beginnt mit einem Signal, das den Chloroplasten betrifft (roter Blitz) z.B. durch Stressbedingungen. AKR2 könnte das entstehende retrograde Signal vom Chloroplasten zum Kern übertragen und dann in den Kern transportiert werden. Im Kern könnte AKR2 die Transkription regulieren, z.B. durch Interaktion mit einem Transkriptionsfaktor (TF). Der Kernexport von AKR2, 
der unter normalen Bedingungen aufgrund der NES stattfindet, kann durch LMBBehandlung inhibiert werden (Abb. 32).

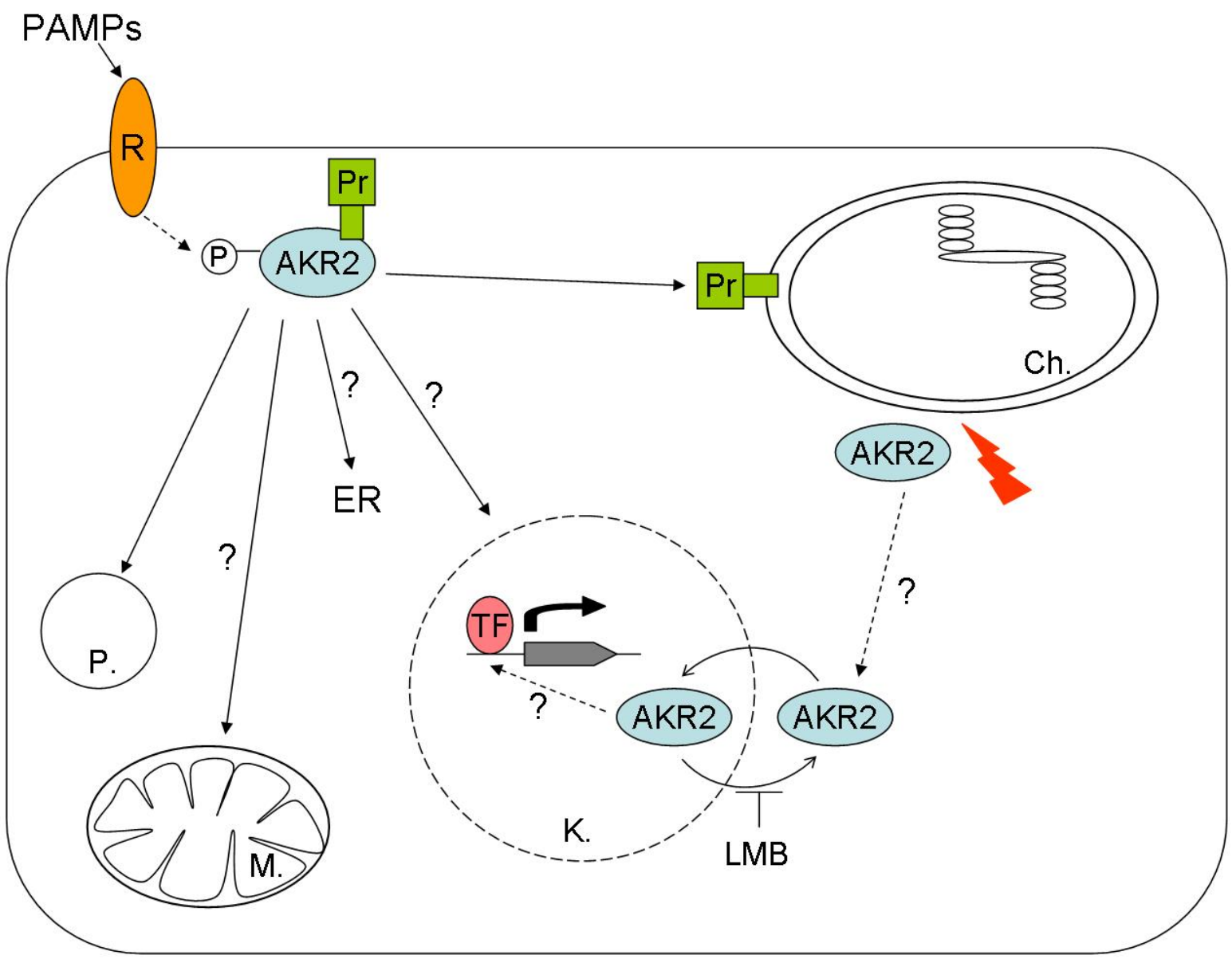

Abbildung 32: Modell der Funktionen von AKR2A und AKR2B in der Zelle. Beschreibung s. Text. Gestrichelte Pfeile bedeuten Signale, durchgehende Pfeile heißt Transport. Abkürzungen: PAMPs: „pathogen associated molecular patterns“, R: Rezeptor, P: Phosphorylierung, Pr: Protein, AKR2: AKR2A und AKR2B, M.: Mitochondrium, P.: Peroxisom, ER: Endoplasmatisches Reticulum, TF: Transkriptionsfaktor, K.: Kern, Ch.: Chloroplast, LMB: Leptomycin B, ?: nicht experimentell überprüfte Funktionen 


\section{Literatur}

Aerts A.M., François I.E., Cammue B.P., Thevissen K. (2008): The mode of antifungal action of plant, insect and human defensins. Cell Mol Life Sci. 65: 2069-79

Albert S., Després B., Guilleminot J., Bechtold N., Pelletier G., Delseny M., Devic M. (1999): The EMB 506 gene encodes a novel ankyrin repeat containing protein that is essential for the normal development of Arabidopsis embryos. Plant $\mathrm{J}$. 17: $169-79$

Alonso J.M., Stepanova A.N., Leisse T.J., Kim C.J., Chen H., Shinn P., Stevenson D.K., Zimmerman J., Barajas P., Cheuk R., Gadrinab C., Heller C., Jeske A., Koesema E., Meyers C.C., Parker H., Prednis L., Ansari Y., Choy N., Deen H., Geralt M., Hazari N., Hom E., Karnes M., Mulholland C., Ndubaku R., Schmidt I., Guzman P., Aguilar-Henonin L., Schmid M., Weigel D., Carter D.E., Marchand T., Risseeuw E., Brogden D., Zeko A., Crosby W.L., Berry C.C., Ecker J.R. (2003): Genome-Wide Insertional Mutagenesis of Arabidopsis thaliana. Science 301: 653-657

Alonso R., Oñate-Sánchez L., Weltmeier F., Ehlert A., Diaz I., Dietrich K., VicenteCarbajosa J., Dröge-Laser W. (2009): A Pivotal Role of the Basic Leucine Zipper Transcription Factor bZIP53 in the Regulation of Arabidopsis Seed Maturation Gene Expression Based on Heterodimerization and Protein Complex Formation. Plant Cell 21: 1747-61

Altschul S.F., Madden T.L., Schäffer A.A., Zhang J., Zhang Z., Miller W., Lipman D.J. (1997): Gapped BLAST and PSI-BLAST: a new generation of protein database search programs. Nucleic Acids Res. 25: 3389-3402

Arabidopsis Genome Initiative (2000): Analysis of the genome sequence of the flowering plant Arabidopsis thaliana. Nature 408: 796-815

Ashburner M., Ball C.A., Blake J.A., Botstein D., Butler H., Cherry J.M., Davis A.P., Dolinski K., Dwight S.S., Eppig J.T., Harris M.A., Hill D.P., Issel-Tarver L., Kasarskis A., Lewis S., Matese J.C., Richardson J.E., Ringwald M., Rubin G.M., Sherlock G. (2000): Gene ontology: tool for the unification of biology. The Gene Ontology Consortium. Nat. Genet. 25: 25-9

Bader S., Kühner S., Gavin A.C. (2008): Interaction networks for systems biology. FEBS Lett. 582: 1220-4

Bae W., Lee Y.J., Kim D.H., Lee J., Kim S., Sohn E.J., Hwang I. (2008): AKR2Amediated import of chloroplast outer membrane proteins is essential for chloroplast biogenesis. Nat Cell Biol. 10: 220-7

Becerra C., Jahrmann T., Puigdomènech P., Vicient C.M. (2004): Ankyrin repeatcontaining proteins in Arabidopsis: characterization of a novel and abundant group of genes coding ankyrin-transmembrane proteins. Gene 340: 111-21 
Beck C.F. (2005) Signaling pathways from the chloroplast to the nucleus. Planta 222: 743-756

Bédard J. und Jarvis P. (2008): Green light for chloroplast outer-membrane proteins. Nat Cell Biol. 10: 120-122

Benito E.P., ten Have A., Klooster J.W. van 't, Kan J.A.L. van (1998): Fungal and plant gene expression during synchronized infection of tomato leaves by Botrytis cinerea. European Journal of Plant Pathology 104: 207-220

Bennett V. und Chen L. (2001): Ankyrins and cellular targeting of diverse membrane proteins to physiological sites. Curr. Opin. Cell Biol. 13: 61-67

Bensmihen S., To A., Lambert G., Kroj T., Giraudat J., Parcy F. (2004): Analysis of an activated $A B I 5$ allele using a new selection method for transgenic Arabidopsis seeds. FEBS Letters 561: 127-31

Bent A.F. (2000): Arabidopsis in planta transformation. Uses, mechanisms, and prospects for transformation of other species. Plant Physiol. 124: 1540-7

Bernard P., Kezdy K.E., Van Melderen L., Steyaert J., Wyns L., Pato M.L., Higgins P.N., Couturier M. (1993): The F plasmid CcdB protein induces efficient ATPdependent DNA cleavage by gyrase. J Mol Biol. 234: 534-41

Blom N., Gammeltoft S., Brunak S. (1999): Sequence- and structure-based prediction of eukaryotic protein phosphorylation sites. J Mol Biol. 294: 1351-1362

Bolton E.T. und McCarthy B.J. (1962): A general method for isolation of RNA complementary to DNA. Proc Natl Acad Sci U S A 48: 1390-1397

Böttner S., Iven T., Carsjens C.S., Dröge-Laser W. (2009): Nuclear accumulation of the ankyrin repeat protein ANK1 enhances the auxin-mediated transcription accomplished by the bZIP transcription factors BZI-1 and BZI-2. Plant J. 58: 914-26

Bowler C., Van Camp W., Van Montagu M., Inze D. (1994): Superoxide dismutases in plants. Crit. Rev. Plant Sci 13: 199-218

Bradford M.M. (1976): A rapid and sensitive method for the quantitation of microgram quantities of protein utilizing the principle of protein-dye binding. Analytical Biochemistry 72: 248-254

Brenner W. (2002): I. Etablierung eines induzierbaren Suizidsystems zur Identifizierung von Mutanten der salizylsäureabhängigen Signaltransduktion II. Expression von tierischen Signaltransduktionskomponenten in Tabak zur Herstellung eines induzierbaren Expressionssystems. Dissertation, Universität Göttingen

Brent R. und Ptashne M. (1985): A eukaryotic transcriptional activator bearing the DNA specificity of a prokaryotic repressor. Cell. 43: 729-36 
Bucher G.L., Tarina C., Heinlein M., Di Serio F., Meins F., Iglesias V.A. (2001): Local expression of enzymatically active class I $\beta-1,3-$ glucanase enhances symptoms of TMV infection in tobacco. Plant J. 28: 361-369

Cao H., Glazebrook J., Clarke J.D., Volko S., Dong X. (1997): The Arabidopsis NPR1 gene that controls systemic acquired resistance encodes a novel protein containing ankyrin repeats. Cell. 88: 57-63

Chinchilla D., Merchan F., Megias M., Kondorosi A., Sousa C., Crespi M. (2003): Ankyrin protein kinases: a novel type of plant kinase gene whose expression is induced by osmotic stress in alfalfa. Plant Mol Biol. 51: 555-66

Chomczynski, P. (1993): A reagent for the single-step simultaneous isolation of RNA, DNA and proteins from cell and tissue samples. Biotechniques. 15: 532-4, 536- 7

Chomczynski P. und Sacchi N. (1987): Single-step method of RNA isolation by acid guanidinium thiocyanate-phenol-chloroform extraction. Anal Biochem. 162: 156-9

Church G.M. und Gilbert W. (1984): Genomic sequencing. Proc Natl Acad Sci U S A. 81: 1991-1995

Clough S.J. und Bent A.F. (1998): Floral dip: a simplified method for Agrobacterium mediated transformation of Arabidopsis thaliana. Plant J. 16: 735-43

Corrêa L.G.G., Riaño-Pachón D.M., Schrago C.G., Vicentini dos Santos R., MuellerRoeber B., Vincentz M. (2008): The Role of bZIP Transcription Factors in Green Plant Evolution: Adaptive Features Emerging from Four Founder Genes. PLoS ONE 3: e2944

Dangl J.L., Dietrich R.A., Richberg M.H. (1996): Death don't have no mercy: cell death programs in plant-microbe interactions. Plant Cell 8: 1793-1807

Dong X.N. (2004): NPR1, all things considered. Curr. Opin. Plant Biol. 7: 547-552

Drummond A.J., Ashton B., Cheung M., Heled J., Kearse M., Moir R., Stones-Havas S., Thierer T., Wilson A. (2009): Geneious v4.7. Available from http://www.geneious.com/

Ehlert A., Weltmeier F., Wang X., Mayer C.S., Smeekens S., Vicente-Carbajosa J., Dröge-Laser W. (2006): Two-hybrid protein-protein interaction analysis in Arabidopsis protoplasts: establishment of a heterodimerization map of group C and group S bZIP transcription factors. Plant J. 46: 890-900

Fan J., Crooks C., Lamb C. (2008): High-throughput quantitative luminescence assay of the growth in planta of Pseudomonas syringae chromosomally tagged with Photorhabdus luminescens luxCDABE. Plant J. 53: 393-9

Feinberg A. P. und Vogelstein B. (1983) A technique for radiolabeling DNA restriction endonuclease fragments to high specific activity. Anal Biochem 132: 6-13 
Feinberg A. P. und Vogelstein B. (1984) A technique for radiolabeling DNA restriction endonuclease fragments to high specific activity. Addendum. Anal Biochem 137: $266-7$

Ferrari S., Plotnikova J.M., De Lorenzo G., Ausubel F.M. (2003): Arabidopsis local resistance to Botrytis cinerea involves salicylic acid and camalexin and requires EDS4 and PAD2, but not SID2, EDS5 or PAD4. Plant J. 35: 193-205

Feys B., Benedetti C.E., Penfold C.N., Turner J.G. (1994): Arabidopsis Mutants Selected for Resistance to the Phytotoxin Coronatine Are Male Sterile, Insensitive to Methyl Jasmonate, and Resistant to a Bacterial Pathogen. Plant Cell. 6: 751-759

Fields S. und Song O. (1989): A novel genetic system to detect protein-protein interactions. Nature. 340: 245-6

Fridborg I., Grainger J., Page A., Coleman M., Findlay K., Angell S. (2003): TIP, a novel host factor linking callose degradation with the cell-to-cell movement of Potato virus X. Mol Plant Microbe Interact. 16: 132-40

Garcion C., Guilleminot J., Kroj T., Parcy F., Giraudat J., Devic M. (2006): AKRP and EMB506 are two ankyrin repeat proteins essential for plastid differentiation and plant development in Arabidopsis. Plant J. 48: 895-906

Gasteiger E., Gattiker A., Hoogland C., Ivanyi I., Appel R.D., Bairoch A. (2003) ExPASy: the proteomics server for in-depth protein knowledge and analysis. Nucleic Acids Res. 31: 3784-3788

Giniger E., Varnum S.M., Ptashne M. (1985): Specific DNA binding of GAL4, a positive regulatory protein of yeast. Cell. 40: 767-74

Govrin E.M. und Levine A. (2000): The hypersensitive response facilitates plant infection by the necrotrophic pathogen Botrytis cinerea. Curr. Biol. 10: 751757

Grene R. (2002): Oxidative Stress and Acclimation Mechanisms in Plants. The Arabidopsis Book. Rockville, MD: American Society of Plant Biologists. doi: 10.1199/tab.0036.1

Guilfoyle T.J. und Hagen G. (2007): Auxin response factors. Curr. Opin. Plant Biol. 10: $453-460$

Haasen D., Köhler C., Neuhaus G., Merkle T. (1999): Nuclear export of proteins in plants: AtXPO1 is the export receptor for leucine-rich nuclear export signals in Arabidopsis thaliana. Plant J. 20: 695-705

Hagar H., Ueda N., Shah S.V. (1996): Role of reactive oxygen metabolites in DNA damage and cell death in chemical hypoxic injury to LLC-PK1 cells. Am. J. Physiol. 271: 209-215 
Hanson J., Hanssen M., Wiese A., Hendriks M.M., Smeekens S. (2008): The sucrose regulated transcription factor bZIP11 affects amino acid metabolism by regulating the expression of ASPARAGINE SYNTHETASE1 and PROLINE DEHYDROGENASE2. Plant J. 53: 935-49

Hartings H., Maddaloni M., Lazzaroni N., Di Fonzo N., Motto M., Salamini F., Thompson R.D. (1989): The $\mathrm{O} 2$ gene which regulates zein deposition in maize endosperm encodes a protein with structural homologies to transcriptional activators. EMBO J. 8: 2795-2801

Hass C., Lohrmann J., Albrecht V., Sweere U., Hummel F., Yoo S.D., Hwang I., Zhu T., Schäfer E., Kudla J., Harter K. (2004): The response regulator 2 mediates ethylene signalling and hormone signal integration in Arabidopsis. EMBO J. 23: $3290-302$

Heinekamp T. (2002): Der bZIP-Transkriptionsfaktor BZI-1 aus Nicotiana tabacum: Analyse der in vivo Funktion durch Modulation der BZI-1Aktivierungseigenschaften in transgenen Pflanzen. Dissertation, Universität Göttingen.

Heinekamp T., Kuhlmann M., Lenk A., Strathmann A., Dröge-Laser W. (2002): The tobacco bZIP transcription factor BZI-1 binds to G-box elements in the promoters of phenylpropanoid pathway genes in vitro, but it is not involved in their regulation in vivo. Mol Genet Genomics. 267: 16-26

Heinekamp T., Strathmann A., Kuhlmann M., Froissard M., Müller A., PerrotRechenmann C., Dröge-Laser W. (2004): The tobacco bZIP transcription factor BZI-1 binds the GH3 promoter in vivo and modulates auxin-induced transcription. Plant J. 38: 298-309

Heldt H.W. (1999): Pflanzenbiochemie. 2. Aufl. Heidelberg: Spektrum

Herrera-Estrella L., Depicker A., Van Montagu M., Schell J. (1992): Expression of chimaeric genes transferred into plant cells using a Ti-plasmid-derived vector. Biotechnology. 24: 377-81

Hill J., Donald K.A., Griffiths D.E. (1991): DMSO-enhanced whole cell yeast transformation. Nucleic Acids Res. 19. 5791

Hofmann N.R., Theg S.M. (2005): Protein- and energy-mediated targeting of chloroplast outer envelope membrane proteins. Plant J. 44: 917-27

Hokema A., Hirsch P.R., Hooykaas P.J.J., Schilperoort R.A. (1983): A binary plant vectorstrategy based on separation of vir and T-region of the Agrobacterium tumefaciens Ti-plasmid. Nature. 303: 179-180

Hu C.D., Chinenov Y., Kerppola T.K. (2002): Visualization of interactions among bZIP and Rel family proteins in living cells using bimolecular fluorescence complementation. Mol Cell. 9: 789-98 
Inoue H., Nojima H., Okayama H. (1990): High efficiency transformation of Escherichia coli with plasmids. Gene. 96 23-28

Invitrogen (2001): Proquest Two-Hybrid System - Instruction Manual

Ito H., Fukuda Y., Murata K., Kimura A. (1983): Transformation of intact yeast

cells treated with alkali cations. J Bacteriol. 153: 163-8

Jakoby M., Weisshaar B., Dröge-Laser W., Vicente-Carbajosa J., Tiedemann J., Kroj T., Parcy F.; bZIP Research Group. (2002): bZIP transcription factors in Arabidopsis. Trends in Plant Science 7: 106-11

Kakizaki T., Matsumura H., Nakayama K., Che F.S., Terauchi R., Inaba T. (2009): Coordination of plastid protein import and nuclear gene expression by plastidto-nucleus retrograde signaling. Plant Physiol. 151: 1339-53

Kaminaka H., Näke C., Epple P., Dittgen J., Schütze K., Chaban C., Holt B.F. $3^{\text {rd }}$, Merkle T., Schäfer E., Harter K., Dangl J.L. (2006): bZIP10-LSD1 antagonism modulates basal defense and cell death in Arabidopsis following infection. EMBO J. 25: 4400-11

Katagiri F., Thilmony R., He S.Y. (2002): The Arabidopsis Thaliana-Pseudomonas Syringae Interaction. The Arabidopsis Book. Rockville, MD: American Society of Plant Biologists. doi: 10.1199/tab.0039

Kirby J. und Kavanagh T.A. (2002): NAN fusions: a synthetic sialidase reporter gene as a sensitive and versatile partner for GUS. Plant J. 32: 391-400

Kliebenstein D.J., Rowe H.C., Denby K.J. (2005): Secondary metabolites influence Arabidopsis/Botrytis interactions: variation in host production and pathogen sensitivity. Plant J. 44: 25-36

Koncz C. und Schell J. (1986): The promoter of TL-DNA gene 5 controls the tissue specific expression chimeric genes carried by a novel type of Agrobacterium binary vector. Mol Gen Genet. 204: 383-396

Koornneef A., Leon-Reyes A., Ritsema T., Verhage A., Den Otter F.C., Van Loon L.C., Pieterse C.M. (2008): Kinetics of Salicylate-Mediated Suppression of Jasmonate Signaling Reveal a Role for Redox Modulation. Plant Physiol. 147: $1358-68$

Koussevitzky S., Nott A., Mockler T.C., Hong F., Sachetto-Martins G., Surpin M., Lim J., Mittler R., Chory J. (2007): Signals from chloroplasts converge to regulate nuclear gene expression. Science. 316: 715-9

Kuhlmann M., Horvay K., Strathmann A., Heinekamp T., Fischer U., Böttner S., Dröge-Laser W. (2003): The alpha-helical D1 domain of the tobacco bZIP transcription factor BZI-1 interacts with the ankyrin-repeat protein ANK1 and is important for BZI-1 function, both in auxin signaling and pathogen response. $J$ Biol Chem. 278: 8786-94 
Kyhse-Andersen J. (1984): Electroblotting of multiple gels: A simple apparatus without buffer tank for rapid transfer of proteins from polyacrylamide to nitrocellulose. J. Biochem. Biophys. Meth. 10: 203-209

Laemmli U.K. (1970): Cleavage of structural proteins during the assembly of the head of bacteriophage T4. Nature. 227: 680-685

Lam E., Kato N., Lawton M. (2001): Programmed cell death, mitochondria and the plant hypersensitive response. Nature. 411: 848-853

Lara P., Oñate-Sánchez L., Abraham Z., Ferrándiz C., Díaz I., Carbonero P., Vicente-Carbajosa J. (2003): Synergistic activation of seed storage protein gene expression in Arabidopsis by ABI3 and two bZIPs related to OPAQUE2. J Biol Chem. 278: 21003-11

Leon-Reyes A., Spoel S.H., De Lange E.S., Abe H., Kobayashi M., Tsuda S., Millenaar F.F., Welschen R.A., Ritsema T., Pieterse C.M. (2009): Ethylene modulates the role of NONEXPRESSOR OF PATHOGENESIS-RELATED GENES1 in cross talk between salicylate and jasmonate signaling. Plant Physiol. 149: 1797-809

Li H.M. und Chiu C.C. (2010): Protein Transport into Chloroplasts. Annu Rev Plant Biol. 2010 Feb 4. [Epub ahead of print]

Locatelli S., Piatti P., Motto M., Rossi V. (2009): Chromatin and DNA modifications in the Opaque2-mediated regulation of gene transcription during maize endosperm development. Plant Cell. 21: 1410-27

Ma J. und Ptashne M. (1987): Deletion analysis of GAL4 defines two transcriptional activating segments. Cell. 48: 847-53

Mitsuda N. und Ohme-Takagi M. (2009): Functional analysis of transcription factors in Arabidopsis. Plant \& Cell Physiology 50:1232-48

Mosavi L.K., Minor D.L. Jr, Peng Z.Y. (2002): Consensus-derived structural determinants of the ankyrin repeat motif. Proc Natl Acad Sci USA. 99: 1602934

Mou Z., Fan W.H., Dong, X.N. (2003): Inducers of plant systemic acquired resistance regulate NPR1 function through redox changes. Cell 113: 935-944

Moulin M., McCormac A.C., Terry M.J., Smith A.G. (2008): Tetrapyrrole profiling in Arabidopsis seedlings reveals that retrograde plastid nuclear signaling is not due to Mg-protoporphyrin IX accumulation. Proc Natl Acad Sci USA. 105: 15178-15183

Mullineaux P., Ball L., Escobar C., Karpinska B., Creissen G., Karpinski S. (2000): Are diverse signalling pathways integrated in the regulation of arabidopsis antioxidant defence gene expression in response to excess excitation energy? Philos. Trans. R. Soc. Lond. B. Biol. Sci 355:1531-40 
Mullis K.B. und Faloona F.A. (1987): Specific synthesis of DNA in vitro via a polymerase-catalyzed chain reaction. Methods Enzymol 155: 335-350

Murashige und Skoog. (1962): A revised medium for rapid growth and bioassays with tobacco tissue cultures. Physiol. Plant. 15: 473-497

Muth J.R., Muller S., Lohmer S., Salamini F., Thompson R.D. (1996): The role of multiple binding sites in the activation of zein gene expression by Opaque-2. Mol. Gen. Genet. 252: 723-732

Nott A., Jung H.S., Koussevitzky S., Chory J. (2006): Plastid-to-nucleus retrograde signaling. Annu Rev Plant Biol. 57: 739-59

Oecking C. und Jaspert N. (2009): Plant 14-3-3 proteins catch up with their mammalian orthologs. Curr Opin Plant Biol. 12: 760-5

Oxborough K. (2004): Imaging of chlorophyll a fluorescence: theoretical and practical aspects of an emerging technique for the monitoring of photosynthetic performance. J of Experimental Botany 55: 1195-1205

Pawson T. und Nash P. (2003): Assembly of cell regulatory systems through protein interaction domains. Science. 300: 445-452

Peck S.C., Nühse T.S., Hess D., Iglesias A., Meins F., Boller T. (2001): Directed proteomics identifies a plant-specific protein rapidly phosphorylated in response to bacterial and fungal elicitors. Plant Cell. 13: 1467-75

Pérez-Rodríguez P., Riaño-Pachón D.M., Corrêa L.G., Rensing S.A., Kersten B., Mueller-Roeber B. (2010): PInTFDB: updated content and new features of the plant transcription factor database. Nucleic Acids Res. 38: D822-7

Pesaresi P., Schneider A., Kleine T., Leister D. (2007): Interorganellar communication. Curr Opin Plant Biol. 10: 600-6

Pfannschmidt T., Schutze K., Brost M., Oelmüller R. (2001): A novel mechanism of nuclear photosynthesis gene regulation by redox signals from the chloroplast during photosystem stoichiometry adjustment. J. Biol. Chem. 276: 36125-30

Pirona R., Hartings H., Lauria M., Rossi V., Motto M. (2005): Genetic control of endosperm development and of storage products accumulation on maize seeds. Maydica. 50: 515-530

Poirier Y. und Bucher M. (2002): Phosphate Transport and Homeostasis in Arabidopsis. The Arabidopsis Book. Rockville, MD: American Society of Plant Biologists. doi: 10.1199/tab.0024

Rechsteiner M. und Rogers S.W. (1996): PEST sequences and regulation by proteolysis. Trends Biochem. Sci. 21, 267-271

Riechmann J.L., Heard J., Martin G., Reuber L., Jiang C., Keddie J., Adam L., Pineda O., Ratcliffe O.J., Samaha R.R., Creelman R., Pilgrim M., Broun P., Zhang 
J.Z., Ghandehari D., Sherman B.K., Yu G. (2000): Arabidopsis transcription factors: genome-wide comparative analysis among eukaryotes. Science 290: 2105-2110

Rogers S.O. und Bendich A.J. (1988): Extraction of DNA from plant tissues. Plant Mol Biol Manual A6:1-10

Rook F., Gerrits N., Kortstee A., van Kampen M., Borrias M., Weisbeek P., Smeekens S. (1998a): Sucrose-specific signalling represses translation of the Arabidopsis ATB2 bZIP transcription factor gene. Plant J. 15: 253-63

Rook F., Weisbeek P., Smeekens S. (1998b): The light-regulated Arabidopsis bZIP transcription factor gene ATB2 encodes a protein with an unusually long leucine zipper domain. Plant Mol Biol. 37: 171-8

Sanger F., Nickler S., Coulson A.R. (1977): DNA sequencing with chain-termination inhibitors. Proc Natl Acad Sci USA. 74: 5463-5467

Sambrook J., Fritsch E.F., Maniatis T. (1989): Molecular cloning: A Laboratory Manual. $2^{\text {nd }}$ edition. Cold Spring Habor, New York: Cold Spring Habor Laboratory Press.

Schäffer A.A., Aravind L., Madden T.L., Shavirin S., Spouge J.L., Wolf Y.I., Koonin E.V. and Altschul S.F. (2001): Improving the accuracy of PSI-BLAST protein database searches with composition-based statistics and other refinements. Nucleic Acids Res. 29: 2994-3005

Sedgwick S.G. und Smerdon S.J. (1999): The ankyrin repeat: a diversity of interactions on a common structural framework. Trends Biochem. Sci. 24: 311-316

Shen G., Kuppu S., Venkataramani S., Wang J., Yan J., Qiu X., Zhang H. (2010): ANKYRIN REPEAT-CONTAINING PROTEIN 2A Is an Essential Molecular Chaperone for Peroxisomal Membrane-Bound ASCORBATE PEROXIDASE3 in Arabidopsis. Plant Cell. Mar 9. [Epub ahead of print]

Strand A., Asami T., Alonso J., Ecker J.R., Chory J. (2003): Chloroplast to nucleus communication triggered by accumulation of $\mathrm{Mg}$-protoporphyrinlX. Nature. 421: $79-83$

Strathmann A., Kuhlmann M., Heinekamp T., Dröge-Laser W. (2001): BZI-1 specifically heterodimerises with the tobacco bZIP transcription factors BZI-2, BZI-3/TBZF and BZI-4, and is functionally involved in flower development. Plant J. 28: 397-408

Swarbreck D., Wilks C., Lamesch P., Berardini T.Z., Garcia-Hernandez M., Foerster H., Li D., Meyer T., Muller R., Ploetz L., Radenbaugh A., Singh S., Swing V., Tissier C., Zhang P., Huala E. (2008): The Arabidopsis Information Resource (TAIR): gene structure and function annotation. Nucleic Acids Res. 36: D100914 
Thomma B.P., Eggermont K., Penninckx I.A., Mauch-Mani B., Vogelsang R., Cammue B.P., Broekaert W.F. (1998): Separate jasmonate-dependent and salicylate-dependent defense-response pathways in Arabidopsis are essential for resistance to distinct microbial pathogens. Proc Natl Acad Sci U S A. 95: 15107-11

Thomma B.P., Tierens K.F., Penninckx I.A., Mauch-Mani B., Broekaert W.F., Cammue B.P. (2001): Different micro-organisms differentially induce Arabidopsis disease response pathways. Plant Physiol Biochem. 39: 673-680

Thomma B.P., Cammue B.P., Thevissen K. (2002): Plant defensins. Planta. 216: 193-202

Tu S.L., Chen L.J., Smith M.D., Su Y.S., Schnell D.J., Li H.M. (2004): Import pathways of chloroplast interior proteins and the outer-membrane protein OEP14 converge at Toc75. Plant Cell. 16: 2078-88

Van Heusden G.P. (2009): 14-3-3 Proteins: insights from genome-wide studies in yeast. Genomics. 94: 287-93

Van Kan J.A. (2006): Licensed to kill: the lifestyle of a necrotrophic plant pathogen. Trends Plant Sci. 11: 247-53

Verma I. M. und Stevenson J. (1997): IkappaB kinase: beginning, not the end. Proc Natl Acad Sci U S A. 94: 11758-11760

Vidal, M. (1997): The Reverse Two-Hybrid System in The Two-Hybrid System. Oxford University Press, New York, 109

Walter M., Chaban C., Schütze K., Batistic O., Weckermann K., Näke C., Blazevic D., Grefen C., Schumacher K., Oecking C., Harter K., Kudla J. (2004): Visualization of protein interactions in living plant cells using bimolecular fluorescence complementation. Plant J. 40: 428-38

Wei L. und Li Y. (2009): Distribution of an ankyrin-repeat protein on the endoplasmic reticulum in Arabidopsis. J Integr Plant Biol. 51: 140-6

Weltmeier F. (2005): Ein Netzwerk von heterodimerisierenden C/S1 AtbZIPTranskriptionsfaktoren und seine Funktion in Seneszenz, Stressantwort und Samenentwicklung. Dissertation, Universität Göttingen

Weltmeier F., Ehlert A., Mayer C.S., Dietrich K., Wang X., Schütze K., Alonso R., Harter K., Vicente-Carbajosa J., Dröge-Laser W. (2006): Combinatorial control of Arabidopsis proline dehydrogenase transcription by specific heterodimerisation of bZIP transcription factors. EMBO J. 25: 3133-43

Weltmeier F., Rahmani F., Ehlert A., Dietrich K., Schütze K., Wang X., Chaban C., Hanson J., Teige M., Harter K., Vicente-Carbajosa J., Smeekens S., DrögeLaser W. (2009): Expression patterns within the Arabidopsis C/S1 bZIP transcription factor network: availability of heterodimerization partners controls 
gene expression during stress response and development. Plant Mol Biol. 69: 107-19

Wessel D. und Flügge U.I. (1984): A Method for the quantitative recovery of protein in dilute solution in the presence of detergents and lipids. Analytical Biochemistry 138: $141-143$

White J., Chang S.Y., Bibb M.J. (1990): A cassette containing the bar gene of Streptomyces hygroscopicus: a selectable marker for plant transformation. Nucleic Acids Res. 18: 1062

Wiese A., Elzinga N., Wobbes B., Smeekens S. (2004): A conserved upstream open reading frame mediates sucrose-induced repression of translation. Plant Cell. 16: $1717-1729$

Wirdnam C., Motoyama A., Arn-Bouldoires E., van Eeden S., Iglesias A., Meins F. Jr. (2004): Altered expression of an ankyrin-repeat protein results in leaf abnormalities, necrotic lesions, and the elaboration of a systemic signal. Plant Mol Biol. 56: 717-30

Woodcock D.M., Crowther P.J., Doherty J., Jefferson S., Decruz E., Noyer Weidner M., Smith S.S., Michael M.Z., Graham M.W. (1989): Quantitative evaluation of Escherichia coli host strains for tolerance to cytosine methylation in the plasmid and phage recombinants. Nucl Acids Res. 17: 3469-3478

Xu X., Chen C., Fan B., Chen Z. (2006): Physical and functional interactions between pathogen-induced Arabidopsis WRKY18, WRKY40, and WRKY60 transcription factors. Plant Cell. 18: 1310-26

Yan J., Wang J., Zhang H. (2002): An ankyrin repeat-containing protein plays a role in both disease resistance and antioxidation metabolism. Plant J. 29: 193-202

Zhang D.P. (2007): Plant science. Signaling to the nucleus with a loaded GUN. Science. 316: 700-1

Zhou X. und Su Z. (2007): EasyGO: Gene Ontology-based annotation and functional enrichment analysis tool for agronomical species. BMC Genomics. 8: 246

Zimmermann P., Hirsch-Hoffmann M., Hennig L., Gruissem W. (2004): GENEVESTIGATOR. Arabidopsis microarray database and analysis toolbox. Plant Physiol. 136: 2621-32 


\section{Anhang}

\subsection{Daten}

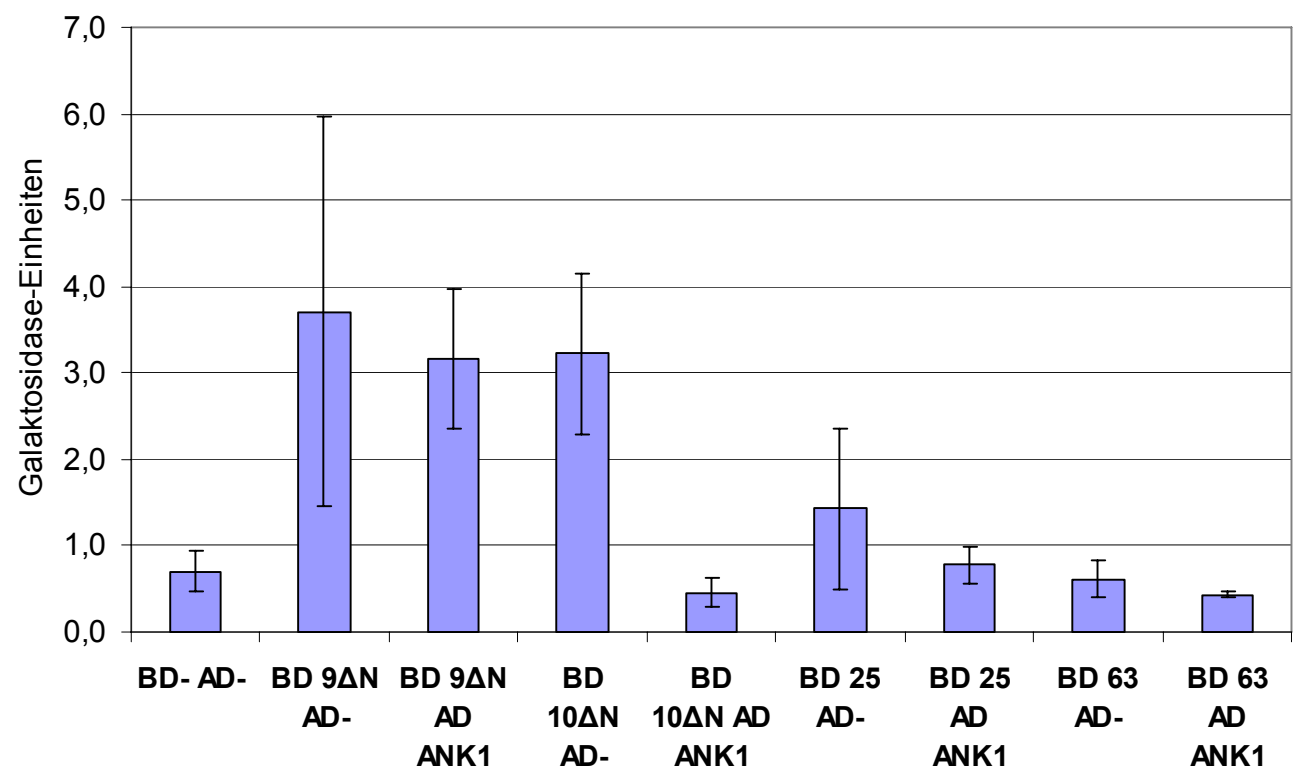

Abbildung 33: oNPG-Test verschiedener Protein-Protein-Interaktionen im Y2H-System. Gal4Bindedomäne (BD)- und Gal4-Aktivierungsdomäne (AD)-Fusionen wurden verwendet, mit pDEST22 (AD) und pDEST32 (BD) als Ausgangsvektoren. -: Leervektoren als Kontrollen, ANK1: Protein aus Tabak, 9 $\Delta \mathrm{N}, 10 \Delta \mathrm{N}, 25$, 63: bZIP-Faktoren aus Arabidopsis. Der Mittelwert wurde jeweils aus den Ergebnissen von 3 unabhängigen Kolonien gebildet.

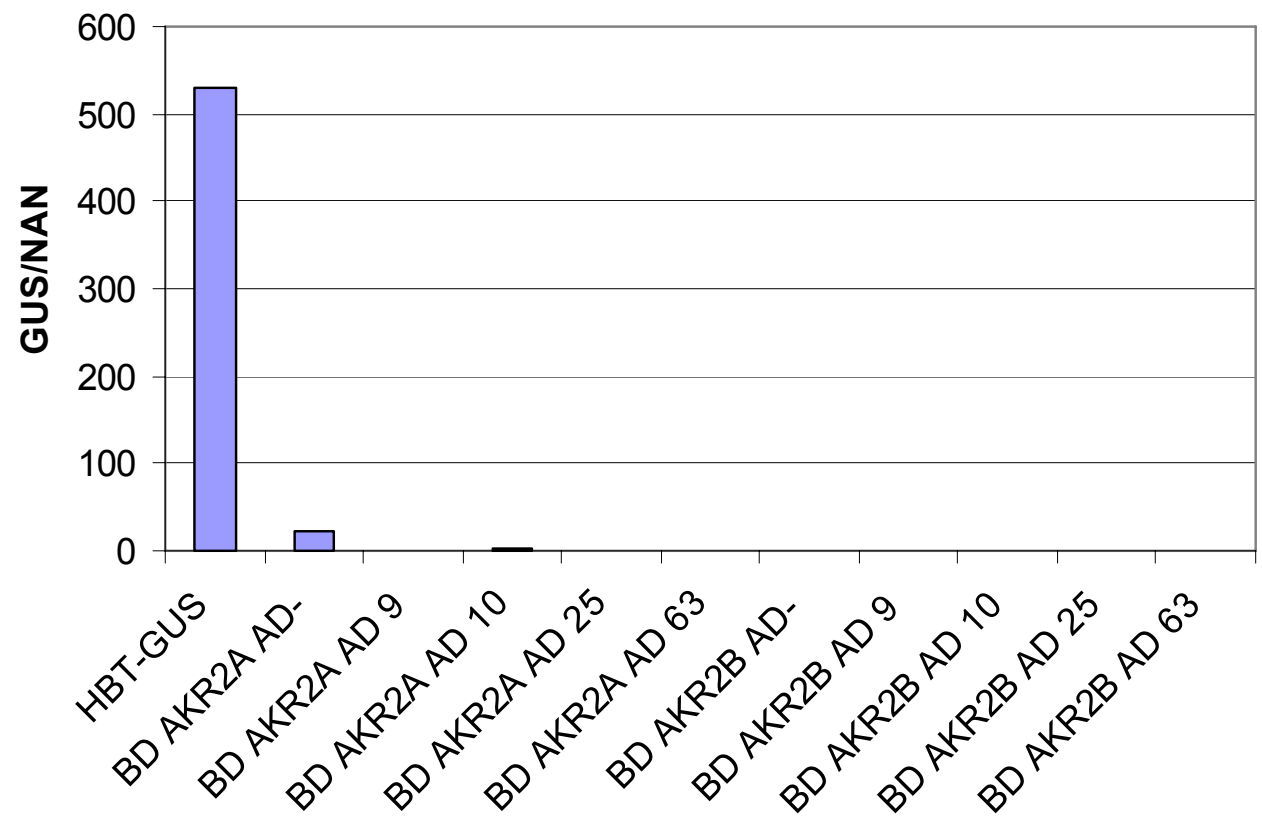

Abbildung 34: Analyse der Protein-Protein-Interaktionen von AKR2A/B und Arabidopsis Gruppe C bZIP-Faktoren in Arabidopsis Protoplasten. In allen Ansätzen wurden $9 \mu \mathrm{g}$ GAL4-UAS4:GUS und $3 \mu \mathrm{g}$ Pro35S:NAN als Reporterplasmide sowie $14 \mu \mathrm{g}$ des jeweiligen Effektorplasmids transformiert. Gal4Bindedomäne (BD)- und Gal4-Aktivierungsdomäne (AD)-Fusionen wurden verwendet. HBT-GUS: Positivkontrolle, -: Leervektoren als Kontrollen, 9, 10, 25, 63: bZIP-Faktoren aus Arabidopsis. Der Versuch wurde zwei mal mit ähnlichen Ergebnissen wiederholt. 


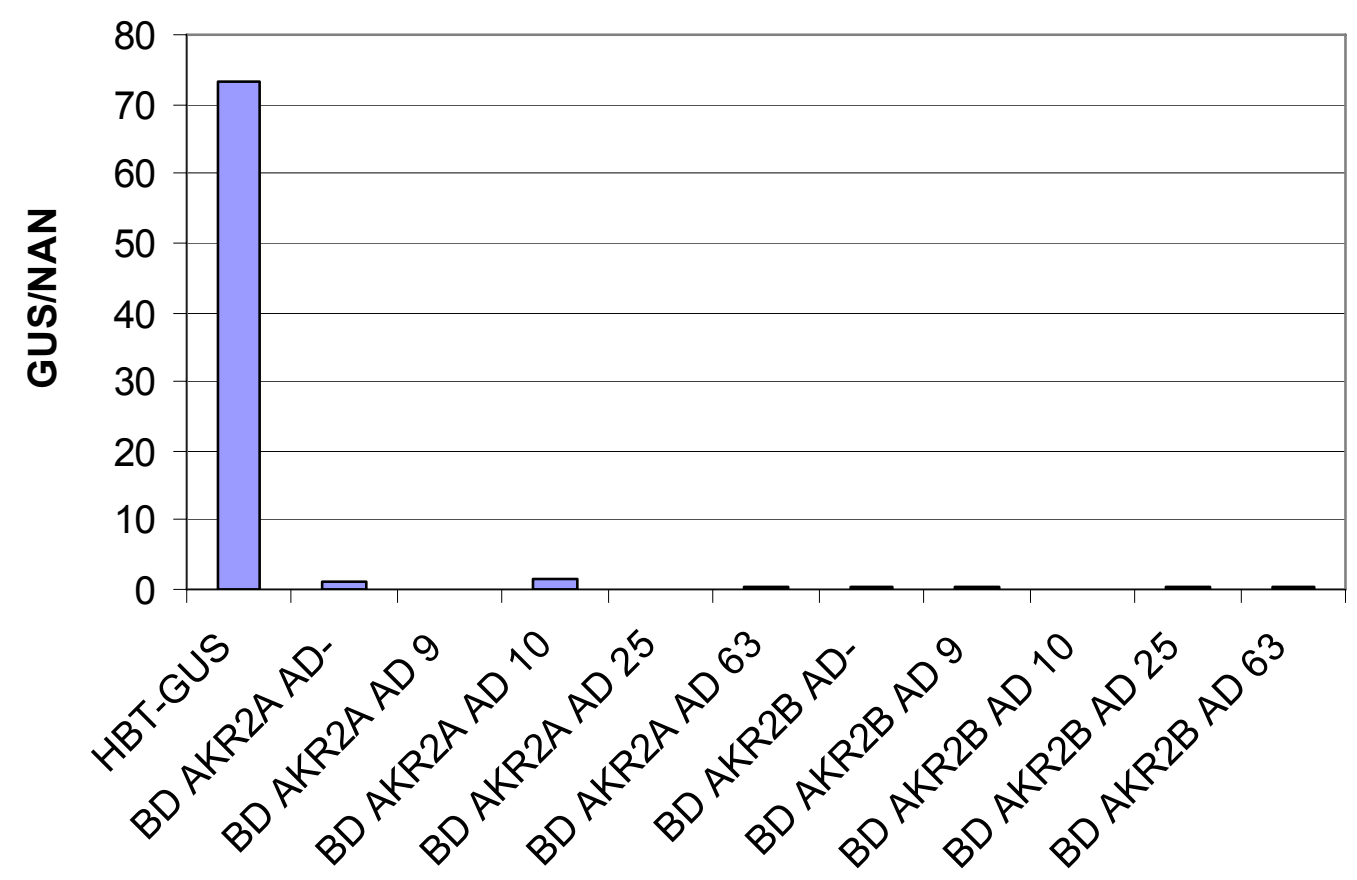

Abbildung 35: Analyse der Protein-Protein-Interaktionen von AKR2A/B und Arabidopsis Gruppe C bZIP-Faktoren in Tabak Protoplasten. In allen Ansätzen wurden $9 \mu \mathrm{g}$ GAL4-UAS4:GUS und $3 \mu \mathrm{g}$ Pro35S:NAN als Reporterplasmide sowie $14 \mu \mathrm{g}$ des jeweiligen Effektorplasmids transformiert. Gal4Bindedomäne (BD)- und Gal4-Aktivierungsdomäne (AD)-Fusionen wurden verwendet. HBT-GUS: Positivkontrolle, -: Leervektoren als Kontrollen, 9, 10, 25, 63: bZIP-Faktoren aus Arabidopsis. Der Versuch wurde zwei mal mit ähnlichen Ergebnissen wiederholt.

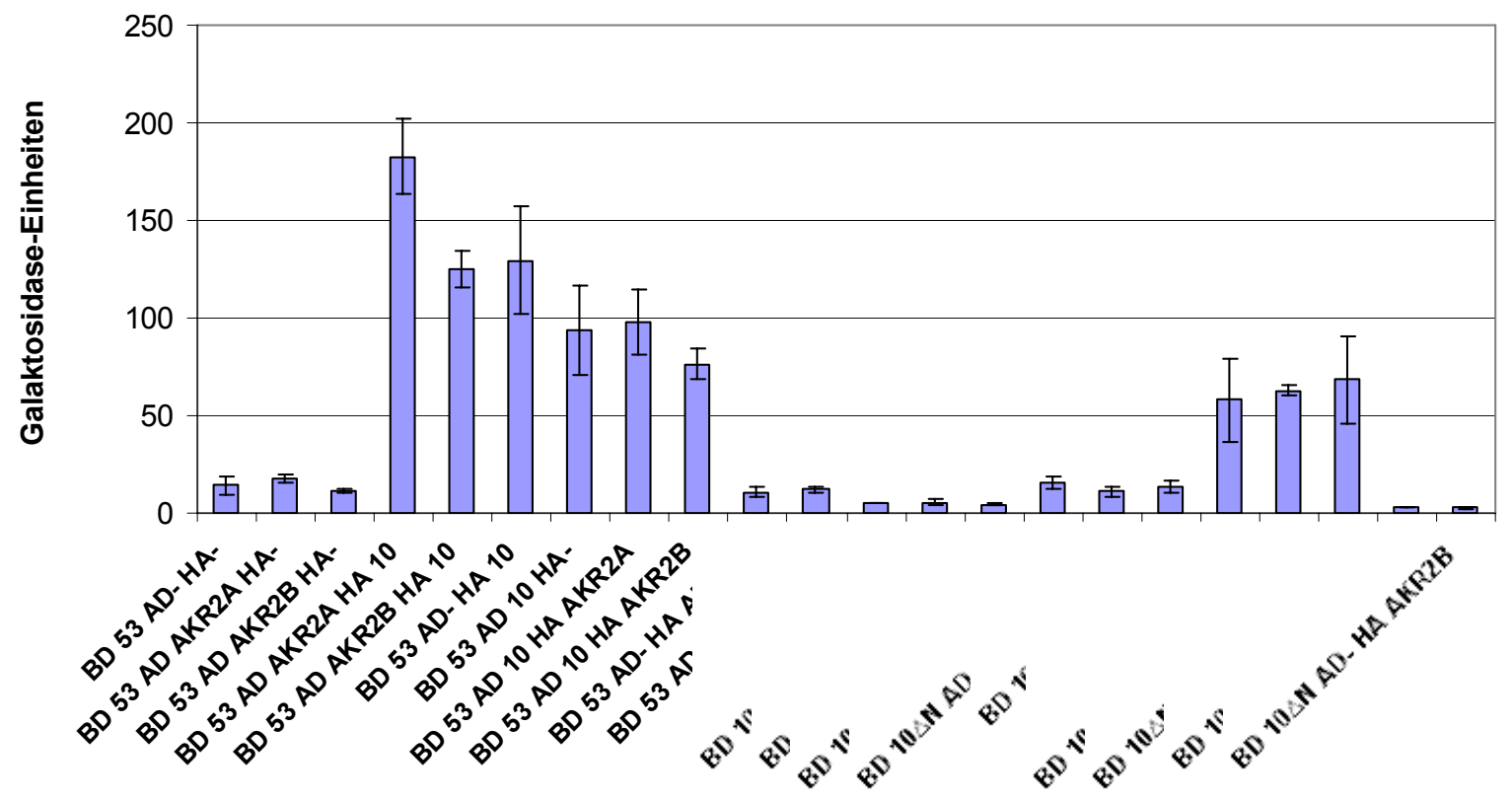

Abbildung 36: oNPG-Test zur Analyse eines putativen trimeren Komplexes der Arabidopsis Proteine bZIP10 (10), bZIP53 (53) und AKR2A/B in Hefe. Gal4-Bindedomäne (BD)-, Gal4-Aktivierungsdomäne (AD) und HA-Fusionen wurden verwendet, mit pDEST22 (AD) und pDEST32 (BD) als Ausgangsvektoren. -: Leervektoren als Kontrollen. Der Mittelwert wurde jeweils aus den Ergebnissen von 3 unabhängigen Kolonien gebildet. Die Interaktion zwischen bZIP10 und bZIP53 ist zu sehen, kann jedoch nicht durch Zugabe von AKR2A/B gesteigert werden. 

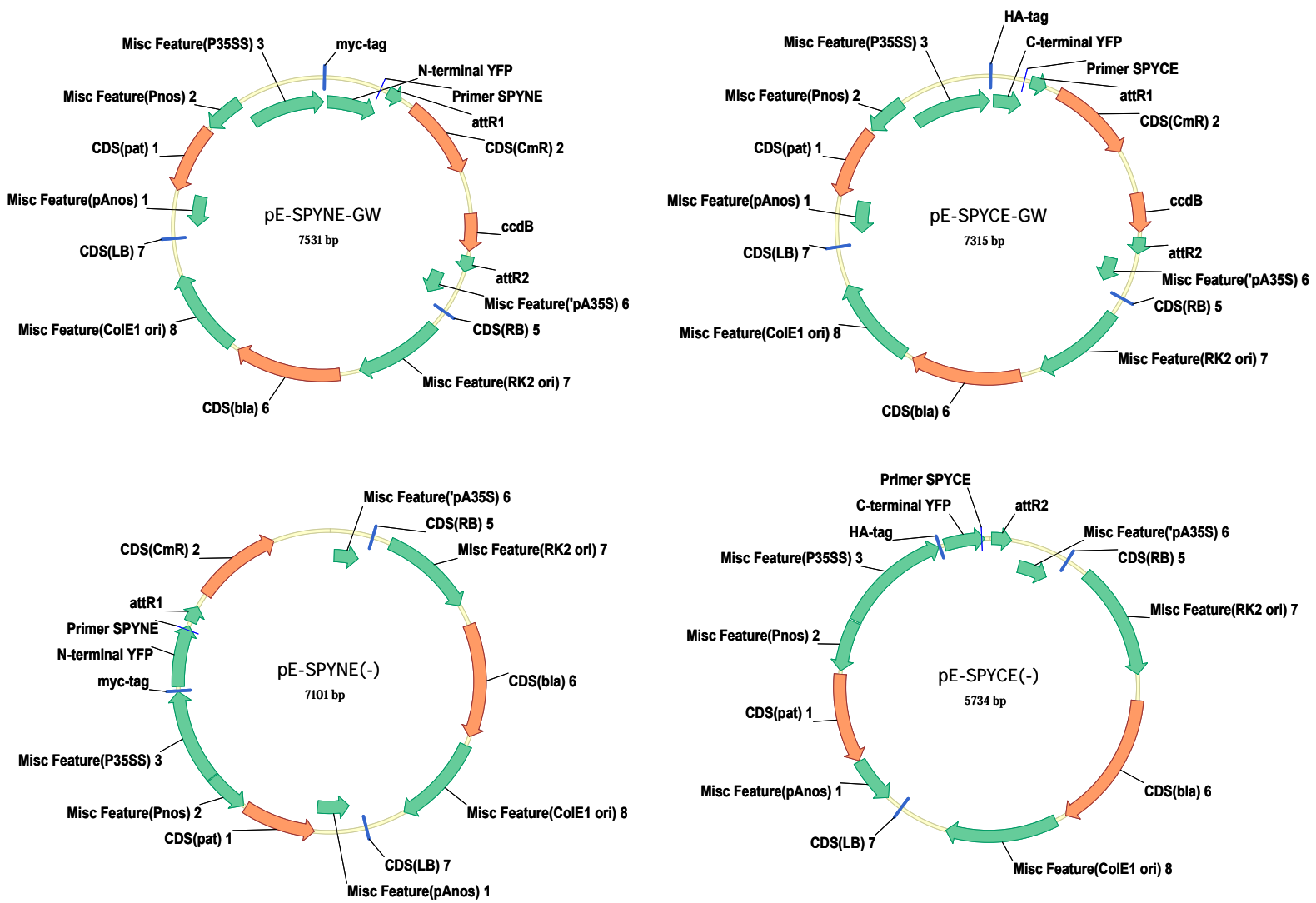

Abbildung 37: Die Gateway-kompatiblen BiFC-Vektoren, die in dieser Arbeit erstellt wurden. Grundlage war $\mathrm{pE}$, ein binärer Gateway-Pflanzenvektor mit Ampicillin-Resistenz (bla). Vor der Gateway-,,site“ wurden die N- bzw. C-terminalen Teile des YFP-Gens inseriert, die dann unter Kontrolle des 35S-Promotors exprimiert werden können. Für die Negativkontrollen wurden Teile des $c c d B-G e n s$ deletiert, damit die Vektoren pE-SPYNE/CE(-) leichter vermehrt werden können. 
Tabelle 25: Die komplette Liste der Gene, die laut Microarray in den AKR2-RNAi Pflanzen stärker, bzw. schwächer exprimiert wurden als im Wildtyp. Ein negatives Vorzeichen bedeutet schwächere Expression in der transgenen Pflanze, je kleiner der P-Wert, desto signifikanter sind die Expressionsdaten. Die Schwellenwerte betragen: log (RNAi/WT): 3, P-Wert: 0,02

\begin{tabular}{|c|c|c|c|}
\hline Gen AGI & $\begin{array}{c}\log \\
\text { (RNAi/WT) }\end{array}$ & P-Wert & Annotation \\
\hline At1g75830 & 10.8 & 0.00317 & plant defensin-fusion protein, (PDF1.1) \\
\hline At5g44420 & 10.6 & 0.00333 & plant defensin protein, (PDF1.2a) \\
\hline At5g59320 & 10.6 & 0.00557 & lipid transfer protein 3 (LTP3) \\
\hline At5g59310 & 10.4 & 0.00852 & lipid transfer protein 4 (LTP4) \\
\hline At5g44430 & 8.5 & 0.00328 & plant defensin-fusion protein, (PDF1.2c) \\
\hline At2g26020 & 7.3 & 0.00681 & plant defensin-fusion protein, (PDF1.2b) \\
\hline At1g80840 & 6.5 & 0.00246 & WRKY40 \\
\hline At4g22690 & 6.5 & 0.00247 & $\begin{array}{l}\text { CYP706A1, cytochrome P450 family protein flavonoid } \\
\text { 3',5'-hydroxylase Hf1 }\end{array}$ \\
\hline At4g24570 & 6.4 & 0.00232 & mitochondrial substrate carrier family protein \\
\hline At2g41100 & 6.2 & 0.00275 & $\begin{array}{l}\text { touch-responsive protein / calmodulin-related protein } \\
3 \text {, touch-induced (TCH3) }\end{array}$ \\
\hline At5g08680 & 5.9 & 0.00297 & ATP synthase beta chain, mitochondrial, putative \\
\hline At3g55980 & 5.8 & 0.00547 & $\begin{array}{l}\text { zinc finger (CCCH-type) family protein, contains Pfam } \\
\text { domains: Zinc finger C-x8-C-x5-C-x3-H type; and } \\
\text { Ankyrin repeat }\end{array}$ \\
\hline At2g26010 & 5.7 & 0.00415 & plant defensin-fusion protein, putative (PDF1.3) \\
\hline At4g30270 & 5.6 & 0.00264 & $\begin{array}{l}\text { endo-xyloglucan transferase /xyloglucan endo-1,4- } \\
\text { beta-D-glucanase MERI-5(B) (SEN4) }\end{array}$ \\
\hline At5g67480 & 5.4 & 0.00254 & $\begin{array}{l}\text { TAZ zinc finger family protein / BTB/POZ domain- } \\
\text { containing protein (BT4) }\end{array}$ \\
\hline At2g18193 & 5.4 & 0.00232 & AAA-type ATPase family protein \\
\hline At1g24260 & 5.4 & 0.00315 & MADS-box protein (AGL9) (SEP3) \\
\hline At4g23600 & 5.3 & 0.00477 & $\begin{array}{l}\text { coronatine-responsive tyrosine aminotransferase / } \\
\text { tyrosine transaminase (CORI3, JR2) } \\
\end{array}$ \\
\hline At2g28630 & 5.2 & 0.00204 & $\begin{array}{l}\text { beta-ketoacyl-CoA synthase family protein } \\
\text { (Very-long-chain fatty acid condensing enzyme 12) }\end{array}$ \\
\hline At5g33355 & 5.0 & 0.00216 & defensin-like (DEFL) family protein \\
\hline At2g04050 & 5.0 & 0.00322 & MATE efflux family protein \\
\hline At2g04040 & 4.9 & 0.005 & $\begin{array}{l}\text { MATE efflux family protein (AtDTX1): detoxifying } \\
\text { efflux carrier for plant-derived antibiotics and other } \\
\text { toxic compounds, including CD2+ }\end{array}$ \\
\hline At2g19800 & 4.9 & 0.00257 & myo-inositol oxygenase family gene (MIOX2) \\
\hline At3g13470 & 4.7 & 0.00244 & chaperonin, putative \\
\hline At3g59930 & 4.7 & 0.00264 & defensin-like (DEFL) family protein \\
\hline At1g61340 & 4.5 & 0.00417 & F-box family protein \\
\hline At3g49620 & 4.5 & 0.00233 & 2-oxoacid-dependent oxidase, putative (DIN11) \\
\hline At1g07940 & 4.5 & 0.00232 & elongation factor 1-alpha/ EF-1-alpha \\
\hline At4g25100 & 4.4 & 0.00232 & Fe-superoxide dismutase (FSD1) \\
\hline At3g48360 & 4.4 & 0.00232 & $\begin{array}{l}\text { BTB and TAZ domain protein } 2 \text { (BT2), component of } \\
\text { the TAC1-mediated telomerase activation pathway }\end{array}$ \\
\hline At1g56240 & 4.3 & 0.00983 & PP2-B13 (Phloem protein 2-B13) \\
\hline At2g15620 & 4.3 & 0.00246 & ferredoxin--nitrite reductase, putative (NIR1) \\
\hline At1g57990 & 4.3 & 0.00248 & purine permease-related (AtPUP18) \\
\hline At5g63160 & 4.2 & 0.00232 & BTB and TAZ domain protein 1 (BT1) \\
\hline At5g46710 & 4.1 & 0.00274 & zinc-binding family protein \\
\hline At5g61160 & 4.1 & 0.00276 & anthocyanin 5-aromatic acytransferase 1 (AACT1) \\
\hline At3g15356 & 4.1 & 0.00341 & legume lectin family protein \\
\hline
\end{tabular}




\begin{tabular}{|c|c|c|c|}
\hline At4g15210 & 4.1 & 0.0143 & $\begin{array}{l}\text { beta-amylase (BMY1)/1,4-alpha-D-glucan } \\
\text { maltohydrolase }\end{array}$ \\
\hline At5g17170 & 4.0 & 0.00257 & rubredoxin family protein \\
\hline At4g34150 & 4.0 & 0.00239 & $\begin{array}{l}\text { C2 domain-containing protein; calcium/lipid-binding } \\
\text { region, calcium dependent membrane targeting }\end{array}$ \\
\hline At3g50480 & 4.0 & 0.00233 & $\begin{array}{l}\text { broad-spectrum mildew resistance RPW8 family } \\
\text { protein (HR4) }\end{array}$ \\
\hline At1g77120 & 4.0 & 0.00269 & alcohol dehydrogenase (ADH1) \\
\hline At1g73540 & 3.9 & 0.00331 & Nudix hydrolase 21, chloroplast precursor (NUDT21) \\
\hline At5g61440 & 3.9 & 0.00295 & thioredoxin family protein \\
\hline At4g08390 & 3.9 & 0.00243 & L-ascorbate peroxidase, stromal (sAPX) \\
\hline At4g37610 & 3.9 & 0.00232 & BTB and TAZ domain protein 5 (BT5) \\
\hline At3g30775 & 3.9 & 0.00301 & proline dehydrogenase (PRODH) (ERD5) \\
\hline At1g76600 & 3.9 & 0.00248 & expressed protein \\
\hline At4g19420 & 3.8 & 0.00234 & pectinacetylesterase family protein \\
\hline At5g44130 & 3.8 & 0.00204 & $\begin{array}{l}\text { Fasciclin-like arabinogalactan protein } 13 \text { precursor } \\
\text { (FLA13) }\end{array}$ \\
\hline At1g04040 & 3.8 & 0.00162 & acid phosphatase class B family protein \\
\hline At3g16530 & 3.8 & 0.00249 & legume lectin family protein \\
\hline At4g33720 & 3.7 & 0.00275 & pathogenesis-related protein, putative; similar to PR-1 \\
\hline At4g13250 & 3.7 & 0.00339 & short-chain dehydrogenase/reductase (SDR) family \\
\hline At4g31700 & 3.7 & 0.00204 & 40S ribosomal protein S6 (RPS6) \\
\hline At3g06650 & 3.6 & 0.00206 & $\begin{array}{l}\text { ACLB-1, One of the two genes encoding subunit B of } \\
\text { the trimeric enzyme ATP Citrate lyase }\end{array}$ \\
\hline At4g27654 & 3.6 & 0.00276 & expressed protein \\
\hline At3g59080 & 3.6 & 0.00246 & aspartyl protease family protein \\
\hline At5g16980 & 3.6 & 0.00268 & $\begin{array}{l}\text { NADP-dependent oxidoreductase, similar to 2-alkenal } \\
\text { reductase }\end{array}$ \\
\hline At2g38470 & 3.6 & 0.00626 & WRKY33 \\
\hline At1g07135 & 3.5 & 0.00293 & glycine-rich protein \\
\hline At5g17350 & 3.5 & 0.00746 & expressed protein \\
\hline At1g72940 & 3.5 & 0.00518 & disease resistance protein (TIR-NBS class), putative \\
\hline At1g07930 & 3.5 & 0.00226 & elongation factor 1-alpha / EF-1-alpha (A4) \\
\hline At4g10270 & 3.5 & 0.00333 & wound-responsive family protein \\
\hline At2g16060 & 3.5 & 0.00232 & non-symbiotic hemoglobin 1 (HB1) (GLB1) \\
\hline At2g30970 & 3.5 & 0.0026 & aspartate aminotransferase 1 (ASP1) \\
\hline At3g51860 & 3.5 & 0.00228 & $\begin{array}{l}\text { Vacuolar cation/proton exchanger } 3(\mathrm{Ca}(2+) / \mathrm{H}(+) \\
\text { antiporter) (CAX3) }\end{array}$ \\
\hline At5g06320 & 3.5 & 0.0032 & harpin-induced (HIN1, NDR1) family protein (NHL3) \\
\hline At4g02520 & 3.4 & 0.00221 & glutathione S-transferase (GST2) \\
\hline At3g26200 & 3.4 & 0.00243 & putative cytochrome P450 (CYP71B22) \\
\hline At2g37770 & 3.4 & 0.00584 & aldo/keto reductase family protein \\
\hline At1g55450 & 3.4 & 0.00204 & embryo-abundant protein-related \\
\hline At1g60950 & 3.3 & 0.00469 & ferredoxin (AtFD2) (FED A) \\
\hline At2g22880 & 3.3 & 0.00248 & VQ motif-containing protein \\
\hline At2g40140 & 3.3 & 0.00526 & zinc finger (CCCH-type) family protein (CZF1/ZFAR1) \\
\hline At4g08950 & 3.3 & 0.00217 & phosphate-responsive protein, putative (EXO) \\
\hline At4g02380 & 3.3 & 0.00264 & LEA5; senescence associated (SAG21) \\
\hline At1g72910 & 3.3 & 0.0035 & disease resistance protein (TIR-NBS class), putative \\
\hline At4g23100 & 3.3 & 0.00232 & $\begin{array}{l}\text { gamma-glutamylcysteine synthetase (GSH1) (RM1) } \\
\text { (CAD2) Required for cell proliferation at the root tip. }\end{array}$ \\
\hline At5g55070 & 3.3 & 0.00232 & 2-oxoacid dehydrogenase family protein \\
\hline At3g14620 & 3.3 & 0.00221 & cytochrome P450, putative (CYP72A8) \\
\hline At2g45180 & 3.2 & 0.00377 & protease inhibitor/seed storage/LTP family protein \\
\hline
\end{tabular}




\begin{tabular}{|c|c|c|c|}
\hline At3g15510 & 3.2 & 0.00926 & no apical meristem (NAM) family protein (NAC2) \\
\hline At1g72900 & 3.2 & 0.00521 & disease resistance protein (TIR-NBS class), putative \\
\hline At3g18130 & 3.2 & 0.00221 & $\begin{array}{l}\text { guanine nucleotide-binding family protein / activated } \\
\text { protein kinase } C \text { receptor (RACK1) }\end{array}$ \\
\hline At1g27730 & 3.2 & 0.00434 & $\begin{array}{l}\text { zinc finger (C2H2 type) family protein (ZAT10) / salt- } \\
\text { tolerance zinc finger protein (STZ) }\end{array}$ \\
\hline At5g14120 & 3.2 & 0.00295 & nodulin family protein \\
\hline At5g49460 & 3.2 & 0.016 & $\begin{array}{l}\text { One of the two genes encoding subunit B of the } \\
\text { cytosolic enzyme ATP Citrate Lyase (ACLB-2) }\end{array}$ \\
\hline At1g29660 & 3.2 & 0.00297 & GDSL-motif lipase/hydrolase family protein \\
\hline At5g01600 & 3.2 & 0.00232 & ferritin 1 (FER1) \\
\hline At2g06850 & 3.2 & 0.00288 & endoxyloglucan transferase (EXGT-A1) \\
\hline At1g54270 & 3.2 & 0.00264 & eukaryotic translation initiation factor 4A-2 (elF-4A-2) \\
\hline At4g32060 & 3.2 & 0.00232 & calcium-binding EF hand family protein \\
\hline At2g15090 & 3.2 & 0.00232 & $\begin{array}{l}\text { 3-ketoacyl-CoA synthase } 8 \text { (Very-long-chain fatty acid } \\
\text { condensing enzyme 8) (KCS8) }\end{array}$ \\
\hline At4g10265 & 3.2 & 0.00349 & wound-responsive protein, putative \\
\hline At4g22470 & 3.2 & 0.0151 & protease inhibitor/seed storage/LTP family protein \\
\hline At1g68530 & 3.2 & 0.00232 & very-long-chain fatty acid condensing enzyme (CUT1) \\
\hline At1g13260 & 3.2 & 0.00255 & AP2/B3 domain transcription factor (RAV1) \\
\hline At5g35735 & 3.2 & 0.00532 & auxin-responsive family protein \\
\hline At3g02550 & 3.2 & 0.00415 & lateral organ boundaries domain protein (LBD41) \\
\hline At2g22500 & 3.1 & 0.00204 & mitochondrial substrate carrier family protein \\
\hline At3g51600 & 3.1 & 0.0036 & nonspecific lipid transfer protein 5 (LTP5) \\
\hline At5g62470 & 3.1 & 0.00308 & $\begin{array}{l}\text { myb family transcription factor (MYB96) Expression is } \\
\text { strongly induced by abscisic acid }\end{array}$ \\
\hline At1g20620 & 3.1 & 0.00232 & catalase 3 (CAT3) (SEN2) \\
\hline At1g07920 & 3.1 & 0.00226 & elongation factor 1-alpha (eEF-1A) (A4) \\
\hline At3g08580 & 3.1 & 0.00278 & ADP/ATP carrier protein 1 (AAC1) \\
\hline At3g45640 & 3.1 & 0.0026 & mitogen-activated protein kinase, putative (MPK3) \\
\hline At5g56680 & 3.0 & 0.00232 & asparaginyl-tRNA synthetase 1, cytoplasmic (SYNC1) \\
\hline At1g28370 & 3.0 & 0.00232 & ERF11, subfamily B-1 protein \\
\hline At3g03470 & 3.0 & 0.00232 & cytochrome P450, putative (CYP89A9) \\
\hline At1g48570 & 3.0 & 0.00233 & zinc finger (Ran-binding) family protein \\
\hline At3g54470 & 3.0 & 0.00231 & $\begin{array}{l}\text { bi-functional orotate phosphoribosyltransferase/ } \\
\text { orotidine-5'-phosphate decarboxylase }\end{array}$ \\
\hline At3g23620 & 3.0 & 0.00204 & brix domain-containing protein \\
\hline At4g14060 & -3.0 & 0.00232 & major latex protein-related / MLP-related \\
\hline At3g56240 & -3.0 & 0.00248 & copper homeostasis factor / copper chaperone $(\mathrm{CCH})$ \\
\hline At3g49780 & -3.0 & 0.0028 & phytosulfokine 4 precursor (PSK4) \\
\hline At5g13900 & -3.1 & 0.00426 & protease inhibitor/seed storage/LTP family \\
\hline At2g44940 & -3.1 & 0.00208 & $\begin{array}{l}\text { DREB subfamily A-4 of ERF/AP2 transcription factor } \\
\text { family }\end{array}$ \\
\hline At4g23700 & -3.1 & 0.00641 & cation/hydrogen exchanger, putative (CHX17) \\
\hline At2g46750 & -3.1 & 0.00303 & FAD-binding domain-containing protein \\
\hline At5g59520 & -3.1 & 0.00232 & zinc transporter (ZIP2) \\
\hline At4g38080 & -3.1 & 0.00204 & hydroxyproline-rich glycoprotein family protein \\
\hline At4g33010 & -3.1 & 0.00276 & $\begin{array}{l}\text { glycine dehydrogenase (decarboxylating), putative } \\
\text { (GLDP1) }\end{array}$ \\
\hline At3g56230 & -3.2 & 0.0034 & speckle-type POZ protein-related \\
\hline At5g15230 & -3.2 & 0.00254 & gibberellin-regulated protein 4 (GASA4) \\
\hline At4g12510 & -3.2 & 0.00276 & protease inhib./seed storage/LTP family \\
\hline At4g15610 & -3.2 & 0.00264 & integral membrane family protein \\
\hline At4g14010 & -3.2 & 0.00252 & rapid alkalinization factor family protein (RALFL32) \\
\hline
\end{tabular}




\begin{tabular}{|c|c|c|c|}
\hline At3g06390 & -3.2 & 0.00232 & integral membrane family protein \\
\hline At4g20390 & -3.3 & 0.00292 & integral membrane family protein \\
\hline At4g31940 & -3.3 & 0.00324 & cytochrome P450, putative (CYP82C4) \\
\hline At2g47130 & -3.3 & 0.00326 & short-chain dehydrogenase/reductase (SDR) family \\
\hline At4g13235 & -3.3 & 0.00305 & $\begin{array}{l}\text { defensin-like family protein, embryo sac development } \\
\text { arrest (EDA21) }\end{array}$ \\
\hline At5g09480 & -3.3 & 0.00458 & hydroxyproline-rich glycoprotein family protein \\
\hline At5g18060 & -3.3 & 0.00206 & auxin-responsive protein, putative \\
\hline At1g76790 & -3.3 & 0.00162 & O-methyltransferase family 2 protein \\
\hline At5g63190 & -3.3 & 0.00232 & MA3 domain-containing protein \\
\hline At2g02130 & -3.3 & 0.00277 & plant defensin-fusion protein, putative (PDF2.3) \\
\hline At2g05440 & -3.3 & 0.00377 & glycine-rich protein \\
\hline At2g42530 & -3.3 & 0.00236 & cold-responsive protein (cor15b) \\
\hline At5g18080 & -3.4 & 0.00226 & auxin-responsive protein, putative \\
\hline At2g35380 & -3.4 & 0.00315 & peroxidase 20 (PER20) (P20) \\
\hline At4g22610 & -3.4 & 0.00311 & protease inhibitor/seed storage/LTP family protein \\
\hline At4g12520 & -3.4 & 0.00264 & protease inhibitor/seed storage/LTP family protein \\
\hline At5g53250 & -3.4 & 0.00232 & arabinogalactan-protein 22 (AGP22) \\
\hline At1g74670 & -3.4 & 0.00234 & gibberellin-responsive protein, putative \\
\hline At1g78340 & -3.4 & 0.00232 & glutathione S-transferase, tau class of GST (GSTU22) \\
\hline At2g40610 & -3.4 & 0.00232 & alpha-expansin, putative (EXPA8) \\
\hline At3g14990 & -3.4 & 0.00387 & $\begin{array}{l}\text { 4-methyl-5(b-hydroxyethyl)-thiazole monophosphate } \\
\text { biosynthesis protein, putative }\end{array}$ \\
\hline At4g14130 & -3.4 & 0.00257 & xyloglucan endotransglycosylase 7 (XTR7) \\
\hline At3g54010 & -3.5 & 0.00421 & $\begin{array}{l}\text { Immunophilin-like protein similar to the p59 FK506- } \\
\text { binding protein (FKBP52) / Pasticcino } 1 \text { (PAS1) }\end{array}$ \\
\hline At2g32870 & -3.5 & 0.00204 & $\begin{array}{l}\text { meprin and TRAF homology domain-containing protein } \\
\text { / MATH domain-containing protein }\end{array}$ \\
\hline At4g22490 & -3.5 & 0.00255 & protease inhibitor/seed storage/LTP family protein \\
\hline At5g37990 & -3.5 & 0.00318 & S-adenosylmethionine-dependent methyltransferase \\
\hline At1g52060 & -3.6 & 0.00268 & jacalin lectin family protein \\
\hline At4g30450 & -3.6 & 0.00295 & glycine-rich protein \\
\hline At1g52070 & -3.6 & 0.00234 & jacalin lectin family protein \\
\hline At5g15970 & -3.6 & 0.00204 & $\begin{array}{l}\text { stress-responsive protein (KIN2) / cold-responsive } \\
\text { protein (COR6.6) }\end{array}$ \\
\hline At5g02780 & -3.6 & 0.0038 & In2-1 protein, putative \\
\hline At5g42180 & -3.7 & 0.00226 & peroxidase 64 (PER64) (P64) (PRXR4) \\
\hline At2g43590 & -3.7 & 0.00264 & chitinase, putative \\
\hline At5g47990 & -3.7 & 0.00268 & cytochrome P450 family protein (CYP705A5) \\
\hline At2g42540 & -3.8 & 0.00232 & cold-responsive protein (cor15a) \\
\hline At5g46890 & -3.8 & 0.00727 & protease inhibitor/seed storage/LTP family protein \\
\hline At1g77940 & -3.8 & 0.00317 & $60 S$ ribosomal protein $\mathrm{L} 30$ (RPL30B) \\
\hline At2g01530 & -3.8 & 0.00342 & major latex protein-related (MLP329) \\
\hline At4g19170 & -3.8 & 0.00442 & 9-cis-epoxycarotenoid dioxygenase, putative (NCED4) \\
\hline At3g25190 & -3.8 & 0.00232 & nodulin, putative \\
\hline At5g09530 & -3.8 & 0.00276 & hydroxyproline-rich glycoprotein family protein \\
\hline At3g23430 & -3.8 & 0.00231 & phosphate transporter, putative (PHO1) \\
\hline At3g28345 & -3.9 & 0.00295 & $\begin{array}{l}\text { ABC transporter family protein, Multidrug resistance } \\
\text { protein } 13 \text { (MDR13) }\end{array}$ \\
\hline At5g50760 & -3.9 & 0.00241 & auxin-responsive family protein \\
\hline At5g24780 & -3.9 & 0.00416 & vegetative storage protein 1 (VSP1) \\
\hline At2g33830 & -3.9 & 0.00231 & dormancy/auxin associated family protein \\
\hline At3g50970 & -4.0 & 0.00248 & $\begin{array}{l}\text { dehydrin xero2 (XERO2) / low-temperature-induced } \\
\text { protein (LTI30) }\end{array}$ \\
\hline
\end{tabular}




\begin{tabular}{|c|c|c|c|}
\hline At2g02100 & -4.0 & 0.00206 & plant defensin-fusion protein, putative (PDF2.2) \\
\hline At1g48750 & -4.0 & 0.00276 & protease inhibitor/seed storage/LTP family protein \\
\hline At5g62920 & -4.0 & 0.00232 & response regulator 6 (ARR6) \\
\hline At2g47270 & -4.1 & 0.00435 & transcription factor/ transcription regulator \\
\hline At1g67870 & -4.1 & 0.00246 & glycine-rich protein \\
\hline At1g18100 & -4.1 & 0.00301 & E12A11 protein \\
\hline At4g29270 & -4.1 & 0.00278 & acid phosphatase class B family protein \\
\hline At4g17340 & -4.1 & 0.00204 & $\begin{array}{l}\text { probable aquaporin (tonoplast intrinsic protein 2.2) } \\
\text { (TIP2.2) (DELTA-TIP2) }\end{array}$ \\
\hline At5g05960 & -4.1 & 0.00254 & protease inhibitor/seed storage/LTP family protein \\
\hline At4g12550 & -4.1 & 0.00231 & auxin-induced in root cultures (AIR1) \\
\hline At1g49570 & -4.2 & 0.00953 & Peroxidase 10 precursor (ATP5a) (PER10) \\
\hline At2g01520 & -4.3 & 0.00341 & major latex protein-related (MLP328) \\
\hline At5g18030 & -4.3 & 0.00257 & auxin-responsive protein, putative \\
\hline At5g62340 & -4.3 & 0.00242 & invertase/pectin methylesterase inhibitor family \\
\hline At1g70880 & -4.4 & 0.00231 & Bet v I allergen family protein \\
\hline At5g10180 & -4.4 & 0.00204 & sulfate transporter 2.1 (AST68) \\
\hline At1g23730 & -4.4 & 0.00454 & $\begin{array}{l}\text { carbonic anhydrase, putative / carbonate dehydratase, } \\
\text { putative }\end{array}$ \\
\hline At1g73330 & -4.5 & 0.00259 & protease inhibitor, putative (DR4) \\
\hline At5g18020 & -4.5 & 0.00232 & auxin-responsive protein, putative \\
\hline At4g37410 & -4.7 & 0.00293 & cytochrome P450, putative (CYP81F4) \\
\hline At4g38860 & -4.8 & 0.00233 & auxin-responsive protein, putative \\
\hline At4g12545 & -4.8 & 0.00258 & protease inhibitor/seed storage/LTP family protein \\
\hline At2g39800 & -4.8 & 0.00232 & P5CS1 \\
\hline At4g26530 & -4.8 & 0.00264 & fructose-bisphosphate aldolase, cytoplasmic \\
\hline At3g22600 & -4.9 & 0.00221 & protease inhibitor/seed storage/LTP family protein \\
\hline At4g19690 & -5.1 & 0.00232 & $\mathrm{Fe}(\mathrm{II})$ transport protein (IRT1) \\
\hline At1g32080 & -5.2 & 0.00246 & membrane protein, putative \\
\hline At5g48000 & -5.3 & 0.00301 & cytochrome P450 family protein, CYP708A2 \\
\hline At2g05510 & -5.3 & 0.00276 & glycine-rich protein \\
\hline At2g33790 & -5.8 & 0.00226 & $\begin{array}{l}\text { pollen Ole e } 1 \text { allergen protein containing } 14.6 \% \\
\text { proline residues }\end{array}$ \\
\hline At3g25830 & -6.3 & 0.00424 & monoterpene 1,8-cineole synthase, atTPS-Cin \\
\hline At4g11320 & -6.5 & 0.00232 & cysteine proteinase, putative \\
\hline At3g25820 & -6.6 & 0.00276 & monoterpene 1,8-cineole synthase, atTPS-Cin \\
\hline At2g14610 & -6.7 & 0.00427 & PR1 \\
\hline At2g02120 & -6.8 & 0.00226 & plant defensin-fusion protein, putative (PDF2.1) \\
\hline At5g47450 & -7.2 & 0.00232 & Tonoplast intrinsic protein (TIP2;3) (DELTA-TIP3) \\
\hline At4g33550 & -7.4 & 0.00248 & protease inhibitor/seed storage/LTP family protein \\
\hline At3g53980 & -8.2 & 0.00252 & protease inhibitor/seed storage/LTP family protein \\
\hline At4g35450 & -10.6 & 0.0161 & AKR2A \\
\hline At2g17390 & -10.6 & 0.00204 & AKR2B \\
\hline
\end{tabular}


Tabelle 26: Die komplette Liste der Gene, die laut Microarray in den Pro ${ }_{35 s}: A K R 2 A$ Pflanzen stärker, bzw. schwächer exprimiert wurden als im Wildtyp. Ein negatives Vorzeichen bedeutet schwächere Expression in der transgenen Pflanze, je kleiner der P-Wert, desto signifikanter sind die Expressionsdaten. Die Schwellenwerte betragen: log (Pro $\left.{ }_{35 s} / \mathrm{WT}\right): 3, \mathrm{P}-\mathrm{Wert}$ : 0,02

\begin{tabular}{|c|c|c|c|}
\hline Gen AGI & $\begin{array}{c}\log \\
\left(\mathrm{PrO}_{35 \mathrm{~S}} / \mathrm{WT}\right) \\
\end{array}$ & P-Wert & Annotation \\
\hline At5g59320 & 14.9 & 0.00561 & lipid transfer protein 3 (LTP3) \\
\hline At5g59310 & 14.9 & 0.0065 & lipid transfer protein 4 (LTP4) \\
\hline At1g75830 & 9.0 & 0.00636 & plant defensin-fusion protein, (PDF1.1) \\
\hline At4g23600 & 8.0 & 0.00518 & $\begin{array}{l}\text { coronatine-responsive tyrosine aminotransferase / } \\
\text { tyrosine transaminase (CORI3, JR2) }\end{array}$ \\
\hline At4g15210 & 7.9 & 0.00621 & $\begin{array}{l}\text { beta-amylase (BMY1)/1,4-alpha-D-glucan } \\
\text { maltohydrolase }\end{array}$ \\
\hline At5g44420 & 7.7 & 0.00773 & plant defensin protein, (PDF1.2a) \\
\hline At4g35295 & 6.7 & 0.00737 & homoserine kinase, putative / HSK \\
\hline At5g44430 & 6.5 & 0.00731 & plant defensin-fusion protein, (PDF1.2c) \\
\hline At4g35610 & 6.2 & 0.00651 & zinc finger (C2H2 type) family protein \\
\hline At4g24570 & 5.9 & 0.00476 & mitochondrial substrate carrier family protein \\
\hline At2g26020 & 5.5 & 0.0157 & plant defensin-fusion protein, putative (PDF1.2b) \\
\hline At1g80840 & 4.4 & 0.00578 & WRKY40 \\
\hline At5g51190 & 4.4 & 0.0055 & ERF protein subfamily B-3 of ERF/AP2 \\
\hline At1g72910 & 4.3 & 0.00515 & disease resistance protein (TIR-NBS class), putative \\
\hline At2g37770 & 4.3 & 0.00625 & aldo/keto reductase family protein \\
\hline At1g66100 & 4.2 & 0.00476 & probable thionin-2.4 precursor \\
\hline At1g27730 & 4.1 & 0.0055 & $\begin{array}{l}\text { zinc finger (C2H2 type) family protein (ZAT10) / salt- } \\
\text { tolerance zinc finger protein (STZ) }\end{array}$ \\
\hline At2g26010 & 4.1 & 0.01 & plant defensin-fusion protein, putative (PDF1.3) \\
\hline At3g28290 & 4.1 & 0.00515 & integrin-related protein $14 a$ \\
\hline At3g55980 & 4.1 & 0.0142 & $\begin{array}{l}\text { zinc finger ( } \mathrm{CCCH} \text {-type) family protein, contains Pfam } \\
\text { domains: Zinc finger C-x8-C-x5-C-x3-H type; and } \\
\text { Ankyrin repeat }\end{array}$ \\
\hline At4g11280 & 3.9 & 0.0105 & $\begin{array}{l}\text { 1-aminocyclopropane-1-carboxylate synthase } 6 \text { / ACC } \\
\text { synthase } 6 \text { (ACS6) }\end{array}$ \\
\hline At3g28300 & 3.9 & 0.0116 & integrin-related protein $14 a($ At14a) \\
\hline At2g16660 & 3.8 & 0.00767 & nodulin family protein \\
\hline At1g72900 & 3.7 & 0.00631 & disease resistance protein (TIR-NBS class) \\
\hline At1g72940 & 3.7 & 0.00711 & disease resistance protein (TIR-NBS class) \\
\hline At5g17350 & 3.7 & 0.00928 & expressed protein \\
\hline At5g25630 & 3.6 & 0.00431 & pentatricopeptide (PPR) repeat-containing protein \\
\hline At1g76600 & 3.6 & 0.00515 & expressed protein \\
\hline At2g41100 & 3.5 & 0.00856 & $\begin{array}{l}\text { touch-responsive protein / calmodulin-related protein 3, } \\
\text { touch-induced }(\mathrm{TCH} 3)\end{array}$ \\
\hline At3g44260 & 3.4 & 0.00518 & CCR4-NOT transcription complex protein \\
\hline At4g17490 & 3.3 & 0.00476 & AtERF6 \\
\hline At1g24260 & 3.3 & 0.00939 & MADS-box protein (AGL9) (SEP3) \\
\hline At2g34430 & 3.3 & 0.0055 & chlorophyll A-B binding protein (LHCB1.4) (LHB1B1) \\
\hline At5g25610 & 3.3 & 0.00617 & dehydration-responsive protein (RD22) \\
\hline At5g61600 & 3.3 & 0.00431 & ERF protein subfamily B-3 of ERF/AP2 \\
\hline At4g27280 & 3.3 & 0.00515 & calcium-binding EF hand family protein \\
\hline At5g47230 & 3.2 & 0.00515 & ethylene-responsive element-binding factor 5 (ERF5) \\
\hline At1g07135 & 3.1 & 0.0058 & glycine-rich protein \\
\hline At4g15760 & 3.1 & 0.00518 & monooxygenase, putative (M01) \\
\hline At2g40140 & 3.1 & 0.00824 & zinc finger (CCCH-type) family protein (CZF1/ZFAR1) \\
\hline At4g34950 & 3.1 & 0.0055 & nodulin family protein \\
\hline
\end{tabular}




\begin{tabular}{|l|l|l|l|}
\hline At5g06320 & 3.0 & 0.00621 & harpin-induced (HIN1, NDR1) family protein (NHL3) \\
\hline At1g75900 & 3.0 & 0.0128 & family Il extracellular lipase 3 (EXL3) \\
\hline At3g57520 & 3.0 & 0.00598 & hydrolase; seed imbibition 2 (SIP2) \\
\hline At3g21720 & 3.0 & 0.00577 & isocitrate lyase, putative (ICL) \\
\hline At5g57240 & -3.0 & 0.0113 & oxysterol-binding family protein \\
\hline At1g18400 & -3.0 & 0.00476 & BR enhanced expression 1 (BEE1) \\
\hline At5g39110 & -3.0 & 0.00513 & germin-like protein, putative \\
\hline & & & protease inhibitor/seed storage/LTP family protein; \\
At5g48485 & -3.1 & 0.00611 & DIR1: DEFECTIVE IN INDUCED RESISTANCE 1 \\
\hline At3g56980 & -3.1 & 0.00518 & OBP3-responsive gene 3 (ORG3) (BHLH039) \\
\hline At2g05510 & -3.2 & 0.00837 & glycine-rich protein \\
\hline At3g05950 & -3.6 & 0.0065 & Germin-like protein subfamily 1 member 7 precursor \\
\hline At3g56970 & -3.6 & 0.00511 & OBP3-responsive gene 2 (ORG2) (BHLH038) \\
\hline At1g65960 & -3.9 & 0.00515 & glutamate decarboxylase 2 (GAD 2) \\
\hline At3g25830 & -4.0 & 0.0128 & monoterpene 1,8-cineole synthase, atTPS-Cin \\
\hline At3g25820 & -4.2 & 0.00756 & monoterpene 1,8-cineole synthase, atTPS-Cin \\
\hline At2g47270 & -4.6 & 0.00601 & transcription factor/ transcription regulator \\
\hline At1g49570 & -5.0 & 0.00862 & Peroxidase 10 precursor (PER10) \\
\hline At1g23730 & -5.8 & 0.0055 & carbonic anhydrase/carbonate dehydratase, putative \\
\hline At5g19890 & -6.4 & 0.00515 & peroxidase, putative \\
\hline At4g33720 & -6.9 & 0.00431 & pathogenesis-related protein, putative \\
\hline At2g14610 & -7.0 & 0.00627 & PR1 \\
\hline
\end{tabular}

\subsection{Abkürzungsverzeichnis}

\subsubsection{Abkürzungen}

4-MU

4-MUG

A

Abb.

A.t.

$A D$

Amp

APS

APX

ARF

ARR

ATP

BD

bidest.

BiFC

bp
4-Methylumbelliferyl

4-Methylumbelliferyl-ß-D-Glucuronid

Adenin

Abbildung

Arabidopsis thaliana (Acker-Schmalwand)

Aktivierungsdomäne

Ampicillin

Ammoniumpersulfat

Ascorbat Peroxidase

"auxin responsive factor"

"Arabidopsis response regulator"

Adenosintriphosphat

Bindedomäne

bidestilliert

"bimolecular fluorescence complementation"

Basenpaar(e) 


\begin{tabular}{|c|c|}
\hline BPB & Bromphenolblau \\
\hline BSA & Rinderserumalbumin \\
\hline bZIP & basischer Leucinzipper \\
\hline bzw. & beziehungsweise \\
\hline $\mathrm{C}$ & Cytidin \\
\hline ca. & circa \\
\hline CaMV & cauliflour mosaic virus \\
\hline cDNA & komplementäre DNA \\
\hline CE & C-terminales Fragment von YFP \\
\hline CIAP & Calf Intestine Alcaline Phosphatase \\
\hline CSM & Complete Supplement Mixture \\
\hline ddNTPs & Didesoxyribonucleotide \\
\hline DMSO & Dimethylsulfoxid \\
\hline DNA & Desoxyribonucleinsäure \\
\hline DNase & Desoxyribonuclease \\
\hline dNTPs & Desoxyribonucleotide \\
\hline DTT & Dithiothreitol \\
\hline ECL & Enhanced Chemilumineszenz \\
\hline EDTA & Ethylendiamin-N,N,N',N'-tetraessigsäure \\
\hline EMSA & Electrophoretic Mobility Shift Assay \\
\hline ER & Endoplasmatisches Reticulum \\
\hline ET & Ethylen \\
\hline et al. & und andere (et alii) \\
\hline EtBr & Ethidiumbromid \\
\hline etc. & und so weiter (et cetera) \\
\hline $\mathrm{EtOH}$ & Ethanol \\
\hline evtl. & eventuell \\
\hline G & Guanin \\
\hline Gal4-AD & Gal4-Aktivierungsdomäne \\
\hline Gal4-BD & Gal4-DNA-Bindedomäne \\
\hline GFP & "green fluorescent protein" \\
\hline $\mathrm{Gm}$ & Gentamycin \\
\hline GO & "Gene Ontology" \\
\hline GUS & ß-Glucuronidase \\
\hline
\end{tabular}




\begin{tabular}{|c|c|}
\hline $\mathrm{H}_{2} \mathrm{O}$ & Wasser \\
\hline $\mathrm{HA}$ & Influenza Hämagglutinin-Protein \\
\hline $\mathrm{HCl}$ & Salzsäure \\
\hline HEPES & 2-[4-(2-Hydroxyethyl)-1-piperazino]-ethansulfonsäure \\
\hline His & Histidin \\
\hline HR & Hypersensitive Reaktion ("hypersensitive response”) \\
\hline HSP & Heringsperma-DNA \\
\hline IPTG & Isopropylthiogalactosid \\
\hline JA & Jasmonsäure \\
\hline KAc & Kaliumacetat \\
\hline $\mathrm{kb}$ & Kilobasen \\
\hline kDa & Kilodalton \\
\hline $\mathrm{Km}$ & Kanamycin \\
\hline LB & "left border" \\
\hline LB-Medium & Luria-Bertani Broth-Medium \\
\hline Leu & Leucin \\
\hline LHC & "light harvesting complex" \\
\hline LMB & Leptomycin B \\
\hline mcs & Multiple Cloning Site \\
\hline MES & $\beta$-Morpholino-ethansulfonsäure Hydrat \\
\hline $\mathrm{MgCl}_{2}$ & Magnesiumchlorid \\
\hline $\min$ & Minuten \\
\hline MOPS & Morpholinopropansulfonsäure \\
\hline mRNA & messenger RNA \\
\hline N.t. & Nicotiana tabacum \\
\hline n.t. & not tested \\
\hline $\mathrm{NaAc}$ & Natriumacetat \\
\hline $\mathrm{NaCl}$ & Natriumchlorid \\
\hline NAN & Neuraminidase \\
\hline NE & N-terminales Fragment von YFP \\
\hline NLS & Kernlokalisationssignal (“nuclear localisation signal”) \\
\hline $\mathrm{O} 2$ & Opaque2 \\
\hline OD & optische Dichte \\
\hline
\end{tabular}




\begin{tabular}{|c|c|}
\hline OEP & $\begin{array}{l}\text { Protein der äußeren Chloroplastenmembran ("outer } \\
\text { envelope protein") }\end{array}$ \\
\hline oNPG & o-Nitrophenyl D-Galactopyranosid \\
\hline ORF & offener Leserahmen (“open reading frame”) \\
\hline $\mathrm{P} 2 \mathrm{H}$ & Protoplasten-Two-Hybrid \\
\hline PAA & Polyacrylamidgel \\
\hline PAGE & Polyacrylamidgelelektrophorese \\
\hline PAMP & "pathogen associated molecular pattern" \\
\hline PCR & Polymerase-Kettenreaktion ("polymerase chain reaction”) \\
\hline PDF & pflanzliches Defensin \\
\hline PEG & Polyethylenglycol \\
\hline $\mathrm{pH}$ & negativ dekadischer Logarithmus der \\
\hline PIPES & 1,4-Piperazin-bis-(ethansulfonsäure) \\
\hline PVDF & Polyvinylidene Fluorid \\
\hline RB & "right border" \\
\hline RFP & "red fluorescent protein" \\
\hline RNA & Ribonucleinsäure \\
\hline RNAi & RNA-Interferenz \\
\hline RNase & Ribonuclease \\
\hline rpm & Umdrehungen pro Minute (“rotations per minute”) \\
\hline RT & Raumtemperatur \\
\hline SA & Salizylsäure \\
\hline SD & Synthetic dropout \\
\hline SDS & Natriumdodecylsulfat \\
\hline SS & einzelsträngig („single stranded“) \\
\hline SSC & Natriumcitrat \\
\hline $\mathrm{t}$ & Reaktionszeit \\
\hline $\mathrm{T}$ & Thymin \\
\hline Tab. & Tabelle \\
\hline Taq & DNA-Polymerase Thermus aquaticus DNA-Polymerase \\
\hline TBE & Tris-Borat-EDTA-Puffer \\
\hline TBS & Tris buffered saline \\
\hline T-DNA & Transfer-DNA \\
\hline TE & Tris EDTA-Puffer \\
\hline
\end{tabular}




\begin{tabular}{|c|c|}
\hline TEMED & $\mathrm{N}, \mathrm{N}, \mathrm{N}^{\prime}, \mathrm{N}^{\prime}$-Tetraethylethylendiamin \\
\hline $\mathrm{T}_{\mathrm{m}}$ & Schmelztemperatur \\
\hline TMV & Tabak Mosaik Virus \\
\hline Toc & „translocase of the outer chloroplast membrane“ \\
\hline Tom & „translocase of the outer mitochondrial membrane“ \\
\hline TPI & Trypsin Protease Inhibitor \\
\hline Tris & Tris-(hydroxymethyl)-aminomethan \\
\hline Trp & Trytophan \\
\hline$U$ & definierte Enzymeinheit (unit) \\
\hline u.a. & unter anderem \\
\hline ü.N. & über Nacht \\
\hline UAS & Upstream Activating Sequence \\
\hline uORF & $\begin{array}{l}\text { offener Leserahmen im } 5 \text { '-UTR ("upstream open reading } \\
\text { frame") }\end{array}$ \\
\hline UTR & untranslatierte Region \\
\hline UV & Ultraviolettes Licht \\
\hline $\mathrm{v} / \mathrm{v}$ & Volumenprozent (volume per volume) \\
\hline Vol. & Volumen \\
\hline$w / v$ & Gewichtsprozent (weight per volume) \\
\hline WT & Wildtyp \\
\hline X-Gal & 5-Brom-4-chlor-3-indolyl- $\beta$-D-galactopyranosid \\
\hline $\mathrm{Y} 2 \mathrm{H}$ & Yeast-two-Hybrid“ \\
\hline YFP & "yellow fluorescent protein" \\
\hline z.B. & zum Beispiel \\
\hline z.T. & zum Teil \\
\hline$\lambda$ & Bakteriophage Lambda \\
\hline
\end{tabular}

\subsubsection{Einbuchstabenkürzel für Aminosäuren}

$\begin{array}{llllll}\text { A } & \text { Alanin } & \text { G } & \text { Glycin } & \text { M } & \text { Methionin } \\ \text { S } & \text { Serin } & \text { C } & \text { Cystein } & \text { H } & \text { Histidin } \\ \text { N } & \text { Asparagin } & \text { T } & \text { Threonin } & \text { D } & \text { Asparaginsäure } \\ \text { I } & \text { Isoleucin } & \text { P } & \text { Prolin } & \text { V } & \text { Valin }\end{array}$




$\begin{array}{llllll}\text { E } & \text { Glutaminsäure } & \text { K } & \text { Lysin } & \text { Q } & \text { Glutamin } \\ \text { W } & \text { Tryptophan } & \text { F } & \text { Phenylalanin } & \text { L } & \text { Leucin } \\ \text { R } & \text { Arginin } & \text { Y } & \text { Tyrosin } & & \end{array}$

\subsubsection{Einheiten}

$\begin{array}{lll}{ }^{\circ} \mathrm{C} & \text { Grad Celsius } & \text { (Temperatur) } \\ \mathrm{D} & \text { Dalton } & \text { (Molekulargewicht) } \\ \mathrm{g} & \text { Gramm } & \text { (Masse) } \\ \mathrm{h} & \text { Stunde } & \text { (Zeit) } \\ \mathrm{I} & \text { Liter } & \text { (Volumen) } \\ \mathrm{M} & \text { mol / } & \text { (Molarität) } \\ \text { min } & \text { Minute } & \text { (Zeit) } \\ \mathrm{mol} & \text { mol } & \text { (Stoffmenge) } \\ \mathrm{S} & \text { Sekunde } & \text { (Zeit) } \\ \mathrm{V} & \text { Volt } & \text { (Spannung) } \\ \Omega & \text { Ohm } & \text { (Widerstand) }\end{array}$

8.2.4 Vorsätze zur Bezeichnung von dezimalen Vielfachen und Teilen von Einheiten

$\begin{array}{lll}\mathrm{k} & \text { kilo- } & \left(10^{3}\right) \\ \mathrm{c} & \text { centi- } & \left(10^{-2}\right) \\ \mathrm{m} & \text { milli- } & \left(10^{-3}\right) \\ \mathrm{\mu} & \text { mikro } & \left(10^{-6}\right) \\ \mathrm{n} & \text { nano- } & \left(10^{-9}\right) \\ \mathrm{p} & \text { pico- } & \left(10^{-12}\right)\end{array}$




\section{Lebenslauf}

\section{Persönliche Daten:}

Name:

Caroline Sophia Carsjens, geb. Mayer

Geburtsdatum:

30.10 .1978

Geburtsort:

Essen

Staatsangehörigkeit: deutsch

\section{Schulbildung:}

1984-1988 Hirschkampgrundschule, Oberhausen

1988-1994 Freiherr vom Stein Gymnasium, Oberhausen

1994-1995 Smithsburg High School, Maryland, USA

1995-1997 Freiherr vom Stein Gymnasium, Oberhausen; Abschluss: Abitur

\section{Studium:}

1997-1998

Studium der Mathematik an der Georg-August Universität Göttingen

$1998-2001$

Studium der Biologie an der Georg-August Universität Göttingen

$2001-2002$

Studium der Biologie an der Universität Bergen, Norwegen

2002-2004

Studium der Biologie an der Georg-August Universität Göttingen

Anfertigung der Diplomarbeit in der Abteilung „Biochemie der Pflanze“ bei Prof. Dr. I. Feußner mit dem Thema: „Isolation und Analyse einer neuen Genfamilie von Glykolat-Oxidasen aus Arabidopsis thaliana"

$2004-2010$

Anfertigung der vorliegenden Dissertation am Lehrstuhl für "Allgemeine und Entwicklungsphysiologie der Pflanze" des Albrecht-von-Haller Instituts für Pflanzenwissenschaften der Georg-August-Universität zu Göttingen bei PD Dr. W. DrögeLaser. 